ACT 141997

OSTI

DOE/MC $31388-5766$

(DE97005467)

\title{
Task 11 - Systems Analysis of Environmental Management Technologies
}

\author{
Topical Report \\ June 1997 \\ By: \\ Mark A. Musich
}

Work Performed Under Contract No: DE-FC21-94MC31388

For

U.S. Department of Energy

Office of Environmental Management

Office of Technology Development

1000 Independence Avenue

Washington, DC 20585
U.S. Department of Energy

Office of Fossil Energy

Federal Energy Technology Center

Morgantown Site

P.O. Box 880

Morgantown, West Virginia 26507-0880

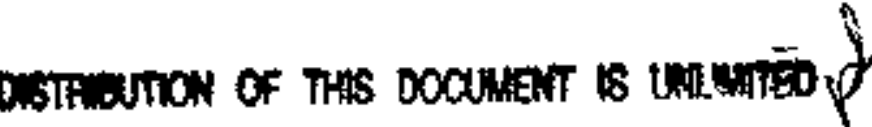

By

Energy \& Environmental Research Center

University Of North Dakota

P.O. Box 9018

Grand Forks, North Dakata 58202-9018 


\section{Disclaimer}

This report was prepared as an account of work sponsored by an agency of the United States Government. Neither the United States Government nor any agency thereof, nor any of their employees, makes any warranty, express or implied, or assumes any legal liability or responsibility for the accuracy, completeness, or usefulness of any information, apparatus, product, or process disclosed, or represents that its use would not infringe privately owned rights. Reference herein to any specific commercial product, process, or service by trade name, trademark, manufacturer, or otherwise does not necessarily constitute or imply its endorsement, recommendation, or favoring by the United States Government or any agency thereof. The views and opinions of authoss expressed herein do not necessarily state or reflect those of the United States Government or any agency thereof. 


\section{DISCLAIMER}

Portions of this document may be illegible electronic image products. Images are produced from the best available orlginal document. 


\section{DISCLAMER}

This report was prepared as an account of work sponsored by an agency of the United States Government. Neither the United States Government, nor any agency thereof, nor any of their employees makes any warranty, express or implied, or assumes any legal tiability or responsibility for the accuracy, completeness, or usefulness of any information, apparatus, product, or process disclosed or represents that its use would not infringe privately owned rights. Reference herein to any specific commercial prodict, process, or service by trade name, trademark, manufacturer, or otherwise does not necessarily constitute or imply its endorsement, recommendation, or favoring by the United States Government or any agency thereof. The views and opinions of authors expressed herein do not necessarily state or reflect those of the United States Government or any agency thereof.

\section{EERC DISCLAIMER}

LEGAL NOTICE This research report was prepared by the Energy \& Environmental Research Center (EERC), an agency of the University of North Dakota, as an account of work sponsored by U.S. Department of Energy Morgantown Energy Technology Center. Because of the research nature of the work performed, neither the EERC nor any of its employees makes any warranty, express or implied, or assumes any legal liability or responsibility for the accuracy, completeness, or usefulness of any information, apparatus, product, or process disclosed, or represents that its use would not infringe privately owned rights. Reference herein to any specific commercial product, process, or service by trade, trademark, manufacturer, or otherwise does not necessarily constitute or imply its endorsement or recommendation by the EERC.

\section{ACKNOWLEDGMENT}

This semiannual report was prepared with the support of the U.S. Department of Energy (DOE), Morgantown Energy Technology Center, Cocperative Agreement No. DE-FC2194MC31388. However, any opinions, findings, conclusions, or recommendations expressed herein are those of the author(s) and do not necessarily reflect the views of the DOE. 


\section{TABLE OF CONTENTS}

LIST OF FIGURES $\ldots \ldots \ldots \ldots \ldots \ldots \ldots \ldots \ldots \ldots \ldots \ldots \ldots$ ii

LIST OF TABLES $\ldots \ldots \ldots \ldots \ldots \ldots \ldots \ldots \ldots \ldots \ldots \ldots \ldots \ldots \ldots$ ii

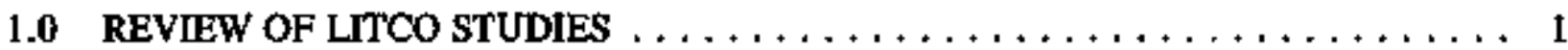

1.1 Introduction/Background $\ldots \ldots \ldots \ldots \ldots \ldots \ldots \ldots \ldots \ldots$

1.2 Objectives $\ldots \ldots \ldots \ldots \ldots \ldots \ldots \ldots \ldots \ldots \ldots \ldots \ldots \ldots \ldots \ldots \ldots$

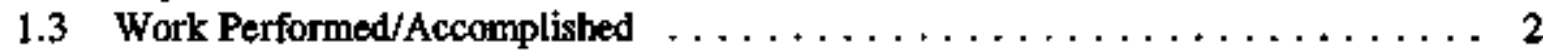

1.3 .1 Systems Engineering Approach $\ldots \ldots \ldots \ldots \ldots \ldots \ldots \ldots \ldots \ldots \ldots$

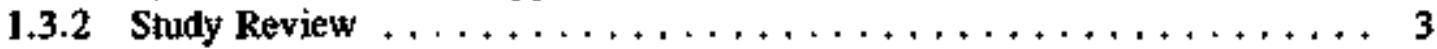

2.0 DEVELOPMENT OF SE TEMPLATE $\ldots \ldots \ldots \ldots \ldots \ldots \ldots \ldots$

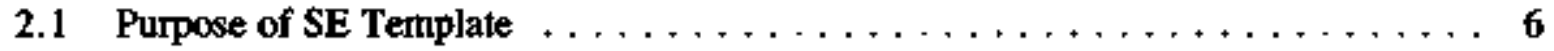

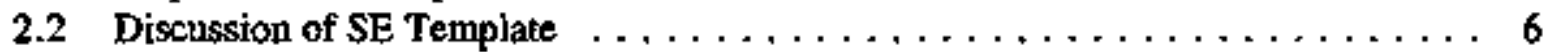

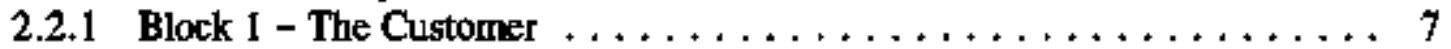

2.2.2 Block 2 - Need, Functions, and System Requirements . . . . . . . 8

2.2 .3 Block 3 - Design Team . . . . . . . . . . . . . . 10

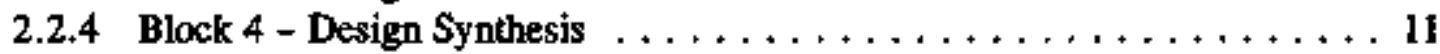

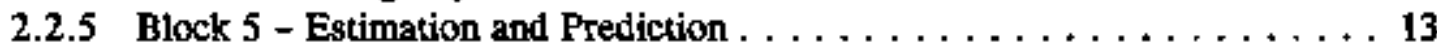

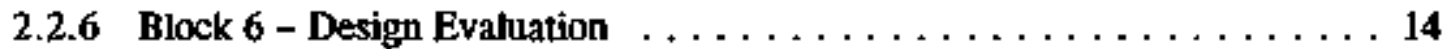

2.2.7 Block 7 - Design Dexision Schema $\ldots \ldots \ldots \ldots \ldots \ldots \ldots \ldots \ldots$

2.2.8 Block 8 - Physical and Economic Databases and Other Studies . . . . . 16

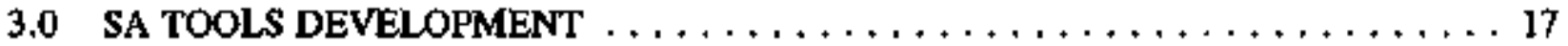

3.1 Process Simulation as an $\$$ A Tool $\ldots \ldots \ldots \ldots \ldots \ldots \ldots \ldots \ldots \ldots$

3.2 Application of Process Simulation for Economic Analysis . . . . . . . . . . . . 19

REVIEW OF THE INTEGRATED THERMAL AND NONTHERMAL TREATMENT SYSTEM STUDIES 


\section{LIST OF FIGURES}

1 Systems engineering template displaying the eight elernents for evaluating a technical

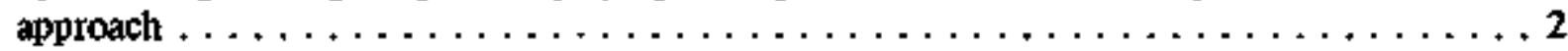

\section{LIST OF TABJUES}

1 Review of the Approach Used in the ITTS and INTS Reports Using the SE Template $\ldots \ldots \ldots \ldots \ldots \ldots \ldots \ldots \ldots \ldots \ldots \ldots \ldots \ldots$

2 Sensitivity Analyses of Critical Assumptions for Selected Systems $\ldots \ldots \ldots \ldots \ldots \ldots$. 5 


\section{TASK 11 - SYSTEMS ANALYSIS OF ENVIRONMENTAL MANAGEMENT TECHNOLOGIES}

\subsection{REVIEW OF LITCO STUDES}

\subsection{Introduction/Background}

A review was conducted of three systems analysis (SA) studies performed by Lockheed Idaho Technologies Company (LITCO) on integrated thermal treatment systerns (ITTSs) and integrated nonthernal treatment systems (INTSs) for the remediation of mixed low-level waste (MLLW) stored throurghout the U.S. Deparment of Energy (DOE) weapons complex. The review was performed by an independent team led by the Energy \& Environmental Research Center (EERC), including Science Applications lnternational Corporation (SAIC), the Waste Policy Institute (WPI), and Virginja Tech. The three studies reviewed were as follows:

- Integrated Thermal Treatment System Study, Phase 1 - issued July 1994

- Integrated Thermal Treatment System Study, Phase 2 - issued February 1996

- Integrated Nonthermal Treatment System Sudy - drafted March 1996

The three studies were commissioned by DOE to be SA studies of environmental masagement (EM) systems. The purpose of LITCO's engineering evaluation of the MLLW treatment system alternatives was to help DOE in the prioritization of research, development, and demonstration activities for remediation technologies. The review of these three studies was structured to further aid DOE in its current and future decision-making processes. The methodology in the studies was compared to a sound systems engineering (SE) approach to help DOE determine which tasks still need to be accomplished to complete a thorough design/review.

\subsection{Objectives}

The goals of the independent review were to provide DOE with the necessary infonnation to determine whether a more detailed analysis of the LITCO studies is warranted, to identify the areas of the sudies that would warrant future attention, and to highlight tasks that would complement the LITCO spudies to form a thorough SE evaluation.

To achieve the above goals, the following objectives were identified: 1) determine whether the assumptions of the reports were adequate to produce an unbiased review of thermal and nonthermal systems, 2) identify areas of the study that could be expanded/ennanced to produce a better decision-making product, and 3) provide a template to guide future SE studies.

The specific issues included within this review were as follows:

- Review facility designs and engineering and operating assumptions

- Review cost estimation methods, bases, and assumptions

- Evaluate the uncertainty of assumptions 
- Review submodeis for both baseline and alternative technologies to assess the sensitivity of planning life-cycle costs (PLCCs) to the assumptions

- Determine which assumptions were critical in determining PLCCs for a given technology and which were critical to the relative technology rankings

- Review the SE/SA approach for potential improvements

\subsection{Work Performed/Accomplished}

The prodact of the LITCO studies review was a report entitled "Review of the Integrated Thermal and Nonthermal Treatment System Sudies." The report covered two primary topics: 1) a description of a technical approach to $S E$ and 2) a review of the LITCO studies.

\subsection{Systems Engineering Approach}

In order to facilitate the application of the SE process to future studies and to facilitate examination of the three LITCO studies relative to the SE process, a generic SE template was developed. The elements of the template are illustrated in Figure 1. A description of the respective blocks and the specific questions addressed by each block, with respect to the LITCO studies, can be found in Appendix A.

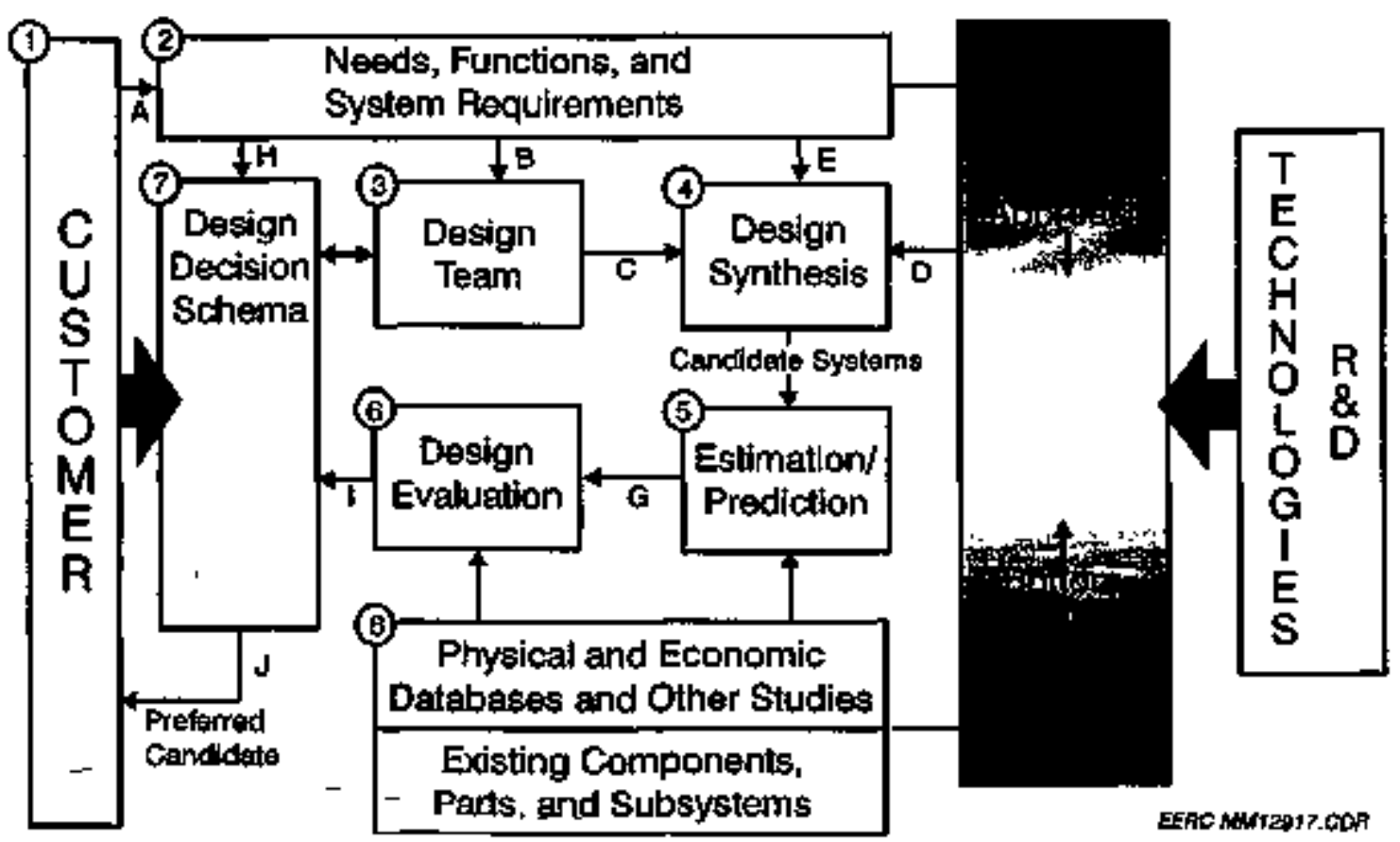

Figure 1. Systems engineering template displaying the eight elements for evaluating a technical approach. 


\subsubsection{Study Review}

The study review discussed the approach used by LITCO relative to an ideal SE approach, the validity of the assumptions made, the sensitivities of the economics to those assumptions, and the quantification of qualitative performance measures. Major findings of the study review are presented below.

The ITTS and INTS stadies used a systems setting to allow the upstrearn and downstream consequences of the use of different technologies (subsystems) to be judged. In addition, total lifecycle cost was used so that technologies at different stages of development could be compared fairly. However, comparison of the LITCO studies to the generic SE template indicated deficiencies in several areas. A review of the three studies is shown in Table 1. It was recognized that the lack of a cormplete SE analysis by LITCO in the three studies was a policy decision by DOE. A full SE review is still needed in order to finally make a decision as to which systems look the most promising and, therefore, which system technologies warrant further development. The EERC recommended that the SE steps that were not done as part of the three studies need to be completed.

A major shortcoming of the LITCO studies was the lack of any recommendations about technology selection. Owing to the design assumptions and the overwhelming operating costs, the sudies produced costs that are essentially equivalent for all the ITTS technical options. The EERC demonstrated that the evaluation of noneconomic performance criteria-cost sensitivity, cost uncertainty, regulatory compliance, implementability, flexibility to handle variable waste, operability, maintainability, availability, and decontamination and decommissioning-using expert judgment and Kepner-Tregoe (KT) methods could provide the missing differentiation among technologies. An example of such an analysis, using the KT approach, for the ITTS Phase 2 systems was carried out. The example showed that a weighted average performance plotted versus cost will bkety show clear difference between the technologies. A thorough application of this method was recommended for the analysis of all developmental technologies to assist in decisions about the viability of technology options. While the ITTS Phase 1 study initiated the application of such an approach, it was not carried out as part of the sudy by LITCO for the reason already cited. The EERC recommends that such analysis needs to be performed by some impartial organization'team in order to provide more focused input to the decision-making process.

In review of the LITCO studies, the EERC identified over 1200 assumptions. Arnong these assumptions, a few critical ones had major impacts on overall life-cycle costs. These major assumptions were subjected to sensitivity analysis to determine their impacts on the overall plant costs defined in the shidies. Significant design conservatism was inherent in the stodjes. For example, all systems were designed for Category 1 seismic region construction, adding $11 \%$ to $16 \%$ to overall plant life-cycle costs. Facility operation was assumed to be only about half time, adding about $20 \%$ to life-cycle cost. Conversely, many developmental systems were assumed to be able to perform; the penalty associated with system failure could add $S \%$ to $10 \%$ to life-cycle cost. The summary of the impacts of major assumptions (with $>10 \%$ impact on PLCC) is shown in Table 2 . 
TABLE 1

Review of the Approach Used in the ITTS and INTS Reports Using the SE Template

\begin{tabular}{|c|c|c|c|}
\hline & ITTS Phase 1 & ITTS Phise 2 & NTS \\
\hline $\begin{array}{l}\text { The Custoner } \\
\text { (Block 1) }\end{array}$ & 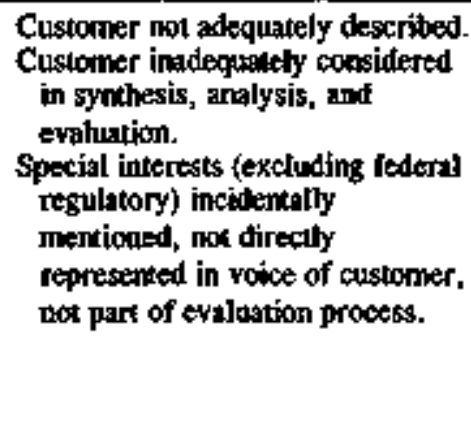 & $\begin{array}{l}\text { Special interests broader in } \\
\text { defimition but still not } \\
\text { represented as custooner or } \\
\text { included in evaluation } \\
\text { process. }\end{array}$ & 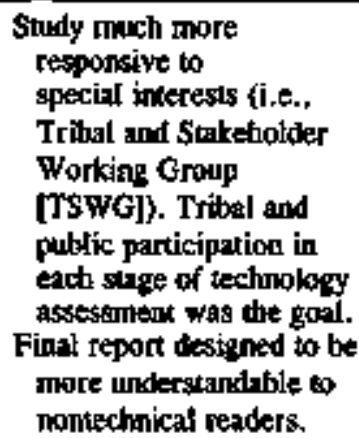 \\
\hline
\end{tabular}

Noed, Functions, and System Requilreatents (Block 2)

\section{Design Team}

(Block 3)

Design Synthesis (Block 4)

Estimation and Prediction (Block S)

Design

Eraluation (Black 6)

Desigo Decision Sthema (Block 7 )

Studies lack adexuate system requirements and need analyses. Parlial functional aralysis altempted for selection and definition of subsystems. No evidence of finctional analysis and șubsequemt ałlocation of system requitements.

No details provided for areas of expertise, areas of responsibility, and criterta for addítion to teann.

Panel of engineers for system down-selecting not described.

Adequate description of alternative systems, bux inadequate traceability to system requirernents. Heavy reliance on bottom-up approach tot system symthesis, Liftle documentation for selection of most tectnologies. Docurnentation provided for dowr-selecting from 12 to 10 systems.
DOE indeinal review panel seyiewed draft report, mut concribuxtions not disclassed. Larger study team then before.

No documentation provided for down-solecting systems.
Matry memiters of suidy team bave changed. TSWG could indirectly be consiatered part of design keam.

TSWG developed list of noncechnical siteria to assist TSWG in technolsoy down-selecting. Evidence for incorporating nontechnical criteria imeo down-selecting noe adequate.

Lacks performance acceptability criteris and larget values. Lacks set of metrics to measure merit of systems.

Lacks consideration for customer (special isterest) input into axceptability meastres. All systems presumed to meet performance requirements.

PLCC estimales catculated tesing the sotnt engineering approach (except no contsideration of time vahe of money, which conld imprece relative costs of the systems). Sensitivity analysis with respect to design and operating assumptions is lacking.

Study results do not faciliente decision making. No axternpt to organize and present tecturical decision criteria.

Systems qualitatively evaluated with respect to tecthoology risk. A quartititive figure-of-merih system comparison started bux not finished.
Systems qualitatively evahuated with respect to technology risk but using different criceria from Phase $I$.

No atterngt al quantitative syseen comparison.
An atempt wos made to present tectinical decision criteria in an organized (tobolar) manner. No afterupt at quantitative system compartson. 
Table 1 (continued)

\begin{tabular}{|c|c|c|}
\hline & ITTS Phese 2 & INTS \\
\hline $\begin{array}{l}\text { Physical and } \\
\text { Econtomic } \\
\text { Databeses and } \\
\text { Other Studies } \\
\text { (Bkock 8) }\end{array}$ & $\begin{array}{l}\text { No discussion on regulation changes and impact on systems. } \\
\text { The spparently large technology databese was not adequately } \\
\text { referenced. }\end{array}$ & $\begin{array}{l}\text { Considerably more } \\
\text { referencing of } \\
\text { tecturodopy databese. }\end{array}$ \\
\hline
\end{tabular}

TABLE 2

Sensitivity Analyses of Critical Assumptions for Selected Systems

\begin{tabular}{lcc}
\hline Assumption & Change in Assumption & Percent Change in PLCC \\
\hline ITTS Baseline & & \\
Seismic Category 1 & Seismic Category 2 & -15.8 \\
50\% Waste Sorted & $75 \%$ waste sorted & +12.3 \\
4032-hr/yr Operation & 8064 -hr/yr operation & -19.3 \\
Minimim Shielding & More extensive shielding & +11.3 \\
GOCO* Operation & Private operation & -17.5 \\
INTS & & \\
Seisquic Cattgory 1 & Seismic Category 2 & -11.7 \\
75\% Waste Sorted & S0\% waste sorted & -13.0 \\
4032-hr/yr Operation & $8064-h / / y r$ operation & -17.0 \\
Unit Disposal Cost $\$ 243 / \mathrm{ft}^{3}$ & Assume \$243 $\pm \$ 100 / \mathrm{ft}^{3}$ & \pm 10.2 \\
Minimum Shielding & More extensive shielding & +12.5 \\
GOCO* Operation & Private operation & -15.9 \\
\hline
\end{tabular}

* Government-owned contractor-operated.

The conclusions of the review were as follows:

- The authors of the LITCO studies have identified and evaluated a wealth of pertinent information on EM cleanup technologies.

- These studies represent a major step forward in the use of an SA to evaluating technologies for use in the remediation of waste sites.

- Although the SA in the LITCO studies was done thoroughly, these studies should be entranceat to terter encompass a futt SE approach.

- The PLCC estimates were calculated in the appropriate level of detail using a sound engineering approach. The only exception is that the tirne value of money (i.e., the use of 
an interest rate to discount future cash flows to their equivalent present value) should have been taken into account.

- The cost-estimating factors used under the GOCO assumption and other very conservative design assumptions (e.g., 4032 operating hours/year) resulted in PLCC estimates that were about one-third higher than in industrial practice.

- No assumptions were found that favored one technology over another. On the contrary, the PLCCs for all of the thermal systems were within the accuracy of the PLCC estimates.

The recommendations of the review were as follows:

- Future such studies should adopt a consistent SE approach similar to the template defined in this report. DOE woukd be well served to develop a Systems Engineering Standard, similar to those already in use by $\mathrm{DOD}^{\prime}$ and $\mathrm{IEEE}_{*}{ }^{2}$ which would serve as the goideline for any future SE studies.

- Noneconomic factors must be considered in a quantitative manner to gain full valtue from the analysis of system alternatives, especially those involving developing technologies that are being considered in competicion for scarce funding. An approach like that cutlined by example in this report should be required for all such SA studies.

- Absolute system costs defined in the three studies should be reexamined, with special emphasis on the major cost sensitivities identified in this report.

- A number of design assurptions warrant further study: 1) one facility to process all MLLW, 2) a feed of "average" waste composition, and 3) the segregation of thermal and nonthermal technologies.

\subsection{DEVELOPMENT OF SE TEMPLATE}

\subsection{Purpose of SE Template}

As part of the effort to evaluate the technical approach of the LITCO studies, an SE template was developed to guide the review of three sndies, the results of which are discussed in Section 2.2. The purpose of the SE template was to prompt critical questions about the design process utilized in the LITCO studies and to enable a fair evaluation of those sudies. The SE template and the derived critical questions, however, can be universally applied to review any proported SE study or any sudy presenting a comparison of system alternatives.

\subsection{Discussion of SE Template}

This section discusses the SE template, previously presented in Figure 1, as well as the questions and points to consider when using the template to evaltate a systems study. Each of the eight blocks in the SE template is further discussed,

${ }^{1}$ DOD-AMSC. Drafi Military Standavd Jor Systems Engineering; Mil-std-499B, Version 2.0, May 1992.

2 IEEE. IEEE Thial-Ulse Standard for Application and Mantigement of the SE Process, IEEEstd, 1220-1994, 1995. 


\subsection{Block I - The Castomer}

The purpose of any system design is to satisfy some customer and stakeholder need. The success of a particular system design is ultimately determined subjectively by the custoner. During the design process, all requirements and decisions should be made from the customer's perspective. Even when the customer is relatively easy to identify, the concerns of "the customer" may not be readily accessible. Accordingly, the customer mist be defined as an all-ixclusive entity. Stakeholders and special interests mist be represented in "the voice of the customer" in a way that reflects the customer's needs and concerns.

Who is the customer?

- Is the customer fully aware and educated as to the need for the system?

- Where is this definition of the customet spelled out?

- Are customer interests generally in agreement or in opposition to each other?

- If the stakeholders and special interests are generally opposed to certain alternatives, is this stated?

How is the roice of the customer "captured?

- Can the customer make effective decisions and give valuable input based on the information available? Is this concern addressed?

- How are the differing opinions of various interests resolved fairly?

- Are all identified interests being represented in the "voice of the customer"? What method is used to ensure representation?

- To what extent is information that represents the "voice of the customer" obtained and used?

- What forum is used to capture the "voice of the customer" (surveys, polls, meetings, interviews, studies, etc.)?

To what extent is the customer involved in dectston making?

- Is the customer directly or indirectly involved in the decision-making process?

- Will only certain interests be active in decision-making, with the remaining interests acting as reviewers?

- Who defines the relationship between decision-making interests and reviewers? Is this made clear?

- What is the purpose of the studies? If the purpose is to evennally facilitate a decision about a preferred alternative system design, then is the audience considered? 
- Is the definition of the customer taken into consideration; i.e., who they are trying to satisfy when presenting the alternative systems?

- In which decisions does the customer participate (decisions at each major milestone, each design change, or when large costs are involved)?

- What weight is given to each interest?

- Is this weighting process relatively more numerical or more subjective in nature?

- Who determines these weights (formally or informally)?

- Is this relationship between the study preparer and all represented in the "voice of the customer" clearly defined?

Are the study decisions traceable to the customer?

- To what extent are the alternative systen designs and decisions traceable to the customer?

- Is sufficient traceability to the customer provided?

- If the "customer" definition is not fully understood at the design level, what criteria are used to synthesize system alternatives?

\subsubsection{Block 2 - Need, Functions, and System Requirements}

The SE approach stems from the identification of a need that develops as a result of a problem or deficiency and the subsequent desire for a system of some type. From the identification of a given need, one must define the basic requitements for the system in terms of input criteria for design. The need and requirements for operation should be clearly defined before problem solutions or system configurations are proposed. Definition of system requirennents should include mission definition, performance and physical parameters, use requirements, deployment and distribution of the system, operational life cycle (horizon), effectiveness factors, and definition of the operational environment. Additionally, any definution of system operationtal requirements should originate with the defined customer requirements.

Arrow A in Figure 1 illustrates the customer inputs to the need definition and requirements specification process. The "voice of the customer" should be the basis for all system requirements. Poorly defined customer requirements or an unclear identification of the customer can lead to a system that either does not satisfy the need or contains superfluous requirements. The definition of the system at this point is purely from a functional viewpoint. The objective is to capture what the system"s overall mission is in a functional sense. At this point, designers should avoid overly constraining the design and should also resist the temptation to jump to the physical manifestation of these requirements.

What are the customer requirements?

- Are all requirements from the customer point of view defined?

- Is the functional nature of the system specified? 
- Are all the requirements related to the functional objective of the system?

- Which requirements are not required to achieve the mission objective? Each requirement must be related functionally to the mission objective.

- Are the customer requirements described in a functional sense? How well are the requirements addressed?

- Are the requirements presented so as to emphasize the main requirements and those that will drive the design the most?

- How are the requirements obvained?

- Is an acceptable method used to extract the requirements from the customer and ensure the completemess of the set of requirements?

- Are the requirements analyzed to deternine whether they were appropriate and functionally correct?

- Are any inconsistencies or problems with the customer requirements pointed out?

- Are the needs/desires of the customer, inchuding stakeholders and special interests, fully represented in qualitative or quantitative terms?

- How are these needs/desires incorporated into the given requirements?

How are customer requirements transiated into system requinements?

- Is it shown how system alternatives meet customer requirements from an operational and functional perspective?

- Is a set of derived system requirements, taken from or translated from the customer requirements, presented?

- Is a functional analysis of the system requirements presented?

- Are functional fiow diagrams of the system generated and presented?

- Are system requirements traceable to the original customer requirements?

- Are performance parameters/requirements such as process rates, system environmental impact, safety, effectiveness, etc., adequately defined and quantifiable measures determined?

- Are the operational environment requirements well defined?

- Are the operational environment requirements sufficient, or are there other questions that need to be answered?

- Are the operational environtnent requirements just assumptions, or are they actual requirements? 


\section{Do the requirenents reflect a systems and life-cycle engineering point of view?}

- Do the requirements consider a time frame for design and development to allow for new, emerging technology refinement?

- What is the time frame for design and development?

- What life-cycle horizon is used for planning?

- What are the avaitable skill levels for operation, maintenarice, support, decontamination and decommissioning (D\&D), and disposal?

- What role do maintenance and support factors play in the defined system requirements to the extent that they influence performance of the system?

- Are D\&D and disposal of the actual system itself considered in the requirements?

- Do the studies consider other life-cycle elements such as maintenance and support?

- Are operational and functional requirements the same for all system alternatives? The only way to ensure a fair comparison is by maintaining consistency in requirements.

\subsubsection{Block 3 - Design Term}

The selection and qualifications of design team members are of utmost importance. It is not enough to have only technological expertise on the design team that relates to the stated need or deficiency represented. A design team that seeks to create a system using systems or life-cycle engineering methodology must have adequate representation from SE as well as chemical engineers, operations engineers, actual users of the system, and others. A design tean that is onesided in its makeup will tend to produce candidate systems that are likewise one-sided. That is, the design will tend to focus too heavily on prime mission equipment and neglect elements such as support, envirommental factors, reliability/availability, and disposability. The design team must have representatives for each of the life-cycle elements that are contained in the set of system requirements. A diversity of perspectives on the design team facilitates consideration of all aspects of the system life cycle. Arrow B in Figure 1 represents a relationship between the set of systen requirements and the selection and makeup of the design team.

\section{What are the quatifications and expertise of the design team members?}

- Are the study design teams appropriately staffed?

- Are all design members qualified for their specific aspect of system design?

- Is the number of team members appropriate?

- Are there too many or too few design members representing a particular aspect of system design on each team?

- Does each of the requirements in the life cycle of the system have a representative on the design team? 
- Is the makeup of the design team presented and justified, along with each team member's responsibilities?

- Are a variety of system aspects represented?

What method was used to select this design team?

- What are the minimum qualifications and system elements represented on the teams?

- Is the makeup of each design team consistent?

Are various aspects of the life cycle represented on the design teann?

- Do design teams include transportation expertise, support expertise, systems engineering expertise, etc.?

Are the motivations/desires of the design team(s) members/contractors consistent with that of the customer?

- Are the concerns of the customer adequately represented on the design teams?

- How is the customer represented on the design team?

- Is bow the customer perceptions and opinions were preserved and used by the design teans discussed?

- Are teams similar in makeup such that meaningful comparison of alternatives can be made between multiple design teams?

- Are consistent design team approaches used? lf not, are the differences known and understood so that the alternative systems from multiple studies can be evaluated fairly against one another?

\subsubsection{Block 4 - Design Syuthesis}

Once a design team and the system operational and functional requirements have been defined, synthesis of various system design alternatives can begin. Depending on the particular phase of system design. design synthesis can consist of technology and system concept identification (in the case of conceptual design) or can be as detailed as compiling various designs for a particular piece of hardware at its most specific level. The objective is to sufficiently describe a number of feasible design alternatives so that analysis and subsequent evaluation and decision making can occur. Design synthesis is a highly subjective and creative process that relies on expert knowledge and state-of-the-art technology identification to synthesize alternative designs. The expert knowledge and experience that is utilized comes from the knowledge and experience of the design team members as represented by Arow $C$ in Figure 1. The preconceived notions of design tearn members about the nature of the system design must be recognized and questioned when proposing cardidate systems.

The candidate system synthesis is driven by a top-down functional definition of the need as well as a bottom-up definition of the set of available technology and system elements. Arrow D in 
Figure 1 represents the input of the two different (but complementary) approsches to system design. It is important to note that the description of each alternative must include system factors and elements other than just the prime process or equipment. Adequate definition of each system alternative must allow for life-cycle analysis and evaluation to reflect the set of determined system requirements. Arrow $\mathbf{E}$ in Figure 1 highlights the defining role that the system requirements play in the synthesis of candidate systems.

How are the various altermatives selected?

- Are all reasonable alternatives being explored?

- What resources are the design teams using to arrive at each alternative?

- Are the methods and sources for the selection of the various alternatives revealed?

- Are the alternatives all existing designs or technologies?

- Are new, emerging technologies explored?

- Does the design effort rely too heavily on either the bottom-up or top-down approach? Both approaches should be utilized in the design synthesis process to ensure a mix of new ideas with proven processes.

- Does the statement of work or design team makeup bias or exclude otherwise reasonable desigo alternatives from consideration?

- Is the exclusion of design alternatives documented?

- Do the design teams sufficiently document the origination of each system alternative?

- Are reasons given for including the candidate system for consideration?

Are altemative selection methods based on stated customer and system requirements?

- If any short listing or exclusion of alternatives occurred, is the justification based on customer and system requirements?

- Does each of the alternatives fit with the stated requirements?

- Are the criteria given for selecting candidate systems?

- Are the selection criteria representative of the entire life cycle?

- Who makes the decision on selection criteria?

- Are each of the alternatives traceable to some or all of the requirements stated?

Are the alternatives defined well enough that meaningful analysis and evaluation can accur?

- Is the set of alternatives defined well enough that some sort of analysis and evaluation can be made? 
- Are the alternatives fully defined from a life-cycle and systems perspective?

- Is sufficient life-cycle information included to estimate and predict parameter values and to evaluate life-cycle cost?

- Does the life-cycle information include at least preliminary ideas about how logistical support, operation, training, maintenance, etc., will be accomplished?

- Can these life-cycle considerations be used as analyses and evaluated against one another?

\section{Are all alternatives comparable?}

- Is each of the alternatives able to be analyzed and evaluated fairly on an equivalent basis?

- Is each of the alternatives defined consistently with the others?

\subsubsection{Block 5 - Estimation and Prediction}

After a set of canơidate systems has been synthesized, each alternative must go through a process of estimation and prediction. Cost and effectiveness measures are generated for these altermatives using established criteria. This SE activity's purpose is to estimate and predict designdependent parameter (DDP) values for each alternative. Estimation and prediction rely on models and simulations to predict parameter values. These models and simulations are based on assumptions, physical laws, and empirical data. Arrow $F$ in Figure 1 represents this available database of physical and econonic factors, as well as existing components, parts, arud subsystems. These parameter values provide a basis for comparison with established design criteria to determine the merit of each alternative. Alternatives that are found to be unacceptable from a performance perspective can be reworked and new alternatives created. Those alternatives that meet all or the most important performance criteria can then be evaluated based on life-cycle costing methodologies.

What are the basic assumptions inherent in each estimation/prediction?

- Are each alternative's DDP values estimated using a consistent set of assumptions?

- Do these assumptions match the assumptions stated in the requirements?

- AIe assumptions too heavily relied on? What are these assumptions?

- Are the models used to estimate values for one alternative consistent with models used on other alternatives?

- Are the assumptions valid? Are they necessary? What overall impact do they have?

- Are the estimates derived from these assumptions important enough to cause possible decision reversal? If so, more work might be needed.

By what means do we consider an alternative's performance acceptable?

- What constitutes ninimum or acceptable system performance? There must be some minimam standard of performance to achieve. 
- Are the acceptable performance criteria presented?

- Are any of the candidate systems not picked for consideration explained?

- When an alternative fails to meet performance criteria, are the deficjencies and areas for improvement identified?

- Are all alternatives held to the same tevel of performance criteria?

How are nonquantifiable parameters handled?

- Is some means provided for determining the "worth" of an alternative design with respect to qualitative parameters such as public confidence, ease of use, etc.?

- Are the qualitative parameters and methods used for determining the "worth" of an alternative design acceptable to the customer? Since these qualitative measures are subjective, care must be taken to capture the opinions of the customer.

- Where are the qualitative parameters discussed? How are they to be handled?

\subsubsection{Block 6 - Design Evaluation}

Given that a set of alternatives minimally satisfies a set of performance criteria, a decision must be made between the alternatives. In order to do this, the cost-effectiveness of the designs needs to be evaluated. As a start, the life-cycle cost of each alternative is determined based on the estirnation and prediction activity just completed. Only after performing a life-cycle cost analysis can a decision be made about the preferred alternative(s). Arrow $G$ in Figure 1 indicates the passing of the estimation and prediction results, the DDP values, to the evaluation step. The entire life cycle "inception to disposal" must be considered in the life-cycle cost analysis. Some methodology must be utilized to estimate life-cycle cost. The cost breakdown structure (CBS) needs to be developed and used for each altenative. It should be obvious from the CBS whether a life-cycle approach to cost estimation is applied. Also, the time value of money principle must be applied.

What is the definition of the system's lfe cycle?

- Is each phase of the life cycle considered?

- Is a life-cycle model presented?

- Is a description of the life-cycle cost elements presented?

- Are all aspects of the system represented in the life-cycle model?

- Is the life-cycle cost estimation procedure defined?

- Are all system elements, i.e., support, operation, maintenance, disposal, training, etc., represented in the life-cycle definition and/or CBS?

By what means is the Iffe-cycle cost calculated?

- What method is used to calculate life-cycle cost? (activity-based costing, CBS, etc.) 
- Is this method utilized consistently over the entire life cycle and across alternatives?

- What assumptions are made that affect life-cycle cost calculations?

- Is the effect of the assumptions on decision reversal examined?

- Which cost assumptions are critical enough to warrant further sudy?

- Are any assumptions, technologies, vague requirements, etc., for further investigation reported or identified? Identification of critical assumptions and others is a fundamental part of the SE process, especially at the conceptual design level.

- What interest rate, tax rate, depreciation rate, etc., is considered?

- Are rent versus buy options defined as mutually exclusive alternatives? If not, design synthesis should be revisited and these alternatives considered.

\subsubsection{Block 7 - Design Decision Schema}

After each alternative has been evaluated with respect to life-cycle cost, a decision can be made as to the preferred alternative(s). Given the variety of opinions represented by the customer and the mumber of decision criteria the customer will have, choosing a preferred alternative is usually not a simple matter of picking the least expensive design. Customer opinion and perception play a large role in this subjective decision-making process. Based on the definition and input from the customer about what is desirable in the system, a decision evaluation can be made. These design criteria are derived from the set of customer and system requirements and are represented by Arrow $H$ in Figure 1. This process of weighing multiple decision criteria against life-cycle cost is mostly subjective. The decision maker must now trade off life-cycle cost against other decision criteria subjectively. These parameter values are passed from the evaluation step along with DDP values, as seen in Arrow $I$. The result is one or more preferted alternatives that can be used to continue the design process to a more detailed level. These preferred alternatives are always ultimately judged by the customer. Arrow $\mathbf{J}$ słows the preferred candidate system being returned for review by the customer.

\section{What method will be used to facilltate the decision-makting process?}

- Is the decision-making process facilitated by the work done to this point?

- Is the study constructed to facilitate the decision-making process?

- Is the ultimate goal to present many altematives for a decision by the customer? Or is the objective of the sndies to select a preferred candidate system or set of candidate systems with which to proceed?

- Are all design decision criteria identified and estimation and prediction completed?

- Do the decision criteria trace back to the customer requirements and concerns?

- Are the alternative systems developed, analyzed, and evaluated in enough detail so that a decision can be reached, or are the systems evaluated in a manner that does not allow for a decision to be made? 
- If the designs are not evaluated well enough, are reasons given?

- Are areas for further sudy identified before a decision can be made?

- Should the decision be made to continue with multiple designs until a better evaluation can be done? What is reported?

- Is the customer, as defined, a major participant in the decision-making process?

- What assures that the "voice of the customer" is represented in the decision-making process?

\section{What are the established decision criteria and thresholds for each?}

- Are the decision criteria and thresholds that define the goals and opinions of the decision maker documented?

- Do the selected criteria adequately reveal the deficiencies and differences between alternatives?

- Are there any customer concerns or opinions that are not addressed that are necessary to satisfy the customer? If so, then requirements and criteria must be added to the design process to correct this deficiency.

- Is the design, synthesis, amalysis, and evaluation process iterative in nature?

\section{How were the decistons reached?}

- Is there traceability within the decision-making process?

- Is traceability provided in decision making? How are longer lists of candidate systems shortened? Where are the criteria for selection?

- Are the decisions documented with the appropriate reasoning and criteria values?

- If the decision makers are not the customer, how are they held accountable to the customer?

- How does the customer have input to the decision-making process? Is this role documented?

- Are the decisions made on a fair or equivalent basis?

\subsubsection{Black 8 - Physical and Economic Databases and Other Studies}

This block represents a resource for the SE process rather than an actual step in the process flow. There exists a body of knowledge that engineers, economists, and scientists rely on to perform analyses and evaluations. This body consists of known physical laws, empirical data, economic forecasts, and other studies. It also conprises those existing system components, parts, and subsysterns that have resulted from previous design efforts. This body of knowledge is great. To what extent it is utilized is a concern in SE. It is very easy in the design of a complex system to 
"reinvent the wheel." Reuse of existing systems and components is encouraged in the SE process. This body of knowledge and experience is utilized more informally than in a formal sense. There are, of course, useful formal treatments of this body of knowledge.

To what extent is rense encouraged and past experience depended on?

- Are all system components "new" designs, or to the selected alternatives build upon previously proven technologies and designs?

- Are uses or reliance on past efforts documented?

- Are uses of past designs and work appropriate for this design effort?

- Is justification provided for use of past designs? Or, should more attention be devoted to new design work?

- Are areas and potential for future and needed research and development identified?

Where do assumptions made during the SE process originate?

- Do assumptions made in estimation and prediction have a basis in fact or in theory?

- Are there sufficient saldies or data to support such assumptions?

- Are economic factors, i.e,, interest rates, tax rates, depreciation, etc., forecast using sound economic priaciples?

- Where estination occurs, are the appropriate assumptions consistent with the alternative design?

What effect does this bady of knowledge or expert knowledge have on the allemative selection and decision-making process?

- Does the body of expert knowledge bias the alternative selection by the design team?

- What criteria are used to make decisions about selected alternatives?

- To what extent is engineering and expert judgment relied on to provide answers or estimates of design parameters, and is this documented?

- What effect do these assumptions have on decision making, and are they adecuately explored?

- Are decisions based on the estimation, prediction, and evaluation activities or solely on enginering judgment, and are these decisions documented and justified?

\subsection{SA TOOLS DEVELOPMENT}

\subsection{Process Stmulation as an SA Tool}

Systems analysis, defined as the prediction of system performance (e.g., operating cost) and evaluation of the performance based on defined criteria, can be facilitated by the utilization of computer simulation or modeling. As part of the systems analysis efforts, the EERC performed 
limited evaluations of two process sirnulation software packages. The ASPEN PLUS v9.3 by AspenTech and PRO/II v4.0 by Simulation Sciences Inc., are similar in many respects. Both offer a relatively comvenient interface between the user and the modeling package with guidance to ensure that all necessary information is provided. They are capable of performing essentially the same unit operations. Their thermodynamic and physical property data sets are both extensive.

The two packages do have some significant differences. ASPEN PLUS runs in a DOS environment and PRO/II is Windows-compatible. ASPEN PLUS is able to deal with coal as well as proximate and ultimate analyses and particle-size distributions where PRO/I cannot. Economic evaluations of a model can be done by ASPEN PLUS but not by PRO/I. ASPEN PLUS is capable of performing automatic sensitivity analyses with graphical representation of the results. The commercial copy, I-year lease for PRO/I with PROVISION interface costs $\$ 15,000$, while a lease for ASPEN PLUS with the sange provisions costs $\$ 30,000$.

Process simulation using either ASPEN PLUS or PRO II is initiated by:

- Drawing the process flowsheet using icons representing unit operations and lines representing streams

- Defining the components that will be found in the streams

- Selecting the themrodynamic methods that will be used in the simulation

- Defining the compositjons and flow rates of feed streams

- Specifying unit operation conditions.

When the model is completed, the simulation is run. Using physical property and thermodynamic data, the software will calculate compositions and conditions of product strearns. The model can then be adjusted to better ernulate actual operating data or to achieve desired results. Parameters can be changed and the simulation run again. A sensitivity analysis can effectively be performed to determine the effect on process performance of an independent operating variable. Similarly, a design specification can be attained by manipulating any specified independent variable.

With necessary information supplied, ASPEN PLUS can calculate equipment costs, capital costs, operating costs, and profitability, with each step building on the previous one. To calculate equipment costs, design type, material of constnuction, and mumber of each piece of equipment must be specified. Also often necessary will be definition of process conditions, equipment dimensions, and values of constants for design equations. The estimation of fixed capital costs requires a project start date. Other factors such as purchase date, production date, interest rate, and labor and overhead costs can be defined by the user or left with default or inferred values. To estimate operating costs, utility costs, prices of raw materials, and operating cost data must be provided. There are three options available when performing a profitability analysis. These are based on initial product selling price, interest rate of return, or net present value of the project. Whichever option is chosen, product prices, estimated start-up costs, estimated working capital, and plant life must be defined. 


\subsection{Application of Process Simulation for Economic Analysis}

A method for removal of organic contaminants such as fuels and pesticides from soil was developed by researchers at the EERC. The process was seen to offer possibilities for soil remediation at smaller, highly contaminated sites. However, before development work on the process was allowed to proceed beyond the bench-scale, two determinations had to be made. The first was whether or not the process could be expected to be economically viable. If the process could not compete with existing remediation methods, continued development would offer little benefit. Secondly, if the process were found to be competitive, identification of parameter(s) with the potential to significantly impact the economics of the process would be most useful. Research directed at better determining the limits and effects of an important parameter would provide the greatest benefit for time and money spent. Improved knowledge of the process would also allow a more accurate economic evaluation of the system as a whole.

Process modeling using ASPEN/PLUS ${ }^{\text {TM }}$ was employed to generate the economic information needed to facilitate the go/no go decision. Experimental data as well as several assumptions were provided by the researchers to describe the process as it was expected to function when scaled up. The profitability analysis of the modeled process found that, at the proposed processing rate of 200 pounds per hour, the cost per unit of soil processed was not competitive. As the primary contributions to cost were capital equipment and operator time, a more likely commercial scale rate of five tons $(10,000$ pounds) per hour was proposed and evaluated. At this processing rate, the process was indicated to be competitive with remediation processes intended for the same purpose.

As the process was apparently competitive, four process parameters that would probably vary within expected ranges were evaluated for effect on profitability. Sensitivity analysis indicated that all of the parameters chosen did affect the cost per unit of soil but, in the ranges evaluated, none individually made the process noncompetitive. One of the parameters was found to have a larger impact on operating costs than any of the others. Greater understanding of the actual range of this parameter would be the most important direction of further research. Two other parameters that had a lesser impact on costs were believed to be able to affect the most important parameter. They must also be looked at for their own effects and for their potential effects on the range of the most important parameter. 


\section{APPENDIX A}

\section{REVIEW OF THE INTEGRATED THERMAL AND NONTHERMAL TREATMENT SYSTEM STUDIES}




\section{REVIEW OF THE INTEGRATED THERMAL AND NONTHERMAL TREATMENT SYSTEM STUDIES}

Final Report

DOE Cooperative Agreement No. DE-FC21-94MC31388

Submitted to:

Mr. Larry K. Rath

U.S. Department of Energy

Morgantown Energy Technology Center

PO Box 880

Morgantown, WV 26507-0880

Submitted by:

Habib A. Durrani, SAIC Thomas A. Erickson, EERC John Etjavec, EERC Wolter J. Fabrycky, VT Mark A. Musich, EERC Lanny J. Schmidt, EERC Everett A. Sondreal, EERC Edward N. Sieadman, EERC John $\mathbf{S}$. Wilson, WPI 


\section{DISCLAIMER}

This report was prepared as an account of work sponsored by an agency of the United States Government. Neither the United States Government, nor any agency thereof, nor any of their employees makes any warranty, express or implied, or assumes any legal liability or responsibility for the accuracy. completeness, or usefulness of any information, apparanus, product, or process disclosed or represents that its use would not infringe privately owned rights. Reference herein to any specific commercial product, process, or service by trade pame, trademark, manufacturer, or otherwise does not necessarily constitute or imply its endorsement, recommendation, or favoring by the United States Government or any agency thereof. The views and opinions of authors expressed herein do not necessarily state or reflect those of the United States Government or any agency thereof.

\section{EERC DISCLAMMER}

LEGAL NOTICE This research report was prepared by the Energy \& Environmental Research Center (EERC), an agency of the University of North Dakota, as an account of work sponsored by U.S. Department of Energy. Because of the research nature of the work performed, neither the EERC nor any of its eniployees makes any warranty. express or implied, or assumes any legal liability or responsibility for the accuracy, completeness, or usefulness of any information, apparatus, product, or process disclosed, or represents that its use would not infringe privately owned rights. Reference herein to any specific commercial product, process, or service by trade name, trademark, manufacturer, or otherwise does not necessarily constitute or imply its endorsement or recommendation by the EERC.

\section{ACKNOWLEDGMENTS}

Because of the short time line involved in producing this review, the rapid acquisition of information was essential. The authors would like to acknowledge the contributions of the following individuals in providing the necessary information to conduct this study: Tom Bechtold (LITCO), Chuck Biagi (MK), Jan Brown (WPI), H.P. Loh (METC), Shawn Looney (VT), and Gary Knight (WPI). 
TABLE OF CONTENTS

LIST OF FIGURES $\ldots \ldots \ldots \ldots \ldots \ldots \ldots \ldots \ldots \ldots \ldots \ldots \ldots \ldots \ldots$ iii

LIST OF TABLES $\ldots \ldots \ldots \ldots \ldots \ldots \ldots \ldots \ldots \ldots \ldots \ldots \ldots \ldots \ldots \ldots \ldots$

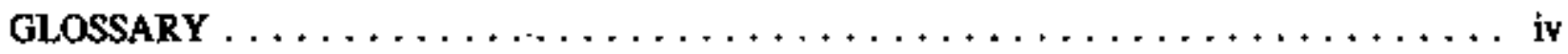

EXECUTIVE SUMMARY $\ldots \ldots \ldots \ldots \ldots \ldots \ldots \ldots \ldots \ldots \ldots$

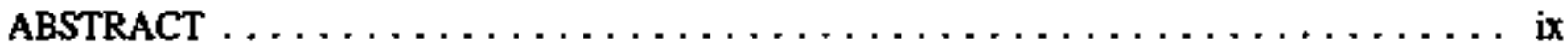

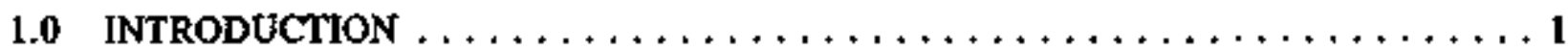

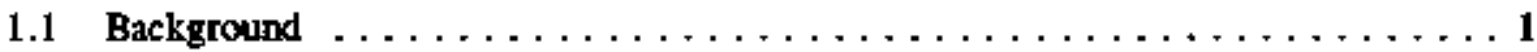

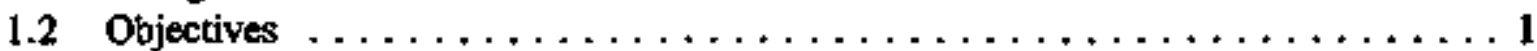

1.3 Review Process and Report Content $\ldots \ldots \ldots \ldots \ldots \ldots \ldots \ldots \ldots \ldots, \ldots \ldots \ldots$

2.0 SYSTEMS ENGINEERING APPROACH $\ldots \ldots \ldots \ldots \ldots \ldots \ldots \ldots \ldots \ldots$

2.1 Template for the Application of SE $\ldots \ldots \ldots \ldots \ldots \ldots \ldots \ldots \ldots \ldots$

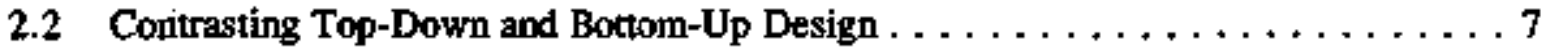

2.3 Inclusion of Performance Measures in Systems Engineering Sudies . . . . . . 8

3.0 REVIEW OF REPORTS $\ldots \ldots \ldots \ldots \ldots \ldots \ldots \ldots \ldots \ldots \ldots \ldots \ldots \ldots$

3.1 Technical Approach $\ldots \ldots \ldots \ldots \ldots \ldots \ldots \ldots \ldots \ldots \ldots \ldots \ldots$

3.1.1 The Systems Engineering Process $\ldots \ldots \ldots \ldots \ldots \ldots \ldots \ldots$

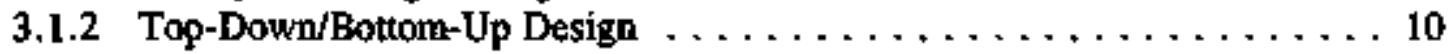

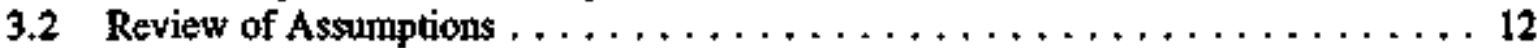

3.2.1 Regulatory $\ldots \ldots \ldots \ldots \ldots \ldots \ldots \ldots \ldots \ldots \ldots \ldots \ldots, \ldots \ldots \ldots$

3.2.2 Waste Characteristics $\ldots \ldots \ldots \ldots \ldots \ldots \ldots \ldots \ldots \ldots \ldots \ldots \ldots$

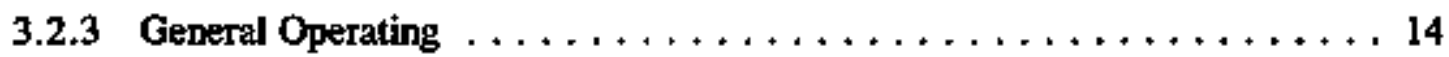

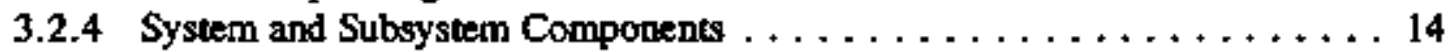

3.3 Economic Predictions and Sensitivities to Predictions $\ldots \ldots \ldots \ldots \ldots \ldots \ldots 14$

3.4 Performance Evaluation of Phase 2 Technologies $\ldots \ldots \ldots \ldots \ldots \ldots \ldots$

4.0 CONCLUSIONS AND RECOMMENDATIONS $\ldots \ldots \ldots \ldots \ldots \ldots \ldots$

EXPANDED DISCUSSION OF SYSTEMS ENGINEERING APPROACH $\ldots \ldots$ Appendix A

UTILIZATION OF THE SYSTEMS ENGINEERING TEMPLATE IN REVIEW OF THE TECHNICAL APPROACH OF THE ITTS AND INTS REPORTS $\ldots \ldots \ldots$ Appendix B

EXPANDED DISCUSSION OF THE TOP-DOWN VERSUS

BOTTOM-UP APPROACH $\ldots \ldots \ldots \ldots \ldots \ldots \ldots \ldots \ldots \ldots \ldots \ldots$ Appendix $C$ 
TARLE OF CONTENTS (continued)

IDENTIFIED ASSUMPTIONS FOR THE ITTS STUDY - PHASE $1 \ldots \ldots \ldots$ Appendix D IDENTIFIED ASSUMPTIONS FOR THE ITTS STUDY - PHASE $2 \ldots \ldots \ldots$ Appendix E IDENTIFIED ASSUMPTIONS FOR THE INTS STUDY $\ldots \ldots \ldots \ldots \ldots \ldots$ Appendix F ASSUMPTIONS FROM THE ITTS PHASES 1 AND 2 REPORTS AND THE INTS REPORT WITH HIGH COST SENSITIVITY AND UNCERTAINTY . Appendix G ASSUMPTIONS OF INTEREST FROM THE ITTS PHASE 2 ANALYSIS OF PERFORMANCE MEASURES $\ldots \ldots \ldots \ldots \ldots \ldots \ldots \ldots \ldots \ldots \ldots \ldots \ldots$ Appendix $H$ EXAMPLE OF EVALUATION OF PERFORMANCE

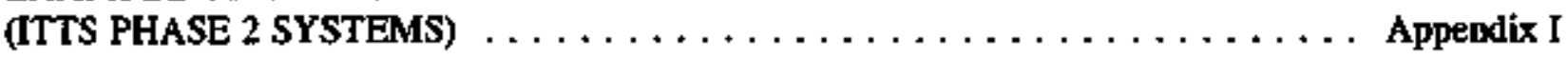




\section{LIST OF FIGURES}

ES-1 Systems engineering template displaying the eight elements for evaluating a technical approach $\ldots \ldots \ldots \ldots \ldots \ldots \ldots \ldots \ldots \ldots \ldots \ldots$

2.1-1 Systems engineering template displaying the eight elements for evaluating a technical approach $\ldots \ldots \ldots \ldots \ldots \ldots \ldots \ldots \ldots \ldots \ldots \ldots$

\section{LIST OF TABLES}

ES-1 Review of the Approach Used in the ITTS and INTS Reports Using the Systems Engineering Template $\ldots \ldots \ldots \ldots \ldots \ldots \ldots \ldots \ldots$ vii

ES-2 Sensitivity Analyses of Critical Assumptions for Selected Systems . . . . . . . . viii

3.1-1 Review of the Approach Used in the ITTS and INTS Reports Using the Systems Engineering Template $\ldots \ldots \ldots \ldots \ldots \ldots \ldots \ldots \ldots \ldots \ldots$

3.2-1 DOE Orders Governing the Regulatory Assumptions Used in the Study . . . . . . 13

3.3-1 Sensitivity of PLCC to Changes in Assumptions: System Al - Baseline System ITTS 、 16

3.3-2 Sensitivity of PLCC to Changes in Assumptions: ITTS Phase 1 Systems $\ldots \ldots \ldots 17$

3.3-3 Sensitivity of PLCC to Changes in Assumptions: ITTS Phase 2 Systems

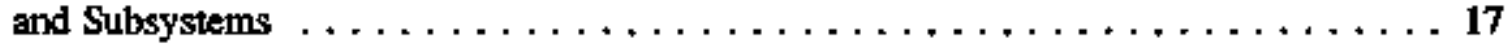

3.3-4 Sensitivity of PLCC to Changes in Assumptions: INTS - System $1 \ldots \ldots \ldots \ldots 18$

3.3-5 Sensitivity of PLCC to Changes in Assumptions for INTS Systems and Subsystems . . 19 


\section{GLOSSARY}

\begin{tabular}{ll} 
APC & air pollution control \\
BDAT & best demonstrated available technology \\
CAA & Clean Air Act \\
CBS & cost breakdown structure \\
D\&D & decontamination and decommissioning \\
DDP & design-dependent parameters \\
DOD & U. S. Department of Defense \\
DOE & U. S. Department of Energy \\
EERC & Energy \& Environmental Research Center, University of North Dakota \\
EM & environmental management \\
EPA & U. S. Environmental Protection Agency \\
ESH & environmental safery and health \\
FOM & figure of merit \\
GOCO & government-owned-contractor-operated \\
IEEE & Institute of Electrical and Electronic Engineers \\
INEL & Idaho National Engineering Laboratory \\
INTS & integrated nonthermal treatment system \\
ITTS & integrated thermal treatment system \\
KT & Kepner-Tregoe \\
LITCO & Lockheed ldaho Technologies Company \\
LLW & low-level waste \\
MEO & tilediated electrochemical oxidatiog \\
METC & Morgantown Energy Technology Center, DOE \\
MK & Mortison-Kmidsen \\
MLLW & Inixed lowrlevel waste \\
MSO & molten salt oxidation \\
NPLCC & nommalized planning life-cycle cost \\
PCB & polychlorinated biphenyl \\
PLCC & planning life-cycle costs \\
PSTP & preliminary site treatment plan \\
R\&D & research and development \\
RCRA & Resource Conservation and Recovery Act \\
SA & systems analysis \\
SAIC & Science Applications International Corporation \\
SCWO & supercritical water oxidation \\
SE & systems engineering \\
SEMP & systems engineering management plan \\
TCLP & toxicity characteristic leaching procedure \\
TSCA & toxic substances control act \\
TSWG & Tribal and Stakeholder Working Group \\
VT & Virginia Tech \\
WPI & Waste Policy Instimte \\
WPS & weighted performance criteria score for entire treatment system \\
WPTSS & sweighted performance criteria score for thermal subsystem \\
& \\
\hline
\end{tabular}




\section{EXECUTIVE SUMMARY}

This report analyzes three systems analysis (SA) studies performed by LITCO on integrated thermal trearment systems (ITTSs) and integrated nonthermal trearment systems (INTSs) for the remediation of mixed low-level waste (MLLW) stored throughout the U.S. Department of Energy (DOE) weapons complex. The review was performed by an independent team of nine researchers from the Energy \& Environmental Research Center (EERC), Science Applications International Corporation (SAIC), the Waste Policy Institute (WPI), and Virginia Tech (VT). The three stodies reviewed were as follows:

- Integrated Thermal Treatment System Sudy. Phase 1 - issued July 1994

- Integrated Thermal Treatment System Suxdy, Phase 2 - issued February 1996

- Integrated Nonthermal Treatment System Study - drafted March 1996

This analysis was performed under Cooperative Agreement DE-FC21-94MC31388 for the DOE Morgantown Energy Technology Center. The purpose of this review was to 1) determine whether the assumptions taken in the studies might bias the resulting economic evaluations of both thernal and nonthermal systems, 2) identify the critical areas of the sardies that would benefit from further investigation, and 3) develop a standard template that could be used in future stadies to produce sound systems engineering (SE) applications.

The three studies evaluated were all commissioned by DOE to be SA studies of Environmental Management (EM) systems. Nonetheless, they were reviewed to how far beyond SA they went along the road toward being full SE studies. To that end, a common framework or template for SE was developed and used to examine the three studies and evaluate the validity and completeness of the approach taken in each. This template is shown below (Figure ES-1).

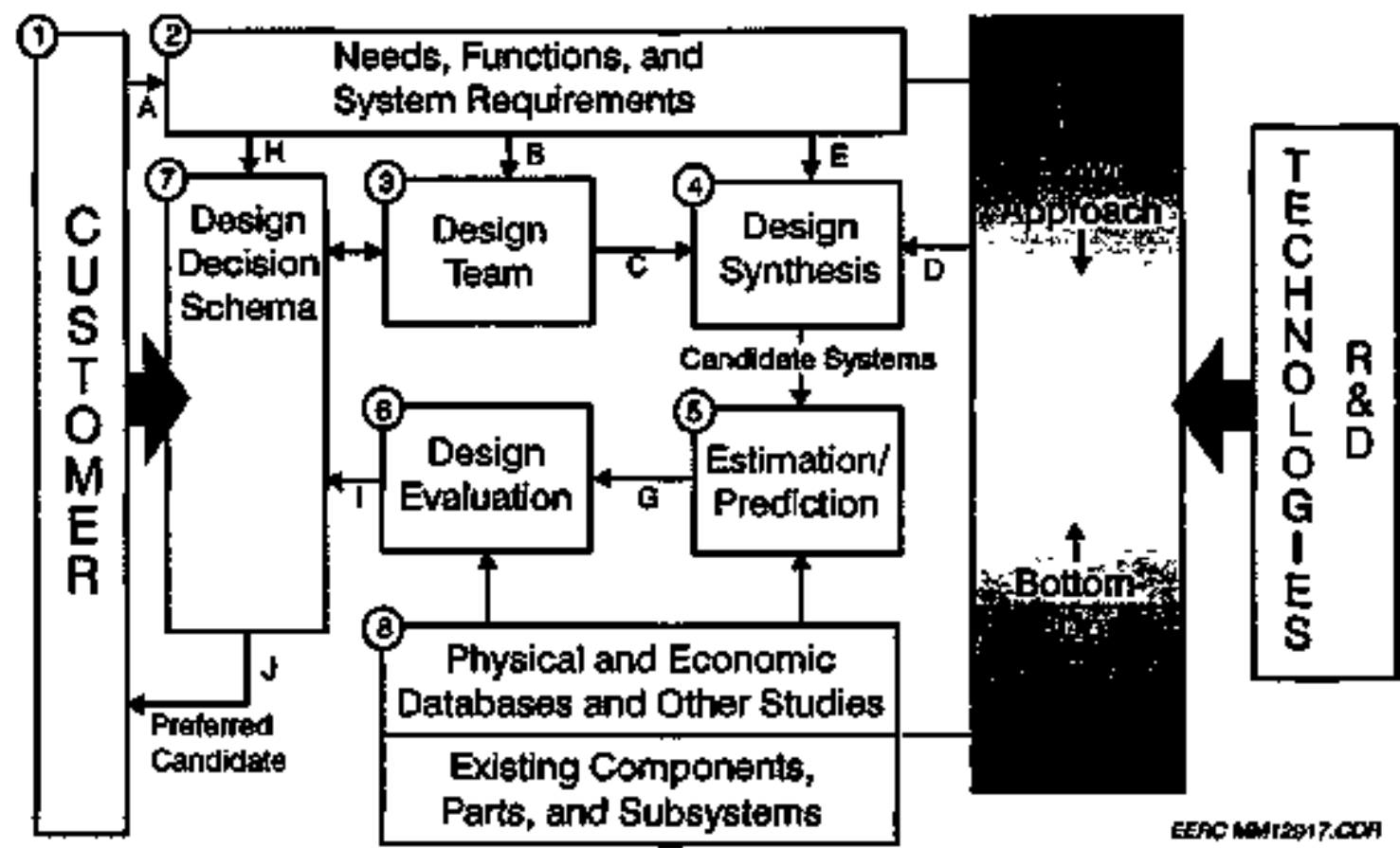

Figure ES-1. Systems engineering template displaying the eight elements for evaluating a technical approach. 
The ITTS and INTS reports represent a great stride forward in the use of a systems approach to the evaluation of waste remediation technologies. Not only were technologies put in a systems serting so as to allow upstream and downstream consequences of the use of the technologies to be judged. but total life-cycle costs were used, so that technologies at different stages of development could be compared. But, it should be recognized that a full SE review is needed in order to finally make a decision as to which systems look the most promising and therefore which (sub)systems warrant further development. So, whichever SE steps were not done as part of the three sudies need to be completed to "finish the job." The review of the three studies in relation to the template is shown in Table ES-1. When reviewing Table ES-1, it should be kept in mind that LITCO (for the very valio reason of potential conflict of interest) was specifically prohibited from carrying its aralysis to the point of making recommendations as to which remediation technologies were the best. So the lack of a complete SE anghysis by LITCO in the three sudies was a direct result of a policy decision by DOE.

The three studies airned to develop life-cycle costs of various technical approaches to remediating MLLWs. Design assumptions used in the studies produced costs that are essentially equjvalent for all the technical options, thus limiting the usefulness of the output in decision making about the developinent prospects for the technologies being considered. The evaluation of noneconomic performance criteria-cost sensitivity, cost uncertainty, regulatory compliance, implementablity, flexibility to handle variable waste, operability, maintainability, availability, and decontarnination and decommissioning - using expert judgment and methods such as the Kepner-Tregoe approach, could provide additional differentiation anong technologies. An example of such an analysis for the ITTS Phase 2 systems was carried out, and is given in Appendix I. The example shows that a weighted average performance plotted versus cost will likely show clear differences between the technologies. The example in Appendix I is given to demonstrate the methodology and should not be taken as definitive, because only a fraction of the important performance measures were used in the analysis, only one engineer evaluated the various performance measures, and only the ITTS-Phase 2 systeras were evaluated. A thorough application of this method is recommended for the amalysis of all developmental technologies to assist in decisions abcut the viability of technology options. While the ITTS Phase 1 study initiated the application of such an approach, it was not carried out as part of the study by LITCO for the reason already cited. This analysis needs to be performed by some organization/team in order to provide more focused input to the decision-making process.

Within the life-cycle cost analyses on the ITTS and INTS, many design assumptions were necessarily made to develop the final results. Over 1200 assumptions were identified in the review. Among these assumptions, a few critical ones had major impacts on overall bife-cycle costs. These major assumptions have been subjected to sensitivity analysis to determine their impacts on the overall plant costs defined in the studies. Significant design conservatism was inherent in the studies. For example, all systems were designed for Category 1 seismic region construction, adding 11 to 16 percent to overall plant life-cycte costs. Facility operation was assumed to be only abott half tine, adding about 20 percent to life-cycle cost. Conversely, many developmental systems were assumed to be able to perform; the penality associated with system failure could add 5 to 10 percent to life-cycle cost. The summary of the impacts of major assumptions (with $>10$ percent impact on planning life-cycle costs [PLCC]) is shown in the following table (Table ES-2).

The conclusions of this analysis are as follows:

- Future such studies should adopt a consistent SE approach similar to the template defined in this report. 
TABLE ES-1

\section{Review of the Approach Used in the ITTS and INTS Reports Using the Systems Engineering Template}

\begin{tabular}{|c|c|c|c|}
\hline & ITTS Pingiol 1 & IITS Plinge 2 & INTS \\
\hline $\begin{array}{l}\text { The } \\
\text { Cystomer } \\
\text { (Glock 1) }\end{array}$ & 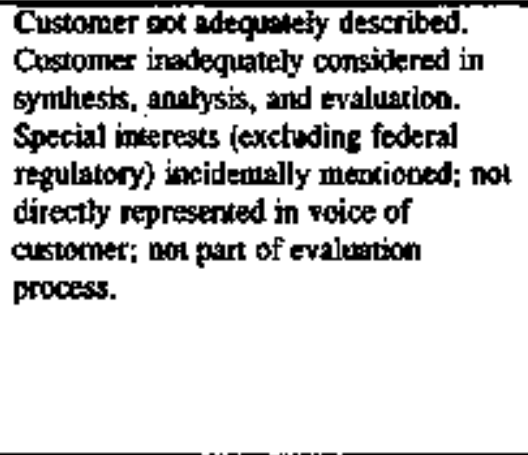 & $\begin{array}{l}\text { Special incerests broader in definition } \\
\text { but stil not represented as custorer } \\
\text { of tincluded in evalonton process. }\end{array}$ & 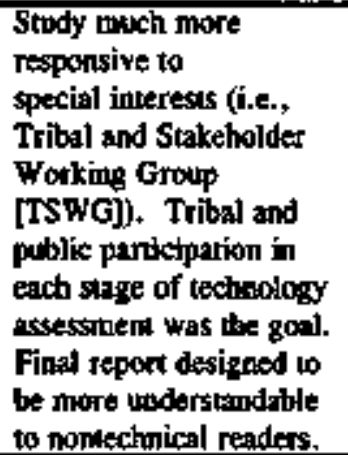 \\
\hline $\begin{array}{l}\text { Need, } \\
\text { Functions, } \\
\text { and System } \\
\text { Requirements } \\
\text { (Bloct 2) }\end{array}$ & $\begin{array}{l}\text { Sudies lack adecinite requitements and } \\
\text { Partial functional analysis attenpted for } \\
\text { No evidenace of fumction:al analysis and s }\end{array}$ & 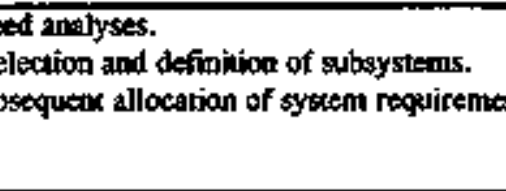 & \\
\hline $\begin{array}{l}\text { Desigen Tearn } \\
\text { (Btock 3) }\end{array}$ & $\begin{array}{l}\text { No details prowhded for areas of } \\
\text { expertise, areas of responsibility, } \\
\text { criteris for addition to team. } \\
\text { Pante of engineers for system dowp- } \\
\text { selecting bot described }\end{array}$ & $\begin{array}{l}\text { DOE inceral review pand reviewed } \\
\text { draft report, but contributions nox } \\
\text { discussed. } \\
\text { Latger study teant than betiore. }\end{array}$ & $\begin{array}{l}\text { Mary members of study } \\
\text { team have changed. } \\
\text { TSWG could indirectly } \\
\text { be considered part of the } \\
\text { desigh wam. }\end{array}$ \\
\hline $\begin{array}{l}\text { Design } \\
\text { Syathesis } \\
\text { (Block 4) }\end{array}$ & 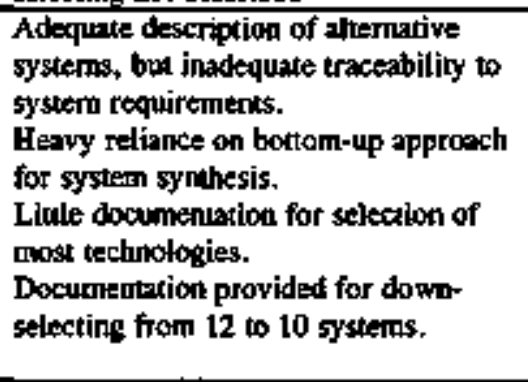 & $\begin{array}{l}\text { No documeriation provided for } \\
\text { down-selecting systems. }\end{array}$ & $\begin{array}{l}\text { TSWG developed list of } \\
\text { pontechnical criteris to } \\
\text { assist TSWG it } \\
\text { technology down- } \\
\text { selecting. } \\
\text { Evldence for } \\
\text { inconporating } \\
\text { nomtedmical criteria into } \\
\text { down-selecting not } \\
\text { adeovale. }\end{array}$ \\
\hline $\begin{array}{l}\text { Estimation } \\
\text { and } \\
\text { Prediction } \\
\text { (Block 5) }\end{array}$ & $\begin{array}{l}\text { Lacks performance acceptabilify criteria } \\
\text { Lacls consideration for customer (speci } \\
\text { All sysiens presumed to meel perfomma }\end{array}$ & $\begin{array}{l}\text { ind carget values. Lacks set of metrics t } \\
\text { interest) inpux into accepcablity measum } \\
\text { e requiremeats. }\end{array}$ & mensure merit of systems. \\
\hline $\begin{array}{l}\text { Design } \\
\text { Evaluation } \\
\text { (Block } 9)\end{array}$ & $\begin{array}{l}\text { PLCC estmates cakculated using the sot } \\
\text { money, which cousd impact selative cost } \\
\text { Sensitivity atholysis with respect to desig }\end{array}$ & $\begin{array}{l}\text { A engineering approach (except to cons } \\
\text { of the systems). } \\
\text { ma opersting assumptions is lacking. }\end{array}$ & fation of time value of \\
\hline $\begin{array}{l}\text { Design } \\
\text { Decision } \\
\text { \$cluema } \\
(\text { Bleck } 7 \text { ) }\end{array}$ & 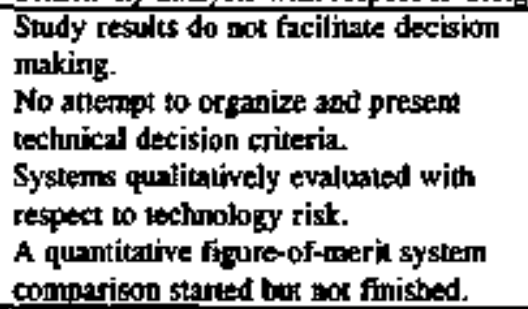 & 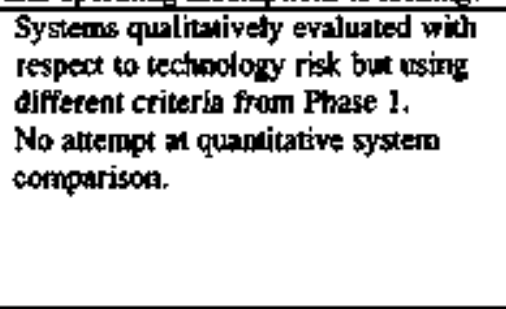 & 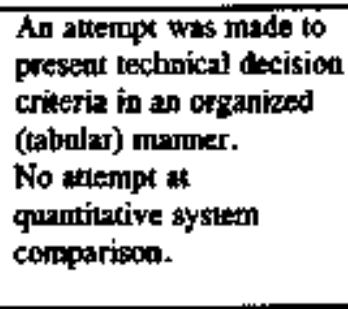 \\
\hline $\begin{array}{l}\text { Physical ofd } \\
\text { Economic } \\
\text { Dobabases } \\
\text { and Otber } \\
\text { Soudies } \\
\text { fylock } 8 \text {. }\end{array}$ & \multicolumn{2}{|c|}{$\begin{array}{l}\text { No discussion on regulation changes and impact on the systems. } \\
\text { The apparenty lage tectuology database was not mieppately referenced. }\end{array}$} & $\begin{array}{l}\text { Considernbly nort } \\
\text { referencing of techtolosy } \\
\text { database. }\end{array}$ \\
\hline
\end{tabular}




\section{TABLE ES-2}

Sensitivity Analyses of Critical Assumptions for Selected Systems

\begin{tabular}{ccc}
\hline ITTS Baseline & & \\
Assumption & Change in Assumption & Percent Change in PLCC \\
\hline Seismic Category 1 & Seismic Category 2 & -15.8 \\
$50 \%$ waste sorted & $75 \%$ waste sorted & +12.3 \\
4032 hr/yr operation & 8064 hr/yr operation & -19.3 \\
Minimum shiejding & More extensive shielding & +11.3 \\
GOCO* operation & Private operation & -17.5 \\
INTS & & \\
\hline Seismic Category 1 & Seismic Category 2 & -11.7 \\
$75 \%$ waste sorted & $50 \%$ waste sorted & -13.0 \\
4032 hr/yr operation & 8064 hr/yr operation & -17.0 \\
Unit disposal cost $\$ 243 / \mathrm{ft}^{3}$ & Asstme $\$ 243 \pm \$ 100 / \mathrm{ft}^{3}$ & \pm 10.2 \\
Minimurn shielding & More extensive shielding & +12.5 \\
GOCO* operation & Private operation & -15.9 \\
\hline
\end{tabular}

* Government-owned-contractor-operated.

- Noneconomic factors must be considered in a quantitative manner to gain full value from the analysis of system atternatives, especially those involving developing technologies that are being considered in competition for scarce funding. An approach like that outlined by example in this report should be required for all such systems analysis stadies.

- A (relatively small) number of assumptions were found that bave major impacts on the PLCC. These assumptions should be reviewed by the whole design team and/or an independent peer review panel to ensure that they are the most reasonable assumptions at this point in time.

- Some design assumptions were very narrowly defined to allow for the initial analysis. These assumptions need to be reevaluated to ensure that final analyses are applicable to the real world. 


\begin{abstract}
ARSTRACT
This report contains a review and evaluation of three systems analysis sudies performed by LITCO on integrated thermal treatment systems and integrated nonthemal treatment systems for the remediation of mixed low-level waste stored throughout the U.S. Department of Energy weapons complex. The review was performed by an independent team of nine researchers from the Energy \& Envirommental Research Center, Science Applications International Corporation, the Waste Policy lnstitute, and Virginia Tect. The three studies reviewed were as follows:

- Integrated Thermal Treatment System Study, Phase 1 - issued July 1994

- Integrated Thermal Treatment System Study, Phase 2 - issued February 1996

- Integrated Nonthennal Treament System Study - drafted March 1996

The puspose of this review was to 1) determine whether the assumptions of the studies were adequate to produce an unbiased review of both thermal and nonthermal systems, 2) to ifentify the critical areas of the studies that would benefit from further investigation, and 3) to develop a standard template that could be used in future studies to assure a sound application of systems enginering.
\end{abstract}




\section{REVIEW OF THE INTEGRATED THERMAL ANB NONTHERMAL TREATMENT SYSTEM STUDIES}

\subsection{INTRODUCTION}

\subsection{Background}

The U.S. Deparment of Energy (DOE) Environmental Management Office of Technology Development (EM-50) conmissioned Lockheed Idaho Technologies Company/ldaho National Engineering Laboratory (LITCO/INEL) to carry out a series of studies to evaluate systern altematives for treating contact-handled, alpha and nonalpha, radioactive mixed low-level waste (MLLW). The MLLW within the DOE complex comprises various organic and inorganic liquids and solids contaminated with radioactive wastes and Rescusce Conservation and Recovery Act (RCRA) metals. The systems are intended to destroy the organic materials and stabilize the remaining material, including radioactive wastes, for long-term storage. The purpose of LITCO's systematic engineering evaluation of a variety of MLLW treatment system alternatives was to help DOE in the prioritization of research, development, and demonstration activities for remediation technologies. The reports resulting from these studies are listed below:

- Integrated Thermal Treatment System (ITTS) Sudy, Phase 1 - issued July 1994

- Integrated Thermal Treatment System (ITTS) Sudy, Phase 2 - issued February 1996

- Integrated Nonthermal Treatment System (INTS) Sudy - drafted March 1996

This report provides a review of these three studies to further aid DOE in its cutrent and future decision-making processes. Since a systerns enginering (SE) approach is ultimately needed for system design, and the LITCO studies are a large part of the whole evaluation process, the methodology in the studies was compared to a sound SE approach. This was done to help DOE determine which tasks still need to be accomplished to complete a thorough design/review.

\subsection{Objectives}

The goals of this review were to provide DOE with the necessary information to determine whether a more detailed review of the LITCO studies is warranted, to identify the areas of the studies that would warrant funure attention, and to highlight tasks that would complement the LITCO studies to form a thorough SE evaluation.

To achieve the above-mentioned goals, the following objectives were identified:

1) determine whether the assurnptions of the reports were adequate to produce an unbiased review of thermal and nonthermal systens, 2) to identify areas of the study that could be expanded/enhanced to produce a better decision-making product, and 3) provide a template to guide funure SE studies.

The specific issues outined by the DOE Morgantown Energy Technology Center to be included within this review were as follows:

- Review facility designs as well as engineering and operating assumptions 
- Review cost estimation methods, bases, and assumptions

- Evaluate uncertainty of assumptions

- Review submodels for both baseline and alsernative technologies to assess sensitivity of planning life-cycle costs (PLCCs) to the assumptions

- Determine which assumptions were critical in determining PLCCs for a given technology and which were critical to the relative technology rankings

- Review the systems engineering/systems analysis approach for potential improvements.

\subsection{Review Process and Report Content}

This review was conducted by a team of nine individuals employed by four different organizations (the Energy \& Envirommental Research Center [EERC], Science Applications International Corporation [SAIC], the Waste Policy Institune [WP], and Virginia Tech [VT]). The review evaluated the data and findings in the three study reports and performed limited spreadsheet calculations to aid in deternining economic sensitivities and performance measures.

This review was initiated in late April of 1996 and concluded approxinately 8 weeks later. Because of the extremely short time line, further review of the LITCO stodies and further analysis of thermal and nonthermal treatment systerns is recommended.

This report covers two primary topics: a description of a thnical approach to SE and a review of the ITTS and INTS snudies. The technical approach section presents a recommended template for future SE studies to ensure more consistent, traceable, and rank-classified results. The review section contains specific comments on the LITCO studies reviewed. It was the authors' intent to produce an easily readable version of the review by relegating the lengthy discussions on approaches and assumptions to the appendices.

\subsection{SYSTEMS ENGINEERING APPROACH}

Systems engineering is a management tool that provides a frarnework for decision making in planning, implementing, and controlling the development and application of new technologies. A recommended SE approach is outlined in detail in Appendix A and discussed briefly below.

The SE approach is a logical implementation process that compares alternative system designs against input requirements by means of a top-down functional analysis. The resulting synthesis can be continuously evaluated for adequacy. Decisions are made on recommended solutions, which can become input for subsequent cycles of SE analysis, leading to final selection and application. A critical element is the ability to feed back SE results to refine input information by verifying and validating input requirements as the results of trade-off studies become available. Cost drivers should be identified early so that they can be evaluated against operational benefits. This continuous review process serves to identify problem areas before they become "embedded" and create significant cost, schedule, or performance impacts. 


\subsection{Template for the Application of SE}

Broadly defined, SE is "the effective application of scientific and engineering efforts to transform an operational need into a defined system configuration through the top-down iterative process of requirements definition, functional analysis and allocation, synthesis, optimization. design, test, and evaluation." ${ }^{n}$ The SE process, in its evolution of functional detail and design requirements, has as is goal achieving the proper balance between operational (i.e., performance), economic, and disposal factors. Inherent in the SE process are the concepts of life cycle and concurrent engineering. The design of systems depends greatly on the effective use of SE as well as traditional design methods that are essentially bottom-up in nature.

In order to facilitate the application of the SE process to futare studies, a generic SE template was developed. The elements of the template are illustrated in Figure 2.1-1, with a description of the respective blocks and the questions addressed by each block discussed below.

\section{BLOCK 1 - The Customer}

The purpose of any system design is to satisfy customer and stakeholder needs. The success of a particular system design is ultimately determined by the customer. During the design process. all requirements and decisions should be determined from that perspective. Stakeholders and special interests must be represented in "the voice of the customer" in a way that reflects their needs and concerns.

Questions to ask:

- Who is the customer?

- How is the "voice of the customer" caprured?

- To what extent is the customer involved in decision-making?

- Are the sardy decisions traceable to the customer?

BLOCK 2 - Need, Functions, and System Requirements

The objective of the block is to define the system's functional mission. The SE study identifies a need to address an opportunity, problem, or deficiency. The identified need(s) are used to define the basic requirements of the system in terms of input criteria for design and operation. These criteria should be defined before system configurations are proposed. Definition of system requirements should include mission, performance and physical pararneters, the operational environment, use requirements, effectiveness factors, deployment and distribution, and the operational life-cycle horizon. In Figure 2.1-1, Arrow A indicates customer inputs defining needs, functions, and requirements. The system should be defimed only by function, not form, at this point.

\footnotetext{
'Blanchard, B.S.; Fabrycky, W.j. Systems Engineering and Anatysis; Second Edirion, Prentice Hall, 1990.
} 


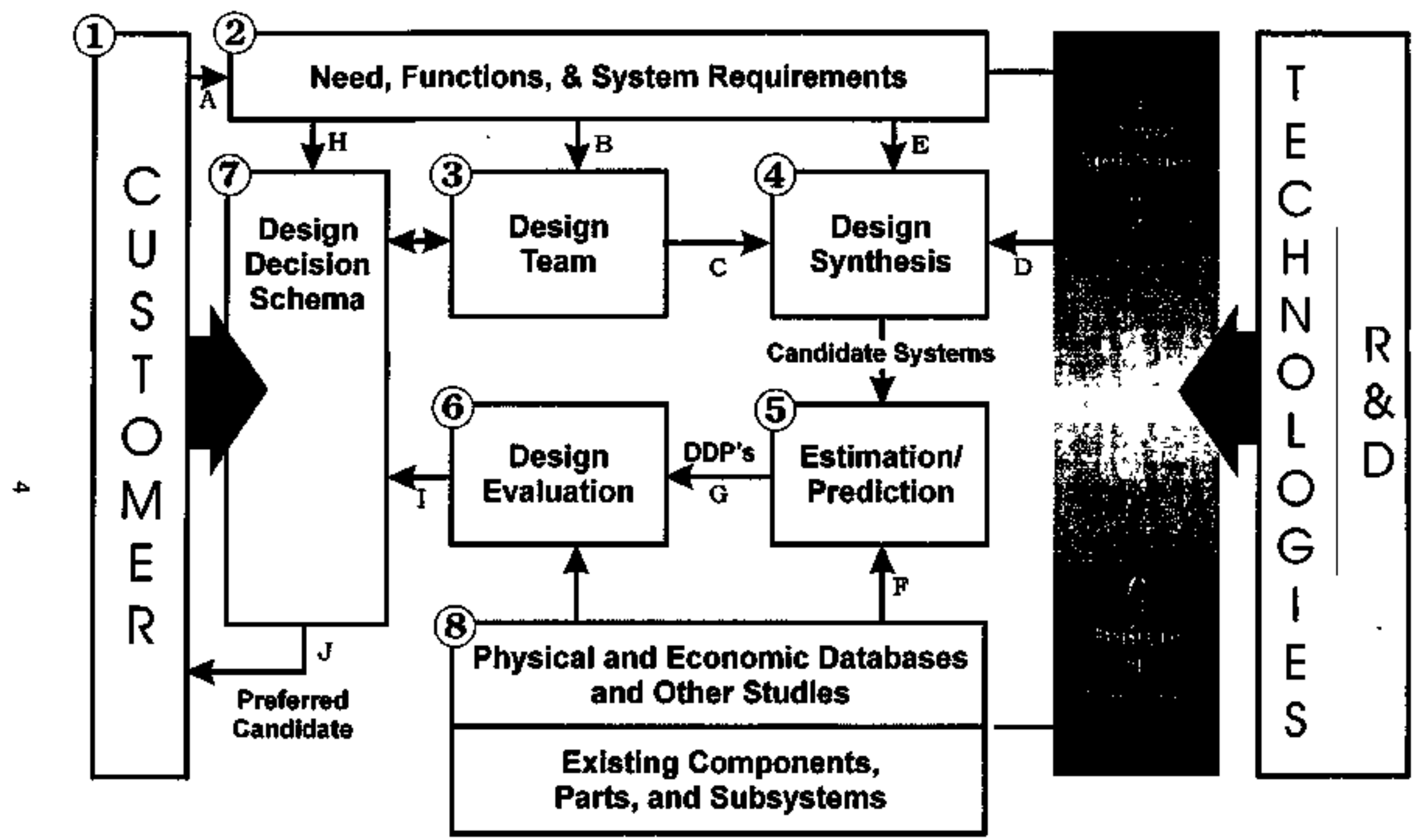

Figure 2.1-1. Systems engineering template displaying the eight elements for evaluating a technical approach. 


\section{Questions to ask:}

- What are the custorner requirements?

- Have customer requirements been translated to system requirenents?

- Do the requirements reflect a systems and life-cycle engineering point of view?

\section{BLOCK 3 - Design Team}

The design team selected must be balanced in terms of in-depth technical expertise and the broader methodology of SE. The team should incluce representation for each of the life-cycle elements contained in the set of system requirements. Measured consideration should be given to all aspects of the design, from the primary mission equipment to the supporting elements or attributes for achieving environmental compliance: fiexibility, reliability, maintainability. availability, and disposibility. A diversity of perspectives on the design team facilitates consideration of all aspects of the system life cycle. Arrow B represents a relationship between the set of system requirements and the selection and makeup of the design team.

Questions to ask:

- What are the quatifications and expertise of the design team members?

- What method was used to select this design team?

- Are various aspects of the system life cycle represented on the design team?

- Are the motivations and desires of the design tean(s) menbers/contractors consistent with those of the customer?

\section{BLOCK 4 - Design Synthesis}

Design synthesis is a creative process that reties on expert knowledge of state-of-the-art technology to describe a number of feasible design alternatives so that an analysis and subsequent evaluation and decision making can occur. Depending on the phase of system design, the synthesis car involve either conceptual elements or particular pieces of hardware at a very detailed level. Input by the design team is represented by Arrow C. The design team members must question their own preconceived vision of the end system when proposing candidate designs. The cancidate system synthesis is driven by both a top-down functional definition of the need and by a bottom-up definition of the available technology for system elements. Arrow D represents the input of these two different, but complementary, approaches to system design. Adequate definition of each system alternative must allow for life-cycle analysis and evaluation to reflect the set of determined system requirements. Arrow E highlights the defining role of system requirements in the synthesis of candidate systems.

Questions to ask:

- How are the various alternatives selected?

- Are alternative selection methods based on stated customer and system requirements? 
- Are the alternatives defined well enough such that meaningful analysis and evaluation can occur?

- Are all alternatives comparable?

\section{BLOCK 5 - Estimation and Prediction}

In the estimation and prediction block, cost and effectiveness measures are generated using models and simulations to predict design-dependent parameter (DDP) values for each alternative. These models and sunulations are based on assumptions, physical laws, ande empirical data. Arrow F represents this available database of physical and economic models, as well as descriptions of existing components, parts, and subsystems. The DDP values provide the basis for comparing system designs against input criteria to determine the merit of each alternative. Alternatives that are found to be unacceptable in performance can be either discarded or reworked and new alternatives created. Alternatives that meet all or the most important performance criteria can then be evaluated based on life-cycle cost.

Questions to ask:

- What are the basic assumptions inherent in each estimation/prediction?

- By what means do we consider an alternative's performance acceptable?

- How are nonquantifiable parameters handled?

BLOCK 6 - Design Evaluation

Life-cycle cost is the basis used for comparing alternative systems that meet minimum requirements by performance criteria. The life-cycle cost of each alternative is determined based on the estimation and prediction activity just completed. Arrow $\mathbf{G}$ indicates the passing of the predicted DDP values to the evaluation step. The entire life cycle "from lust to dust" must be considered using a cost breakdown structure (CBS) developed for each alternative. including the time value of money. The selection of preferred alternative(s) can only be made after the life-cycle analysis is completed.

Questions to ask:

- What is the definition of the system's life cycle?

- By what means is the life-cycle cost calculated?

\section{BLOCK 7 - Design Decision Schema}

Given the variety of customer needs and perceptions included in the input criteria in Block 2, choosing a preferred alternative is usually not just the simple matter of picking the least expensive design. Input ctiteria derived from customer and system requirements are represented by Arrow $\mathbf{H}$ and the DDP values and life-cycle costs by Arrow I. The decision maker must now trade off lifecycle cost against other decision criteria subjectively. The result is one or more preferred altematives that can be used to continue the design process to a more detailed level. These preferred alternatives are always ultimately judged by the customer; therefore, we show Arrow J renurning the preferred candidate system for review by the customer. 
Questions to ask:

- What method will be used to facilitate the decision-making process?

- What are the established decision criteria and thresholds for each?

- How were the decisions reached?

\section{BLOCK 8 - Physical and Economic Databases and Other Studies}

This block represents a resource for the SE process rather than an actual step in the process flow. There exists a body of knowledge that engineers, economists, and scientists rely on to perform analysis and evaluation tasks. This body consists of known physital laws, empirical data, econonic forecasts, and other studies and models. It also includes descriptions of existing system components, parts, and subsystems. It is very important to use existing databases in SE to avoid "reinventing the wheel." This body of knowledge and experience can be utilized both formally and informally in performance of SE studies and the decisions that follow.

Questions to ask:

- To what extent is reuse encouraged and past experience depended on?

- Where do assumptions made during the SE process originate?

- What effect does this body of knowledge or expert knowledge have on the alternative selection and decision-making process?

\subsection{Contrasting Top-Down and Bottom-Up Design}

Traditional engizeering design methodology is based on a bottom-up approach. Starting with a set of known elements, design engineers synthesize the product or system by finding the most appropriate combination of system elements. However, unless the product is quite simpie, it is unlikely that the functional need will be met on the first attempt. After determining the performance deviation from what is required (by prediction, simulation, measurement, or other means), the combination of elements is altered, and the system performance determined again.

A top-down approach to design is evoked by SE. Starting with requirements for the external behavior of any part of the system (expressed in terms of the function provided by that part externatly or to other parts of the system), that behavior is analyzed to identify its functional characteristics. These functional behaviors are then described in more detail and made more specific.

There are two main differences between the bottom-up and top-down approaches: In bottomup design, physical realizability in terms of known elements is assured, whereas at the end of the top-down design process, the systems elements are stitl functional entities. Their physical realizability is not guaranteed. In the top-down approach, the requirements are ideally always satisfied through every step of the design process (as an inherent part of the methodology), whereas in the bottom-up approach, the methodology provides no assurance that this witl oceur. Most projects will employ both methodologies-first SE to reduce the complexity by partitioning the system into its elements and then bottom-up design to realize the elements. 
A more thorough discussion contrasting top-down and bottom-up methodology is presented in Appendix C.

\subsection{Inclusion of Performance Messures in Systems Engineering Studies}

It is important when performing a systems analysis study to include the ability to measure both economics and performance. The economic measure commonly used, preliminary life-cycle cost, is easy to grasp, but the measure of performance for a system becomes more subjective and complicated. Evaluation of noneconomic performance criteria of the system technologies, to be discussed in Section 3.4, was performed using an adaptation of a form of decision analysis described by Kepner and Tregee. ${ }^{2}$ This systematic approach to assist decision making produces a quantitative ranking of alternatives based on the experiences and facts avalable to the decision maker(s).

The first step is to establish the relative importance of each objective, or, in this case, performance criteria, with respect to all other objectives. This is accomplished through mumerical weighting. The lowest-weight, or least important, objective is taken as the baseline standard against which all other objectives are ranged or ranked. The second step is to judge the performance of each alternative, in this case systems and subsystems, against the objectives (performance criteria). This is done by mumerically scoring each alternative with respect to each objective using any suitable scale, with the best alternative(s) receiving the highest score and all other alternatives scored relatively. The third step consists of multiplying the weight of each objective by the score assigned to each alternative. The fourth step consists of adding up the weighred scores to generate a total for each alternative. The results serve to quantify the altematives and help to identify the best course of action.

\subsection{REVIEW OF REPORTS}

This section of the review discusses the approach used by LITCO for their studies relative to an ideal SE process, the validity of the assumptions made, the sensitivities of the economics to those assumptions, and the quantifications of performance measures. The studies perfotmed have identified a wealth of qualitative information on perticent environmental management (EM) cleantup technologies, but the systems evaluation performed was not carried to its logical conclusion of ranking systems based on explicit cost and performance criteria. This review concentrates on the quantitative application of SE and the generation of results that can be used to make decisions.

\subsection{Technical Approach}

This section summarizes the review of the technical approach of the LITCO studies. This review was directed from a SE perspective. The various aspects of SE, as well as comments and review of the LITCO suidies are presented. It should be stated again that LITCO was asked to perform a systems analysis of each of the potential remetiation technologies; it was not asked to perform a full systerns engineering design. But, sixce SE is ultimately needed to complete the system design process, the LJTCO studies were compared to the SE template to determine what

${ }^{2}$ Kepner, C.H; Tregoe, B.B. The Retionst Manager; MoGraw-Hill Book Company; New York, New York. 1965. 
pieces were still missing. These pieces must be filled in by some organization(s)/team(s). The statement that the LITCO saudies are deficient as SE sudies should not be construed as a criticism of LJTCO-they did what they were commissioned to do, which was systerns analysis. The deficiencies pointed out below (in Section 3.1) are meant to serve as a guide for DOE, detailing the steps necessary to complete the systems design and evaluation process.

\subsubsection{The Systems Engineering Process}

As already defined in Section 2.1, SE is the effective application of scientific and engineering efforts to transform an operational need into a defined system configuration through the top-down iterative process of requirements definition, functional analysis and allocation, synthesis, optimization, design, test, and evaluation. The SE process has as its goal achieving the proper balance between operational (i.e., performance), economic, and disposal factors. It is this balance of factors that this review examines. Appendix A goes into much greater detail about the nature and application of SE and how this balance is achieved.

Inherent in the SE process are the concepts of life cycle and concurrent engineering. It is very important that all aspects of the system life cycle be represented in each phase of system design. Attention must be paid to all phases of the life cycle early in design to avoid problems and surprises later and to ensure that the operational need is futfilled. Subsystem and life-cycle phases cannot be considered independently. It is also important that the design of various elements of the system be pursued and analyzed concurrently with each of the other elements. These principles, atong with adherence to the functional, top-down definition of system elements, are the fundamentals of SE.

A conceptual systems desiga study, or in this case a preconceptual study, has as its basis a need and requirements analysis. The problem and need to be filled must be fully understood. Any conceptual design study should begin with a complete neets analysis. The problem must be defined from a functional point of view. The LITCO studies did not devote enough effort or time to these fundamental activities. The "functional requirements" and "functional allocation diagrams" spoken of in the studies are not consistent with SE. In the studies, it is stated that "functional requirements" were developed for each alternative system. The inconsistency here is that there exists only one fumctional mission to perform, regardless of system alternatives. There should be only one set of functional requirements. The system needs to be defined from a functional point of view before physical realization of the system can occur.

The LITCO studies do define candidate systems and their developmental requirements quite well. However, there is no traceability during the synthesis of these alternatives. All candidate systems must derive from and be traceable back to the systent operational and functional requirements. The studies are deficient in documentation of the candidate system synthesis process. Since the candidate systems are not readily traceable to these requirements, there is to insurance that the chosen "systems" actually perforn the mission at hand.

Additionally, the LITCO soudies did not fully explore an appropriate means of decision making. This approach was started in the ITTS Phase 1 study, but was abandoned (as directed by DOE). A set of decision-making criteria must be developed and adhered to consistently from the initiation of any study. As it has been assumed that each of the systems performs nominally well, 
then the design decisions must be based on economics and other, subjective, criteria. The LITCO studies do not adequately spell out the design criteria or facilitate decisions. The life-cycle cost analysis in the LITCO studies, although prepared using a sound enginering approach, has limited utility because there is no sizeable difference in the candidate systems as far as life-cycle cost goes.

The lack of customer involvement, principally in the ITTS sudies, is of concern because without "the voice of the customer," the design and acceptance of any system may be compromised. Care must be taken to identify and consider "the customer" throughout the design process. There is insufficient evidence of consideration for special interest or stakeholder concerns in the ITTS studies. In contrast, and to the benefit of the study, the concerns of the customer are addressed in the INTS suxdy. Although these studies wire commissioned to be otly a systems analysis of various MLLW remediation tecknologies, they still represent a major step forward in the use of a SE approach to evaluating those technologies. Further, although the SE in the sudies was far from complete, marked improvement in applying SE principles was noted for the INTS report. However, although a set of nontechnical principles was devised by a working group of the special interests, the final step of incorporation of these principles into decision making must still be made.

The technical approach review of the IITS and INTS studies, gaided using the eight-block SE template ciscussed in Section 2, is summarized in Table 3.1-1. A summary of the base study review comments is given in the ITTS Phase 1 column. Subsequent changes or improvements in methodology or content for the IMTS Phase II and the INTS studies are indicated in the respective colsmns. These comments summarize a more detajled examination of the LITCO studies found in Appendix B.

\subsubsection{Top-Down/Bottom-Up Design}

Appendix $\mathrm{C}$ gives a more detailed description of the relationship between the top-down and bottom-up approaches to design. The LITCO ITTS and INTS snudies primarily used a bottom-up methodology. In Section 1.2 of the ITTS study (Phase 1) and Section 1.8 of the INTS sudy, it is stated that "A key to accurate evaluation of the thermal treatment systems is using an integrated systems engineering approach." However, the SE design process depends on a rigorcus, systematic approach to need and requirements definition followed by functional analysis. In using a bottom-up approach, as is the case with these sudies, the functional analysis is often neglected, and expert judgment and creativity are relied upon as the sole method of design synthesis.

SE does not replace the need for bottom-up design. At some point in the design process there has to be a transition from the functional (or abstract) to the physical. Most development programs will employ both methodologies: first SE to reduce the complexity and partition the system into its elements and then bottom-up design to realize the elements. The two approaches must complement each other.

On balance, the ITTS and INTS studies do not sufficiently address the input requirements and functional analysis needed to ensure a system design that meets all performance requirements and fulfills the functional mission. These studies provide a good technical review of the various technologies that may be useful in a MLLW treatment system, but they do not adequately perform the type of functional analysis that is needed to select the preferred system warranting further development. 
TABLE 3.1.1

Review of the Approach Used in the ITTS and INTS Reprrts Using the Srstems Engineering Template

\begin{tabular}{|c|c|c|c|}
\hline & [TTS Phase 1 & ITTS Phase 2 & INTS \\
\hline $\begin{array}{l}\text { The Customer } \\
\text { (Block 1) }\end{array}$ & $\begin{array}{l}\text { Customier not adequately describefi. } \\
\text { Customer inadequately considered in } \\
\text { symthesis, analysis, and evaluation. Special } \\
\text { interests (excluding federal segulatory) } \\
\text { incidentally mentioned, not directly } \\
\text { represented in roice of custoner; bot purt of } \\
\text { evaluation process. }\end{array}$ & $\begin{array}{l}\text { Special interests bronder in definition, but } \\
\text { still not represented as customer or } \\
\text { incluled ì evaluation process. }\end{array}$ & 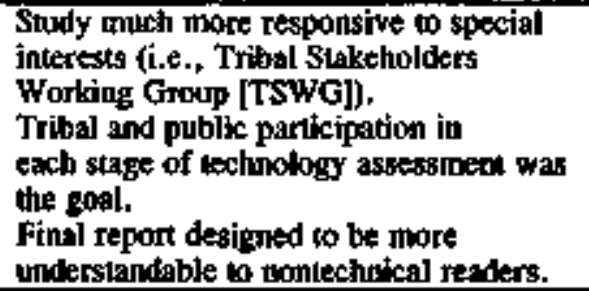 \\
\hline $\begin{array}{l}\text { Need, Functions, and } \\
\text { System Requirements } \\
\text { (Block 2) }\end{array}$ & \multicolumn{3}{|c|}{ 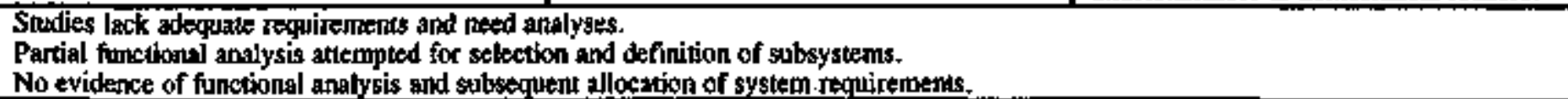 } \\
\hline $\begin{array}{l}\text { Design Team } \\
\text { (Block 3) }\end{array}$ & $\begin{array}{l}\text { No details provided for areas of expertise, } \\
\text { arteas of responsibility. criteria for addition to } \\
\text { tean. } \\
\text { Panel of engineers for system down-selecting } \\
\text { not described. }\end{array}$ & $\begin{array}{l}\text { DOE internal review panel reviewed draft } \\
\text { report, tut contributions not discussed. } \\
\text { Larger sturly thand than before. }\end{array}$ & $\begin{array}{l}\text { Many members of study team have } \\
\text { changed. } \\
\text { TSw } \text { could indirectly be considered part } \\
\text { of the design tean. }\end{array}$ \\
\hline $\begin{array}{l}\text { Design Synthesis } \\
\text { (Block 4) }\end{array}$ & $\begin{array}{l}\text { Adequate description of ahernative systems, } \\
\text { but inadiequate traceability to system } \\
\text { requirements. } \\
\text { Heary reliance on bottom-up approxch for } \\
\text { systern synthesis. } \\
\text { Litule documentation for selection of most } \\
\text { tectmologies. } \\
\text { Documemation provislod for down-selectiog } \\
\text { from } 12 \text { to } 10 \text { syatem designs. }\end{array}$ & $\begin{array}{l}\text { No documentation provided for down- } \\
\text { selecting systen designs. }\end{array}$ & $\begin{array}{l}\text { TSWG developed list of nortechnical } \\
\text { criteria to assist TSWG in technology } \\
\text { down-selectiog. } \\
\text { Evidence for incorposating nontechnics } \\
\text { criteria into down-selecting not adequate. }\end{array}$ \\
\hline $\begin{array}{l}\text { Estimation and } \\
\text { Prediction } \\
\text { (Block 5) }\end{array}$ & \multicolumn{3}{|c|}{ 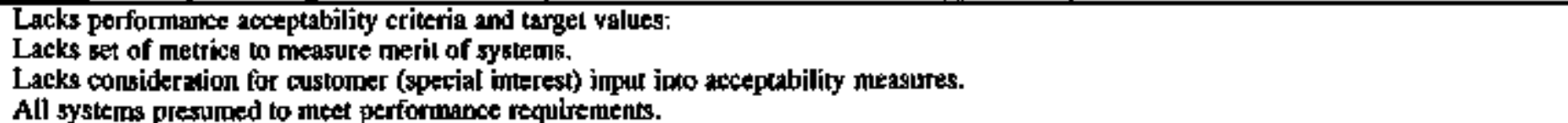 } \\
\hline $\begin{array}{l}\text { Design Evaluation } \\
\text { (Block 6) }\end{array}$ & \multicolumn{3}{|c|}{ 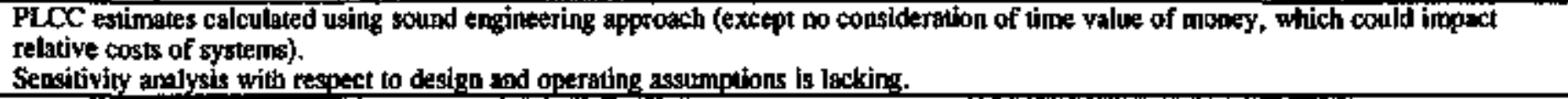 } \\
\hline $\begin{array}{l}\text { Desigin Decision } \\
\text { Schema } \\
\text { (Elock } 7 \text { ) }\end{array}$ & $\begin{array}{l}\text { Study resolts do not facilitate decision } \\
\text { making. } \\
\text { No attempt to organize and present technical } \\
\text { decision criteria. } \\
\text { Systems qualftatively evaluated with respect } \\
\text { to technology risk. } \\
\text { A quarxitative figure-of-merit system } \\
\text { comparison started but not finished. }\end{array}$ & $\begin{array}{l}\text { Systems qualitatively evaluated with } \\
\text { respect to techoology rist but using } \\
\text { different criteria from Phase } 1 \text {. } \\
\text { No artempl at quanlitative system } \\
\text { comparison. }\end{array}$ & $\begin{array}{l}\text { An attedipt was piade to present lechnlcal } \\
\text { decision criteria tim an organized (tabutar) } \\
\text { manner. } \\
\text { No attempt at quantitative system } \\
\text { comparison }\end{array}$ \\
\hline $\begin{array}{l}\text { Finysical and } \\
\text { Econtomic Databases } \\
\text { and Other Studies } \\
\text { (Blixt 8) }\end{array}$ & \multicolumn{2}{|c|}{$\begin{array}{l}\text { No discussion on tegulation changes and impact on the systems. } \\
\text { The apparently large techunology data bases is not adequately referenced. }\end{array}$} & $\begin{array}{l}\text { Considerably move relereacing of } \\
\text { technology dausbase. }\end{array}$ \\
\hline
\end{tabular}




\subsection{Review of Assumptions}

The assumptions used within the SE study are discussed broadly below. Over 1200 assumptions were identified by the review team as listed in Appendices D, E, and F. The discussion below does not attempt to address all of the specific assumptions, but rather the underlying themes. Section 3.3 addresses assumptions with economic consequences and examiznes the sensitivity of PLCC to the critical assumptions; Section 3.4 addresses assumptions based on performance criteria. It is noted that the origins of many of the assumptions were not traceable, but for this review it is immaterial whether any particular assumption was dictated by DOE, stakeholders, or LJTCO (or Morrison-Knudsen [MK])-the effect on the SE study is still the same.

The following discussion is divided into regulatory. waste characteristics, general operating. and system and subsystem component assurnptions. In general, the three LITCO stuoties do not aid decisions about which subsystems and systems are best, based on cost. This is largely due to the broad assumptions that were made, such as assuming a single processing site and an average waste stream. The result is an averaging effect that tends to make most systems look similar and to deemphasize the differences that would warrant selection or rejection.

\subsection{Regulatory}

The treatment of regulatory assumptions in the LITCO studies was appropriate; however, the DOE orders have since been changed or canceled. But upon close examination, although many of the orders have changed in identification, they have not changed substantially in content. Table 3.2-1 lists the primary DOE orders cited in the studies and the currently applicable replacement DOE orders. Future studies should reference the new numbers. The moving regulatory targets (DOE regulations, disposal waste characterization, waste inventories, anti others) can significantly inflenence the results of a large study. It is important that the study include a view of the future, so far as it can be reasonably predicted. The sudies did show evidence of a futuristic view of the regulations for trace metal emissions by assuming more stringent limits than currently required by EPA.

\subsubsection{Waste Characteristics}

The waste characteristics tiscussed here include both the input and output (for disposal) waste streams, as well as the isstes related to characterizing wastes. For this study, an average waste stream was assumed for designing all systems. This assumption provides a basis (although it is artificial) for designing and costing a waste treatment system, but it is not particularly meaningful. The notion of treating an "average" waste streant is problematic. The wastes that will be processed will have various ranges of radionuclides, inorganics, and drganics. For an accurate comparison of technologies, the systems considered need to be designed to handle this waste variability. The variability of the waste stream will most likely have the largest effect on the nonthermal systems. This important operating characteristic, flexibility, is discussed in Appendix I (for the ITTS Phase 2 systerns). 
DOE Orders Governing the Regalatory Assumptions Used in the Sudy

\begin{tabular}{|c|c|c|}
\hline $\begin{array}{c}\text { Old DOE } \\
\text { Order }\end{array}$ & $\begin{array}{c}\text { New DOE } \\
\text { Order }\end{array}$ & Title/Comments \\
\hline $5000.3 B$ & 0232.1 & Occursence Reporting and Processing of Operations Information \\
\hline 15402 & 0460.1 & $\begin{array}{l}\text { Hazardous Material Packaging for Transportation - Administrative } \\
\text { Procedures }\end{array}$ \\
\hline $4330.4 A$ & $4330.4 B$ & Maintenance Management Program \\
\hline 4700.1 & 0430.1 & Project Management System \\
\hline 5400.1 & O231.1 & $\begin{array}{l}\text { General Environmental Protection Program. Parts of Chapters } 2 \text { and } \\
3 \text { were canceled. }\end{array}$ \\
\hline 5400.3 & N1321.139 & $\begin{array}{l}\text { Hazardous and Radioactive Mixed Waste Program, which was further } \\
\text { replaced. }\end{array}$ \\
\hline 5480.13 & $5480.1 \mathrm{~B}$ & $\begin{array}{l}\text { Environmental, Safety \& Health (ES\&H) Program for DOE } \\
\text { Operations. The ES\&H Order 5480.1B was canceled. }\end{array}$ \\
\hline 5480.4 & 0440.1 & $\begin{array}{l}\text { Enviromental Protection, Safecy, and Health Protection Standards, } \\
\text { DOE Order } 5480.4 \text { was canceled in part, and parts of Attaclmment } 2 \\
\text { and } 3 \text { were replaced. }\end{array}$ \\
\hline $5480.7 \mathrm{~A}$ & 0420.1 & Fise Protection \\
\hline 5480.11 & $10 C F R 835$ & Radiation Protection Program \\
\hline $5500.2 \mathrm{~A}$ & 0151.1 & Planning and Preparedness for Operational Emergencies \\
\hline $5820.2 \mathrm{~A}$ & $5820.2 \mathrm{~B}$ & $\begin{array}{l}\text { Radioactive Waste Management. A new order will be issued in the } \\
\text { near future. }\end{array}$ \\
\hline $6430.1 \mathrm{~A}$ & 0430.1 & General Design Criteria. \\
\hline
\end{tabular}

The waste inventory is another moving target that affected the outcome of this study. The data in the MLLW inventory report dated April 1993 indicated a total volume of 247,036 $\mathrm{m}^{3}$. Data collected for the Preliminary Site Treatment Plan (PSTP) in 1995 for MLLW indicate that the total amount of MLLW (debris, organic combustibles, sludges, soils, special group, and wastewaters) was $217,772 \mathrm{~m}^{3}$. The more current data should be used in any funire aralysis. The estimated rate of increase in MLLW (from the April 1993 report) is about 55,982 $\mathrm{mt}^{3}$ per year.

Although they were not addressed during the review of these spudies, a close look should be taken at the geographical distribttion of the various wastes and their priority for cleamup. These issues should be addressed in more detail since they will have a large influence on the assumptions of input wastes, transportation, site location(s), and system designs.

The underlying assumption that cursent analytical techniques for characterizing imput wastes and for determining the long-term stability (e.g., leachability) of the innal waste form are adequate is highly uncertain. The currently accepted techniques, although accepted by regulatory agencies, are not sufficiently precise and accurate, and some do not alequately represent the disposal environment. A continuing effort to improve characterization methods is needed and is already ongoing. However, in the meantime, evaluation and application of cleanap technologies must proceed based on methods that are less than fully adequate. The effect of recognizing the 
limitations of current methods is to give additional weight to those performance criteria that enlance regulatory compliance (i.e., conservative design).

\subsubsection{General Operating}

The surdies were based on a significant anount of overdesign. The principal assumptions concerned were that all equipment was to be designed for a Seismic Category 1 site, a high capacity factor of $125 \%$, only 4032 hours of operation/year, and all stainless steel construction. These assumptions are not typical of system designs that are commonly used in industry. If these assuntptions are being used to ensure contingency, then they should be labeled as such. In future studies, general operating and design factors should be justified in greater detail.

The assumption of a single site to process all wastes leads to the blurring of the technology comparisons. Although this assumption provides a basis for these studies, it is an artificial basis, and therefore it does not allow technology comparisons in a realistic setting. Factors such as geographic distribution of wastes, areas closed to the transport of hazardous wastes, aftid the design. of simpler, smatler systems for specialized puposes warrant far greater consideration.

\subsubsection{System and Subsystem Components}

The systems created and subsystems chosen for inclusion within a study greatly influence the results of the study. Although it is not practical to study every system that lays claim to being able to clean up MLLW, it is important that a thorough screening methodology be employed. The INTS studies used a technology selection group in making such decisions. Although a discussion of how selections were chosen was provided, an approach similar to the Kepner-Tregoe approach shown in Appendix I would be more advantageous for initial screening. If a single subsystem is chosen to represent a group of technologies, then it is important to discuss the sensitivity of the overall results to that assumption. Atso, as already stated, simple and smaller systems should be considered for processing certain categories of waste where permitted.

\subsection{Economic Predictions and Sensitivities to Predictions}

Over 1200 assumptions were made in the three LITCO reports, all of which are listed in Appendix D (ITTS - Phase 1), Appendix E (ITTS - Phase 2), and Appendix F (INTS). The goals of sifting out the critical assumptions and quantifying the sensitivity of the PLCC to each one were accomplished in two stages.

First, all the assumptions were evaluated using engineering judgement and given two scores (on a $1-10$ scate): a score for uncertainty (1 = the assumption will almost certainly be inue, and 10 $=$ the assumption will almost certainly urn out to be wrong) and a second score for sensitivity ( $I=$ the PLCC for the system will change very little if the assumption is changed, and $10=$ the PLCC for the system will change dramatically if the assumption is changed). The long list of assumptions was then boiled down to a much shorter list of "critical assumptions," which are those assumptions having both bigh uncertainty ( 25 ) and high sensitivity ( 25 ). These assumptions are listed in Appendix $\mathrm{G}$. The much reduced list has about $\mathbf{5 0}$ assumptions (or groups of closely related assumptions). 
The second stage was to examine each of the assumptions (or groups of assumptions) to determine quantitatively the sensitivity of the PLCC to a step change in the assumption. This analysis was carried out using the PLCC spreadsheets developed by Morrison Kmudsen

Corporation. The results of the sensitivity analyses are presented in Tables 3.3-1 to 3.3-5. The tables give the assumptions, the hypothetical changes in the assumptions, and the impacts of the changes on the PLCCs in both dollars (rounded to the nearest million) and as a percept of the baseline cost (total PLCC). Within each table, the assumptions are presented in order from the most beneficial change to the most harmful (costly).

Table 3.3-1 summarizes the assumptions in the ITTS snudjes that affect all systems similarly. For simplicity, the sensitivities were calculated for the baseline system (A-1) only. As shown in the table, there are three assumptions that have a very large impact on the PLCC of the system: 1) operating for only 4032 hours/year, 2) a government owned-contractor operated (GOCO) facitity, and 3) a Seismic Category 1. If any or all of these assumptions could be changed to the extent indicated, the savings in PLCC could be up to $\$ 833$ million (38\%). It should be noted that the total savings is lower than the sulm of the savings for the indjidual assumptions because there is an interaction between them. Of course, there are also some assumptions that are optimistic. For example, if $75 \%$ of the waste required sorting (rather than $50 \%$ ). the cost would increase substantially (\$267 million).

Tables 3.3-2 and 3.3-3 list assumptions in the ITTS studies that are system-specific. The point was to look for assumptions that favor one system or technology over another. The only such assumption found for ITTS Phase 1 was the assumption of $100 \%$ sorting for Systems B1 and D1, while other systems require only $50 \%$ of the waste to be sorted. If that were relaxed to only $75 \%$ sorting. it would change the ranking of the systems, but neither of the two systems would become the best (cheapest). For ITTS Phase 2, no assumptions were found that would significantly alter the standing of any particular technology.

The assumptions in the INTS surdy that affect all systems similarly are given in Table 3.3-4. As with the ITTS systems, there is potential for substantial cost savings. The same three assumptions that were extremely irmportant in the ITTS study were also important in the INTS study. If those three assumptions were changed to the extent indicated in Table 3.3-4, the savings in PLCC could be up to $\$ 1078$ million ( $34 \%$ ). In addition, it was assumed that $75 \%$ of the waste for the INTS systems required sorting; if that alone were decreased to $50 \%$, $\$ 412$ million (13\%) would be saved. Likewise, there is also the potential for cost increases.

The assumptions that affected only specific INTS technologies are given in Table 3.3-5. None of them penalized any particular system in favor of another.

\subsection{Performance Evaluation of Phase 2 Technologies}

In selecting EM technologies for implementation, aoneconomic performance factors need to be considered along with life-cycle cost. Noneconomic factors have particular importance where the costs of competing systems are similar and/or diverse regulatory requirements must be met, as is the case for the systems compared in the LITCO sudies. Different sets of performance criteria are presented in each of the three reports for the L.dTCO sadies (Phase 1 ITTS, Table 6-1; Phase 2 
TABLE 3.3-1

Sensitivity of PLCC to Changes in Assumptions: System A1 - Baseline System ITTS

\begin{tabular}{|c|c|c|c|c|c|}
\hline \multicolumn{2}{|c|}{$\begin{array}{l}\text { Assumpcion } \\
\text { No.* } \\
\text { Phase }\end{array}$} & Assumption & Change in Assumption & $\begin{array}{l}\triangle S P L C C, \\
\text { millions }\end{array}$ & $\triangle P L C C, \%$ \\
\hline 2 & 3 & $\begin{array}{l}\text { Operation of the facility is assumed to be } 4032 \text { bours } \\
\text { per year. }\end{array}$ & $\begin{array}{l}\text { Assume } 8064 \text { hours per year } \\
=0.63 \times \text { consinuction cosis }+0.5 \times \text { receiving and } \\
\text { inspection labor. }\end{array}$ & -418 & -19.3 \\
\hline & 16 & $\begin{array}{l}\text { Assume government owhed-contractor operated } \\
\text { (GOCO). Indirect cosis = } 29 \% \text {. construction } \\
\text { management }=17 \% \text {, management reserve }=10 \% \text {, } \\
\text { contingency }=25 \% \text {, design }+ \text { inspection }+ \text { project } \\
\text { mantagement }=42 \% \text { of construction cost. Contingency } \\
=25 \% \text { of operating and maintenance cost. }\end{array}$ & $\begin{array}{l}\text { Assume privately owned, } \\
\text { Assume indirect cosus }=25 \% \text {, consinuction management = } \\
5 \% \text {, management reserve }=0 \% \text {, contingency }=10 \% \text {, design } \\
+ \text { inspection }+ \text { project managemert }=20 \% \text { of construction } \\
\text { cost. Contingency }=10 \% \text { of operating and oraintenance } \\
\text { cost. }\end{array}$ & -379 & -17.5 \\
\hline 3 & 2 & $\begin{array}{l}\text { Facilities will be designed for a moderate-hazard } \\
\text { classification and Seismic Category } 1 .\end{array}$ & $\begin{array}{l}\text { Assume Seismic Category } 2 \\
=0.4 \times \text { constnuction costs. }\end{array}$ & -342 & -15.8 \\
\hline 12 & 4 & $\begin{array}{l}\text { Triple containment will be used for all process steps } \\
\text { from waste sorting through waste stabilization. Double } \\
\text { containment is used for other processes if there is limit } \\
\text { potential for air emissions. }\end{array}$ & $\begin{array}{l}\text { Assume double rather than triple, and single rather than } \\
\text { double } \\
=0.5 \times \text { (buikling ecsts of all subsystems exeep } \\
\text { administration). }\end{array}$ & -120 & -5.5 \\
\hline 1 & 1 & $\begin{array}{l}\text { The same unit disposal cost of } \$ 243 / \mathrm{f}^{3} \text { is used for all } \\
\text { waste disposal regardless of its form. }\end{array}$ & Assume $\$ 243 \pm \$ 100 / \mathrm{ft}^{3}$ & \pm 98 & \pm 3.7 \\
\hline 10 & & $\begin{array}{l}\text { A contingency of } 25 \% \text { is applied to all components th } \\
\text { production factity construction costs. }\end{array}$ & $\begin{array}{l}\text { Assume a contingency of } 10 \% \\
=0.4 \times \text { contingency cosis for all components. }\end{array}$ & -77 & -3.6 \\
\hline 11 & & $\begin{array}{l}\text { Decontamination and decommisstioning (D\&D) is } \\
\text { estimated at } \$ 450 / f^{2} \text {. }\end{array}$ & $\begin{array}{l}\text { Assume } \pm 50 \% \\
=\mathrm{D} \& \mathrm{D} \cos t s \times(1 \pm 0.5)\end{array}$ & \pm 27 & \pm 1.2 \\
\hline 9 & & $\begin{array}{l}\text { Five low-temperature stabilization agenus meet } \\
\text { implementability requirements. }\end{array}$ & $\begin{array}{l}\text { Assume lechnology fails } \\
\text { = cost of subsystem }+1 \text { year of operating costs. }\end{array}$ & +72.7 & $+3,4$ \\
\hline 5 & & $\begin{array}{l}\text { Vitrlfication techuotogles meet implententability } \\
\text { requirements. }\end{array}$ & $\begin{array}{l}\text { Assume technology fails } \\
=\text { cost of subsystem }+1 \text { year of operating costs. }\end{array}$ & +87.5 & +4 \\
\hline 4 & & System will incorporate minimum shieldimg. & $\begin{array}{l}\text { Requires more extensive shielding } \\
\Rightarrow 2.0 \times \text { brilding construction costs. }\end{array}$ & +244 & +11.3 \\
\hline 6 & 13 & $50 \%$ of the waste requires sorting. & $\begin{array}{l}\text { Assurine } 75 \% \text { of the waste requires sorting } \\
=1.5 \times \text { (construction costs + annayal operating costs). }\end{array}$ & +267 & +12.3 \\
\hline
\end{tabular}

* See Appendix $G$ for a more detailed description of the LITCO assumption. The "Assumption No." is the number of the assumption in Appendix $G$ for ITTS. 
TABLE 3.3-2

Sensitivity of PLCC to Changes in Assumptions: ITTS Phase / Systems

\begin{tabular}{|c|c|c|c|c|}
\hline $\begin{array}{l}\text { Assumption } \\
\text { No." }\end{array}$ & Assumption & Charge in Assumption & $\begin{array}{l}\triangle S P L C C \\
\text { millions }\end{array}$ & $\underset{\%}{\triangle P L C C}$ \\
\hline 7 & $\begin{array}{l}\text { For systems BI and DI, it ts assumed that } 100 \% \text { of the } \\
\text { waste requires sonitog. }\end{array}$ & $\begin{array}{l}\text { Assume } 75 \% \text { rather than } 100 \% \\
=0.75 \times \text { construction costs }+0.75 \times \text { operating cousts. }\end{array}$ & -157 & -7.0 \\
\hline 8 & $\begin{array}{l}\text { For systems A4 and D], it is assumed that } 90 \% \text { of the } \\
\text { lime is recycled. }\end{array}$ & $\begin{array}{l}\text { Assume thas } 10 \% \text { of the lime is recycled } \\
=2 \times \text { polymer }+1.5 \times \text { equipment } \cos 1 \text { for secondary } \\
\text { stabilization. }\end{array}$ & +31 & +1.4 \\
\hline
\end{tabular}

* See Appendix $\mathrm{G}$ for a more delaiked description of the UTCO assuraprion. The "Assumption No." is the nurnber of the assumption in Appendix $\mathrm{O}$ for rrTS-Phase 1.

TABLE 3.3-3

Sensitivity of PLCC to Changes in Assumptions: ITTS Phase 2 Systems and Subsystems

\begin{tabular}{|c|c|c|c|c|}
\hline $\begin{array}{l}\text { Assumption } \\
\text { No,", }\end{array}$ & Assumplion & Change in Assumption & $\begin{array}{l}\text { ASPLCC. } \\
\text { millions }\end{array}$ & $\triangle \mathrm{PLCC}, \%$ \\
\hline 10 & $\begin{array}{l}\text { Joule-heated melter subsystem wifl meet } \\
\text { requirentents. }\end{array}$ & $\begin{array}{l}\text { Subsystem fails to function properly and must be replaced } \\
\text { - construction coss of Joule-heated melcer }+1 \text { year operating } \\
\text { cost. }\end{array}$ & +78.6 & +4.1 \\
\hline 12 & SCWO subsystem will ineet requirements. & $\begin{array}{l}\text { Subsystem falls to function properly and must be replaced } \\
=\text { construction cost of SCWO }+1 \text { year operating cost. }\end{array}$ & +79.2 & +3.7 \\
\hline 14 & Incinerators will meet requiremenls. & $\begin{array}{l}\text { Subsystem fails to function properly and must be replaced } \\
=\text { construction cost of incinerator }+1 \text { year operating cost. }\end{array}$ & +188.2 & +4.2 \\
\hline $\mathbf{1 1}$ & MEO subsystem will meet requirements. & $\begin{array}{l}\text { Subsystem fails to furction properly and musi be replaced } \\
=\text { construction cost of MEO }+1 \text { year operating cost. }\end{array}$ & +88.2 & +4.2 \\
\hline 9 & $\begin{array}{l}\text { Steam gasifier subsystem will meet } \\
\text { requireupents. }\end{array}$ & $\begin{array}{l}\text { Subsystem falls to function properly and must be replaced } \\
=\text { construction cost of stean gasifier }+1 \text { year operating cost. }\end{array}$ & +94.3 & +4.3 \\
\hline $\mathbf{s}$ & Plasma furnace will met requitemenas. & $\begin{array}{l}\text { Subsystem falls to function properly and must be replaced } \\
=\text { construction cost of plastra furnace }+1 \text { year operating cost. }\end{array}$ & +95 & +4.5 \\
\hline $\mathbf{8}$ & Molien metal subsysiem will meet requitements. & $\begin{array}{l}\text { Subsystem falls to fupction properly and must be teplaced } \\
=\text { construction cost of molten metal }+1 \text { year operating cost. }\end{array}$ & +96.2 & +5.1 \\
\hline 6 & Flasma gasifier will meet requitemems. & $\begin{array}{l}\text { Subsystem fals to function properly and must be replaced } \\
\text { c construction cost of gesifier }+1 \text { year operating cost. }\end{array}$ & +96.8 & $+\mathbf{5 . 0}$ \\
\hline 15 & APC subsystem will meet requirements. & $\begin{array}{l}\text { Subsystem fails to function properly and must be teplaced } \\
\text { = construction cost of APC + 1 year operating cost. }\end{array}$ & +107 & +4.9 \\
\hline 7 & $\begin{array}{l}\text { MSO meets DOE objectives for life-cycle cost } \\
\text { and scherdule. }\end{array}$ & $\begin{array}{l}\text { Subsystem fails to furction properly and must be replaced } \\
=\text { comstnction cost of MSO }+1 \text { year operating cost. }\end{array}$ & +126 & +5.5 \\
\hline
\end{tabular}

* See Appendix $\mathrm{G}$ for a more delaibed description of the LiTCO assumption. The "Assumption No." is the mumber of the assumption in Appendix $\mathrm{O}$ for ITTS - Phase 2. 
TABLE 3.3-4

Sensitivity of PLCC to Changes in Assumptions: INTS - System 1

\begin{tabular}{|c|c|c|c|c|}
\hline $\begin{array}{l}\text { Assumption } \\
\text { No." }\end{array}$ & Assumption & Change in Assumption & $\begin{array}{l}\triangle S P L C C, \\
\text { millions }\end{array}$ & $\triangle P L C C, \%$ \\
\hline 3 & $\begin{array}{l}\text { Operation of the facility is assumed to be } 4032 \text { hours per } \\
\text { year. }\end{array}$ & $\begin{array}{l}\text { Assume } 8064 \text { hours per year } \\
=0.63 \times \text { construction costs }+0.5 \times \text { receiving and } \\
\text { inspection labor. }\end{array}$ & -542 & -17.0 \\
\hline 14 & $\begin{array}{l}\text { Assume GOCO. } \\
\text { Indirect costs }=29 \% \text {, constnuction managemept }=17 \% \text {, } \\
\text { management reserve }=10 \% \text {, contingency }=25 \% \text {, design } \\
+ \text { inspection }+ \text { project magnagement }=42 \% \text { of } \\
\text { construction cost. Contingency }=25 \% \text { of operating and } \\
\text { maintenance cost. }\end{array}$ & $\begin{array}{l}\text { Assume privately owned. } \\
\text { Indirect costs }=25 \% \text {, construction manggemenl }=5 \% \text {, } \\
\text { management reserve }=0 \% \text {, contingexy }=10 \% \text {, design } \\
+ \text { inspection }+ \text { project management }=20 \% \text { of } \\
\text { construction cost. Cootingency }=10 \% \text { of operating and } \\
\text { mainuenarice cost. }\end{array}$ & -506 & -15.9 \\
\hline 12 & $75 \%$ of the waste requires sorting. & $\begin{array}{l}\text { Assume } 50 \% \text { of the waste requires sorting } \\
=0.67 \times \text { (construction costs }+ \text { annual operating costs } \\
\text { for teceiving and inspection). }\end{array}$ & -412 & -13.0 \\
\hline ] & $\begin{array}{l}\text { Facilities will be designed for a moderate-hazard } \\
\text { classification and Seismic Calegory } 1 .\end{array}$ & $\begin{array}{l}\text { Assume Sejsmic Canegory } 2 \\
=0.4 \times \text { construction costs. }\end{array}$ & -372 & 11.7 \\
\hline 13 & $\begin{array}{l}\text { The same unit disposal cost of } \$ 243 / \mathrm{f}^{3} \text { is used for all waste } \\
\text { disposal regardless of its form. }\end{array}$ & Assurne $\$ 243 \pm \$ 100 / \mathrm{ft}^{\prime}$ & \pm 371 & \pm 10.2 \\
\hline 2 & $\begin{array}{l}\text { Triple contalnment will be used for all process steps from } \\
\text { waste sorting through waste stabilization. Dowble } \\
\text { contaimmem is used for other processes if there is limit } \\
\text { potential for air emissions. }\end{array}$ & $\begin{array}{l}\text { Assume dovble rather than triple, and single rather than } \\
\text { double } \\
=0.5 \times \text { (building cost of all subsystems except } \\
\text { administralion). }\end{array}$ & -181 & -5.7 \\
\hline 15 & $\begin{array}{l}\text { A contingency of } 25 \% \text { is applied to atl components in } \\
\text { produclion facility constnection costs. }\end{array}$ & $\begin{array}{l}\text { Assume a comingency of } 10 \% \\
=0.4 \times \text { contingency costs fot all compontents. }\end{array}$ & -70 & -2.2 \\
\hline 16 & Equipment cost based on use of stainless steel. & $\begin{array}{l}\text { Assume equipment cost was based on mild steel } \\
=0.67 \times \text { equipment cost. }\end{array}$ & -64 & -2.0 \\
\hline 4 & $\begin{array}{l}\text { Stabilization formulas = } 1 \text { part polymer to } 1 \text { part waste; } 1 \\
\text { part ceramic additives to I part waste; and } 2 \text { parts grout to } \\
1 \text { part waste. }\end{array}$ & $\begin{array}{l}\text { Assume polymer is } 1,5: 1 \text {, grout is } 3: 1 \text {, and ceramic is } \\
1.5: 1: \text { The capital cost for each secondary stabilization } \\
\text { method will be increased by } 14 \% \text {. Disposal costs are } \\
\text { increased by } 25 \% \text {. Materials costs are iracreased by } \\
50 \% \text {. }\end{array}$ & +275 & +7.5 \\
\hline & System will incorporate minimum shielding. & $\begin{array}{l}\text { Requires more extensive shieiding } \\
=2.0 \times \text { byilding construction costs. }\end{array}$ & +399 & +12.5 \\
\hline
\end{tabular}


TABLE 3.3.5

Sensitivity of PLCC to Changes in Assumptions for INTS Systems and Subsystems

\begin{tabular}{|c|c|c|c|c|}
\hline $\begin{array}{l}\text { Assumption } \\
\text { No. }\end{array}$ & Assumption & Change in Assumption & $\begin{array}{l}\triangle \$ P L C C, \\
\text { millions }\end{array}$ & $\underset{\%}{\triangle P L C C}$ \\
\hline 10 & $\begin{array}{l}\text { Phosphate-bonded ceramic subsysten will meet } \\
\text { requiremeris. }\end{array}$ & 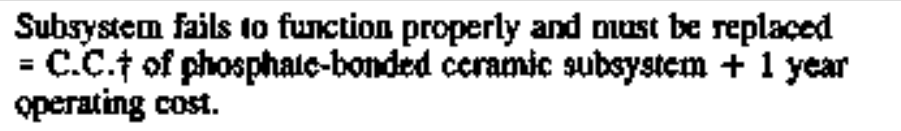 & +124 & +3.7 \\
\hline 9 & Actid digestion subsystem wilt meet requirements. & $\begin{array}{l}\text { Subsystem fails to function properly and must be replaced } \\
\text { = C.C. of acid digestion + I year operating cost. }\end{array}$ & +126 & +3.7 \\
\hline 6 & Vactrum desorption subsystem will meet requirements. & $\begin{array}{l}\text { Subsystem fails to function properly and must be replaced } \\
=\text { C.C. of vacuum desorption }+1 \text { year operating cost. }\end{array}$ & +127 & +4.1 \\
\hline 7 & $\begin{array}{l}\text { Catalytic wet oxidation subsystem will meet } \\
\text { requirements. }\end{array}$ & $\begin{array}{l}\text { Subsystem fails to function properly and must be replaced } \\
- \text { C.C. of calalytic wet oxidation }+1 \text { year operating cost. }\end{array}$ & +129 & +3.8 \\
\hline 5 & $\begin{array}{l}\text { Mediated electrochemical oxidation subsystem will } \\
\text { meet requirements. }\end{array}$ & $\begin{array}{l}\text { Subsystem fails to funetion properly and must be replaced } \\
=\text { C.C. of MEO + } 1 \text { year operating cost. }\end{array}$ & +136 & $+4,3$ \\
\hline 8 & Aqueous washing subsystem will meet requirements. & $\begin{array}{l}\text { Subsystem fails to hunction properly and must be replaced } \\
=\text { C.C. of aquewus washing }+1 \text { year operating cosi. }\end{array}$ & +139 & $+\mathbf{4 . 2}$ \\
\hline 4 & $\begin{array}{l}\text { SYSTEM 4: Stabilization formulas = } 1 \text { part polymer } \\
\text { to } 1 \text { part waste; } 1 \text { part ceramic additives to ! part } \\
\text { waste; and } 2 \text { parts grout to } 1 \text { part waste. }\end{array}$ & $\begin{array}{l}\text { Assume polymer is } 1.5: I \text {, groot is } 3: I \text {, and ceramic is } 1,5: 1 \text {. } \\
\text { The capital cost for each secondary stabilization method will } \\
\text { be increased by } 14 \% \text {. Disposal costs are increased by } 25 \% \text {. }\end{array}$ & +213 & +5.7 \\
\hline 4 & $\begin{array}{l}\text { SYSTEM 5: Stabilization fommulas I I pant polymer } \\
\text { to I part waste; } 1 \text { part ceramic additives to I part } \\
\text { waste; and } 2 \text { parts grout to } 1 \text { part waste. }\end{array}$ & $\begin{array}{l}\text { Assume polymer is } 1.5: 1 \text {, grout is } 3: 1 \text {, and ceramic is } 1.5: 1 \text { : } \\
\text { The capital cost for each secondary stabilization method will } \\
\text { be inereased by 14 } 0 \text {. Disposal costs are increased by } 25 \% \text {. }\end{array}$ & +237 & +6.3 \\
\hline 11 & SYSTEM 2: The excess water is discharged. & The excess water is grout stabilized. & +250 & +7.1 \\
\hline 4 & $\begin{array}{l}\text { SYSTEM 2: Stabilization formulas = } 1 \text { part polyner } \\
\text { to } 1 \text { part waste; } 1 \text { part ceramic additives to I part } \\
\text { waste; and } 2 \text { parts grout to } 1 \text { part waste. }\end{array}$ & $\begin{array}{l}\text { Assume polymer is } 1.5: 1 \text {, grout is } 3: 1 \text {, and ceramic } 1.5: 1 \text {; } \\
\text { The captial cost for each secondary stabillzation method wilt } \\
\text { be increased by } 14 \% \text {. Disposal costs are increased by } 25 \% \text {. }\end{array}$ & +251 & +7.2 \\
\hline 4 & $\begin{array}{l}\text { SYSTEM 3: Stabilization formalns = } 1 \text { part polyner } \\
\text { to } 1 \text { part waste; } 1 \text { part ceratile additives to I part } \\
\text { waste; and } 2 \text { parts growt to } 1 \text { part waste. }\end{array}$ & $\begin{array}{l}\text { Assume polymer is } 1.5: 1 \text {, grout is } 3: 1 \text {, and ceramic is } 1.5: 1 \text {; } \\
\text { The capital cost of each secondary stabilization method will } \\
\text { be increased by } 14 \% \text {. Disposal costs are increased by } 25 \% \text {. }\end{array}$ & +274 & +7.4 \\
\hline
\end{tabular}
"See Appendix $\mathbf{G}$ for a more detailed description of the LTTCO assumption. The "Assumption No," is the number of the assumption in Appendix $\mathbf{G}$
for INTS.

+ Cost of construcition. 
ITTS, Table 5-1; and INTS, Table 6-1). Only the Phase 1 sudy proposes numerical weighting factors for noneconomic perfomance criteria. No quantitative rating based on performance criteria was assigned to any of the 24-systems included in the ITTS and INTS studies, which would have allowed direct comparison leading to selection or rejection.

A structured evaluation of the nine Phase 2 systems and the baseline system was undertaken in the course of this review to illustrate the type of andlysis that can and should be performed to deal quantitatively with the wealth of qualitative information presented in the LITCO snudies. The comparisons generated are not meaningful for selection purposes, considering the linited depth of the current review (only a small subset of the important performance criteria was evaluated, only ITTS Phase 2 systems were included, and only one engineer performed the evaluation), but they do serve the intended purpose of illustrating the methodology. The analysis and detailed discussions are given in Appendix $\mathbf{I}$.

Such a quantitative analysis of the performance measures is necessary to complete the evaluation process. The process allows a focused discussion of the relative importarce of each of the performance measures, and it enables the condensation of the multitude of performance measures down to a single quantitative measure of merit. Both of these are important benefits of the method. Therefore it is strongly urged that this or a simitar methodology be used.

\subsection{CONCLUSIONS AND RECOMMENDATIONS}

The conclusions of this review are as follows:

- The authors of the LITCO studies have identified and evaluated a wealth of pertinent information on EM cleanup technologies.

- These studies represent a major step forward in the use of a systems approach to evaluating technologies for use in the remediation of waste sites.

- Although the systerns analysis in the LITCO studies was done thoroughly, these studies should be enhanced to better encompass a full SE approach.

- The PLCC estimates were calculated in the approptiate level of detail using a sound engineting approach. The only exception is that the tine value of money (i.e., the use of an interest rate to discount future cash flows to their equivalent present value) should have been taken into account.

- The cost-estimating factors used under the GOCO assumption and other very conservative design assumptions (e.g., 4032 operating hours/year) resulted in PLCC estimates that were about one-third higher than in industrial practice.

- No assumptions were found that favored one technology over another. On the contrary, the PLCCs for all the thermal systems were within the accuracy of the PLCC estimates. 
The recommendations of this review are as follows:

- Future such studies should adopt a consistent SE approach similar to the template defined in this report. DOE would be well served to develop a Systems Engineering Standard. similar to those already in use by DOD" $^{3}$ and IEEE," which would serve as the guideline for any funure SE studies.

- Noneconomic factors must be considered in a quantitative manner to gain full value from the analysis of system alternatives, especially those involving developing technologies that are being considered in competition for scarce funding. An approach like that outlined by example in this report should be required for all such systems analysis studies.

- Absolute system costs defined in the three studies should be reexamined, with special emplasis on the major cost sensitivities identified in this report.

- A number of design assumptions warrant further study: 1) one facility to process all MLLW, 2) a feed of "average" waste composition, and 3) the segregation of thermal and nonthermal technologies.

${ }^{3}$ DOD-AMSC. Droft Matitany Standard for Systems Engineering; Mil-std-4998, Version 2.0, Mry 1992.

"LEEE. IEEE Triat-Use Standard for Application and Sanagement of the SE Process, EEEEsd, 1220-1994, 1995. 
APPENDIX A

\section{EXPANDED DISCUSSION OF SYSTEMS ENGINEERING APPROACH}




\section{EXPANDED DISCUSSION OF SYSTEMS ENGINEERING APPROACH}

Systems engineering (SE) is the powerful technical tool for program managers. SE mast be applied properiy and fashioned for the specific application.

The process of SE provides a framework for application and involves three steps:

- Planning for SE

- Implementing the SE process

- Controlling the SE effort

\section{Planning Systems Engineering}

In the concept exploration and definition phase, a large amount of trade-off study effort is required. This effort supports the translation of operational needs to technical system alternatives. The output of this phase is broad, high-level specifications defining system alternatives. As the program progresses through development and into the full-scale production and deployment phase, $\mathrm{SE}$ requirements remain. However, the scope of the effort changes significantly. At this time, a firm baseline should have been defined, and production or construction specifications should exist. $\mathrm{SE}$ is more a maintenance effort at this point and entails the development of system modifications as processes, procedures, or capabilities are revised. SE still performs the task of monitoring and managing systems integration activities. As system problens arise, SE is needed to perform tradeoff anslysis and determine solutions.

A system engineering management plan (SEMP) is used to define the organization that will perform SE on the program. The SEMP should be prepared as early as practicable in the life cycle (nomally during concept explotation and definition). As the progtam progresses through its life cycle, the SEMP should be updated to reflect tailoring of the SE effort. The SEMP has three basic sections, which should define the following:

- The methodology established for technical program planning and control.

- The detailed SE process to be utilized and the tailoring to be applied.

- The integration and coordination of engineering specialty efforts to achieve a best mix of technical and performance values.

The SEMP can either be a stand-alone document or it can be abbreviated. An abbreviated SEMP would incorporate, by reference, other plans (such as the reliability plan, interface agreements, logistics support plan, and program management documentation). These plans should collectively address all the necessary SE requirements. The goal is to minimize formal documentation while maximizing the benefits achieved from the SE process. 


\section{Implementing Systems Engineering}

The benefits of SE are realized through effective implementation. SE is a logical and iterative process that takes input requirements and functional analyses and then alfocates them functionally. These functions are then traded off as alternative solution sets are developed. This process of synthesis resuits in candidate solutions that can be evaluated for adequacy. A decision is made on the recormmended solution(s). This is documented and becomes the input on the next cycle of the SE effort.

A critical element of the SE process is the ability to feed back results of the process to refine imput information. This provides a means of verifying and validating input requirements as the results of trade-off sudies become available. Cost drivers are identified early so that they can be evaluated against operational benefits. This continuous review process shovid help identify problem areas before they become embedded and cause significant cost, schedule, or performance impacts.

In the concept exploration and definition phase, input requirements are in the form of bighlevel operational meeods. The SE process must translate these requirements into the conceptual functions that must be performed to satisfy the need. This translation is called furctional analysis.

Functional analysis is a top-down process. Global requirements are broken down into ever smaller and more quantifiabie functions. These functions represent a set of capabilities which, when properly combined, will satssfy user need. Once the functional analysis is completed, the process of synthesizing an alternative can begin.

Various combinations of functional elements are traded off against the requirements. These trade-off sndies examine the aflocation of responsibility and resources to the various functions. The results of this trade-off and alkocation effort are sets of potential system solutions. These synthesized alternatives are then evaluated against quantifiable measures of effectiveness. The evaluation is used to weigh the various alternative approaches, which can then be selected for further definition. Efforts during the SE process are documented in trade-off studies and evaluations. System specifications are developed for the best alternatives. They become input data to the next life-cycle phase.

Work breakdown structures are a product of the functional analysis and allocation process. As the global requirements are broken down into smaller functions, definable work packets are identified and incorporated into the managerial work breakdown structure.

As a program goes through the remaining phases of the life cycle, the SE process described above is repeated. More and more refined outputs are provided as the system becomes better understood and defined. It is essential that progress toward detail be uniform.

During the demonstration and validation phase, the system specifications of alternative concepts are functionally analyzed. This results in more detailed stbfinctions for trade-off analysis. The synthesis process yiejds engineering models that can be evaluated against the original requirements. Evaluation allows for the selection of a preferred technical approach. Finalized 
system specifications and subsystem performance specifications are developed for input to the next phase.

The development phase uses finalized system specification as inpuss. Functional analysis is the process that translates these subsystem performance requirements into detailed product furctions. Detailed system synthesis and design trade-off sudies are performed. Various detailed designs are integrated and interfaced into a system prototype that can then be evaluated. Based on the protorype's success during evaluation, a decision can then be made to produce the final design. As a result of this SE effort, detailed system, subsystem, and product specifications, along with drawing packages and other engineering data required for production or construction, are developed.

As the construction and deployment phase begins, the $S E$ process is used once again. Input data are functionally analyzed and synthesized to develop a set of production processes and work sheets, which provide producible end products. A configuration aldit process is used to verify the suitability of this documentation.

The SE process (functional analysis, synthesis, evaluation, and decision) is applicable across all phases of the life cycle. The degree of focus and level of documentation detail will change, but the basic process remains. The SE process logically breaks the wotk task into definable and manageable subelements. It integrates and interfaces the design and build efforts of these subelements so that a total capability is provided in response to the original user requirements.

\section{Controlling Systems Engineering}

Depending on the phase of the life cycle, the SE effort can represent a significant portion of the overall cost.

Various tools are available to assist in controlling the SE process. These include the following:

- Systems engineering management plan - The SEMP provides a plan for establishing a SE effort. It defines the actual methods and procedures to be followed in the SE process. It also defines the control strucnure to ensure total system integration.

- Formal reviews - During the development phases of the life cycle, a series of reviews should be conducted. These reviews (systems requirements review, system design review, preliminary design specification, and critical design review) provide an opportunity to assess the state of the technical effort; review in detail the system functional analysis and synthesis process; determine the adequacy of the resultant alternatives in satisfying the requirements; and provide a vehicle for making and documenting program decisions.

- Informal technical reviews - Formal reviews present an opportunity for reviewing a project's technical status. However, they occur infrequently and will not provide the degree of interchange necessary to ensure that the SE process is adequate. They provide a 
snapshot in time, but do not provide reat-time status information. Periodic and informal technical reviews can fill the need for real-time situation monitoring.

- Technical performance measurements - These represent a set of key parameters, which are monitored as the program progresses through the development cycle. These quantitative measures can be trakked against program goals and provide a way to assess overall technical status. They provide data for problem analysis and corrective action and act as early waming indicators.

- Management control systems - As the SE process progresses, one output is increasingly detailed work breakdowns. These work packets are the entities upon which cost and schedule stanus information is collected. Through management review, they provide visibility into the program's problem areas. These problem areas then become candidates for informal review and for development of alternative action plans.

\section{Systems Engineeriag Outputs}

Output benefits from a successful SE process may be expected. Some of these are listed below.

- Ensures fully integrated engineering effort throughout the entire system life cycle.

- Conducts system definition and designi on a total-system basis to achieve required effectiveness within cost, schedule, performance, and risk limits.

- Establishes system requirements that meet user needs and priorities.

- Totally integrates all system and subsystem design and related requirements.

- Establishes effective interfaces within and between the system for maximum compatibility and interoperability.

- Establishes, integrates, and maintains an effective work breakdown structure throughout the system's life cycle.

- Evaluates, documents, and tracks system changes and technical decisions that affect the overall performance, schedule, effectiveness, logistics, and system life-cycle cost.

- Provides a framework of system requirements to be used as design, performance, support, and test criteria and provides source datz for contract work statements, specifications, test plans, design drawings, and other engineering documentation.

- Identifies high-risk and problem areas early in development and throughout the system's life cycle, continuously evaluating the system design and other support areas. 


\section{APPENDIX B}

UTILIZATION OF THE SYSTEMS ENGINEERING TEMPLATE IN REVIEW OF THE TECHNICAL APPROACH OF THE ITTS AND INTS REPORTS 


\section{UTILIZATION OF THE SYSTEMS ENGINEERING TEMPLATE IN REVIEW OF THE TECENICAL APPROACH OF THE ITTS AND INTS REPORTS}

As part of the effort to evaluate the technical approach of the LITCO studies, a systems engineering (SE) template was developed to guide the review of the snidies. The resulting template was meant to prompt critical questions sbout the design process utilized in the LITCO studies and to enable a fair evaluation of those studies. This appendix contains that template as well as questions and points considered in the evaluation of the stodies. It should be stated again that LITCO was asked to perform a systems analysis of each of the potential remediation technologies; it was not asked to perform a full systerns engineering design. But, since SE is ultimately needed to complete the system design process, the LITCO studies were compared to the SE template to deternine what pieces were still missing. These pieces must be filled in by some organization(s) $f$ team(s). The statement that the LITCO studies are deficient as SE studies should not be construed as a criticism of LITCO-they did what they were commissioned to do, which was systems analysis.

The essence of this template and evaluation effort is the eight-block morphology presented in Figure B-1. Each block in this morphology is further specified on subsequent pages along with questions and points to be addressed.

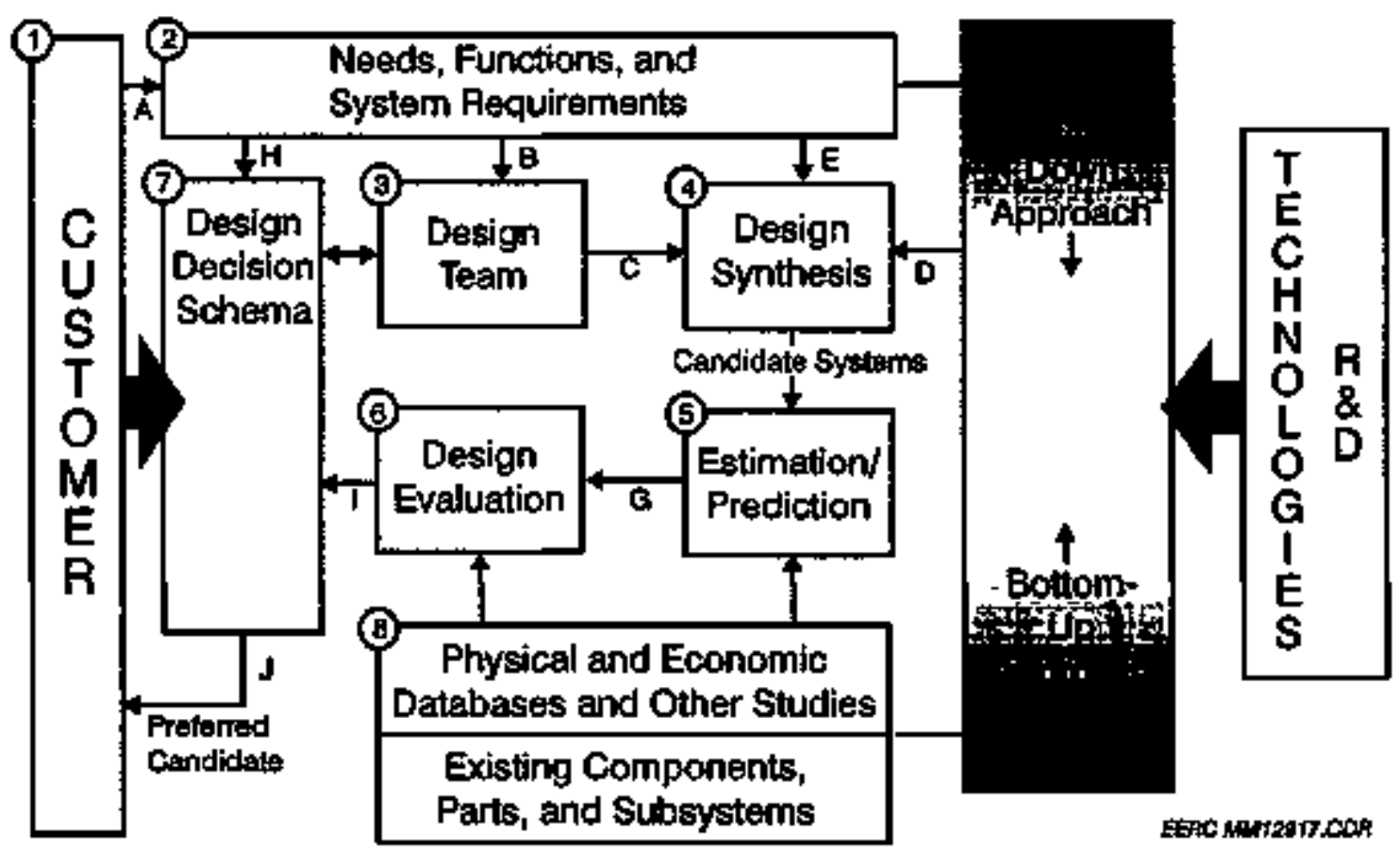

Figure B-1. Systens engineering template displaying the eight elements for evaluating a technical approach. 


\section{BLOCK 1 - THE CUSTOMER}

\section{About This Block}

The purpose of any system design is to stitsfy some customer and stakeholder need. The success of a particular system design is ultimately determined subjectively by the customer. During the design process, all requirements and decisions should be made from the customer's perspective. Even when the customer is relatively easy to identify, the concerns of "the custorner" may not be readily accessible. Accordingly, the customer must be defined as an all-inclusive entity.

Stakeholders and special interests must be represented in "the voice of the custoner" in a way that reflects their needs and concerns.

\section{Questions and Points to Consider}

Who is the customer?

- Is the customer the U.S. Department of Energy (DOE), society as a whole, Native American tribes, engineering companies, etc., or some mixture thereof?

- Is the custorner fully aware and educated as to the need for this treatment system?

- Where is this definition of the customer spelled out in the LITCO studies?

- Are customer interests generally in agreement or in opposition to each other?

- If the stakeholders and tribal interests are generally opposed to certain treatments and storage ideas, is this stated?

How is the "voice of the customer" captured?

- Can the customer make effective decisions and give valuable input based on the information available?

- Do the LITCO studies address this concern? How?

- How are the differing opinions of various interests resolved fairly in the LITCO sudies?

- Are all identifud interests being represented in the "voice of the customer"?

- What method is used to ensure this in the LITCO struties?

- To what extent ate the LITCO sudies responsible for obcaining and using information that represents the voice of the customer?

- What forum is used to capture this voice (surveys, polls, meetings, interviews, sudies, etc.)? 


\section{To what extent is the customer involved in decision-making?}

- Is the custoner directly or indirectly involved in the decision-making process?

- $O$, will only certain interests be active in decision-making, with the remaining interests acting as reviewers?

- Who defines this rejationship (DOE, , etc.)?

- Do the LITCO studies make this clear?

- What is the purpose of these studies? If the purpose is to eventually facilitate a decision about a preferred alternative system design, then do the studies consider their audience?

- That is, do the LITCO studies take into consideration the definition of the customer, i.e., who they are trying to satisfy when presenting the alternative systems?

- In which decisions does the customer participate (decisions at each major milestone, each design change, or when large costs are involved)?

- What weight is given to each interest?

- Is this weighting schema relatively more numerical or more subjective in nature?

- Who deternines these weights (formally or informally)?

- Is this relationship between DOE, LITCO, Tribal Stakeholders Working Group (TSWG), etc., clearly defined?

Are the study decisions traceable to the customer?

- To what extent are the alternative designs and decisions traceable to the customer in the studies?

- Do the LITCO reports provide sufficient traceability to the customer?

- If the "custorner" definition is not fully understood at the design jevel, what criteria are used to synthesize candidate systems in the studies?

\section{Evaluation of the LITCO Studies}

The integrated thermal treatment system (ITTS) and integrated nonthennal treatment system (INTS) sndies inadequately consider the customer in the synthesis, analysis, and evaluation of the treatment technologies. In the ITTS sudies, only incidental mention is made of stakeholder and customer considerations with regard to evaluation of alternative technologies. There is not adequate traceability in the design synthesis to say what motivated the partictlar synthesis based on needs of the customer. 
The INTS study does a much better job of representing the customer interests than the ITTS Studies (Phases 1 and 2). The INTS study tries to document the input and concerns of the customer into the design synthesis portion of the report, but falls short. The INTS TSWG, which for the first time represented various tribal and nontribal interests, appeared to be a useful forum for DOE and tribal/stakeholder interaction. The INTS study report appeared to be somewhat more readable and understandable by the nontechnical teader.

\section{BLOCK 2 - NEED, FUNCTIONS, AND SYSTEM REQUIREMENTS}

\section{About This Block}

The Systems Engineering (SE) approach stems from the identification of a need that develops as a result of a problem or deficiency and the subsequent desire for a system of some type. From the identification of a given need, one must define the basic requirements for the system in terms of input criteria for design. The need and requirements for operation should be clearly defined before problem solutions or system configurations are proposed. Definition of system requirements should include mission definition, performance and physical pararneters, use requirements, deployment and distribution of the system, operational life cycle (horizon), effectiveness factors, and definition of the operational environment. Additionally, any definition of system operational requirements should originate with the defined customer requirements. Arrow A illustrates the customer inputs to the need definition and requirements specification process. The "voice of the customer" should be the basis for all system requirements. Poorly defined customer requirements or an unclear identification of the customer can lead to a system that either does not satisfy the need or contains superfluous requirements. The definition of the system at this point is purely from a functional viewpoint. The objective is to capture what the system's overall mission is in a functional sense. At this point, designers should avoid overly constraining the design and should also resist the semptation to jump to the physical manifestation of these requirements.

\section{Questions and Points to Consider}

\section{What are the customer requirements?}

- Are all requirements from the customer point of view defined?

- Is the functional nature of the system specified in the LITCO studies?

- Are afl the requirements related to the functional objective of the system?

- Each requirement must be related functionally to the mission objective. Which requirements are superfluous?

- Does the LITCO study relate these customer requirements in a functional sense?

- How well does the LITCO study address these requirements? 
- Does the LITCO present these requirements so as to emphasize the main requirements and those that the desiga will be most driven by?

- How are these requirements obtained?

- Is an acceptable method used to extract these requirements from the customer and ensure the completeness of the set of requirements?

- Do the LITCO studies analyze the requirements to determine whether they were appropriate and functionally correct?

- Do the LITCO studies point out any inconsistencies or problems with the customer requitements?

- Are the needs/desires of the tribes, general public. contractors. DOE, etc., fully represented in qualitative or quantitative terms?

- How are these incorporated into the given requirements in the studies?

How are customer requirements translated info system requirements?

- Do the studies show how the system meets customer requirements from an operational and functional perspective?

- Do the LITCO studies present a set of derived system requirenents taken from, or translated from, the customer requirements?

- Do the studies contain a functional analysis of the system requirements?

- Are functional flow diagrams of the system generated and presented in the studies?

- Are system requirements traceable to the original customer requirements?

- Are perfonnance parameters/requirements such as volume of waste treated per day, system environmental impact, safety, effectiveness of treatment, etc., adequately defined and quantifiable measures determined?

- Are the operational environment requirements well defined?

- Are these operational environment requirements sufficient or are there other questions that need to be answered?

- Are these operational environment requirements just assumptions or are they actual requirements?

- If they are not given as requirements, do the LITCO sndies pursue various operating environment candidates along with the candidate systems developed? 


\section{Do the reguinements refiect a systems and life-cycle engineering point of view?}

- Do the requirements consider a time frame for design and development to allow for new, emerging technology refinement?

- What is the time frame?

- What life-cycle horizon is used for planning?

- What are the avajlable skill levels for operation, maintenance, stpport, and disposal?

- What role do maintenance and support factors play in the defined system requirements to the extent that they influence perfornance of the system?

- Is disposal of the actual system itself considered in the requirements?

- The LITCO studies ctain an "integrated system engineering approach." Yet the "systems" they describe contain only prime mission equipment and processes. Where do the sudies consider other life-cycle elements?

- Why do the LITCO studies refer to development of operational and functional requirements for each candidate system? All operational and functional requirements for the treatment systern should be the same for all candidates. The only way to ensure a fair comparison is by maintaining consistency in requirernents.

\section{Evaluation of the LFTCO Studies}

Definition of the system from a functional viewpoint is necessary before the physical form is realized. In the technical approach section of each of the three studies, it is stated that "functional and eperational requirenents . . . were developed for each system." However, the functional need and reçuirements for the treatment system should not change whether thermal, nonthermal, or some as yet undiscovered option. There should be one set of requirements for the ireatment of mixed low-level waste (MLLW), and these requirements should be the same and consistent across all system alternatives. These studjes suffer from a lack of adequate requirements and need analyses. A significant portion of any preconceptral or conceptral design process is this analysis activity. These snidies show little to no evidence of such activity.

The only evidence of functional analysis in the shidies is the selection and definition of subsystems. The subsystems seem to have been separated along functional lines. However, this is simply a list of functions. A true, effective functional analysis would go into depth as to how these functional elements fit together and interact. What are the inputs and outputs? Finally, an appropriate functional analysis leads to an effective allocation of system requirements to functional elements. Only then can meaningful design synthesis accur. There is no evidence or traceability to a functional analysis and subsequent allocation of system requirements. 


\section{BLOCK 3 - DESIGN TEAM}

The selection and qualifications of design team members are of utmost importance. It is not enough to have only technological expertise on the design team that relates to the stated need or deficiency represented. A design team that seeks to create a system using systems or life-cycle engineering methodology must have adequate representation from SE as well as chemical engineers, operations engineers, acnual users of the system, and others. A desigit teamt that is onesided in its makeup will tend to produce candidate systems that are likewise one-sided. That is, the design tends to focus too beavily on prime mission equjpment and reglect elements such as support, environmental factors, reliability/availability, and disposability. The design team must have representatives for each of the life-cycle elements that are contained in the set of system requirements. A diversity of perspectives on the design team facilitates consideration of all aspects of the system Jife cycle. Arrow B in Figure B-1 represents a relationship between the set of system requirements and the selection and makeup of the design team.

\section{Questions and Points to Consider}

\section{What are the qualfications and expertise of the design team members?}

- Are the LITCO study design teams appropriately staffed?

- Are all design members qualified for their specific aspect of system design?

- Is the number of team members appropriate?

- Are there too many or too few design menbers representing a particular aspect of system design on each team?

- Does each of the requirements in the life cycle of the system have a representative on the design team?

- Do the LITCO studies justify and present the makeup of the design team, along with each team member's responsibilities?

- Are all design team members chenical or environmental engineers, or are a variety of system aspects represented?

\section{What method was used to select this design team?}

- What are the mimimum qualifications and system elements represented on the teams?

- Is the makeup of each of the LITCO design teams consistent?

Are various aspects of the life cycle represented on the design team?

- Do the LITCO design teams include transportation expertise, support expertise, systems engineering expertise, etc.? 
Are the motivations/desines of the design team(s) members/contractors consistent with that of the customer?

- Basically, are the concerns of the customer adequately represented on the design teams?

- How the customer represented on the design team?

- Do the LITCO studies discuss how the customer perceptions and opinions were preserved and used by the design teams?

- Are the design teams one-sided? Are all the members from one discipline?

- Are teams similar in makeup such that meaningful comparison of alternatives can be made between multiple design teams?

- Are the LITCO studies consistent in their design team approaches?

- If not, are the differences known and understood so that the candidate systems from each sudy can be evaluated fairly against one another?

\section{Evaluation of the LITCO Studies}

Not much information is given regarding the design teams. The design team members and affiliations were tisted, although no specific details were provided with regard to areas of expertise, specific areas of responsibility in the study, or criteria for selection to the study team.

Several additional questions arise. The size and composition of the study teams differed, and few design team members were consistent across all teams. Can the design alternatives be compared on an equivalent basis? What or who ensured that the level of effort was the same for the definition, analysis, and subsequent evaluation of all alternatives?

\section{BLOCK 4 - DESIGN SYNTHESIS}

Once a design team and the system operational and functional requirements have been defined, synthesis of various system design alternatives can begin. Depending on the particular phase of system design, design synthesis can consist of technology and system concept identification. in the case of conceptual design, or can be as detailed as compiling various designs for a particular piece of hardware ar its most specific tevel. In any case, the objective is to sufficiently describe a number of feasible design alternatives so that an ajalysis and subsequent evaluation and decision-making can occur. Design synthesis is a highly subjective and creative process that relies on expert knowledge and state-of-the-art technology identification to synthesize alternative designs. The expert knowledge and experience that is utilized comes from the knowledge and experience of the design team members as represented by Arrow C in Figure B-1. It is important to realize that each design team member has his/her own vision of the end system. It is important that team members realize this and force themselves to question their own preconceived notions about the nature of the system design when proposing candidate systems. 
The candidate system synthesis is driven by a top-down functional definition of the need as well as a bottom-up definition of the set of available technology and system elements. Arrow D represents the input of the two different (but complementary) approaches to system design. It is important to nore that the description of each alternative must include system factors and elements other than just the prime process or equipment. Adequate definition of each system alternative must allow for lifecycle analysis and evaluation to reflect the set of determined system requirements. Arrow E highlights the defining role that the system requirements play in the synthesis of candidate systems.

Questions and Points to Consider

How are the various altematives selected?

- Are all reasonable alternatives being explored?

- What resources are the design teams using to artive at each alternative?

- Do the LITCO studies reveal the methods and sources for the selection of the various altematives?

- Are the alternatives all existing designs or technologies?

- Are new, emerging technologies explored?

- In other words, does the design effort rely too heavily on either the botrom-up or topdown approach?

- Both approaches should be utilized in the design synthesis process. This ensures a mix of new ideas with proven processes.

- Does the statement of work or design team maketp bias or exclude otherwise reasonable design alternatives from consideration?

- Do the LITCO studies document the above?

- Do the design reams sufficiently document the origination of each system alternative?

- Do the LITCO studies give the reasons for including the candidate system for consideration?

Are alternative selection methods based on stated customer and system requirements?

- If any short listing or exclusion of alternatives occurred, is the justification rooted in customer and system requirements?

- Does each of the alternatives fit with the stated requirements?

- Do the LITCO sudies give the criteria for selecting candidate systems? 
- Ase these criteria representative of the eatire life cycle?

- Who makes the decision?

- Ultimately, each of the alternatives generated should be traceable to some or all of the requirements stated.

Ane the alternatives defined well enough that meaningful anabysis and evaluation can occur?

- ls the set of alternatives defined welf enough that some sort of analysis and evaluation can be made?

- Ate the alternatives fully defined from a life-cycle and systems perspective in the sudies?

- Do the LITCO studies include sufficient life-cycle information to estimate and predict parameter values and to evaluate life-cycle cost?

- Do they include at least preliminary ideas about how logistical support, operation, training, etc. will be accomplished?

- Can these life-cycle considerations be used as analyses and evaluated against one another?

Are all allernatives comparable?

- Is each of the atternatives able to be analyzed and evaluated fairly, on an equivalent basis?

- In other words, is each of the alternatives defined consistently the others?

\section{Evaluation of the LITCO Studies}

There is certainly adequate description of each of the alternative systems in the LITCO studies. However, neither the ITTS or INTS studies provide adequate traceability back to system requirements. The design teams relied too heavily on the bottom-up approach to synthesize system altermative designs. There appears to be little, if any, reliance on system requirements to dickate the design synthesis process. The ITTS studies do not document the reasoning behind the selection of each of the technologies. The INTS sndy provides a discussion of the technology and system selection process; this fulfilled the obligation to the TSWG to provide documentation of the process. However, there is not strong evidence that TSWG principles were used in the downselecting process.

The studies concentrated primarily on technology jentification and selection. A true systems approach would have also considered many other factors such as facility configurations, geographic locations and trade-offs, transportation aspects, etc. It is important for the sudies to identify and document the design synthesis process from the top-down perspective as well as the bottom-up perspective to ensure that the design alternatives produced can meet system requirements and satisfy the system need. 


\section{BLOCK 5 - ESTIMATION AND PREDICTION}

After a set of candidate systems has been synthesized, each alternative must go through a process of estimation and prediction. Cost and effectiveness measures are generated for these alternatives using established criteria. This SE activity's purpose is to estimate and predict design dependent parameter (DDP) values for each alternative. Estimation and prediction rely on rnodels and simulations to predict parameter values. These models and simulations are based on assumptions, physical laws, and empirical data. Arrow F in Figure B-1 represents this available database of physical and economic factors, as well as existing components, parts, and subsystems. These parameter values provide a basis for comparison with established design criteria to determine the merit of each alternative. Alternatives that are found to be unacceptable from a performance perspective can be reworked and new alternatives created. Those alternatives that meet all or the most inportant performance criteria can then be evaluated based on life-cycle costing methodologies.

\section{Questions and Points to Consider}

\section{What are the basic assumptions inherent in each estimation/prediction?}

- Are each alternative's DDP values estimated using a consistent set of assumptions?

- Do these assumptions match the assumptions stated in the requirements in the studies?

- Do the LITCO studies rely too heavily on assumptions? Which ones? This may indicate an area for further investigation.

- Are the models used to estimate values for one alternative consistent with models used on other alternatives?

- Are we sure we are not setting up an apples-to-oranges comparison later in the studies?

- Are the assumptions valid? Are they necessary? What overall impact do they have? Are the estimates derived from these assumptions important enough to cause possible decision reversal (e.g., assuming Seismic Category $I$ in the nonthermal study)? If so, more work might be needed.

By what means do we consider an altemative's performance acceptable?

- There must be some minimum standard of performance to adhere to. What constinutes acceptable perfotmance of the treatment system?

- Do the LITCO studies relate the acceptable performance criteria?

- Are any of the candidate systems not picked for consideration explained in the LITCO study? 
- When an alternative fails to meet performance criteria, are the deficiencies and areas for improvement identified?

- Do the LITCO sudies present this information?

- Are all alternatives held to the same level of performance criteria?

\section{How are nonquasifiable parameters handled?}

- Is there some means for determining the "goodness" of an alternative design with respect to quatitative measures such as public confidence, ease of use, etc.?

- Are the methods used for determining the "goodness" of these measures acceptable?

- Do the parameters meet with the approval of the customer?

- Where in the LITCO sndies are these parameters discussed? How are they to be handled?

- Do the measures represent the view of the customer?

- Since these qualitative measures are subjective, care must be taken to capure the opinions of the customer.

\section{Evaluation of the LITCO Studies}

The stadies do a good job of collecting and describing each of the alternative system designs. What is lacking is a definitive set of metrics to measure the merit of each of the systems. Accordingly, the studies do not adequately organize and define the set of metrics that will be used to measure the system's effectiveness. Many characteristic metrics of the system alternatives are presented in the studies. However, the origins of many of the parameter values are not documented in enough detail. It is well understood that at the preconceptual design stage, many of the metrics used will have to rely on expert judgment and experience to assign values, but these need to be documented for funure design efforts.

These sudies lack consideration for the customer's input into acceptability measures, etc. The customer to be strveyed to obtain this information. Various qualitative measures need to be estimated. These types of measures are not given the sarne treatment as the readily quantifiable measures such as mass-flow rates, etc.

Additionally, the studies do not set forth a set of criteria by which the alternative systems can be judged from a performance acceptability perspective. Definitive measures for acceptable performance need to be set forth in the studies. These measures and their target values need to be listed and clearly stated so that each alternative's performance can be judged. In summary, a traceable set of performance criteria from which to make a statement as to the effectiveness of a particular system design is lacking. 
The studies incorrectly assume that all alternative systems equally meet the prescribed regulatory and functional requirements. As a consequence, there are mo minimum standards of performance to meet or exceed; i.e., all systems immediately meet or exceed (to an unspecified level) the performance criteria.

The studies do a reasonable job of defining deficiencies and areas of improvement.

\section{BLOCK 6 - DESIGN EVALUATION}

The basis for the evaluation of candidate systems is life-cycle cost. Given that a set of alternatives minimally satisfies a set of performance criteria, a decision must be made between the alterantives. In order to do this, the cost-effectiveness of the designs needs to be evaluated. As a seart, the life-cycle cost of each altetnative is determined based on the estimation and prediction activity just conpleted. Arrow $G$ in Figure B-1 indicates the passing of the estimation and prediction results, the DDP values, to the evaluation step. The entire life cycle "from lust to dust" must be considered in the life-cycle cost analysis. Some methodology must be utilized to estimate life-cycle cost. The cost breakdown structure (CBS) needs to be developed and used for each alternarive. Ir should be obvious from the CBS whether a life-cycle approach to cost estimation is applied. Also, the time value of money principle is applied here. Only after performing a lifecycle cost analysis can a decision be made about the preferred altemative(s).

Questions and Points to Consider

What is the definition of the system's life cycle?

- Each phase of the life cycle must be considered.

- Is there a life-cycle model contained in the LITCO studjes?

- Do the LITCO studies contain a description of the life-cycle cost elements?

- Are all aspects of the system represented in the life-cycle model?

- Do the LITCO sadies define the life-cycle cost estimation procedure?

- Are all system elements, i.e., support, operation, disposal, training, etc. represented in the life-cycle definition and/or CBS?

By what means is the life-cycle cost calculated?

- What method is used to calculate life-cycle cost in the studies? (activity-based costing, CBS, etc.)

- Is this method utilized consistently over the entire life cycle and across alternatives?

- What assumptions are made that affect life-cycle cost calculations in each study? 
- Do the LITCO studies examine the effect of these assumptions on decision reversal?

- Which cost assumptions are critical enough to warrant further study?

- Identification of these critical assumptions and others is a fundamental part of the SE process, especially at the conceptual design level. Do the LITCO suidies report or identify any assumptions, technologies, vague requirements, etc. for further investigation?

- What interest rate, tax rate, depreciation rate, etc,, is considered?

- Are rent versus buy options delineated as mutually exclusive alternatives? If not, design synthesis should be revisited and these alternatives considered.

\section{Evaluation of the LITCO Studies}

Largely, the methodology for calculating life-cycle cost from the system designs was consistent with sound engixeering methods. However, there seems to be no consideration of the "time-value of money" principle in these life-cycle cost calculations. This is a consideration that can cause decision reversal in the selection of candidate systems.

The life cycie of the systems was not completely described; specifically, decontamination and decommissioning were neglected. The pubtished life-cycle cost results are quite minimal, thus decision making or reconstruction by an independent reviewer is made difficult. Further, sensitivity analysis with respect to critical design and operating assumptions or parameters was not performed.

\section{BLOCK 7 - DESIGN DECISION SCHEMA}

After each alternative has been evaluated with respect to life-cycle cost, a decision can be made as to the preferred altemative(s). Given the variety of opinions represented by the customer and the number of decision criteria the customer will have, choosing a preferred alternative is usually not a simple matter of picking the least expensive design. Customer opinion and perception play a large role in this subjective decision-making process. Based on the definition and input from the customer about what is desirable in the system, a decision evaluation can be made. These design criteria are derived from the set of customer and system requirements and are represented by Arrow $\boldsymbol{H}$ in Figure B-1. This process of weighing multiple decision criteria against life-cycle cost is mostly subjective. The decjsion mater must now trade off life-cycle cost against other decision criteria subjectively. These parameter values are passed from the evaluation step along with DDP values, as seen in Arrow I. The result is one or more preferred alternatives that can be used to continute the design process to a more detailed level. These preferred alternatives are always ultimately judged by the customer; therefore, we show Arrow J returning the preferred candidate system for review by the customer. 


\section{Questions and Points to Consider}

\section{What method will be used to factlitate the decistion-making process?}

- The definition of the customer and ensuring all voices are heard plays a large part in determining what decision-making tool is used.

- Is the decision-making process facilitated by the work done to this point?

- Are the LITCO studies constructed to facilitate the decision-making process?

- Is the ultimate goal of the studies to present many alternatives for a decision by the customer? Or, is the objective of the studies to select a preferred candidate system or set of candidate systerns to proceed with?

- Are all design decision criteria identified and estirnation and prediction completed?

- Do the decision criteria trace back to the customer requirements and concerns?

- Are the alternative systems developed, analyzed, and evaluated in enough detail so that a decision can be reached, or are the systerns evaluated in a manner that does not allow for a decision to be made?

- If the LITCO studies do not evaluate the designs well enough, to they give reasons?

- Are there areas for further study identified in the studies before a decision can be made?

- Should the decision be to continue with multiple designs until a better evaluation can be done? What do the studies say?

- Is the customer, as defined, a major participant in the decision-making process?

- If not, what assures that the "voice of the customer" is represented in the decision-making process?

What are the established decistont criteria and thresholds for each?

- Are the decision criteria and thresholds that define the goals and opinions of the decision maker documented?

- Do the selected criteria adequately reveal the deficiencies and differences between alternatives?

- Are there any customer concerns or opinions that are not addressed that are necessary to satisfy the customer? If so, then requirennents and criteria must be added to the designt process to correct this deficiency. 
- Are the LITCO snudies jterative in nature, or do they just complete one iteration of design synthesis, analysis, and evaluation?

\section{How were the decisions reached?}

- Is there traceability within the decision-making process?

- Do the LITCO studies provide traceability in decision making? How are the longet tists of candidate systems shortened? Where are the criteria for selection?

- Are the decisions made documented with the approptiate reasoning and criteria values?

- If the decision makers are not the customer, how are they held accountable to the customer?

- How does the customer have ingut to the decision-making process? Is this role documented?

- Are the decisions made on a fair or equivalent basis?

\section{Evaluation of the LITCO Studies}

In the end, the ITTS and INTS studies do not provide the proper information to facilitate the decision-making process. The candidate systems cannot easily be compared, so there is no real basis for a decision. The ITTS Phase 1 report initiated, but did not conclude, a "quantitative systerns cormparison" of the system attributies using an approach the authors called figure-of-merit (FOM) analysis. There is no description, however, of how the weighting factors or scoring guidelines were developed. This approach, a valid methodology to assist decision making, was incorrectly abandoned in the ITTS Phase 2 and INTS sudies.

The main problem with the ITTS and INTS study approach is that only technical ctiteria ase presented. The decision between alternatives needs to be made in the face of multiple criteria, only a few of which are going to be technical in nature. Most of the design decisions will be made based on much more stbjective criteria and characteristics. It is those criteria that these studies should concentrate on in the preconceptual stage of design.

\section{BLOCK 8 - PHYSICAL AND ECONOMIC DATABASES AND OTHER STUDIES}

This block represents a resource for the SE process rather than an actual step in the process flow. There exists a body of knowledge that engineers, economists, and scientists rely on to perform analyses and evaluations. This body consists of known physical laws, empirical data, economic forecasts, and other studies. It also comprises those existing system components, parts. and subsystems that have resulted from previous design efforts. This body of knowledge is great. To what extent it is utilized is a concern in SE. It is very easy in the design of a complex system to "reinvent the wheel." Reuse of existing systerns and components is encouraged in the SE process. 
This body of knowledge and experience is utilized more informally than in a formal sense. There are, of course, useful formal treatments of this body of knowledge.

Questions and Points to Consider

To what extent is reuse encouraged and past experience depended on?

- Are all system components "new" designs, or do the selected alternatives build upon previously proven techrologies and designs?

- Are these uses or reliance on past efforts documented in the LITCO sudies?

- Are uses of past designs and work appropriate for this design effort?

- Do the LITCO studies provide justification for these uses? Or, should more attention be devoted to new design work?

- Do the LITCO studies identify areas and potential for future and needed research and development?

Where do assumptions made during the spstems engineering process originate?

- Do assumptions made in estimation and prediction have a basis in fact or in theory?

- Are there sufficient studies or data to support such assumptions?

- Are economic factors, i.e., interest rates, tax rates, depreciation, etc., forecast using sound tconomic principles?

- Where estimation occurs, are the appropriate assumptions consistent with the alternative design?

What effect does this body of knowledge or expen knowledge have on the alternative selection and decislon-making process?

- Does the body of expert knowledge bias the altemative selection by the design team?

- What criteria are used in the LITCO studies to make decisions about selected alternatives?

- To what extent is engineering and expert judgment relied on to provide answers or estimates of destgn parameters?

- Is this documented?

- What effect do these assumptions have on decision making, and are they explored in the LITCO studies? 
- Are decisions based on the estimation, prediction, and evaluation activities or solely on engineering jưgment?

- Are these decisions documented and justified?

\section{Eraluation of the LITCO Studies}

The studies do a reasonable job of reviewing the technology and system deficiencies and requixed areas of development. References to regulations are mumerous, but manly of these are obsolete or have been superseded. Accordingly, it would be good if each cited regulation could be updated and the impact of the change on the MLLW treatment problem explained. Further, given the apparently large technology database, there was little referencing in the ITTS studies. The INTS study included more referencing with respect to the evaluated technologies. 


\section{APPENDIX C}

\section{EXPANDED DISCUSSION OF THE TOP-DOWN VERSUS BOTTOM-UP APPROACH}




\section{EXPANDED DISCUSSION OF THE TOP-DOWN VERSUS BOTTOM-UP APPROACH}

Traditional engineering design methodology is based on a bottom-up approach. Starting with a set of known elements, design engineers synthesize the product or system by finding the most appropriate combination of system elements. However, unless the product is quite simple, it is unlikely that the functional need will be met on the first attempt. After determining the performance deviation from what is required (by prediction, simulation, measurement, or other means), the combination of elements is attered and the system performance determined again.

\section{Top-Down rersus Bottom-Up Design}

This bottom-up process is iterative, with the number of iterations (and design efficiency) determined by the experience and creativity of the designer, as well as by the complexity of the system or product. As the complexity of the product increases, it is less likely that the desigter will come close to the required performance on the first try. It is also tmlikely that an adjustment in the combination of elements will actualty lead to an improvement. The effort involved in the iterative process, compared to the effort for the initial design, increases rapidly with increasing system complexity.

A top-down approach to design is evoked by systems engineering (SE). Starting with requirements for the external behavior of any part of the system (expressed in terms of the function provided by that part externally or to other parts of the system), that behavior is analyzed to identify its functional characteristics. These functional behaviors are then described in more detail and made more specific through a process of refinement. Next, the appropriateness of this choice of functional components is verified by synthesizing the original part.

Two characteristics of the top-down process are:

- The process is applicable to any part of the system. Starting with the system as a whole. repeated application of this process will result in a partitioning of the system into smaller and smaller elements.

- The process is self-consistent. External properties of the whole system, as described by the inputs and outputs and relations between parts, must be reproduced by the external properties of the set of interacting elements.

The first step of the analysis is to recognize the general functions involved in transforming imputs into outputs. That is, one must abstract from the particular case to the underlying generic case and represent this case by a number of interacting functional elements. The use of functional elements lies at the core of the SE methodology because:

- A particular tunctional element is applicable to a whole class of systems. Consequently, one needs only a limited number of such elements to represent a large number of real systems. 
- Functional elements inherently reflect the top-down approach. That is, a particular functional element is applicable or appropriate to a certain level of the top-down hierarchy.

- Functional elements provide a link in the specification of a system. Design-dependent parameters such as reliability, maintainability, producibility, performance, and others are related to functional elements of the system.

- Functional elements allow one to pursue system design work weli before physical manifestations have been defined. This contrasts with designing a system by using the bottom-up methodoiogy, where one starts out with a defined set of real elements (components) and synthesizes a system out of members from the set.

There are two main differences between the bottom-up and top-down approaches: In bottomup design, physical realizability in terms of known elements is assured, whereas at the end of the cop-down design process, the systems elements are stitl functional entities. Their physical realizability is not guaranteed. In the top-down approach, the requirements are ideally always satisfied through every step of the design process (as an inherent part of the methodology), whereas in the bottom-up approach, the methodology provides no assurance that this will occur.

The extent to which the top-down process is applied as a complexity-reducing step depends on the complexity of the product or system to be designed. As products get more and more complex (i.e., consisting of more and more interacting elements and characterized by more and more paraneters), the probability of selecting a combination of elements that will result in performance being anywhere near user requirements diminishes, as does the probability of picking a new combination that will result in an inprovement.

SE is not likely to replace bottom-up design. In the end, every project must involve some physical object that meets the need. At some point in the design process, there must be a transition from the functional (or abstract) to the physical. Most projects will employ both methodologies: first $\mathrm{SE}$ to reduce the complexity by partitioning the system into its elements, and then botton-up design to realize the elements. This is best illustrated by the " $\mathrm{V}$ " system design and development model as jllustrated below. 


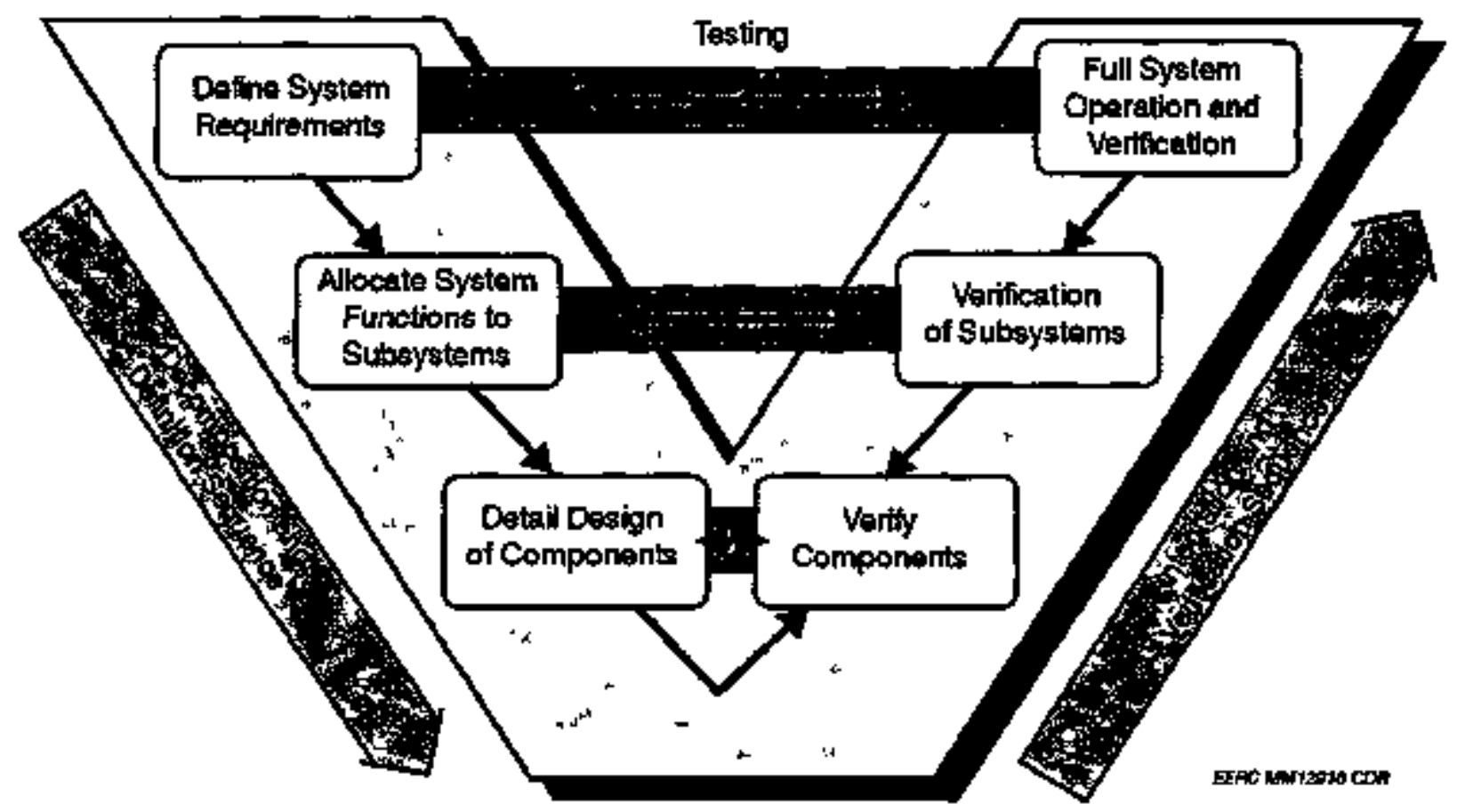

Figure C-1. V diagram representing both top-down and bottom-up systems engineering. 


\section{APPENDIX D}

\section{IDENTIFIED ASSUMPTIONS FOR THE ITTS STUDY - PHASE 1}


No. Sect. Page Uf $\mathbf{s}^{*}$

a) Regulations, Pormiting and staknholder input

$\begin{array}{lll}1 & 1.2 .0 & 4 \\ 2 & \text { A-1.3 } & \text { A-5 } \\ 3 & \text { A-1,4 } & \text { A-5 }\end{array}$

4

$\begin{array}{ccc}5 & \text { A-1.5.1 } & \text { A.B } \\ B & 1.3 .2 & 10\end{array}$

$7 \quad$ A-1.5.1 A-B

8 A-1.5.2 A-B

$9 \quad$ A-1.5.3 A-B

$10 \quad A-1.5 .3 \quad A-6$

11 A-1.5.4 A-7 97

12 A-1.5.5 A-S

13 A-1.5.6 A-9

14 A-1.5.7 A-10

$15 \quad$ A-1.6.1 A-11

16 A-1.6.2 A-11

37 A-1.8.33 A-1t

$18 \quad$ A $1.7 \quad$ A.12

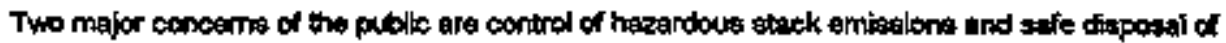

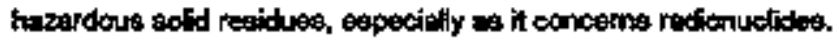

Main themed treatment unit in ITTS must conform to TSCA; apecial consideration for PCB under 40 CFR $761.00-761.70$

Lintid partities of CERCLA (buried) watet may ba treated.; ta RCRA (stored) wasto will bo troated

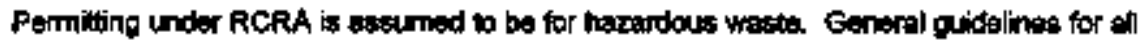

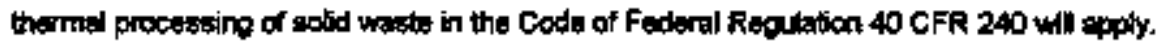
RCRA permiting imotres additional regulationg apphing to partiatar systems depending on the type of procens used.

Listed (haxpidous) waste at designated by the EPA is grospmed to bo treated.

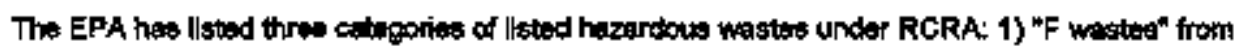

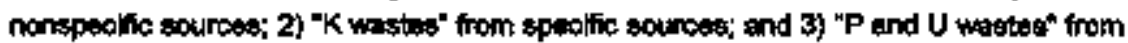

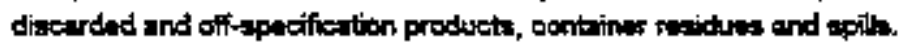

Wastes, whethey liated or not must be characterized by testing or prox procese knowledge to

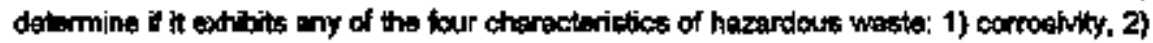
igritabitity, 3) reactivity, and 4) tonity.

Maneganent of secondary waxtets ghal be according to EPA "derived from" nulp

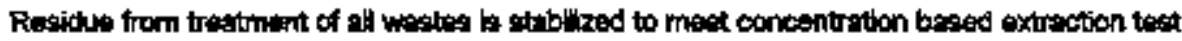
(TCLP) (40 CFR 268.41); requirement ia stso port of DOE Order 5820.1A

Llsted wasto, ofter treatrinent, must be disposed of in an interim etotus or newty permitted RCRA conforming Subthts C Iandfil

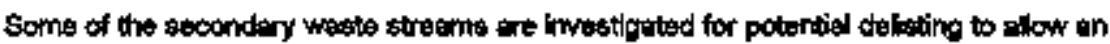
exolusion pethwoy for the wasto to becontie resulated as nonthezardous

Thermed tinits shal be permitted for RCRA regulation: acoording to 40 CFR 270 .62 which

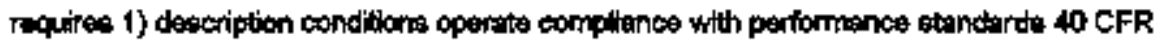

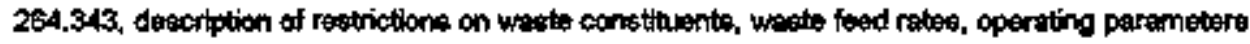
ocording to 40 CFR 254.345, propoest for trial bum plan.

Thermal trealment thel be stupject to RCRA permit trial bum plan and information to be proyded Listed in 40 CFR $270.62(\mathrm{~b})(2)$

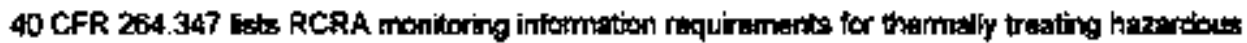
watos

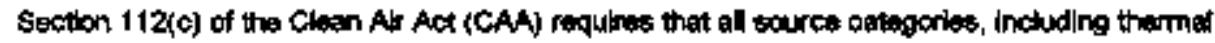
treatront, be identified and that technology boend emiasion standards be promulgated for each

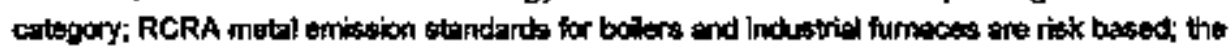
mavimum achievable control standards are to be based on the beak technology currenty

Permits are now required for all mnjor new sourses; requires entinearing justification of focitity

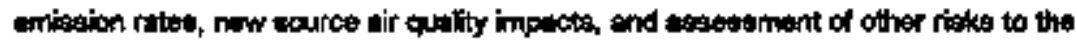

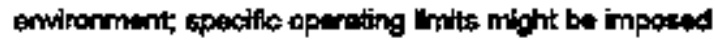

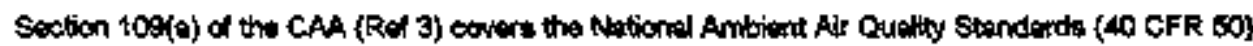
shown in Tablo A-1

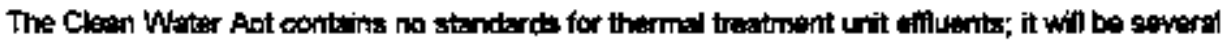
years 


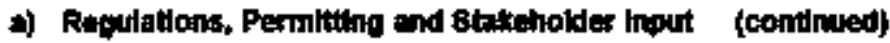

\begin{tabular}{|c|c|c|}
\hline 19 & $A-2.0$ & A. 12 \\
\hline 20 & A-2.1 & A.12 \\
\hline 21 & $A-2.1 .1$ & A-12 \\
\hline 22 & A-2.1.2 & $A-12$ \\
\hline 23 & A-2.1.3 & A-12 \\
\hline 24 & A-2.1.4 & A-12 \\
\hline 25 & A-2.1.5 & A-12 \\
\hline 26 & A-2.1.5.1 & A-13 \\
\hline 27 & $A+2.1 .5 .2$ & A-16 \\
\hline 29 & A.22 & A-16 \\
\hline 29 & A-2.3 & A-16 \\
\hline 0 & A-2.4 & A-16 \\
\hline 91 & $A=2.6$ & A-15 \\
\hline 32 & $A-26$ & $A-16$ \\
\hline 33 & $A-27$ & A-17 \\
\hline 44 & A-28 & A-17 \\
\hline
\end{tabular}

b) input Wast Chavactoriatic:
Tables A-2 and A-3 show emiselan (current end proposed) for nonmotris and metofit for the ITTS deolon

Acconding to 40 CFR 264.343 theimed trectment units opereted In eccordance with perrit requirementes must ment the folowing performanca stondards:

Destrution ramonal efficiency (DRE) of 99.99\% for eech POHC dosigneted in permit

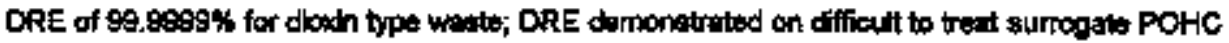

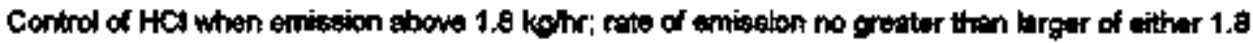
kghr or 1\% of HCli in thetk gie befow APC

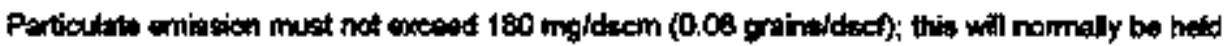
ot 0.015 grains based an Huricipal Waste Incinorator Standarda and recont EPA pottey

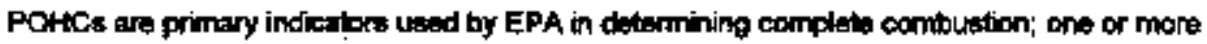
POHCs will be specified in poimit from those listed in 40 CFR Part 281 App VII; EPA reguletion of

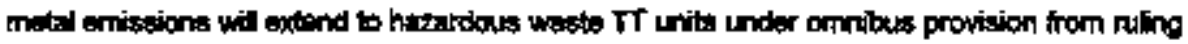
made for treeting hazaritess wostes in boikers and industriled furneces

EPA reqpires no finite lent for CO provided that the concentroption of hyctrocarbons in stack gas

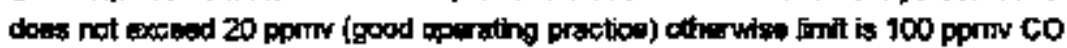

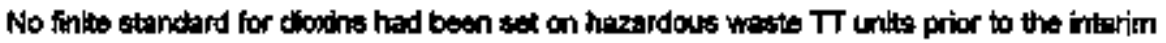
stanctard sot Ntoy 1993

EPA Drafi Strategy of 1993 - ?

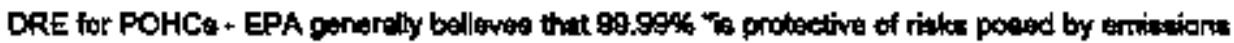
of crganic constithwents, in the waste undar vithally overy scanario of which the agoncy is awere"; CAA interpreted by some stetes requiling egrregate risk for carcinogento of 1 in milion, DFE of

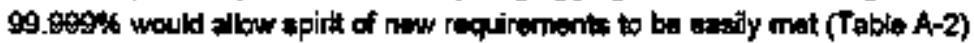

Cerbon monoxide and HC - BIF rule FR 56 (35)7155 (1991) 8t: CO iavals of 100 ppmv (technology based standtird) wing $\mathrm{HC}$ of $20 \mathrm{ppm}$

Particulate matter smallor than 10 microns - EPA in May 1993 draft strategy document omnibus provizion linits to $34 \mathrm{mg}$ ictem

Motals - EPA intends to apply the BIF metal emiseikn stendards 56 FR 35 p. 7131 *t 404 (1991) to hazardouts waste $T$ urits using omribus provis lon

HCI - 40 CFR 264.343 motricts to $1.8 \mathrm{~kg} / \mathrm{hr}$ or $1 \%$ of value in ofuck before APC, whichover io beror,

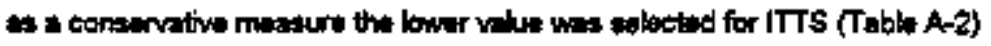

Dioudns - Germen end Dutch governments linit doxins and furans to $0.1 \mathrm{ng} / \mathrm{cm}$; technology bosed standard achlewable using carbon fitration

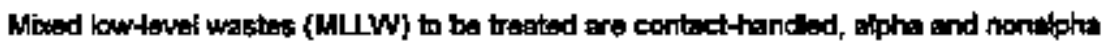

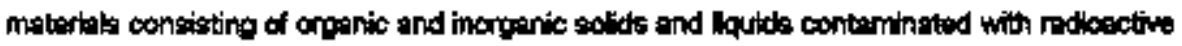
substances.

$36 \quad 1.1 .0 \quad 1$

$37 \quad 1.1 .0 \quad 3$

39 A-5.1 A-19 8 B 7

Regutetions prornulgated by DOE and EPA govem the thagon, turtimant, and disposol of these wastos

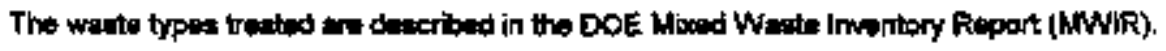

ITTS ahall treat the whete typas deacribed in Tuble A-4 Phtise 1 toport 
No. Sect. Pag. UE

b) Input Wartio Charectanistion

$\begin{array}{lllll}39 & 1.3 .2 & 10 & \text { B } & 8 \\ 40 & 1.3 .2 & 10 & & \\ 41 & 1.3 .2 & 10 & & \\ 42 & \text { A-4.4.1 } & \text { A }-50 & 9 & 2\end{array}$

c) Wasto Charapterketion

\begin{tabular}{|c|c|c|}
\hline 43 & $A-3.0$ & A-17 \\
\hline 44 & $A-3.1 .1$ & A-17 \\
\hline 45 & A-3.1.1 & A-17 \\
\hline 45 & A.3.1.2 & A-17 \\
\hline 47 & A-3.1.2 & A-17 \\
\hline 48 & A.3.1.2 & A.17 \\
\hline 49 & A-3.1.2 & A-17 \\
\hline 50 & A-3,1.2 & A-17 \\
\hline 51 & $A-3.1 .2$ & A.18 \\
\hline 52 & $A-3.1 .2$ & $A+18$ \\
\hline 53 & $A-3.1,2$ & A-16 \\
\hline 54 & $A-3.1 .2$ & $A+18$ \\
\hline 6 & A-3.1.2 & A-18 \\
\hline 66 & A-3.1.3 & A-18 \\
\hline 57 & A-3.1.3 & A-19 \\
\hline 58 & $A-3.2 .1$ & $A-18$ \\
\hline$\infty$ & $A-3.22$ & A-18 \\
\hline 60 & A-3.3.1 & $A-19$ \\
\hline
\end{tabular}

(continua,d)

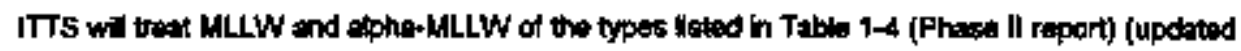
from Table 1-4 Phowe I report) All wasto is contect handed

It is acsumed that input wasto conteins EPA+lsted and charecterlettc weate.

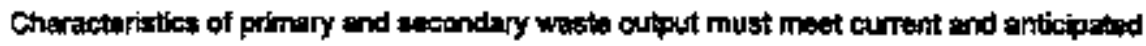
disposel regulations auch an 40 CFR 268 tor aubutancess regulated by RCRA and DOE order $5820.2 \mathrm{~A}$

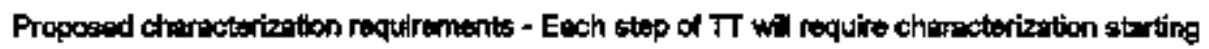
with weste contaliners to final waste forms, ofltoes, scnubber solids

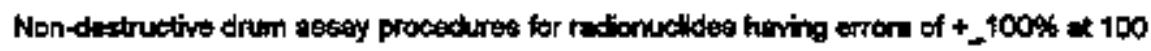
manocuried per brem (nClg) ans exnoldered adequate for ctrarecterizing input.

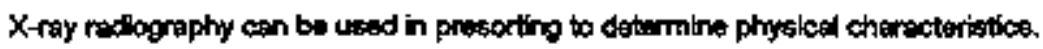

Chemical andysis for RCRA orgenics and hasardous motals according to the following:

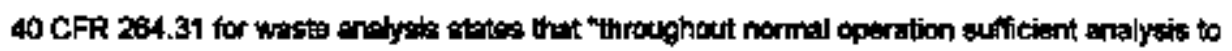
verity waste foed whith physicel and chembell limits apeciled in pemit

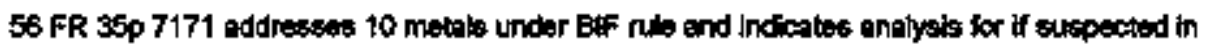
woste

During trid bum cortain therecterization requirement entust be met

47 FR 122 p. 27528 provides guidanos in terms of detection firits that might be needed for weste ehareterizition

EPA obes not discourage use of characterization to detine waste feede into varbus groups

40 CFR 255,341 for wasts anabais requies (for faed) heating value, halogen and sulfur contrent,

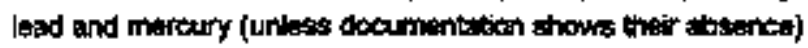

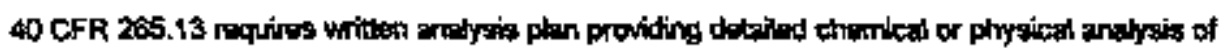
represuntrotivo striplo

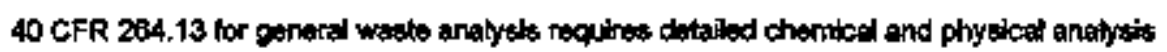
before treatrment of representive ample

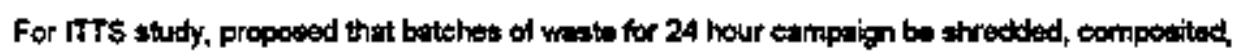
mixed and complete suite of EPA SW-846 anelyses be performed on composise

EPA SWSB46 adopted for anahyies of apha contaminated miod wasto

Stack gas simpling methods should comply with 40 CFR 60 App A

Mettrods of offass charneteriation will be contained in DOE roport "Characterization for Traptrmant of Contrinetized Low-Leved Wastas" Mery 1993

EPA procedure SW-840 wil be trand for andyzing werubber solutiona.

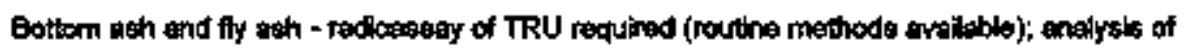

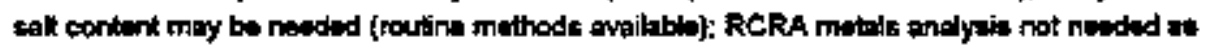

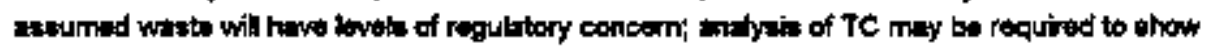
absence of earbons 
No. Sect. Page $\mathbf{u}^{*} \mathbf{s}^{*}$

c) What Characteriention (conthusid)

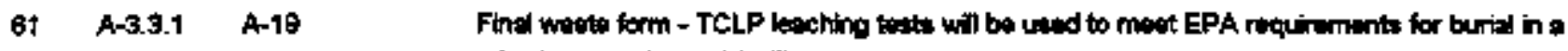
miod wate dieposal teitity.

d) Coneral Deistin and Operating Assumptions

\begin{tabular}{|c|c|c|c|c|c|}
\hline 62 & 1.10 & 1 & & & 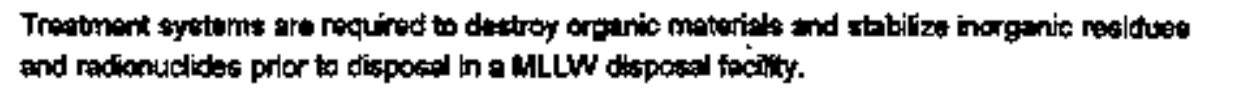 \\
\hline 60 & t.1.0 & 2 & & & 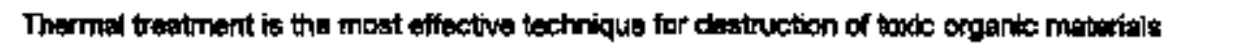 \\
\hline 64 & 1.1 .0 & $\mathbf{2}$ & & & 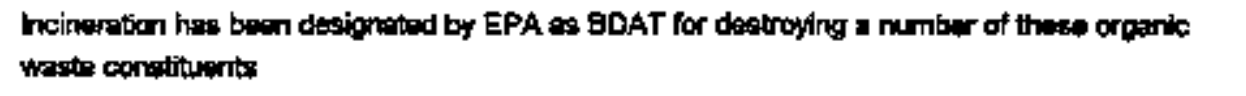 \\
\hline es & 1.1 .0 & 2 & & & 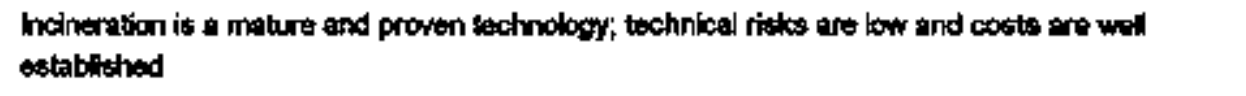 \\
\hline 56 & 1.2 .0 & 3 & & & 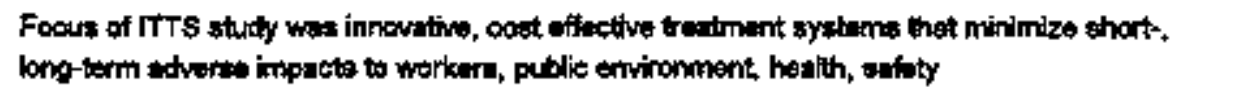 \\
\hline 67 & 1.2.0 & 3,4 & & & 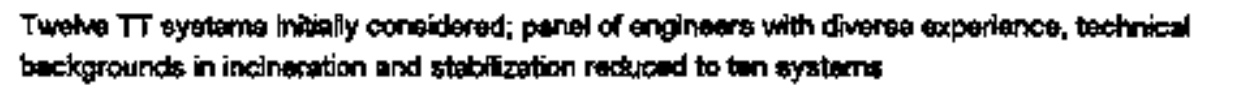 \\
\hline 68 & 1.20 & 4 & & & 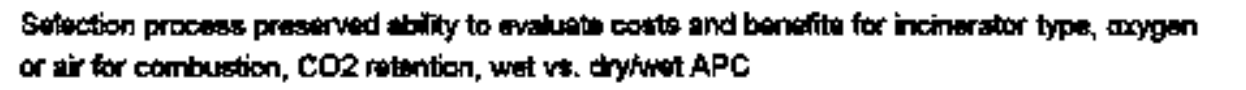 \\
\hline 69 & 1.2 .0 & 4 & 3 & 7 & 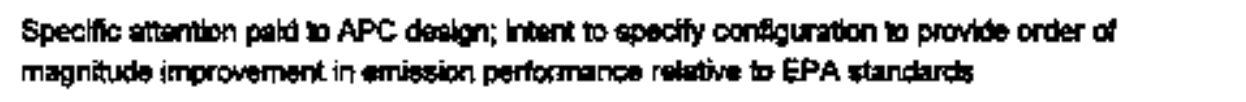 \\
\hline 70 & 1.2 .0 & 7 & & & 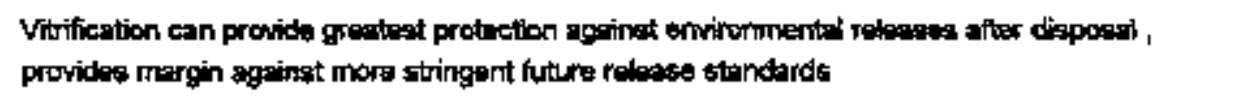 \\
\hline 71 & 1.2 .0 & 7 & & & $\begin{array}{l}\text { Amabamation presumed to be best stabizzition mithod for marchry sinos listed by EPA as } \\
\text { BDAT }\end{array}$ \\
\hline 72 & 1.2 .0 & 7 & & & 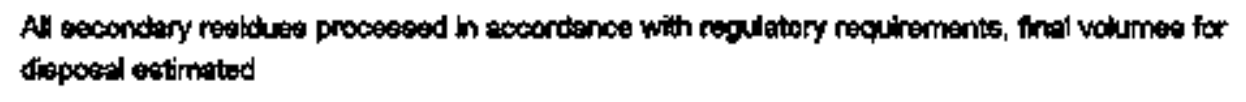 \\
\hline 73 & 1.2 .0 & 7 & $\mathbf{9}$ & 2 & Costos estimated assuming system is government owned and condractor operatud (GOCO) \\
\hline 74 & 1.2 .0 & 7 & & & Transportation and dispossal costrs applied to disposel volum far each systam in PLCC estimate \\
\hline 75 & 1.3 .2 & 11 & 9 & 6 & $\begin{array}{l}\text { The nomtrel capreity of the system thell be es thoum In Teble 1-4 (Phase II report) (updeted } \\
\text { from Table A-5 Prace I report) }\end{array}$ \\
\hline 76 & 1.3 .2 & 11 & & & 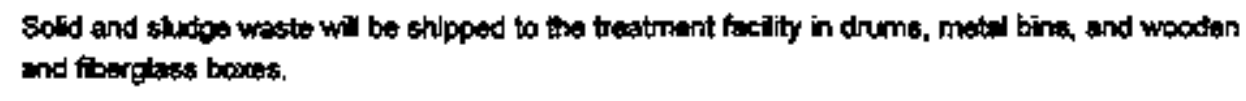 \\
\hline 77 & 1.3 .2 & 11 & & & 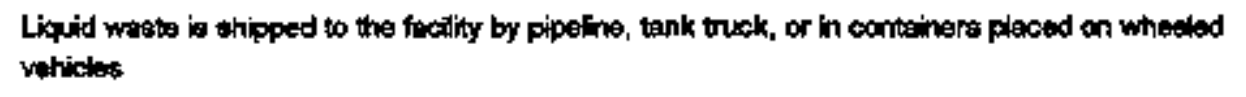 \\
\hline 78 & $A-4.4 .1$ & $A-30$ & $\theta$ & 2 & 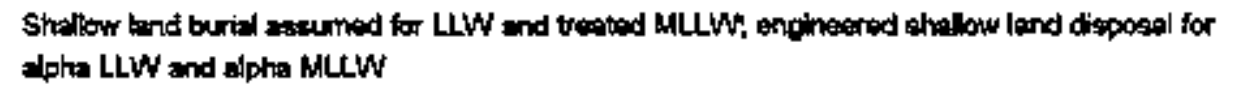 \\
\hline 79 & A-4.4.2 & A-31 & & & Final wate form is a stable and leach resistent sold prostucad by vitritionstion of sofidfiction \\
\hline 80 & A.4.4.1 & A-31 & & & $\begin{array}{l}\text { Find wasto furn tefisfies performence scsessment requlrements for alpha concentrations up to } \\
\text { ge nCilg TRU }\end{array}$ \\
\hline 81 & A.5.2 & A-27 & & & 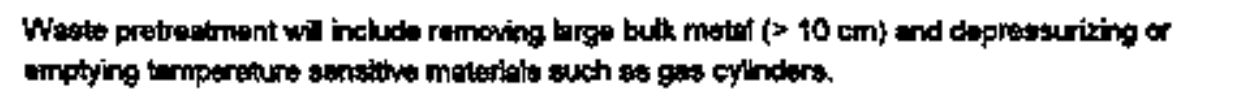 \\
\hline
\end{tabular}

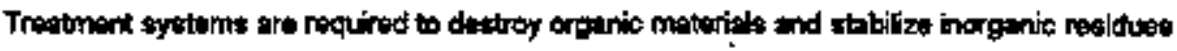

Incinoration has been desioneted by EPA \& SDAT for destroying a number of the:se orpanic holineration is a mabre and proven sechnolosy; tochnical fitks are low and costs ore wol estabifithed

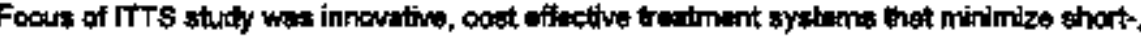

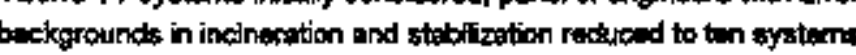

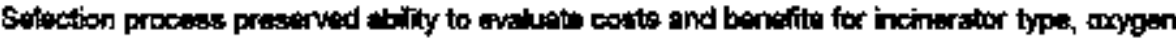

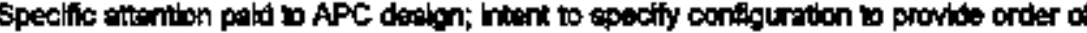

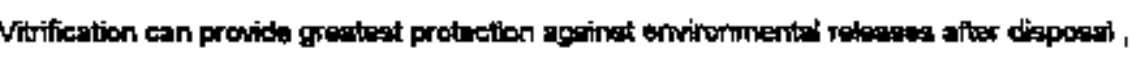
provides mergin agoingt mora stringent future relosese stindards

Amagamation presumed to be best stabifization mithod for marcury sinos listed by EPA es:

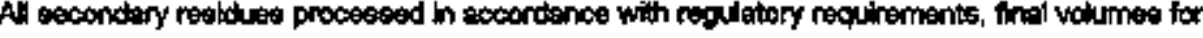




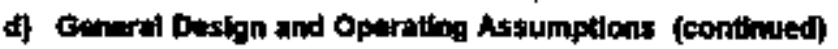

\begin{tabular}{|c|c|c|c|c|c|}
\hline 62 & A-5.3.1 & A-26 & & & 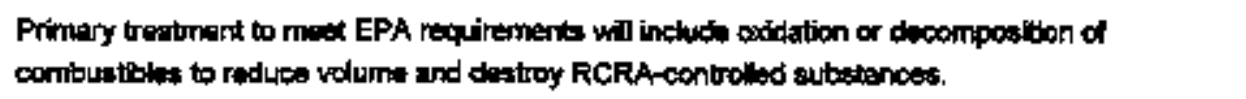 \\
\hline 8 & A-5.3.1 & A-29 & & & 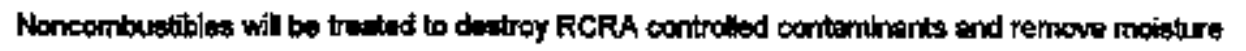 \\
\hline 84 & & & 8 & $\mathbf{B}$ & Engineered dispoest fexilty used for costing \\
\hline 85 & A-4.4.1 & $A-30$ & 夏 & 9 & 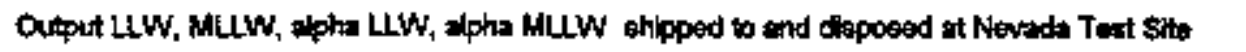 \\
\hline 83 & A-4.4.1 & A. 30 & 8 & 2 & 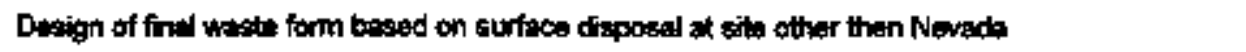 \\
\hline 的 & A-4.4.1 & $A-30$ & 3 & $\mathbf{8}$ & 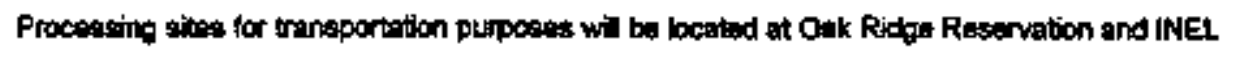 \\
\hline 86 & A-4.4.2 & A-31 & & & 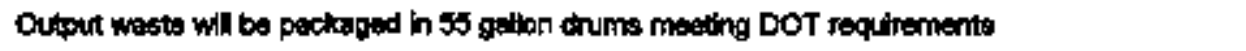 \\
\hline 89 & A-4.4.2 & A-31 & & & 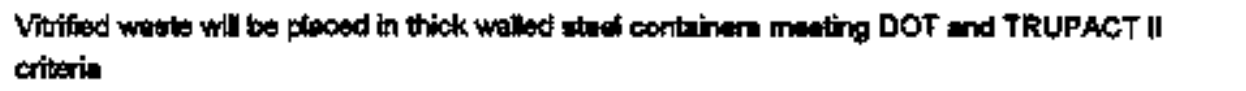 \\
\hline$\infty$ & A.4.4.2 & A-31 & $\mathbf{5}$ & 7 & 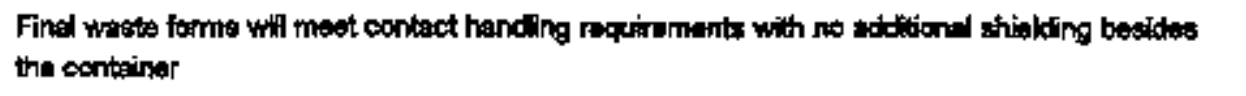 \\
\hline 91 & 1.3 .2 & 10 & B & 7 & System wil inosporat mintmum shistaing; shiekling not a factor in system performentco \\
\hline 92 & A-6.1 & A.34 & 8 & 8 & 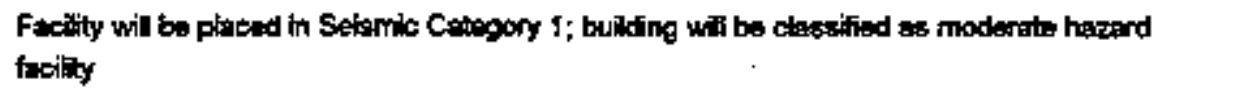 \\
\hline 93 & $A-0.1$ & $A-34$ & 9 & 2 & 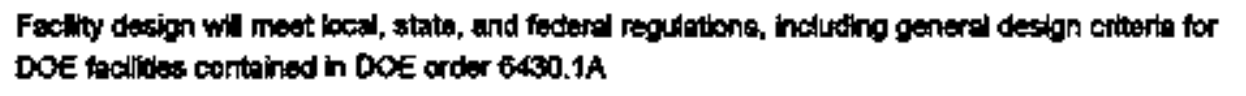 \\
\hline 94 & $A-6.1$ & A-34 & 9 & 2 & 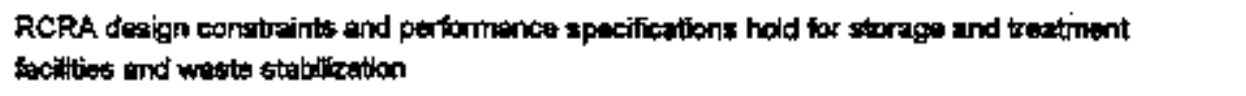 \\
\hline 95 & 1.3.4 & 15 & 8 & 5 & 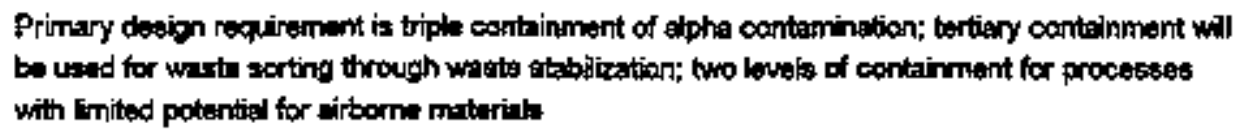 \\
\hline 98 & 1.3 .4 & 14 & & & 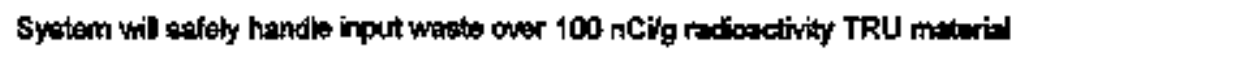 \\
\hline 97 & 1.1 & 2 & & & Evaluated thermel treatrinent technologlest an woll developied \\
\hline 的 & 1.3 .4 & 14 & & & 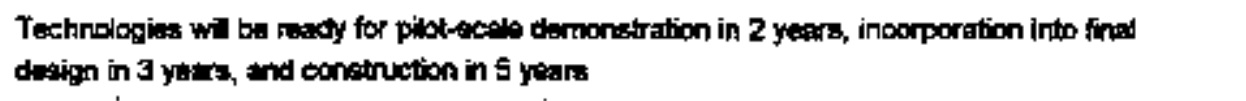 \\
\hline 89 & & . & & & Sirce capacity for indoor storage of HLLW dums to 2 to 6 weeks \\
\hline 100 & A.4.4.2 & A-31 & 7 & 7 & $\begin{array}{l}\text { Find wasts forme for LLW will be dellstablo to reduce the cost of dispoud (Subtitio D versis } \\
\text { Subtitie C). }\end{array}$ \\
\hline 101 & A-4.4.2 & A-31 & & & 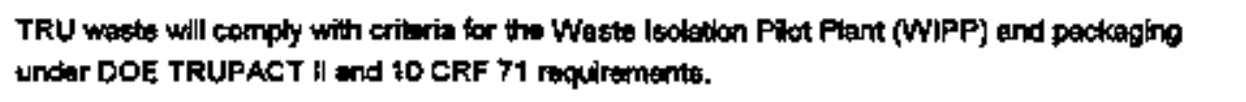 \\
\hline 102 & 3.3 & 57 & 3 & 8 & 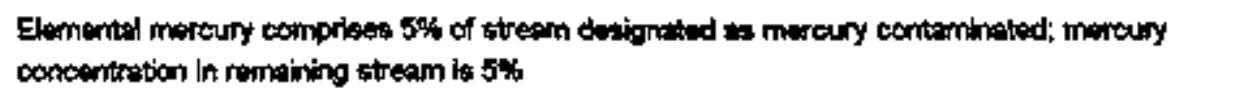 \\
\hline 103 & 3.3 & 50 & 9 & 6 & 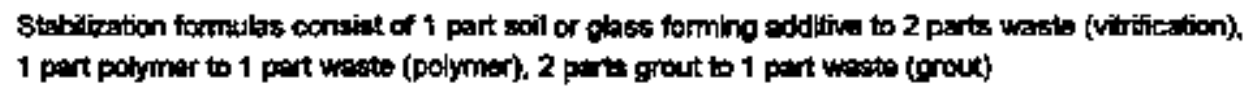 \\
\hline 104 & 3.3 & 58 & 7 & $\mathbf{a}$ & CO2 aberorption, ime recycing is so\% and rejection ts $10 \%$ \\
\hline 105 & 3.3 & 58 & 3 & $\mathbf{a}$ & 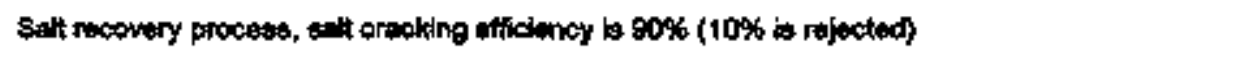 \\
\hline 106 & 3.3 & $\mathbf{s g}$ & 3 & $\theta$ & Meted recovered from incinerrtor feed is $1 \%$ of inpul wasts \\
\hline 107 & 3.3 & 58 & 3 & $\mathbf{8}$ & Orgenics recovered th thermal dosorgtion are $5 \%$ of food \\
\hline
\end{tabular}


of General Design and Operating Assumptions (continued)

\begin{tabular}{|c|c|c|c|}
\hline 3.3 & sis & $\mathbf{\theta}$ & 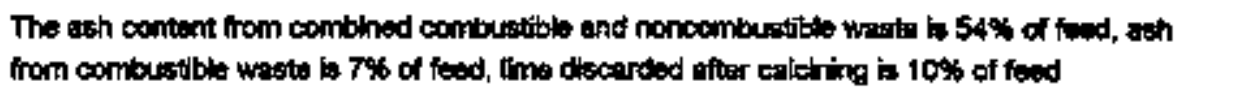 \\
\hline 3.3 & 58 & 6 & 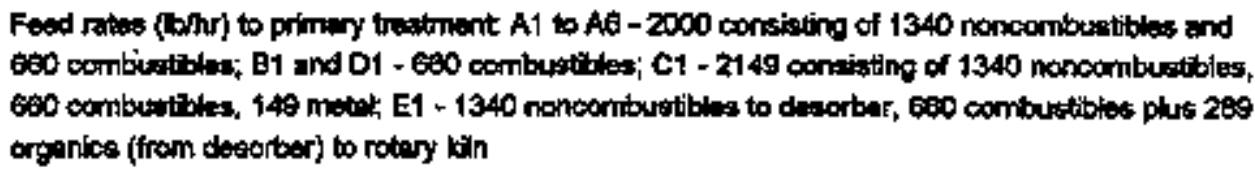 \\
\hline 3.3 & 58 & 3 & 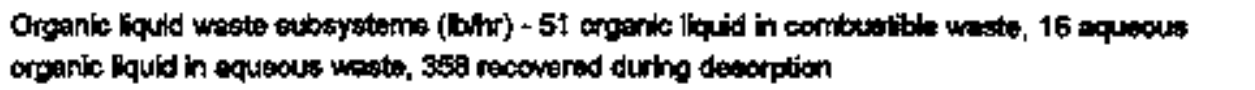 \\
\hline A.6.1 & A-34 & 3 & Processs twits will be designed for $125 \%$ of the expected mese thew retes. \\
\hline A-5.1 & A-19 & & 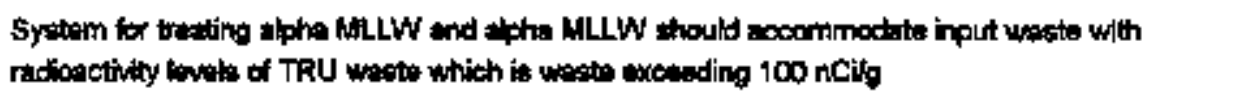 \\
\hline A.6.4 & A-35 & 9 & 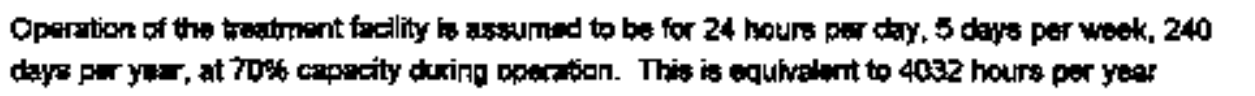 \\
\hline A-6.4 & A-35 & 8 & 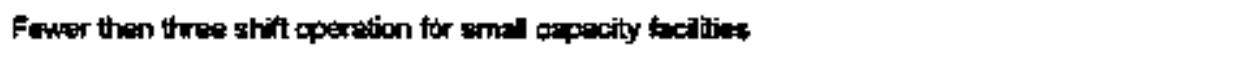 \\
\hline 5.1 & 107 & & 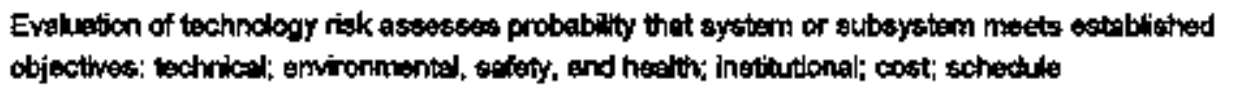 \\
\hline 5.21 & 108 & & 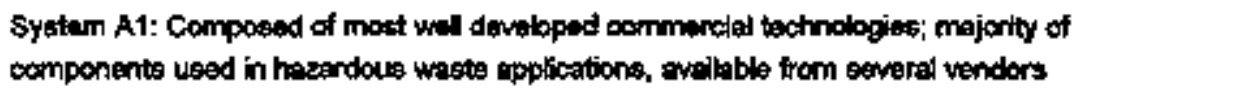 \\
\hline $\mathbf{5 . 2 . 1 . 1 . 1}$ & 109 & & Technices objectivear complemce with permilting - no problems \\
\hline 5.2 .1 .1 .1 & 109,110 & & 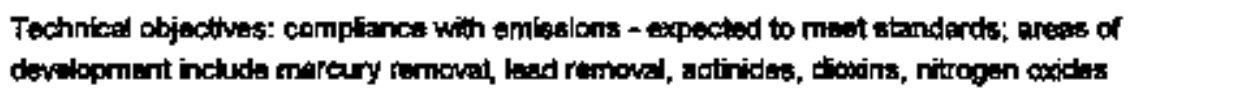 \\
\hline 5.2.1.1.1 & 111 & & 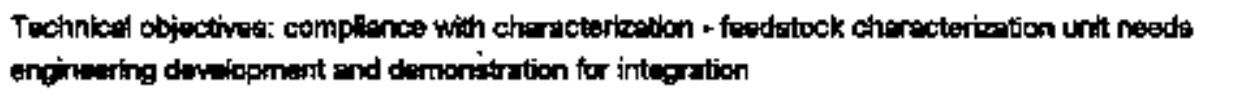 \\
\hline 5.2.1.1.1 & 111,112 & & 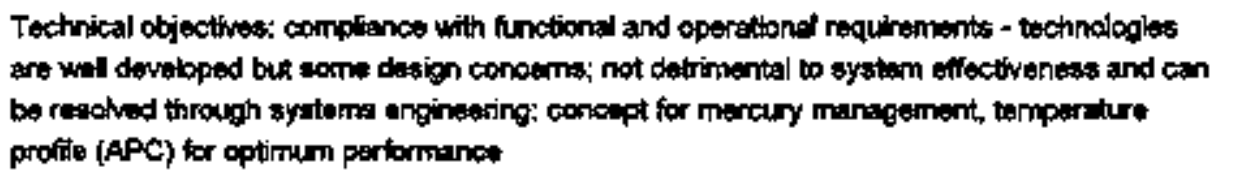 \\
\hline 5.2.1.1.1 & 142 & & 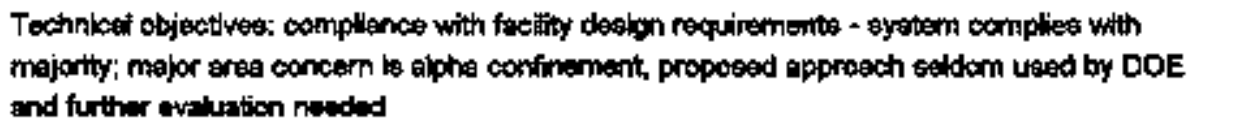 \\
\hline 5.21 .1 .2 & 142,113 & & 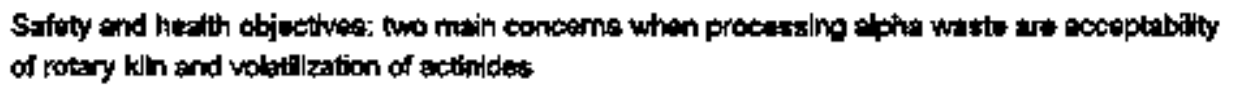 \\
\hline 5.21 .1 .2 & 112,113 & & 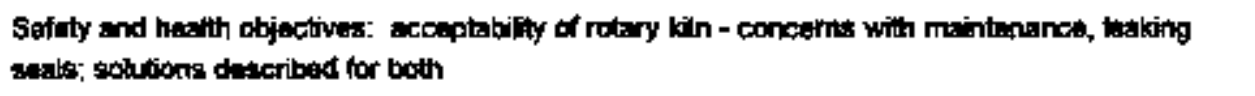 \\
\hline $5.2 . \$ .1 .2$ & 112,113 & & $\begin{array}{l}\text { Salety and health objectives: volatization of actinides - potental reiegse to atmoephere is } \\
\text { greptest ESAH concerm; futher study required }\end{array}$ \\
\hline 5.2 .1 .1 .3 & 113 & & 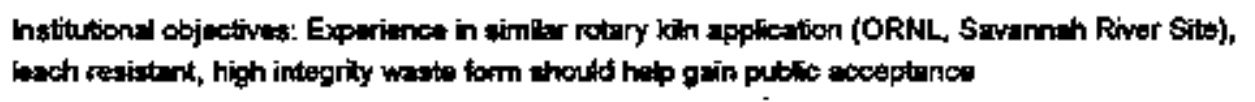 \\
\hline 5.2.1.1.3 & 113 & & 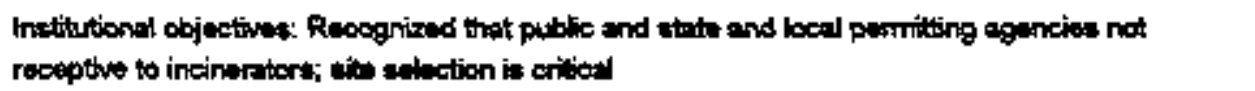 \\
\hline 5.2 .1 .1 .4 & $1+3$ & & Cost objoctive: Cost risk low for nonipha waste, risk of cost owerrung high for alphe wasto \\
\hline
\end{tabular}


d) Generad Design and Operathg Assiumptions (conthued)

\begin{tabular}{lrr}
126 & 5.21 .1 .4 & 113 \\
129 & 5.21 .1 .5 & 114 \\
130 & 5.2 .1 .2 .1 & 114 \\
& & \\
131 & 5.2 .1 .2 .1 & 114 \\
& & \\
132 & 5.2 .1 .2 .2 & 115.116 \\
& & \\
133 & 5.21 .2 .2 & 115,116 \\
134 & 5.2 .1 .23 & 116,117 \\
\hline 135 & 5.2 .1 .2 .3 & 116.117
\end{tabular}

$136 \quad 5.2 .1 .24 \quad 118$

$137 \quad 5.2 .1 .2 .4 \quad 118$

$139 \quad 5.2 .1 .2 .5 \quad 118$

$139 \quad 5.2 .1 .2 .5 \quad 118$

$140 \quad 5.2 .1 .2 .6 \quad 116$

$\begin{array}{lll}141 & 5.2 .1 .2 .6 & 118\end{array}$

$142 \quad 5.2 .1 .27 \quad 118,119$

$143 \quad 5.2 .1 .27 \quad 118,119$

$144 \quad 5.2 .1 .2 .7 \quad 118,119$

$145 \quad 5.2 .1 .2 .8 \quad 119$

$146 \quad 5.2 .1 .2 .8 \quad 119$

$147 \quad 5.2 .1 .2 .8 \quad 119$

$148 \quad 5.2 .2 .9 \quad 119$

$149 \quad 5.21 .2 .9 \quad 119$

$5505.2 .1 .2 \$ 0 \quad 119,120$

$\$ 51 \quad 5.2 .1 .2$ to 119,120

$152 \quad 5.2 .1 .211 \quad 120$

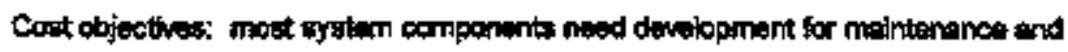

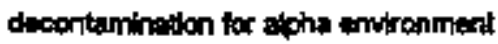

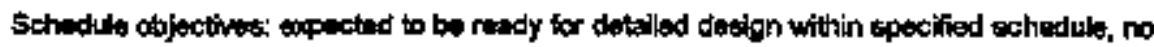
igrificent development problerns or delaye expected

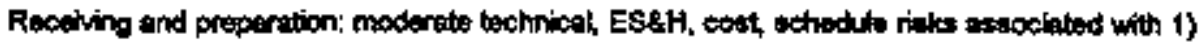

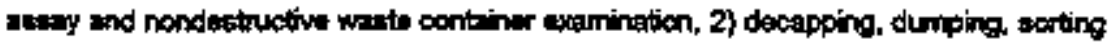

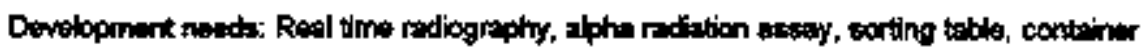
decoposing

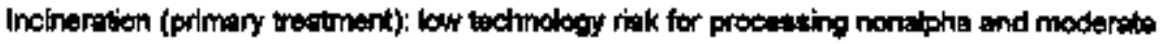
technology riak for alpha wosts;

Devilopment neede for. shredders and pther feed preperation equlpment, sclids teptration,

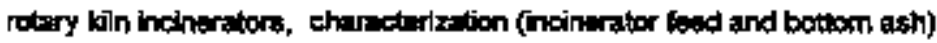

Ar Pollution Control: most equipment (exceet monituing) well dewloped arkd widedy usied (Inclustry) but extenolwe denelopment for system integration

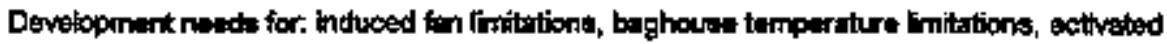

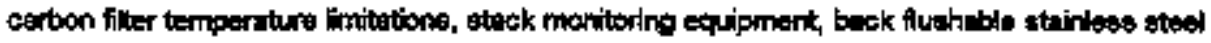
HEPA filtar:

Lead Recovery: moet equipment well developed and widety used (industry), technology rizk it low

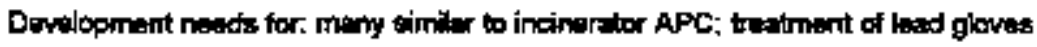

Mercury amalomation: wel developed and widahy used (fncustry); technology slek lo low

Dovelopment noeds: primaihy syshem integration

Metal decontamination well developed with mony units uad in nueloos indugtry; technology riak is low

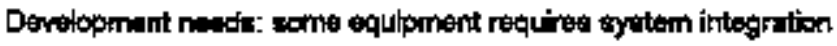

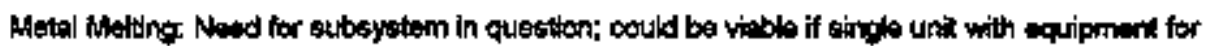

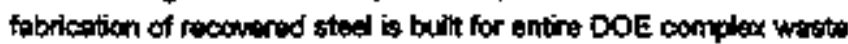

Eqpipment is weil devebpad (operating units in US and Germany); technology risk is low

Development needis: thaing apents, system thiogriton of some equipent

Specilal waste treatment desioned and deweloped on case by cese besits

Wate list must be developed and gandidete processest shutied

Anticipated woth to rotactive moted (e-g sodium contemineted debris)

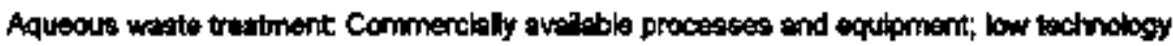
risk

Development needs: minor, appropech of precipitation, flltation, ion exchange, activated carbon for mercury remoned must be findized

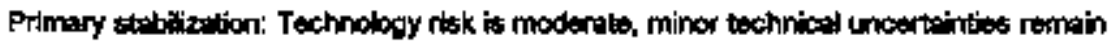

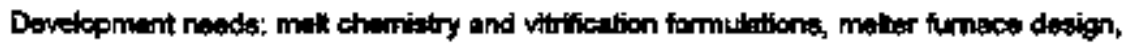

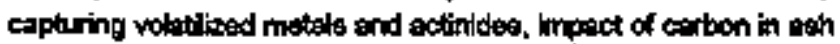

Secondary stabillzation; cormmercially aweilete equipment, low tachnology ritk 
d) Eeneril Design and Operating Acsinptions (comtinued)

\begin{tabular}{|c|c|c|}
\hline 153 & 5.2 .1 .2 .11 & 120 \\
\hline 154 & 5.2.1.2.12 & 120,121 \\
\hline 155 & 5.2 .1 .2 .12 & 120,121 \\
\hline 15 委 & 522 & 121 \\
\hline 157 & $522 t .1$ & 121 \\
\hline 158 & 5.2.2.1.2 & 121 \\
\hline 159 & 5.2 .2 .1 .2 & 121 \\
\hline 160 & 5.2 .2 .2 & 121,122 \\
\hline 161 & 5.2 .2 .2 & 121.122 \\
\hline 162 & 5.2 .3 & 122 \\
\hline 169 & 5.2 .3 .1 .1 & 122 \\
\hline 164 & 5.2.3.1.2 & 122 \\
\hline 165 & 5.2 .4 & 123 \\
\hline 168 & 5.2 .4 .1 .7 & 123 \\
\hline 167 & 5.2 .4 .1 .1 & 123,124 \\
\hline
\end{tabular}

$\begin{array}{ccc}188 & 52.4 .1 .2 & 124 \\ 169 & 5.2 .4 .1 .3 & 124 \\ 170 & 5.2 .4 .1 .3 & 124 \\ 171 & 5.2 .4 .2 .1 & 124,125 \\ & & \\ 172 & 5.2 .4 .21 & 124,125 \\ 173 & 5.2 .4 .2 .2 & 125 \\ 174 & 5.2 .4 .22 & 125 \\ 175 & 5.2 .5 & 125 \\ 176 & 5.25 .1 .1 & 126\end{array}$

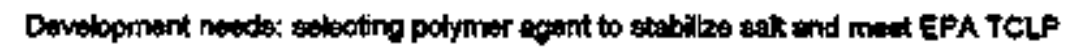

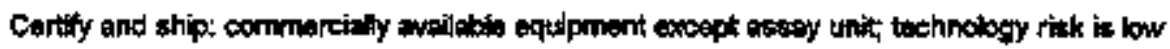

Development neods: assay unit (sema ass recelving and prepanation)

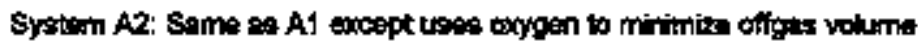

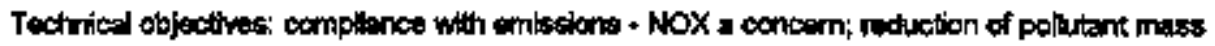
emission rate by using oxygen (lower ofigas wolocites)

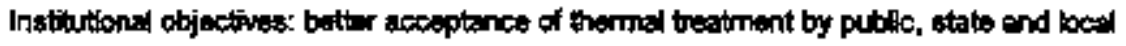
agencies dua to reduoed offgas wayme

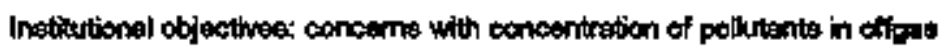

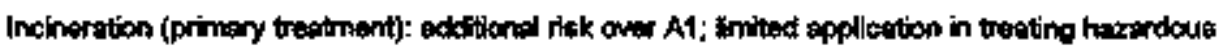
watioto

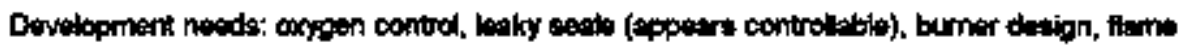
propagotion and control, prevention of ash slagging. NOX cortool

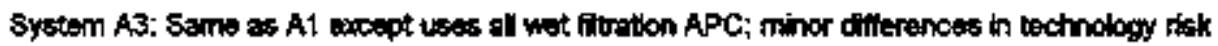

Technical objectives; mercury managemont - AFC scrubber Equor may noad adotitional tragtment stop; brger aquocus wasts trestment

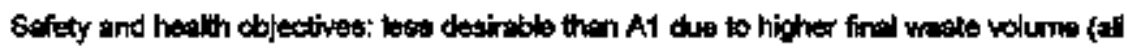

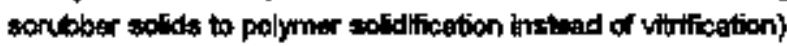

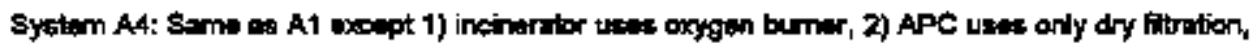
3) $\mathrm{CO} 2$ retertion addact hlgher dytum technology risk than $\mathrm{A1}$

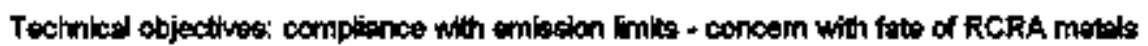

Techutel abjactives: compliance with functional and operationel requirements - dervelopment for zero gir inleakefe (gneatest obstacle to debyed rekeoe), sarrping methods for detecting EPA controlod pollutents in spont tine, metheds for seporating and releasing inert asces and

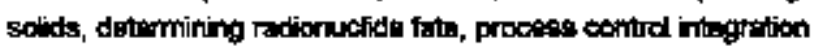

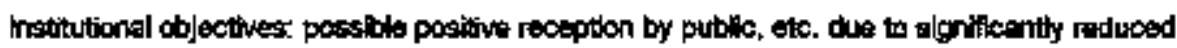
offges and delay loabre

Cost objoctives: $\mathrm{CO} 2$ notention it infancy, cost of system and wasto disposal not accurately colimated

Sthodulo objectives: $\mathrm{CO}$ retention in infancy, many umeartaintios in procose dewelepmont tming

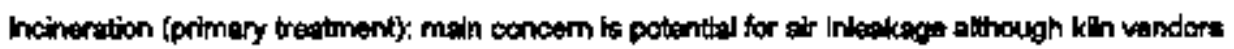
have significenfly adverced techolowy

Deweboment needs: seals, oxygen bumer desion, fleme controd, combustion oxygen control, asch elagging prevention

APC (CO2 tetention); considered to haw hlgh tectnological disk; frat of a kind application in ITTS Devebpment neads: many (undained) in prototype emironment

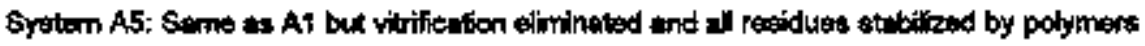

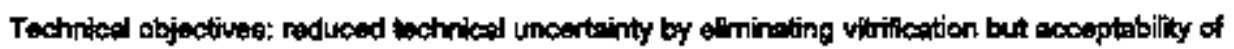

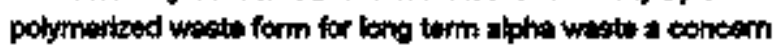


No. Soct. Page $\mathbf{w} \mathbf{s}^{*}$

d) General Design and Opwitiond Astumptions (coritnued)

$\begin{array}{rcr}177 & 5.2 .5 .1 .2 & 126 \\ 178 & 5.25 .1 .3 & 126 \\ 179 & 5.25 .1 .3 & 126 \\ 190 & 5.2 .5 .2 & 126 \\ 181 & 5.2 .6 & 126\end{array}$

$182 \quad 5.2 .6 .1 .1 \quad 126,127$

\begin{tabular}{|c|c|c|}
\hline 183 & 5.2.8.1.2 & 127 \\
\hline 184 & 5.2 .6 .1 .3 & 127 \\
\hline 185 & 5.26 .1 .3 & 127 \\
\hline 6 & 5.2 .6 .2 & 127 \\
\hline 97 & 5.2 .6 .2 .1 & 127 \\
\hline 88 & 5.2B.2.1 & 127 \\
\hline 189 & 5.26 .2 .2 & 127 \\
\hline 80 & 5.2 .6 .2 .2 & 127 \\
\hline 91 & 5.3.1.1 & 120,129 \\
\hline 32 & 5.3 .1 .2 & 129 \\
\hline & 5.3 .2 & 129 \\
\hline & 5.3.2.1 & $\$ 29$ \\
\hline & 5.3 .22 & 129 \\
\hline & 5.3 .2 .3 & 129,130 \\
\hline & 5.3 .2 .2 & 129 \\
\hline & 5.3 .23 & 120,130 \\
\hline & 5.4 .0 & 13 \\
\hline
\end{tabular}

$200 \quad 5.4 .1 .1 .1 \quad 430,131$

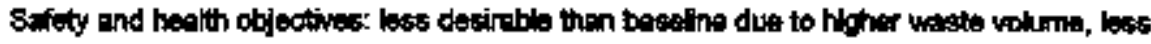
stable and more leacheble woste

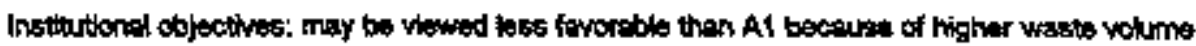
Institutionet pbjectives: lower totol offags volume (no vitritlex)

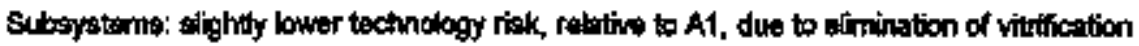
System A6: Same es AB except for 1) ectweted cartben in APC is recycled, 2) matal salids separtion unit wded to incineretur feed prepartion, 3) APC alk recovery procoses; higher tachnology itsk then A?

Tectinicel abjectives: camplianca with henctional and operationel recpiremento - dovelopment

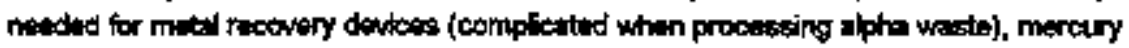

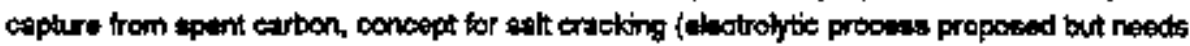
evaluation)

Irstutiond objetives: mey be received mort pasitively due to wasto minimization

Cost objectives: selt recovery process; yet in bo defined, einel part LCC

Schodul objectived: many uncertoritios in development timino

Subeyshma: higher technology rikk than A1

meinertion: concorn it complaseted front and"

Development needs: foed preparation to remove metels

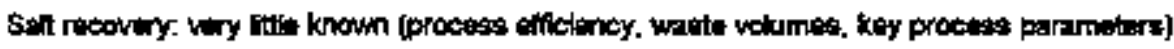

Development needs: evalation of sak recovery options

temperature operation; greater technology risk than A1 athough components commercialty complicate process controx lower reliablity and avalabiity

Tochnicul objectlvea: concerns ane dring of noncombustibles (machanical and controt

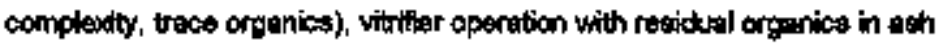

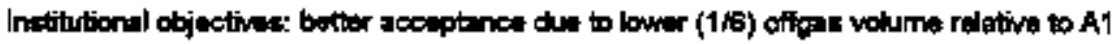

Subsystems: geviter tactinalogy isks rative to A1

Recelving and preperetion: higher sorting demand thes increases okze and complexity

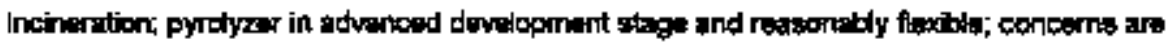

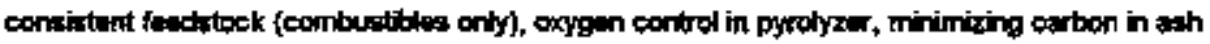

Incineration: for vitriter, no data on linit on carbon in ash before quaity of vitified wasto affected

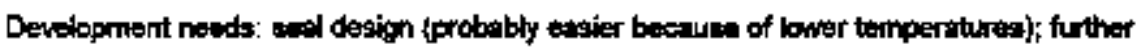

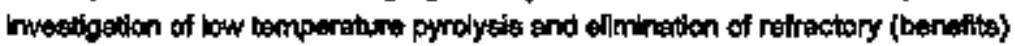

Dewaicpmant neacts: pyrobysiz and vitrification tests to determine carbon in ash linits and how to

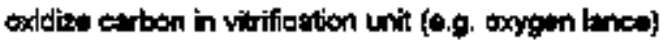

System C1: technology currently lesed in motolunglcal industry, dffiers from A1 in that coxphustion and vitrification in seme usit, and rrobel melting eliminated; higher risk than A1 dua to back of

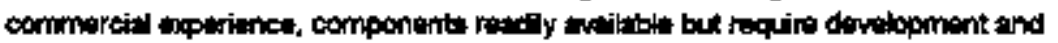
domonstration for intepration

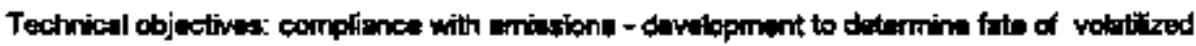

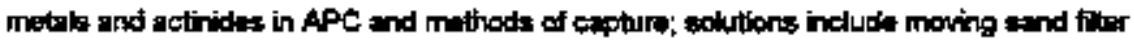


d) Cencral Design and Operating Astimptions (continuad)

$201 \quad 5.4 .1 .1 .2 \quad 13$

$202 \quad 5.4 .2 \quad 131.132$

203

$5.4 .2 \quad 131,132$

204

$5.4 .2 \quad 131, \$ 32$

205

$5.5 .0 \quad 132$

206

5.5.1.1.1 132

207

5.5.1.1. 133

208

5.5.1.2

133

209

5.5.1.3 133

210

5.5.1.4 133

211

$5.5 .2 \quad 134$

212

5.5.2.1 134

213

$5.5 .2 .2 \quad 134$

21

$5.5 .22 \quad 134$

$215 \quad 5.5 .2 .3 \quad 134$

$216 \quad 5.5 .23 \quad 134$

$217 \quad 5.6 .0 \quad 134,135$
1

2

3

34

34
34
134
35

35

5.6 .2135

Technical objecthess compliance with functional and oporibionel requirements - technology in in

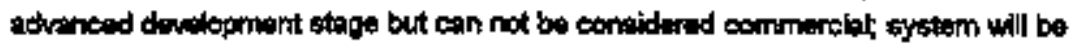
commerctelly svaleble within required time frome

Subeyeteme: overall technelogy rigks lowe than baseine, higher technology risk for primary troatumant

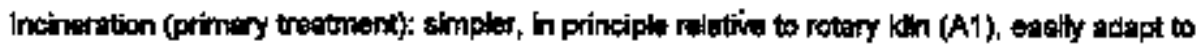

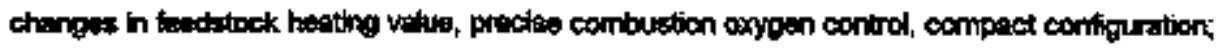

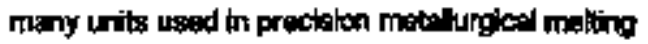

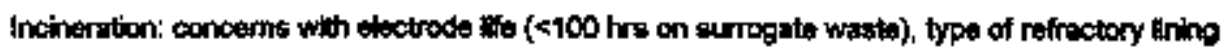

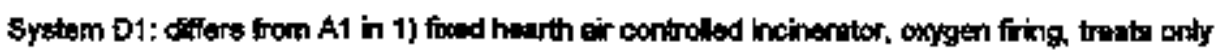

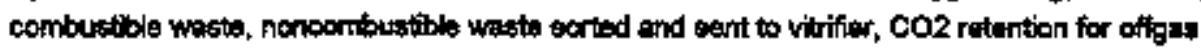
dischurge delay; higher techrology riek companed to A1

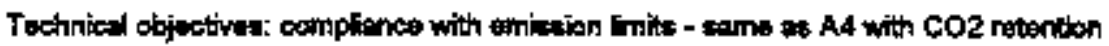

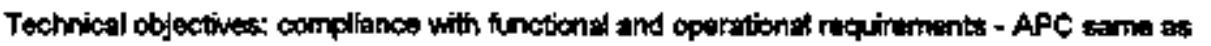
A4, acid gas removel in vituifier APC dus to treatment of noncombustibles (with potentiol residuel

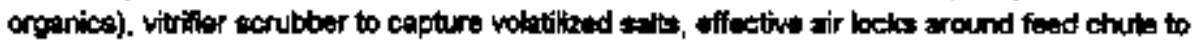
provent ait indeakage

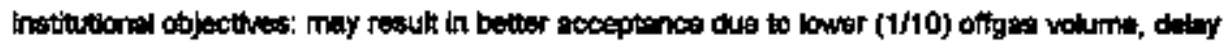
feature that prevents reicage of pollutants

Cost objectives: COZ reftention in infoncy, cost of system and final wasts dispesal can not be estitioted accurtiely

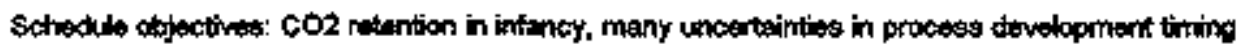

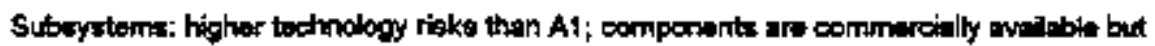
requ:ie developintit, denconstration, ojatem integration

Receiving and preparation: hidher soxting dernands causes more complex and barper syltem

Incheration: concerns are minimizing air inlokege

Development needs: selection of fixed hasth tumace design

APC CO2 retention: ane concenrs is A4

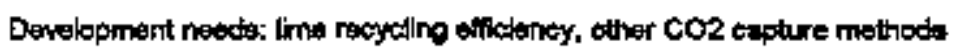

Syetem E1: characterized by minimal procesoing, difiere from A1 in 1) thermal decorber for

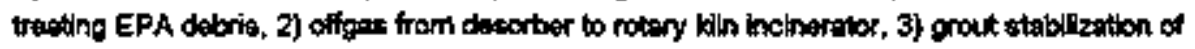
derorber nolite; higher technology risk than A1

Technices abjecthes: compliance with sunctionat and operetionel requirementse + ouvaral lerger

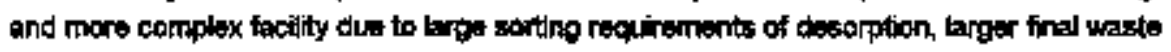
volume, find wasto form loses stoble

Insthutional objectrves: possible lower acceptobilty due to higher find waste voluma, less ctable waste form, even though lessis offors

Subsystarm: Adding thermil desorber produces higher tachnology risks; components are

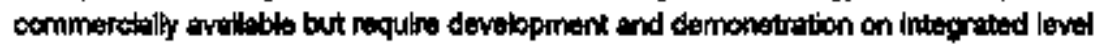

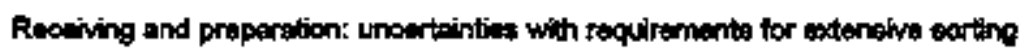

Pritnary treotunent concerms with muting phestic in desorber 
d) General Dosion and Operation Kasimptions (contiolend)

\begin{tabular}{|c|c|c|c|}
\hline 273 & 5.6 .2 & 135 & \\
\hline 224 & A-5.2 & $A-27$ & \\
\hline 225 & A-5.2 & $A-Z 7$ & \\
\hline 225 & A.5.2 & $A-27$ & \\
\hline 227 & A 45.2 & $A-27$ & \\
\hline 228 & A.S.2 & A- 27 & \\
\hline 229 & A.5.2 & $A+28$ & \\
\hline 230 & A.52 & $A-28$ & \\
\hline 231 & A.5.2 & A-28 & \\
\hline 232 & A.5.2 & A-28 & \\
\hline 235 & A-5.2 & $A-28$ & 6 \\
\hline 234 & A.5.3.1 & $A-28$ & $\mathbf{B}$ \\
\hline 235 & A.5.3.1 & $A-2 B$ & \\
\hline 235 & A.5.3.1 & A- 28 & \\
\hline 237 & A.5.3.1 & $A-2 B$ & \\
\hline 238 & A-5.3.1 & $A-29$ & \\
\hline 239 & A.5.3.1 & $A-29$ & 3 \\
\hline 240 & A.5.3.1 & $A-29$ & \\
\hline 291 & A-5.3.t & A-29 & \\
\hline 242 & A-5.3.t & $A-29$ & \\
\hline 243 & A.5.3.1 & A-29 & \\
\hline
\end{tabular}

$244 \quad$ A-5.3.1 A-29
$245 \quad$ A-5.3.1 A-29

Development neadx aperotino temperature of decorter to get good criptic desorption Lead in any form to be removed as best as reasonebly posible, sent to appopriats treatriont Buk rrercury end dil wroste suspected of mencury contenination worted, went to meacury treatrment

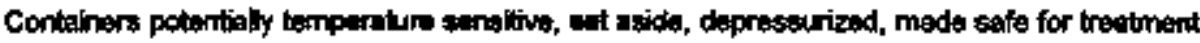
Corthiners of whot not requifing acring should be proct:ted intect, if appropriate for system Waste containers decontaminated or processed with bulk motels if not procossud with wasto

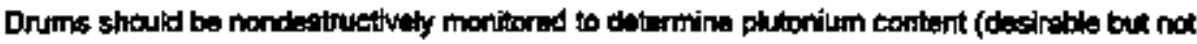

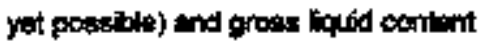

Vepor eamples to be taken on-line with direct readout of compostion from shredded wisto in samping bin

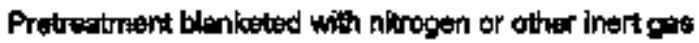

In-toakeor to primary thermal treatmant should be eatimated

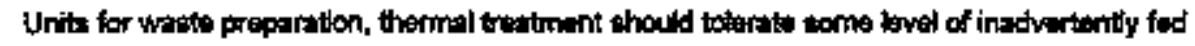
aplosive moturiats

2 Lovels of substances in offors from primary toutmert must meat requiments set forth in RCRA and TSCA

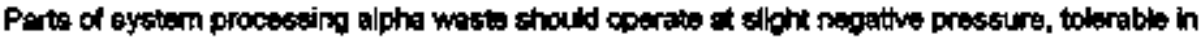
leakage providied

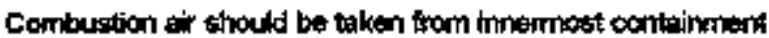

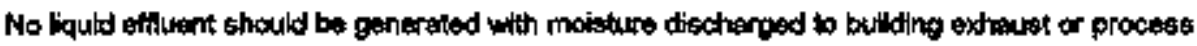
otock

Process monitoring and contud thould be recorded and audiked and be wefficienthy respontive

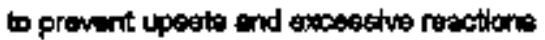

At polytion contol systems must meet or exosed carrent, anticipated regulpions with perfomanes specification: aft to mest or extend current regulationst by 10 times

Trestment and continment syotems should be foxtole to oceormmodete maximum process upots and plures

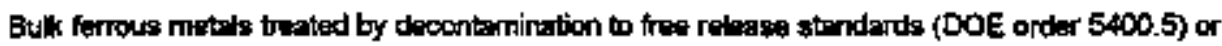
by metal melting to destroy RCRA contaminants, remove surtace conlamination)

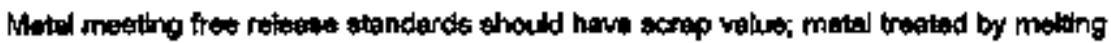

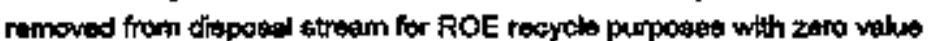

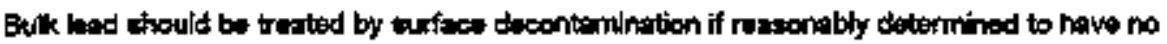

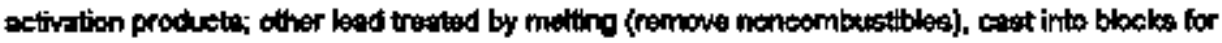

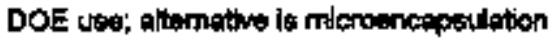

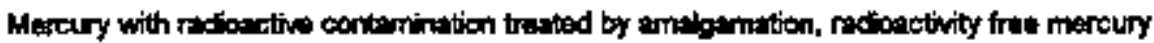
should be recovered (distiletion and ceptume), sold as screp

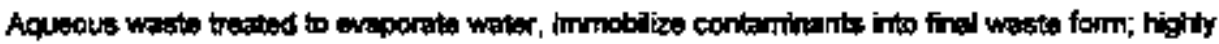

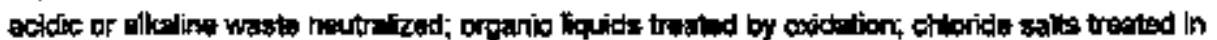

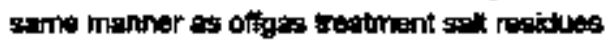

System desigred for 20 your operating lite; particular attention to ease of maintenance and selection of materitite to troid corrosion frilures 
No. Sect. Page $\mathbf{U}^{*} \mathbf{s}^{* 4}$

d) Generd Desion and Oparating Assuriptions (conthued)

$\begin{array}{lll}247 & A-5.3 .2 & A-29 \\ 248 & A-5.3 .2 & A-29 \\ 249 & A-5.3 .2 & A-29 \\ 250 & A-5.3 .2 & A-29 \\ 254 & A-5.3 .2 & A-29 \\ 252 & A-5.3 .2 & A-29 \\ 253 & A-5.3 .2 & A-30 \\ 254 & A-5.3 .2 & A-30 \\ 256 & A-5.3 .2 & A-30 \\ & & \\ 265 & A-5.3 .2 & A-30\end{array}$

$257 \quad$ A.5.3.2 A-30

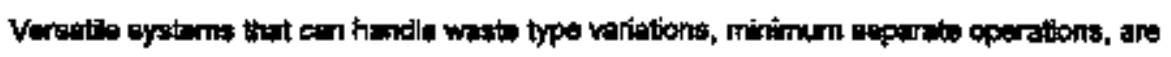
dosirable

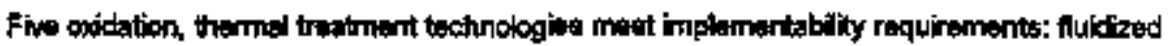

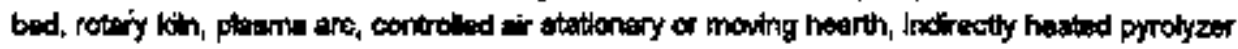

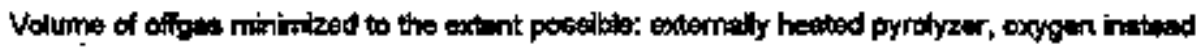
of eir, recycing goses, lont reolderce times

Flid bed systerns chould recycle inert heating material

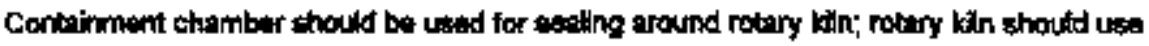
double sasts with intemel pressume edjustmint;

Combetsitan etr ohould bo taken from socondary conteinment zone

Foasiblity converting RCRA metels and ox/des from chloride salks should be eveluated

Volatiration of motals kept to minimum for systoms deaigned to retin most mateds in boftom ash

Toxic weondwy waste from APC comberted to nontoxic (non RCRA controlled) LLW if economicenty justiond

APC should offer best decontamintelon factor for radioactive materiels and best removel erriciency for toxic materials; should provide redundancy of setact components to sllow limited maintiftonce while andint

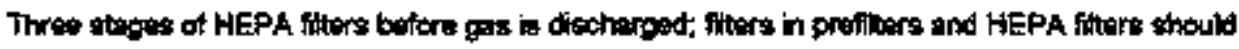
be procesosetio in thermel treatment unit

High veor pressile motrls should be captured by APC for high volatily gystems.

APC should use dry or toul ty first step to minimize radioective wet efilluent

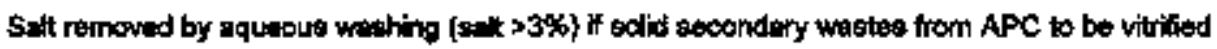

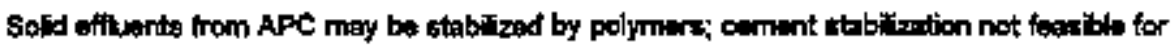
hight salk contienk (not yot datermined)

$\begin{array}{lllll}263 & \text { A-5.3.2 } & \text { A-30 } & \\ 264 & \text { A-5.3.2 } & \text { A-30 } & 4 & \\ 205 & \text { A-5.3.2 } & \text { A-30 } & 7 & 7\end{array}$

[Stpertund sol] sotisfies)

Find secondary residues, died if wht, then consolidated into waste form for neer surfaces disposal; waste form should sllow eosy movement (65 galbn dnum)

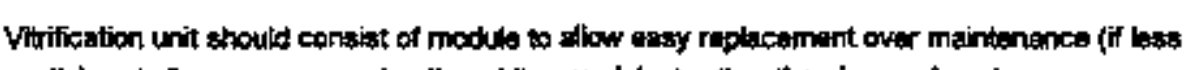

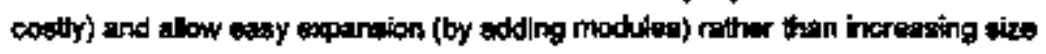

$263 \quad$ A.5.3.2 A.30 $7 \quad 7$

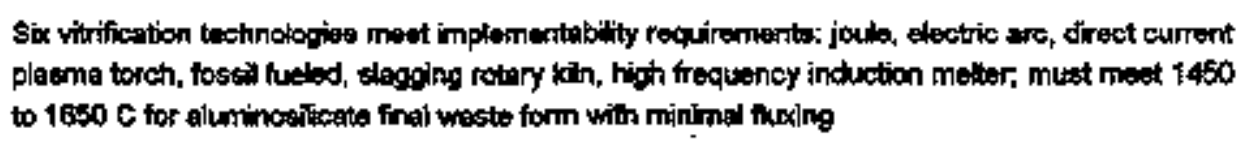

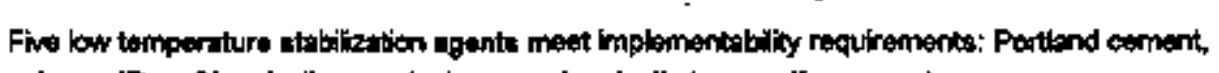
polymer (Dow Chemicol), pozzotank cement, polyethylene, suffur cement

d-1) System A1 - Rolary KChn with Alr and Drywht APC
$267 \quad 21.1 \quad 17$

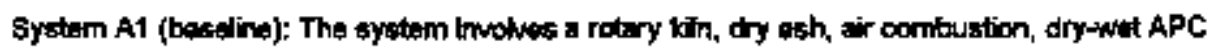
$269 \quad 2.1 \quad 17$

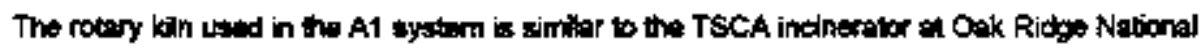 Letporatory (ORNL). 


\begin{tabular}{|c|c|c|c|c|c|}
\hline No. & sect. & Page & $\mathbf{U}^{*}$ & $\mathbf{S}^{*}$ & ITTS PHASE 1 - ASSUMPTIONS OR DESIGN FEATURES \\
\hline$d-1)$ & System A1 & - Rota & $\mathbf{r} \mathbf{K}$ & h with & in Afr and Drywhet APC \\
\hline 200 & 29.1 & 17 & & & 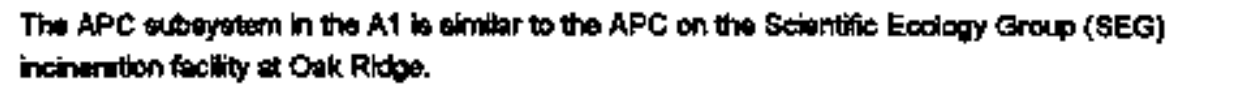 \\
\hline 270 & $\mathbf{2 1 . 1}$ & 17 & & & Soids rusidues are stabillzed by a combinetion of vitrilketion end potymer soifification \\
\hline 271 & 2.1 .1 & 17 & 8 & 8 & $\begin{array}{l}\text { Contaminated soi from errironmanted restoration prograns may be used as, one of the } \\
\text { vituifcetion additives. }\end{array}$ \\
\hline d-2) & Systom A2 & - Roth & ry $\mathbf{M T}$ & With & th Oxygen and Dryhtet APC \\
\hline 272 & $\mathbf{2 . 1 2}$ & 23 & & & 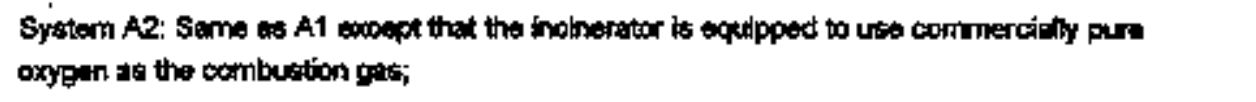 \\
\hline 273 & 21.2 & 23 & & & 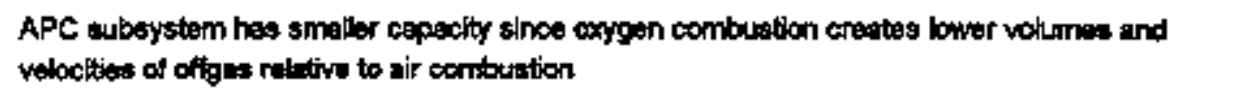 \\
\hline d-3) & Systimin $n$ & - Rotar & $\mathbf{r} \mathbf{K}$ & inth & th Alr and Wet $A P C$ \\
\hline 274 & 2.1 .3 & 23 & & & $\begin{array}{l}\text { System A3: Same as A1 wocept that APC aboystem vees all wot fitration and clering } \\
\text { techniquex }\end{array}$ \\
\hline$d-4$ & syatem A & - Roth & $\mathbf{r} \mathbf{K}$ & with & th Oxygea and CO2 Rotention \\
\hline 275 & 21.4 & 23 & & & 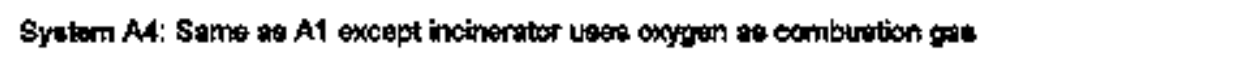 \\
\hline 276 & 2.1 .4 & 23 & & & $\begin{array}{l}\text { APC uses corventional dry fillation with remonel of CO2 by abeaption onto lime (or dolemitos) in } \\
\text { fluidized bed }\end{array}$ \\
\hline 277 & 2.1 .4 & 23 & & & Ot gos entiched who acyoen and recycled to incinerater \\
\hline 278 & 2.1 .4 & 23 & 7 & 7 & Spent line recycled as many as ten times by calcining \\
\hline 279 & 2.1.4 & 25 & 7 & 7 & $\begin{array}{l}\mathrm{CO} 2 \text { bs monitored and discherged; celcining can be done on or off wite or spent lime can be } \\
\text { disposed }\end{array}$ \\
\hline 280 & 2.1 .4 & 23 & & & Receiving and preparation different from A1, bulk metales, elag and tar formers removed \\
\hline 281 & 2.1.4 & 23 & & & Aqueous wasto treatrment byger than basesine in order to hande water condensed from off gest \\
\hline d-5) & System As & - Roth & $\mathrm{ry}$ & it wilth & th Alf and Polymar Stabllzatbon \\
\hline 282 & 2.1.5 & 24 & & & System A5: Same as A1 except primary stabilization method uses polymers instiead of vituifieation \\
\hline 283 & 2.1.5 & 24 & 吾 & 6 & 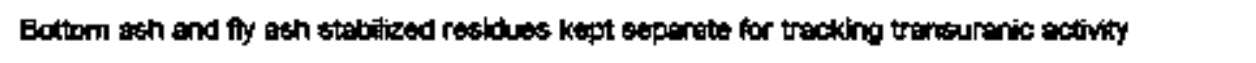 \\
\hline d-6) & Systein AB & - Rotol & $\Gamma \mathbf{Y} \mathbf{K}^{\prime \prime}$ & nith & th Alr and Heximom Racyeling \\
\hline 284 & 2.1 .6 & 24 & & & 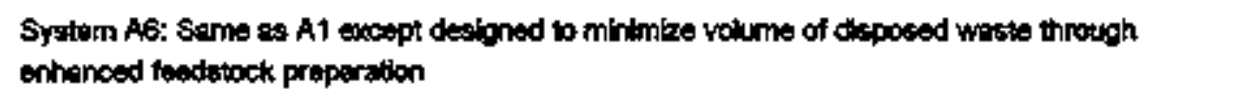 \\
\hline 285 & 2.1 .6 & 24 & & & 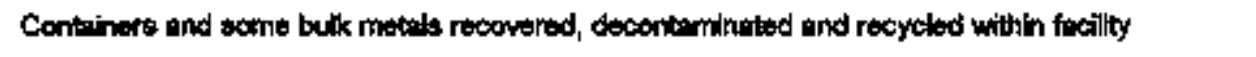 \\
\hline 296 & 2.1.6 & 24 & & & 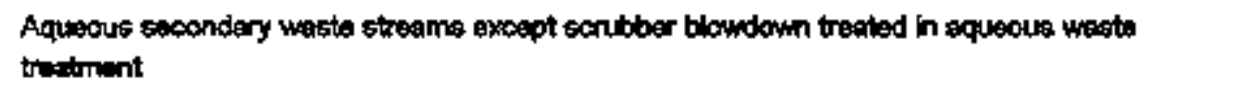 \\
\hline 287 & 2.1.6 & 24 & & & 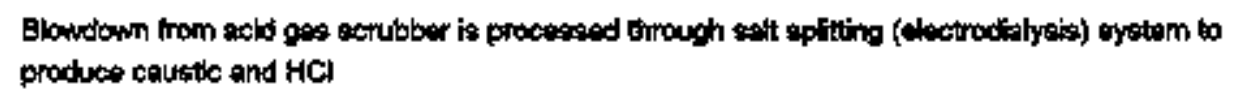 \\
\hline
\end{tabular}


No. Sect. Page $\frac{L^{*}}{-\mathrm{S}^{* *}}$

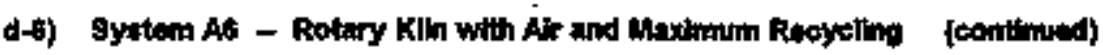

\begin{tabular}{|c|c|c|}
\hline $298 \quad 2.1 .6$ & 24 & Calsic can be reckeled to wet section of APC \\
\hline 2.1.6 & 24 & 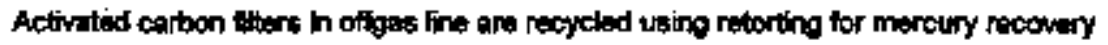 \\
\hline 2.1.6 & 24 & Stainlust eteol HEPA thers are clopened ond roused \\
\hline
\end{tabular}

\begin{tabular}{|c|c|c|c|c|}
\hline 291 & 2.2 & 24 & 56 & 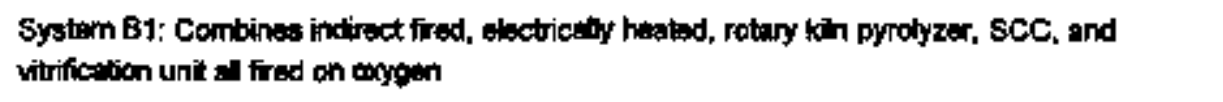 \\
\hline 202 & 22 & 24 & & 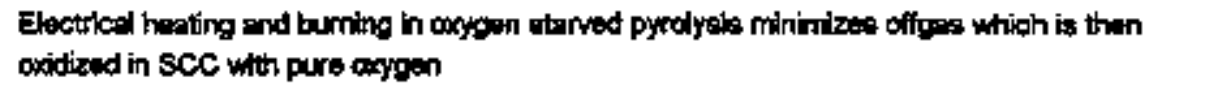 \\
\hline 293 & 2.2 & 24 & & Standard wet-dry APC and feedetock preparation stubsystems \\
\hline 294 & 2.2 & 24 & & 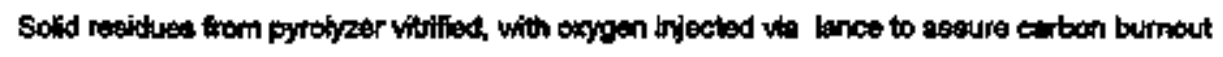 \\
\hline 298 & 22 & 24 & & Offyst from pyrolyzer and vitritiar ooidizad in ame SCC and AFC units \\
\hline 297. & 2.2 & 24 & & 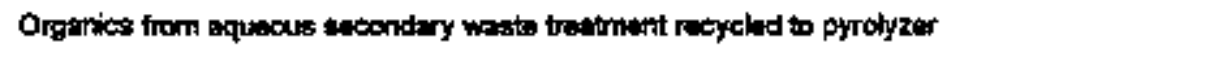 \\
\hline 297 & 2.2 & 24 & & $\begin{array}{l}\text { Sludges from proctpitation and fitration to promery ctotlization or polymer stabilzation if } \\
\text { necossery }\end{array}$ \\
\hline
\end{tabular}

d-6) 8yatem C1 * Plasmin Harth with Alr and Drymet APC

\begin{tabular}{|c|c|c|c|}
\hline 298 & 2.3 & 26 & 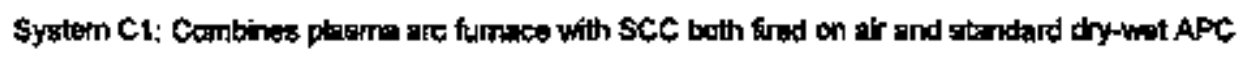 \\
\hline 299 & 2.3 & 26 & 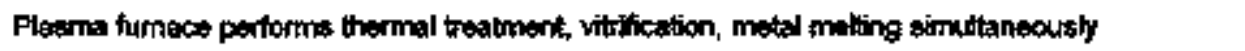 \\
\hline 300 & 2.3 & $\mathbf{2 6}$ & 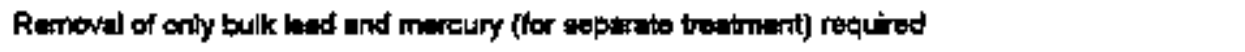 \\
\hline 301 & 2.3 & 26 & 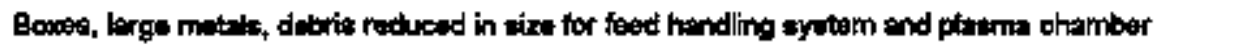 \\
\hline 302 & 2.3 & 26 & 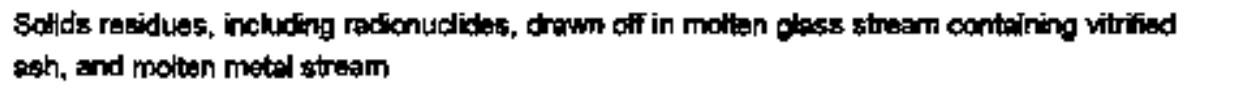 \\
\hline 303 & 23 & 26 & 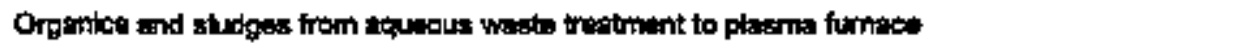 \\
\hline
\end{tabular}

d-8) System 01 .. Fired Hearth with Oxypen and Coz Retention

\begin{tabular}{|c|c|c|c|c|c|}
\hline 304 & 24 & $\mathbf{2 7}$ & & & 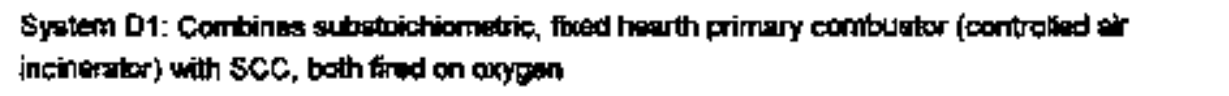 \\
\hline 305 & 2.4 & 27 & & & 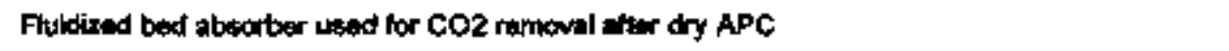 \\
\hline 306 & 2.4 & 27 & & & 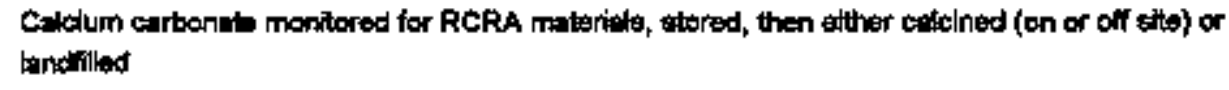 \\
\hline $\mathbf{3 0 7}$ & 2.4 & 27 & & & 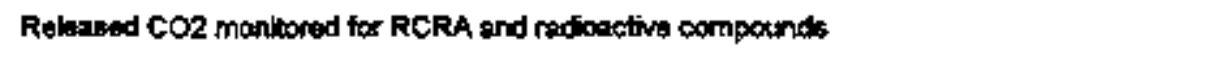 \\
\hline 308 & 2.4 & 27 & 7 & 7 & 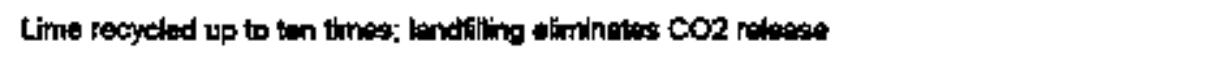 \\
\hline 300 & 24 & 27 & & & 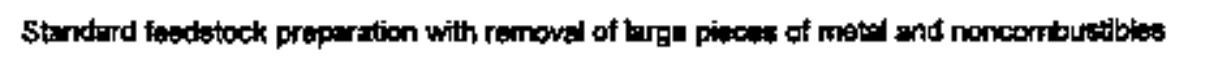 \\
\hline 310 & 2.4 & 27 & & & Orgentes and studgos from aqueas wate tretrment to fixed heerth \\
\hline
\end{tabular}

d-10) System E1 - Dutris Desorption and Grouting with Rotary Kin for Combusullates

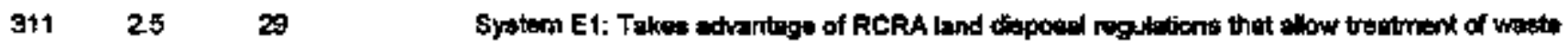

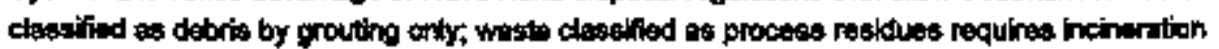


No. Sect. Page U* 8*

d-10) 8ystem E1 - Dubtia Dutopption and Grouting with Rotary Kin tor Combustibles (continged)

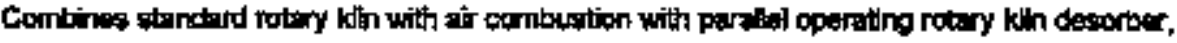

$\begin{array}{lll}312 & 25 & 25 \\ 313 & 25 & 29 \\ 314 & 2.5 & 29 \\ 315 & 2.5 & 29 \\ 316 & 2.5 & 29 \\ 317 & 2.5 & 29\end{array}$

29

$x$

*) Subsystem Design and Operating Assumptions

Sourcess of study information inoluded vendor cotangs providing tochnicel date and prices, and direct contects with bivelopus and vanders of new tacherologins.

e-1) Recelving and Preperadon

$\begin{array}{lllll}319 & 2.1 .1 .1 & 18 & & \\ 320 & 21.1 .1 & 18 & & \\ 321 & 2.1 .1 .1 & 18 & & \\ 322 & 2.1 .1 .1 & 18 & & \\ 323 & 21.1 .1 & 18 & & \\ 324 & 2.1 .1 .1 & 18 & 9 & 2 \\ 325 & 21.1 .1 & 18 & & \\ 328 & 2.1 .1 .1 & 18 & 9 & 0 \\ & & & & \\ 327 & 21.1 .1 & 18 & 9 & 5 \\ & & & & \\ 328 & 21.1 .1 & 18 & 9 & 6 \\ 329 & 21.4 .1 & 23,28 & 9 & 3 \\ 330 & 21.1 .1 & 5.28,29 & 9 & 3 \\ 331 & 2.1 .1 .1 & 28 & & \end{array}$

All Systems Crenes and fork lit trucks unloed weste containere from thooming vahiches The phystes state of the input westo is identiled by reatime redlography (RTR).

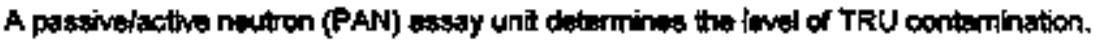

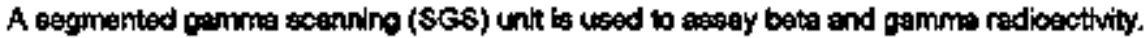

Each trit of wate input is arsigned a bar code for computer tracking.

Incoming waste ts classified as either sorting required (SR) or sorting not required (SNR) depending on its characterization.

Containers decapped by saw on gantry, Socting on a teble by mestepr-gtave and hydrestic maniputator:

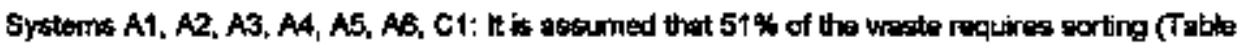
$3-9$ Fhase II report)

Systerms B1 and 01: It is assamed that 100\% of the waste requ|res sorting (Table 3-9 Phase t report\}

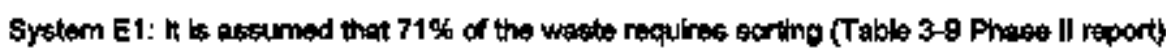

Systerns A4 and D1: Bulk motal, tor and sfag formers remowed

Systems B1, O1, E1: Most of nonoombustble bulk materiel separated out

System C1: Minimal processing with removal orly of bulk bad and marary, brase pieces of motal and dobrits roduced in size, motal not needing moling to decontaminetion

e-2) Primary Trestment

$332 \quad 2.1 .1 .2 \quad 18$

Systems A1, A3, A5: The primary treotment inchudes a foed atrecter, a characherization unit, a

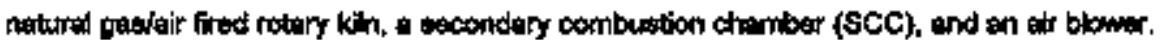

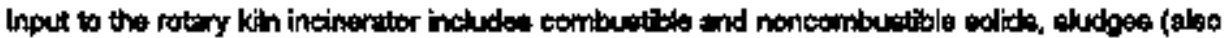
from aqueous trestuntit), and orgatic liquidt.

$334 \quad 2.1 .1 .2 \quad 18$ hoppers 


\begin{tabular}{|c|c|c|c|c|c|}
\hline No. & sect. & Page & $\mathbf{U}^{*}$ & 8*4 & ITTS PHASE 1 - ASSUMPTIONS OR DESIEN FEATURES \\
\hline$(-3)$ & \multicolumn{2}{|c|}{ Prinky Traktiment } & \multicolumn{2}{|c|}{ feontinered } & and) \\
\hline 335 & 2.1.1.2 & 18 & & & 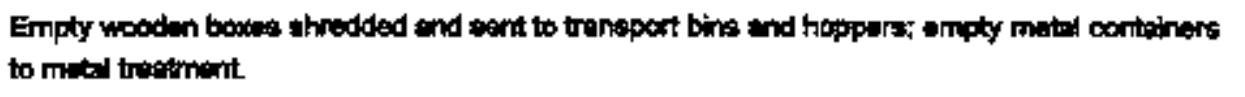 \\
\hline 338 & 21.1 .2 & 18 & & & Bins and hapers are eempled and anabyzed before beling fad to the incintirator. \\
\hline 337 & 21.1 .2 & 18 & & & 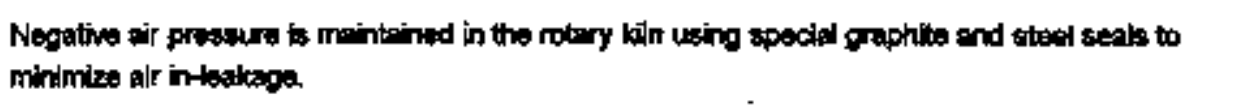 \\
\hline 339 & $\mathbf{2 . 1 . 1 . 2}$ & 18 & 3 & 6 & Secondary corfinement to providad for the bustine incinenter by a matat housing. \\
\hline 330 & 2.1 .1 .2 & 23 & & & 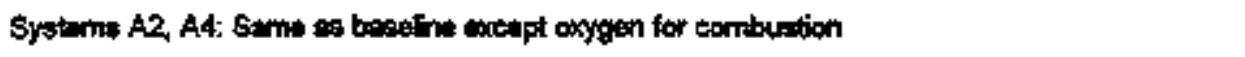 \\
\hline 340 & 21.1 .2 & 26 & 5 & 6 & Syatim Bt: Pyrobyzer, SCC, dryer are integrated with whifietion trit (vitifier type ?) \\
\hline 341 & 2.4 .1 .2 & 25 & & & Noncombustible wasto fed to drye flong with sol or addlivives \\
\hline 342 & 2.1 .1 .2 & 25 & & & 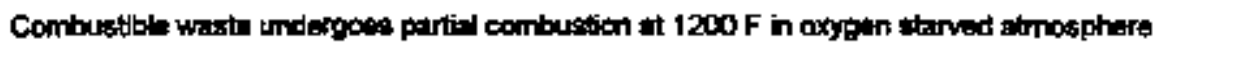 \\
\hline 349 & 2.1 .1 .2 & 25 & & & 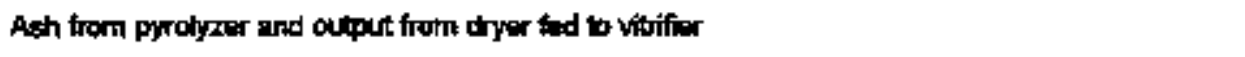 \\
\hline 344 & 2.1.1.2 & 25 & & & 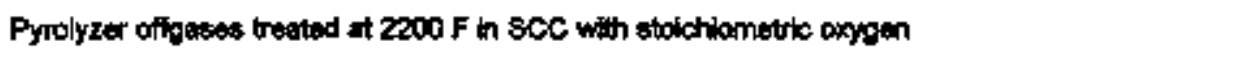 \\
\hline 345 & 2.1 .1 .2 & 26 & & & 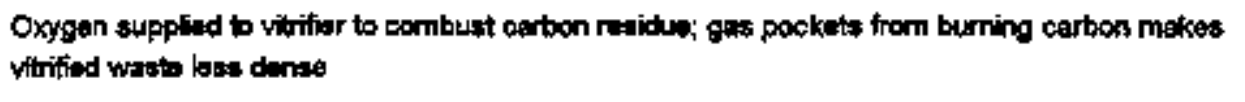 \\
\hline 346 & 2.1 .1 .2 & 26 & & & 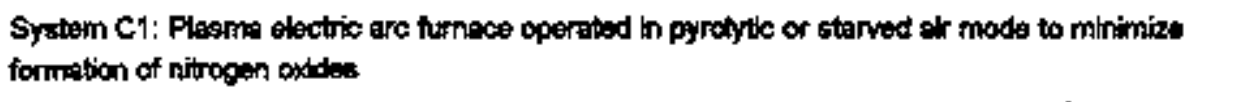 \\
\hline 347 & 2.1 .1 .2 & 26 & & & Off gased bumed in SCC using ai \\
\hline 348 & $2 .\{.1 .2$ & 28 & & & 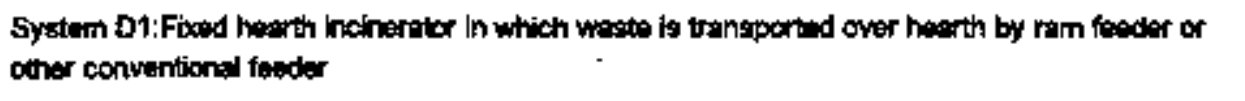 \\
\hline 349 & 21.1 .2 & 28 & - & & Screw corrveyor stirs agh pils and mowes to wh pots \\
\hline 350 & $2.1 . \$ .2$ & 28 & & & 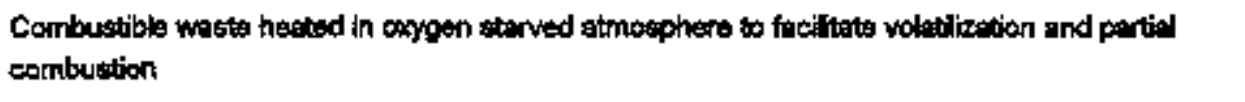 \\
\hline 351 & 2.1 .1 .2 & 28 & & & Off gases ate butmed in SCC taing excess oxygen \\
\hline $35 \mathbf{2}$ & 21.12 & 29,30 & & & 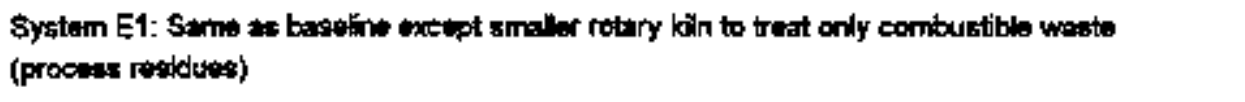 \\
\hline 353 & 2.1 .1 .2 & 29,30 & & & $\begin{array}{l}\text { Indirectly heated caloiner for tharmal desorption seperates VOC from noncombustible (RCRA } \\
\text { debris end sod) }\end{array}$ \\
\hline 354 & 2.1 .1 .2 & 29,30 & & & 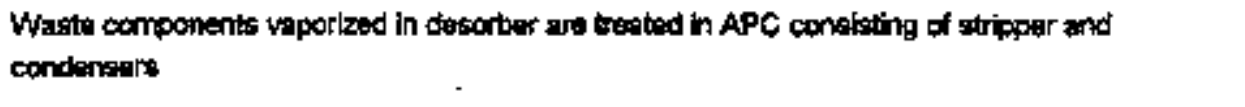 \\
\hline 35 & $\mathbf{2 . 1 . 1 . 2}$ & 29,30 & & & Orgrencl lquids from desorber stint to rotary $k$ ln \\
\hline 356 & 2.1.1.2 & 29,30 & & . & 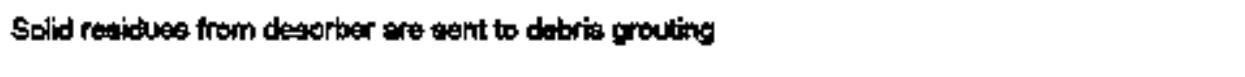 \\
\hline (-) J) & Ale Pollut & on Contra & I (AP & & $\cdot$ \\
\hline 357 & 2.1 .1 .3 & 19 & & & 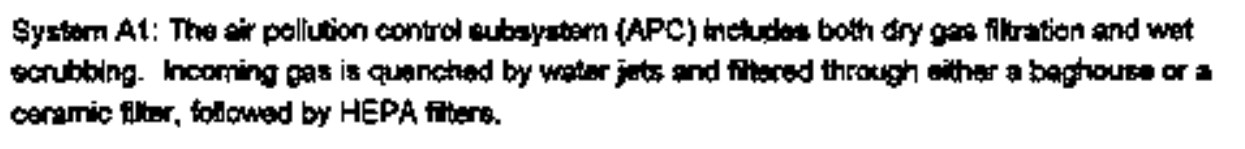 \\
\hline 308 & 2.1 .1 .3 & 19 & & & 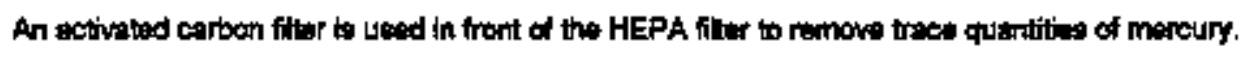 \\
\hline 359 & 2.1 .1 .3 & 19 & & & 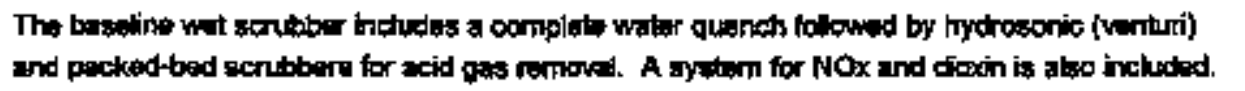 \\
\hline
\end{tabular}




\begin{tabular}{|c|c|c|c|c|c|}
\hline No. & sect. & Page & $\mathbf{U}^{\boldsymbol{*}}$ & $\mathbf{S}^{\star \bullet}$ & ITTS PHASE 1 - ASSUMPTIONS OR DESIGN FEATURES \\
\hline$(-3)$ & Alr Poilut & an Contre & A & ac) & (continued) \\
\hline 360 & 2.1.1.4 & 18 & & & 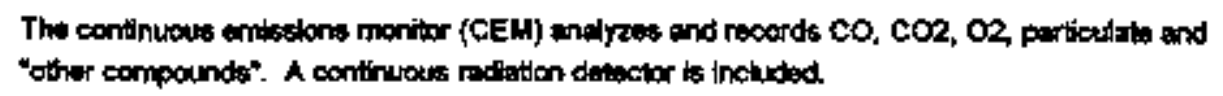 \\
\hline 361 & 2.1.1.4 & 18 & & & System AZ: emafex capocity dus to bxyon uas in tha former and \\
\hline 362 & 2.1.1.4 & 19 & & & 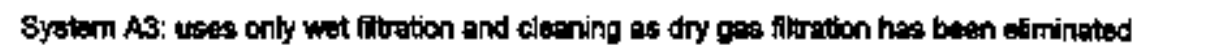 \\
\hline 363 & 2.1.1.4 & 19 & & & 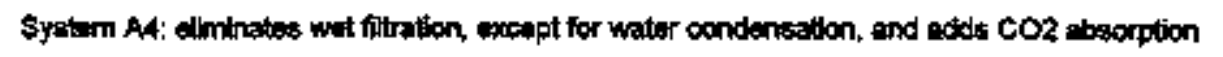 \\
\hline 364 & 2.1 .1 .4 & 48 & & & Syom AS: Same $=\mathrm{A1}$ \\
\hline 365 & 2.1.1.4 & 18 & & & 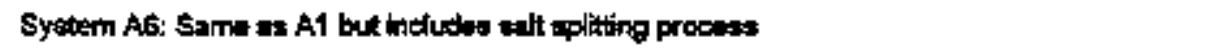 \\
\hline 366 & $2 . \$ .1 .4$ & 19 & & & System B1: Smaller cipacty than A1 due to indtect hesting with oxygen combution \\
\hline 307 & 21.1 .4 & 19 & 3 & $B$ & 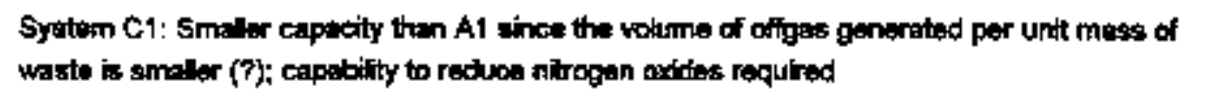 \\
\hline 368 & 2.1.1.4 & 19 & & & 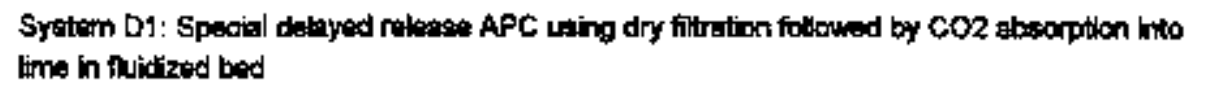 \\
\hline 309 & 2.1.1.4 & 19 & & & $\begin{array}{l}\text { Walior vapor from incinerator first condensed, femaining pas stored, sampled, refersed if } \\
\text { meating requlrements }\end{array}$ \\
\hline 370 & 2.1 .1 .4 & 19 & 7 & 7 & Limo or dolomitie recyeled up to ten times in calcining lime recovery syotem \\
\hline 37 & 2.1.1.4 & 19 & 7 & 7 & 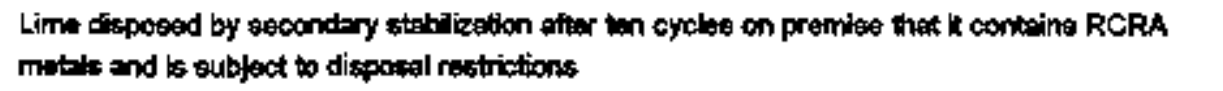 \\
\hline 372 & 2.1.1.4 & 19 & & & System Et: Smaller than A1 \\
\hline e-4) & Primary 6 & ablikzatto & & & \\
\hline 373 & 2.1.1.10 & 21 & & & System A1: Vitrifestion used to convert inctheretor ath to waste lorm sutable for disposal \\
\hline 374 & 2.t.1.10 & 21 & 7 & 7 & $\begin{array}{l}\text { Soll (including contaminated soll from DOE installations) or chemical addithes () uodd as glass } \\
\text { formers }\end{array}$ \\
\hline 375 & 2.1 .1 .10 & 21 & & & Input waste must be property characterized for proper incinerator ash prectiction \\
\hline 376 & 2.5 .1 .10 & 21 & & & 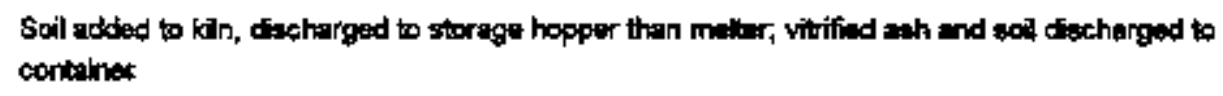 \\
\hline 377 & 21.1.10 & .21 & & & Contsiner coofed, capped, sent to swiping and decontsmination \\
\hline 378 & 2.1 .1 .10 & 21 & & & Decontomination if nectesany by high presolue water jets \\
\hline 379 & 21.9 .10 & $2 \mathbf{2 t}$ & & & brepested container to assay, oertifieation, and shipped to storage or disposial \\
\hline 390 & 2.1 .7 .10 & 21 & & & Melter has dry filtration APC \\
\hline 381 & 2.1 .7 .10 & 21 & & & Systems AZ, A3, A4, AG: Same as A1 \\
\hline 382 & $2 \uparrow .1 .10$ & 21 & & & 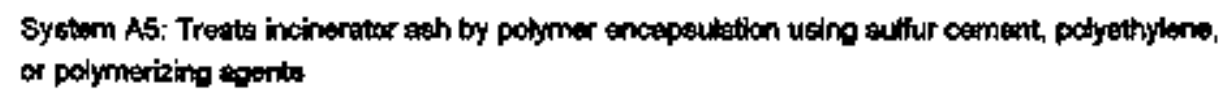 \\
\hline 383 & 2.1.1.10 & 21 & & & 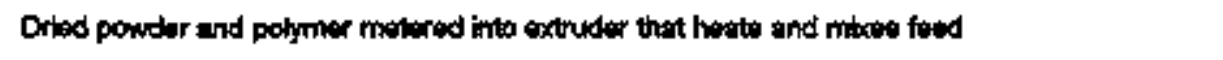 \\
\hline 384 & 2.1.1.10 & 21 & & & Extrudar feeds mixture to chum which is capoed, sent to swiping and decortamination \\
\hline 385 & 2.1.1.10 & 21 & & & 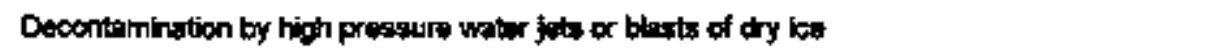 \\
\hline 398 & 2.1 .1 .10 & 21 & & & 1nspected contriner wo suray, certification, then shipped to storage or disposal \\
\hline 387 & 21.1.10 & 21 & & & 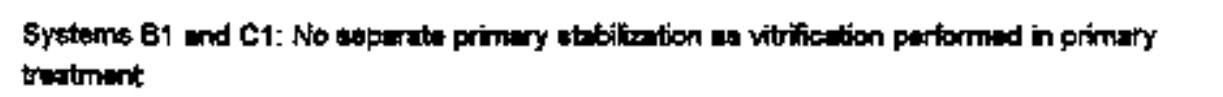 \\
\hline
\end{tabular}




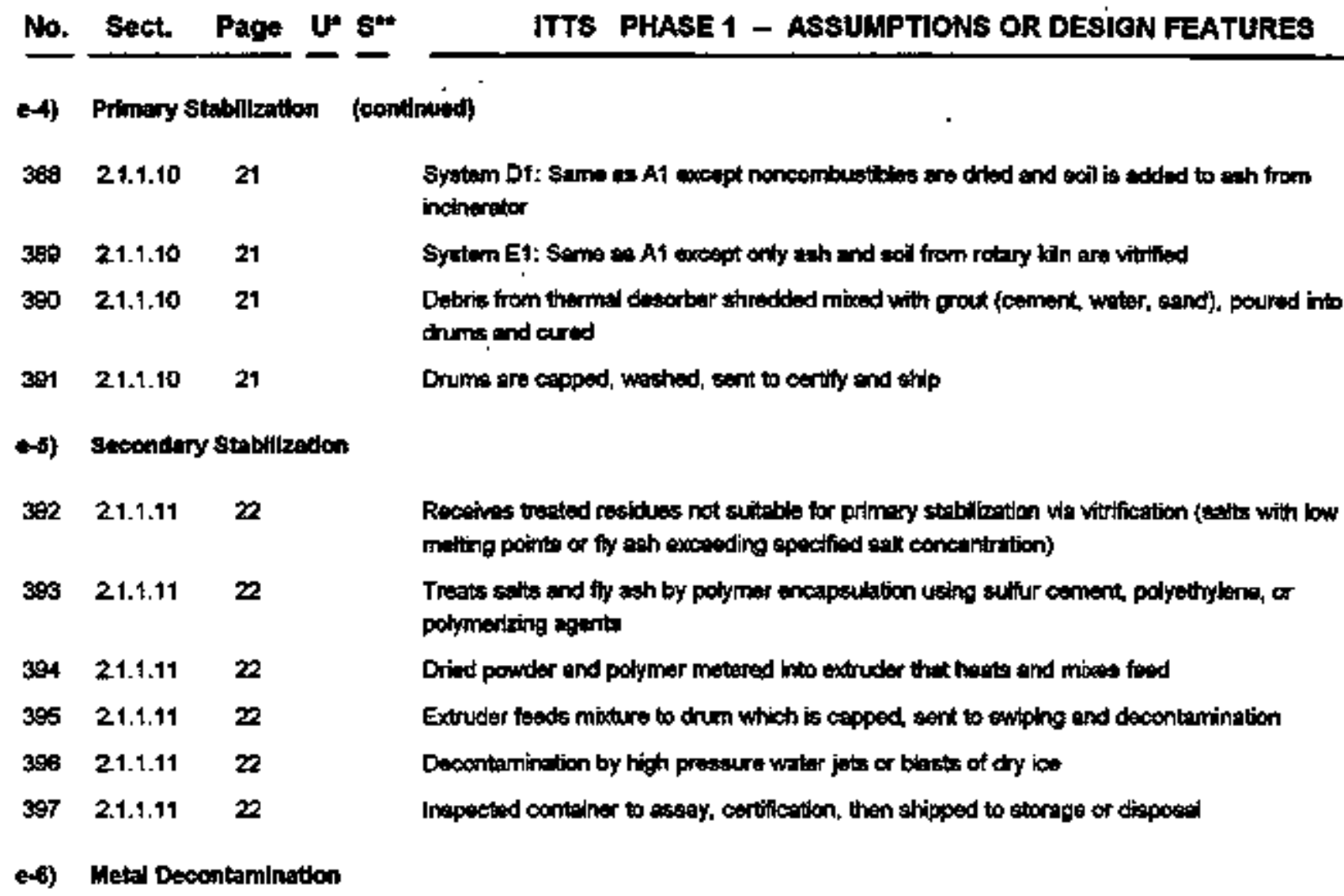

$\begin{array}{lll}398 & 2.1 .1 .6 & 19 \\ 389 & 2.1 .1 .6 & 19\end{array}$

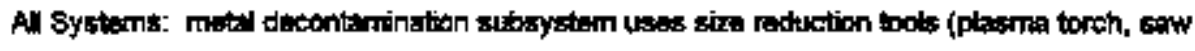
and sheor

Abreshe blasting (with dry ke to minimiza liquid waste genoration) to reimove entrained and ourfoce contanination.

a-7) Mntil Malting

$\begin{array}{ccc}400 & 2.1 .1 .7 & 20 \\ 401 & 2.1 .1 .7 & 20 \\ 402 & 2.1 .1 .7 & 20 \\ 403 & 21.1 .7 & 20 \\ 404 & 2.1 .1 .7 & 20 \\ 405 & 2.3 & 26 \\ 4-8) & \text { L.14 Recomvery } \\ 406 & 2.1 .1 .4 & 19 \\ 407 & 2.1 .1 .4 & 19 \\ 408 & 2.1 .1 .4 & 19 \\ 409 & 2.1 .1 .4 & 19 \\ 410 & 2.1 .1 .4 & 19\end{array}$

All Systoms excopt C1: motal meiting, used when surface decomtamination cernot be accomplishod.

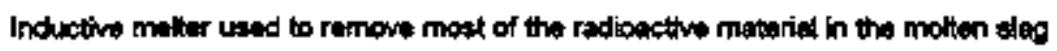

Sleg cast in container, cocled, inepected, esosyed, and ehipped to etorege or diepoest

Cleen motal is poured into ingots, cooled, sent for DOE rausa

incuction melier ueed of Aluration APC

System C1: mital melfing accompiahed in primery treatmont

Af Syaterns: Subaystem conaiats of decontmination train and stectriedly heatod rousting oven

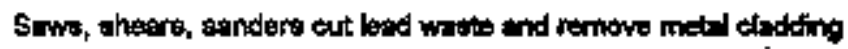

Searing and abrasive blating booths for decontarinetion

Dven molks lead that cen net be deconteminoted by mectronicoll meone

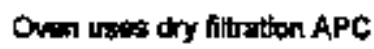


No. Sect. Page $U^{*} \mathbf{s}^{* *}$

-e) Aqueous Wats Tratiment

$\begin{array}{lll}411 & 2.1 .1 .9 & 20 \\ 412 & 2.1 .1 .9 & 20 \\ 413 & 2.1 .1 .9 & 20 \\ 414 & 21.1 .9 & 20\end{array}$

$415 \quad 21.19 \quad 20$

$416 \quad 2.1 .1 .9 \quad 20$

$417 \quad 2.1 .1 .9 \quad 20$

$418 \quad 2.1 .9 \quad 20$

$419 \quad 2.1 .1 .9 \quad 20$

e-10) Hercury Amalonmation

$420 \quad 2.1 .1 .5 \quad 19$

-11) Special, Waste Treatnent

$421 \quad 2.1 .1 .0 \quad 20$

e-12) Gertify and shlp

$\begin{array}{lll}422 & 2.1 .1 .12 & 22 \\ 423 & 2.1 .1 .12 & 22 \\ 424 & 2.1 .1 .12 & 22 \\ 425 & 2.1 .1 .12 & 22 \\ 426 & 2.1 .1 .12 & 22\end{array}$

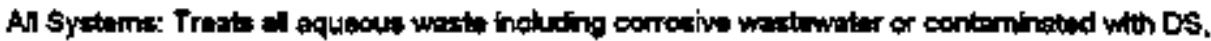
Ss, organios, havy metal

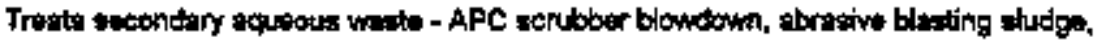
conteiner rinso watier,

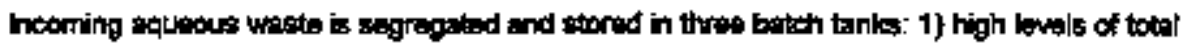

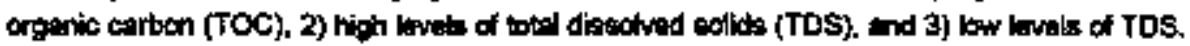

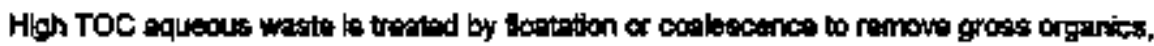

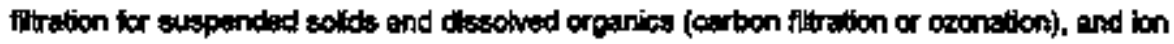

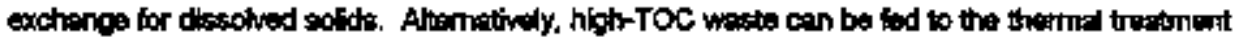
stosystom.

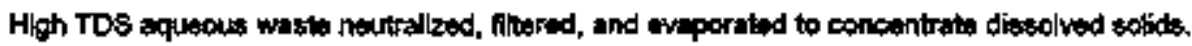

Low TDS rqueous wathe is fittered, tranted uting a tribon firter or obonition to remove diasolved organics, end by ion wehinge to remove distohed wolits.

S|udges from aquacus waste treatment are concentrated and send to the stabilization oyotem(6).

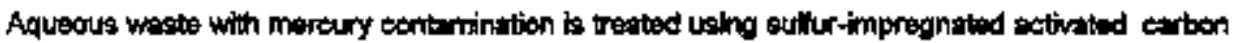
and mercury-selective ion exchanto resins.

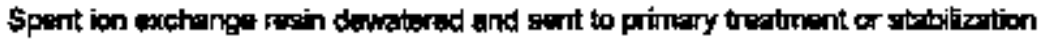

All Systeras: meicury th contrminated solids recovered by retorting and condensalion. Retorted

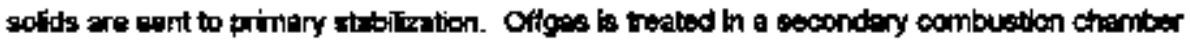

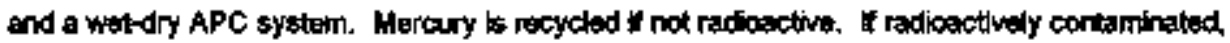
it is amalgarrated with einc or copper for athbilization and diaposeal.

Al Systerms; No conceptual deston has bo developed for "special wastes", which will be deal with on a cose-by-cese bosis. A cost allowance of $\$ 3$ millan is inctuded in cost estimates.

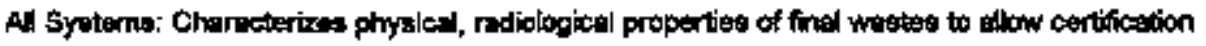
for trankeportetent, btorege, dieposal

RTR examines for hornogtaneity, and thes water

TRU or alpha processed waste meatured by PAN for TRU concentration

SCS unit assoys beta and gamtrit reditortivity

Waste to temporery starage or shipped to on-gite ox off-itito diteposel

7) Lif: Cyol Cost and Sensitivity Analysts

$\begin{array}{lll}427 & 4.0 & 76 \\ 428 & 4.0 & 76 \\ 429 & 4.0 & 76\end{array}$

Transportation costs included on generic basis, wall fraction ( $-5 \%)$ of totol LCC

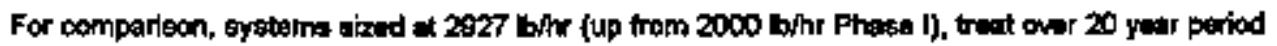

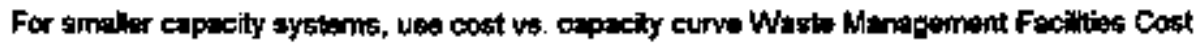
Informattors Repert 
No. Sect. Page $U^{*} \mathbf{s}^{\text {n* }}$

7) Lte Cycle cost and sensthrity Anityals (oontinued)

\begin{tabular}{|c|c|c|c|c|c|}
\hline 430 & 4.0 & 78 & 9 & 8 & One system uand for entire invantory and this dosigned for elphe waste \\
\hline 431 & 4.1 & 76 & & & 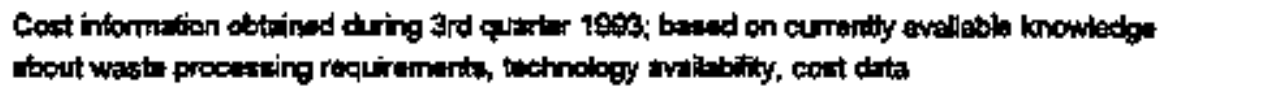 \\
\hline 432 & 4.1 & 76 & 9 & 2 & Facilitis are povermmort onned and contractor cperated (COCO) \\
\hline 433 & 4.1 & 76 & & & Traetrint unt rates by dividing toted PLCC estimete by totel operating hours por year \\
\hline 434 & 4.2 & 76 & & & 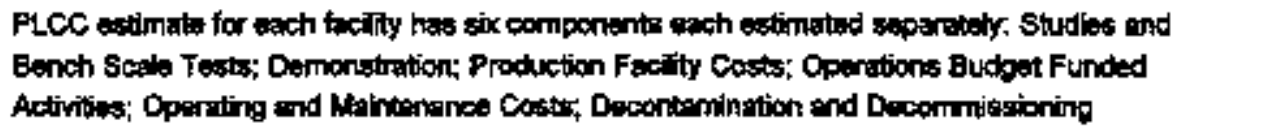 \\
\hline 135 & $\mathbf{4 . 2 . 1}$ & 78 & & & 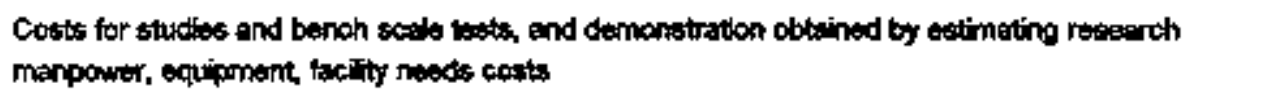 \\
\hline 438 & 4.2 .2 & 78 & & & 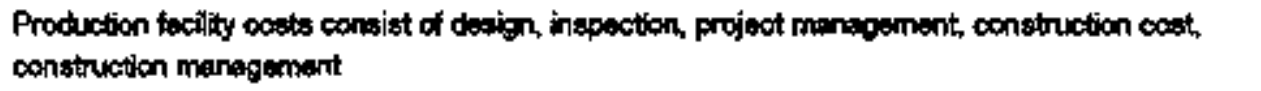 \\
\hline 437 & 4.2 .2 .1 & 78 & & & 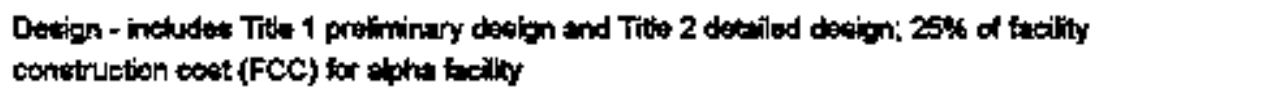 \\
\hline 438 & 4.2.2.2 & 78 & & & Inspection - inchudes TThe 3 engineerlag support during construetion; $7 \%$ ef FCC \\
\hline 439 & 4.22 .3 & 78 & & & 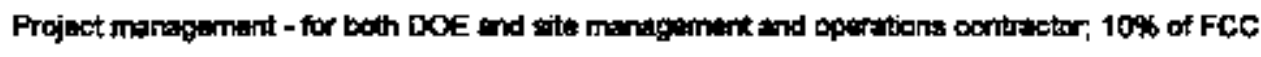 \\
\hline 440 & 4.22 .4 & 78 & & & 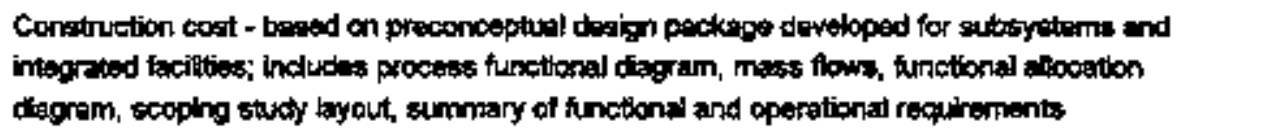 \\
\hline 441 & 4.2.2.4 & 78 & & & Three parts to construction cost - buikting end atuctures, equipment, indirect costs \\
\hline 442 & 4.2 .2 .4 & 78 & 9 & B & 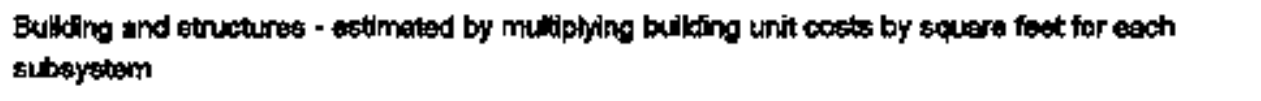 \\
\hline 443 & 4.224 & 78 & 9 & a & 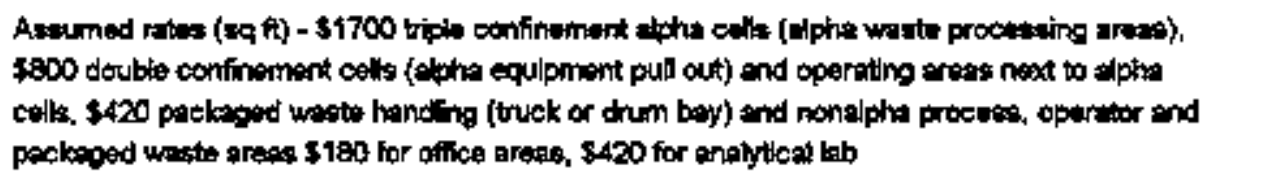 \\
\hline 444 & $4,2.24$ & 78 & & & Rates inckude materiats ind baber, uilities, lighting, HVAC, sita dovalopment \\
\hline 445 & 4.2 .24 & 78 & & & Utilitis $\Rightarrow$ and access road agsurned to bo within 100 foot of treatment frecility \\
\hline 446 & 4.2 .24 & 78 & & & $\begin{array}{l}\text { Not incluted - speciat staes support, foundations, ventilation ducts and hoods tor processes } \\
\text { companents }\end{array}$ \\
\hline 447 & 4.2 .2 .4 & 79 & $\mathbf{g}$ & B & 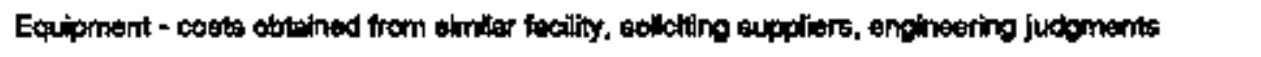 \\
\hline 448 & 4.22 .4 & 79 & & & Installation costis based on individuel equipment requirements \\
\hline 449 & 4.2 .2 .4 & 79 & & & 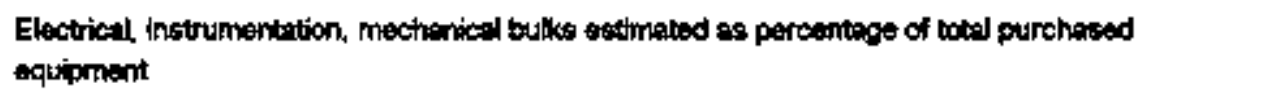 \\
\hline 450 & 4.2 .2 .4 & 79 & & & 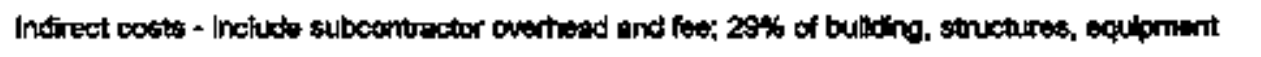 \\
\hline 451 & 4.2 .2 .5 & 79 & & & 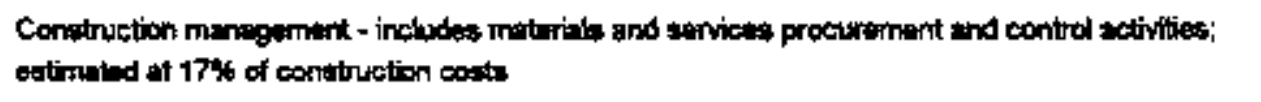 \\
\hline 452 & 4.2 .25 & 79 & & & Manegement reserve - 10\% of conatruction couta \\
\hline 453 & 4.2 .2 .5 & 79 & $\theta$ & 9 & 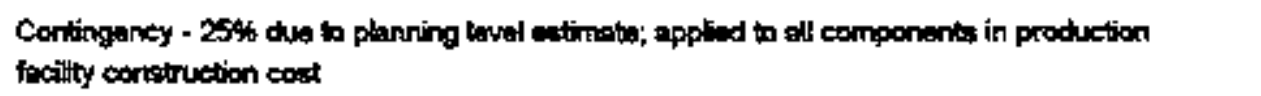 \\
\hline
\end{tabular}


No. Sect. Page $u^{*} \mathbf{s}^{*}$

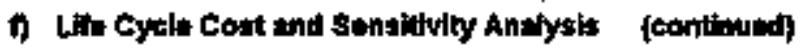

\begin{tabular}{|c|c|c|c|c|c|}
\hline 454 & 42.3 & 80 & & & 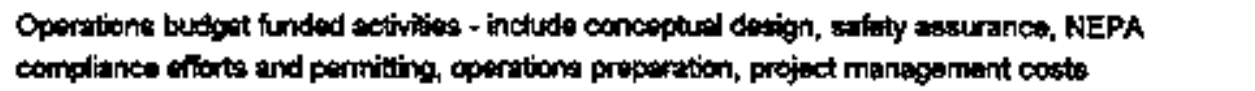 \\
\hline 455 & 4.2 .3 & 80 & & & Conceptued dasign and setety assurance + $1.5 \%$ and $1 \%$ of FCC \\
\hline 450 & 4.2.3 & so & 、 & & NEPA, RCRA, TSCA, CAA, wto and locil pormits - \$6 millon \\
\hline 457 & 4.2 .3 & 80 & & & 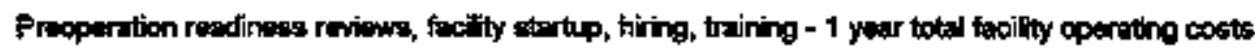 \\
\hline 458 & 42.4 & $\mathbf{B O}$ & & & 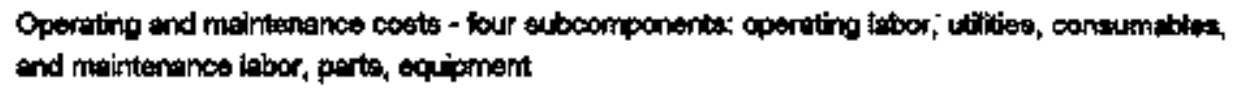 \\
\hline 450 & 4.2 .4 & 80 & & & 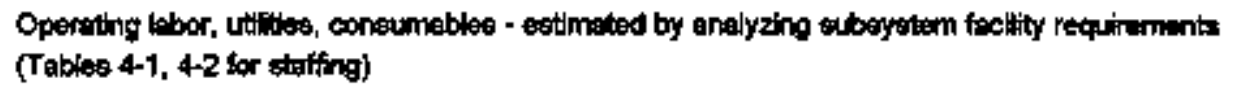 \\
\hline 450 & 424 & BO & & & 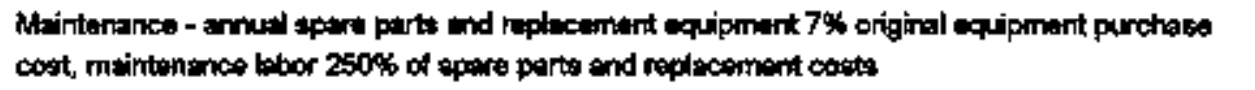 \\
\hline 461 & 4.2 .5 & 80 & 7 & B & 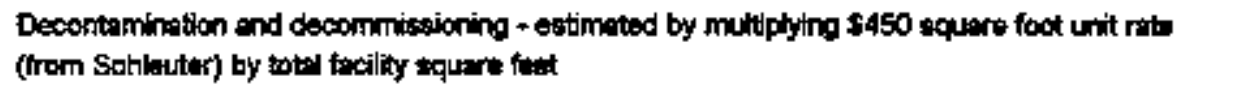 \\
\hline 462 & 4.3 & 然 & $\mathbf{9}$ & $\theta$ & 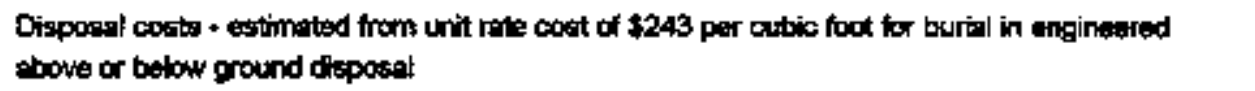 \\
\hline 483 & 4.4 & 82 & & & Total Syctem Lifa Cycle Cost - sum of treatment and disposed ocests \\
\hline 484 & 4.8 & 82 & & & 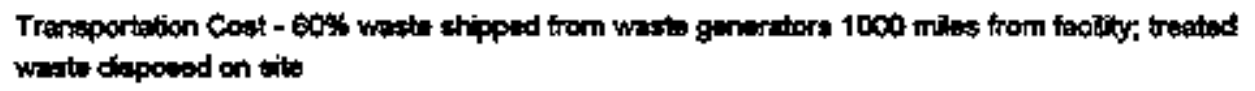 \\
\hline 465 & 4.8 & a2 & & & Weste containers contact handed with no special overpaok, shipped in enclosied trallers \\
\hline 466 & 4.8 & 82 & & & $\begin{array}{l}\text { Waste hes } 35 \text { ib cubic foot averege dersity, volume waste shipped to } 290 \text { cuble foot per } \\
\text { shiphnit }\end{array}$ \\
\hline 467 & 4.8 & 82 & & & Cost for shipment is $\$ 4 / \mathrm{m}$ lie per shipment (feed 7), fxed costs $\$ 880$ per shipment \\
\hline
\end{tabular}

NOTE: $v$ The uncertainty in an assumption

(on a scale of 1 - 10 with 10 being the most uncertain)

* 8 The sensilivity of the Tolal PLCC to changes in the assumption

(on a scale of $\mathbf{i}-10$ with 10 being the most senstiviv)

Both Uncertainly and Sertsilivity were based on engineering judgement;

no quantitative evaluations were made at this stage of the review of the reports. 


\section{APPENDIX E}

\section{IDENTIFIED ASSUMPTIONS FOR THE ITTS STUDY - PHASE 2}


NO SEC FACE CCATERAM -...-...
ASSUMTIONS OR DESAGN FEATURES

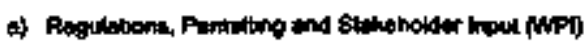
\begin{tabular}{lllllllllllll}
\hline & 140 & 14 & 1 & 1 & 1 & 1 & 1 & 1 & 1 & 1 & 1
\end{tabular}

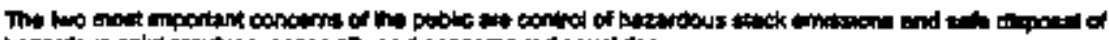

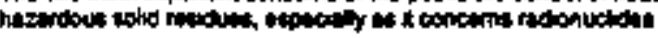

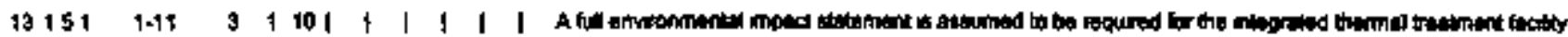

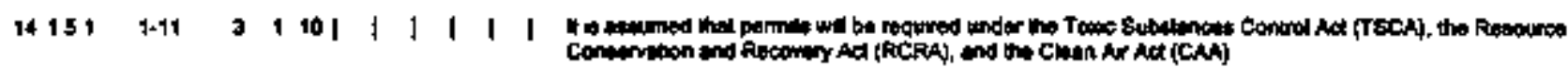

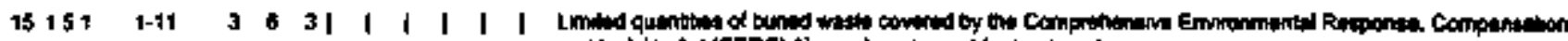

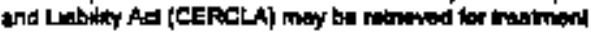

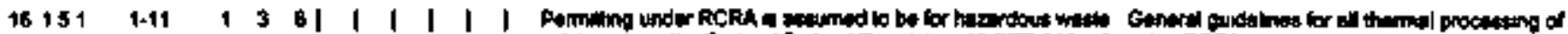

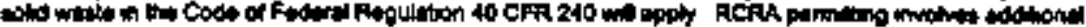

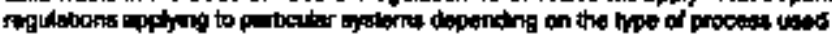

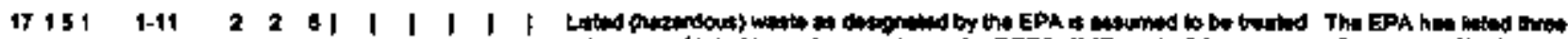

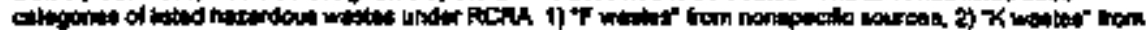

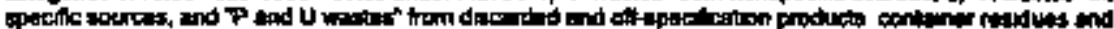 ipent?

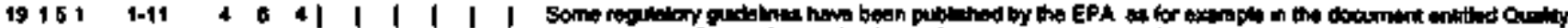

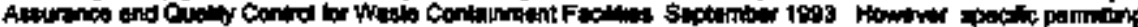

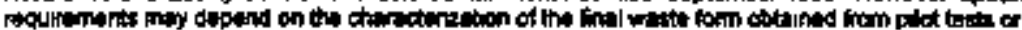 depromataliones

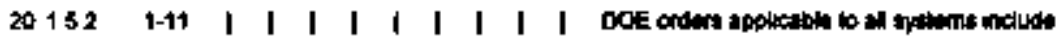

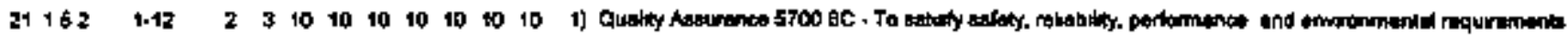

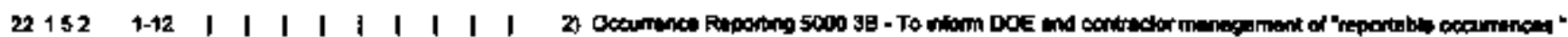

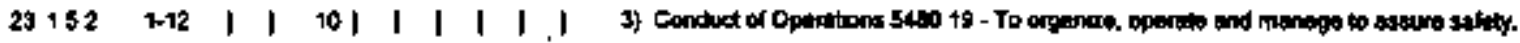

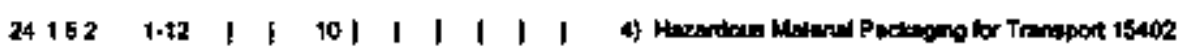

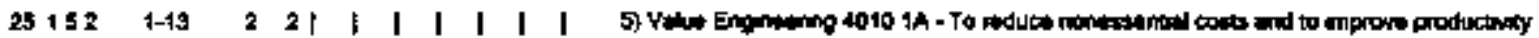
$261621.533510 ! \mid$ | I I I

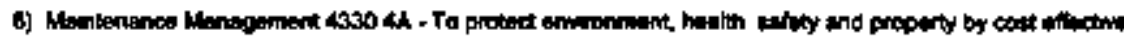 मा4

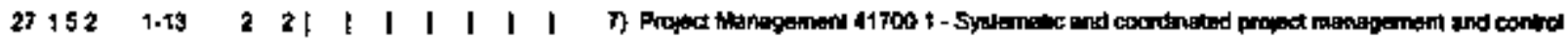

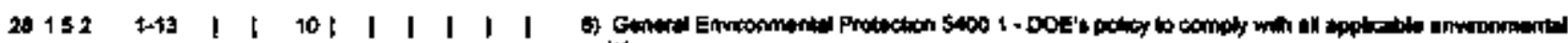 Swoulation:
39162 t-to | | | | | | | | |

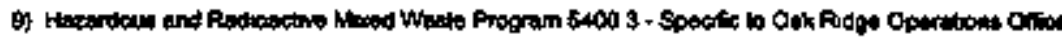
30152 1.14 | | 101 | | | | |

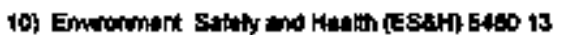
$3152 \quad 1.44|| 10 \mid$ | | | | |

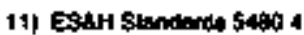
$32162 \quad 9.14$ | 131 | I | | |

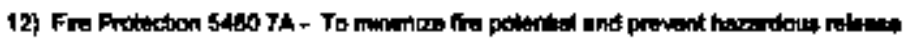
$33152|-14| 101$ | $|1|$ |

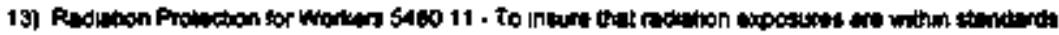
341521.14 | 17 | | | | | |

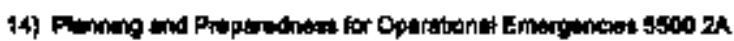
35152 1.15 $35 \mid$ | 1 | | | |

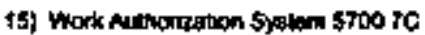
$38152 \quad 1.16 \quad 33101$ | 1 | 1 |

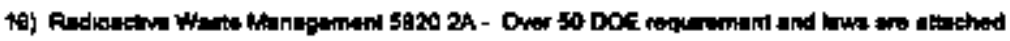

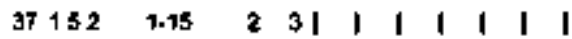

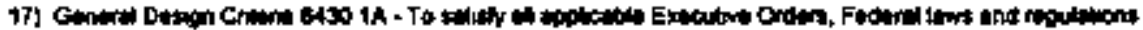

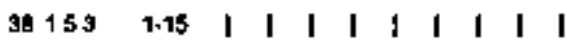
36 153 1.15 | I nol | t | I |

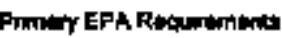
401532 1.15 I I 101 | $\mid 1$

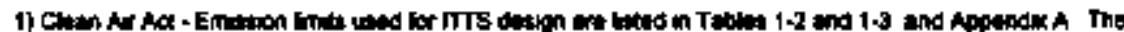

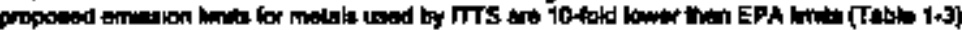
411532 1.15 $2 * 71|| \begin{array}{llll}\mid & 1 & 1\end{array}$
$421 \$ 32$ 1-17 3 9 \$ | I I |

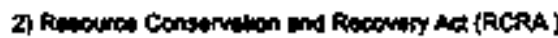

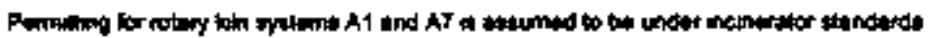
43 T532 1-17 30 a $5 \uparrow$ |

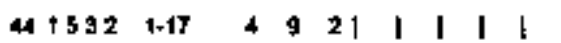

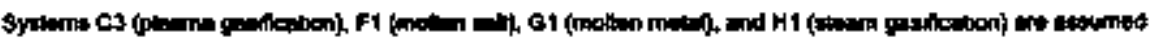

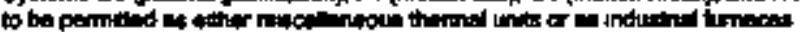

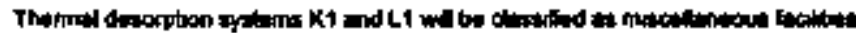

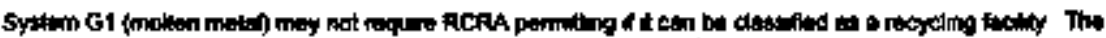

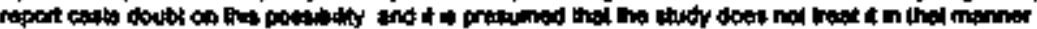

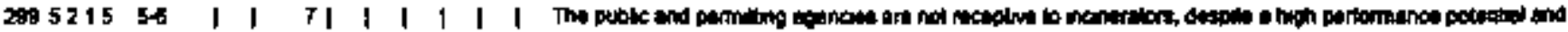




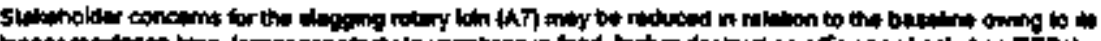

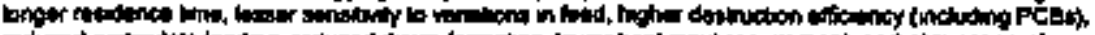

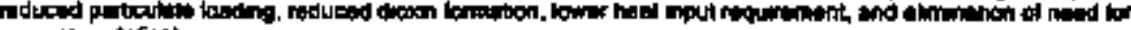

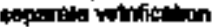

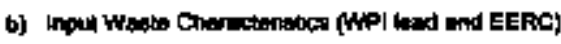
1110 1.4 | | | | | | | | | | |

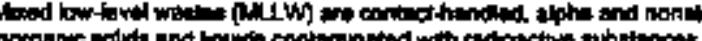
$5120 \quad 1-2$ | | | | | | | | | |

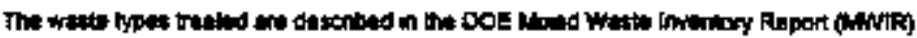 $100 \mathrm{nc}$ 的

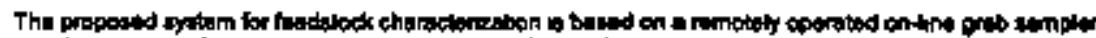

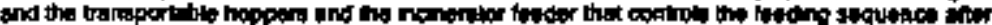

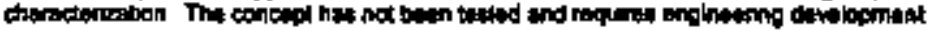
C) Wa:b Chvactarmiton (WPI had and EERC)
18151 1.11 1 2 2 日)

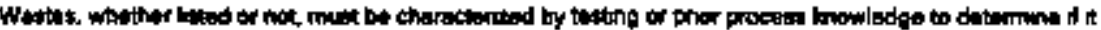

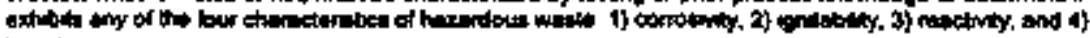 veocesty

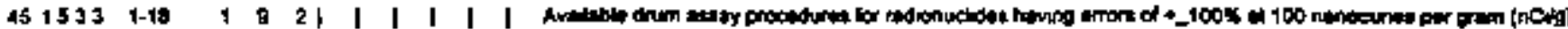

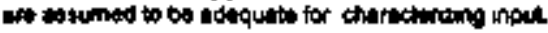

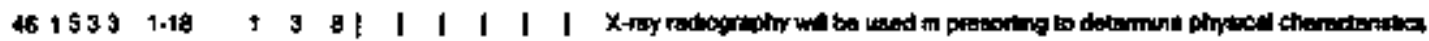

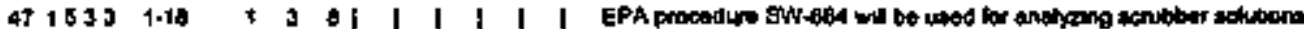

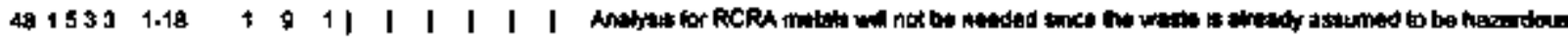

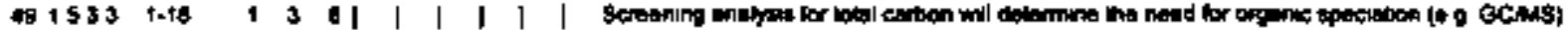
$50 \begin{array}{lllllllllll}1533 & 1-18 & 1 & 5 & 3 & 1 & 1 & 1 & 1 & 1 & 1\end{array}$

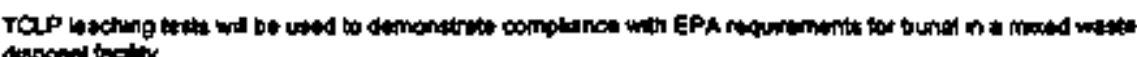 otopoed teaty

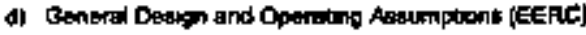

\begin{tabular}{|c|c|c|c|c|c|c|c|c|c|}
\hline 2110 & 1.1 & I & I & I & I & $b$ & † & 1 & 1 \\
\hline 3110 & $1-1$ & 2 & 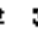 & 31 & 1 & 1 & p & 1 & 1 \\
\hline 4120 & $1+2$ & I & 1 & 1 & I & I & I & I & I \\
\hline ஜ130 & $1-3$ & I & I & I & I & I & I & I & I \\
\hline $7+10$ & 1.3 & I & 1 & I & 1 & I & I & I & I \\
\hline 8140 & 14 & & 8 & 81 & I & 1 & 1 & 1 & \\
\hline
\end{tabular}

10140 14 I I E I I I I I I

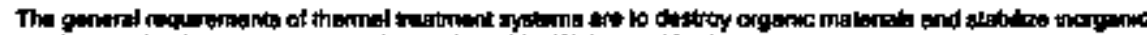

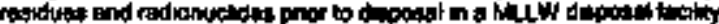

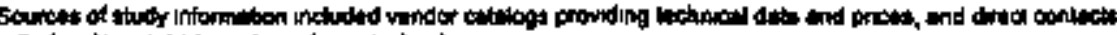

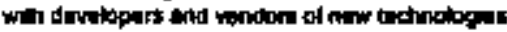

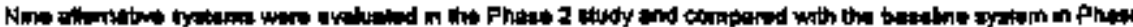

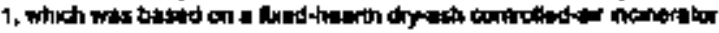

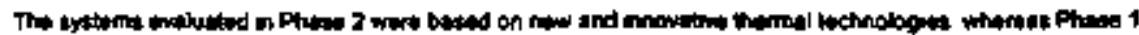

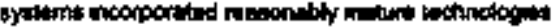

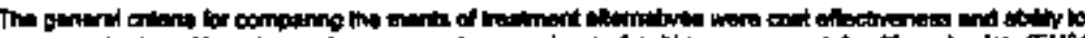

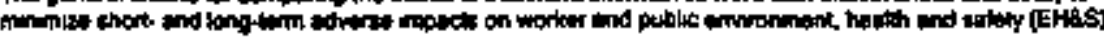

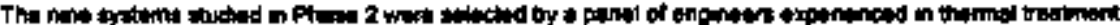

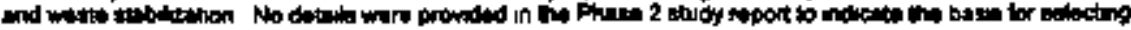
the iptains atuded

$\begin{array}{llllllllll}10140 & 14 & \text { I } & \text { I } & \text { B I } & 1 & 1 & \mid & 1 & 1 \\ 12140 & 1.5 & 1 & 1 & 1 & 1 & 1 & 1 & 1 & 1\end{array}$

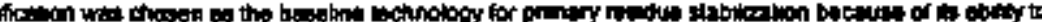

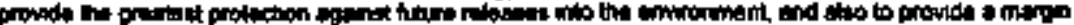

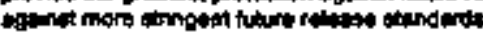

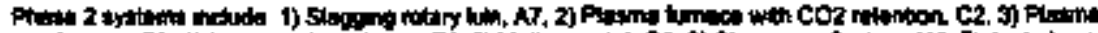

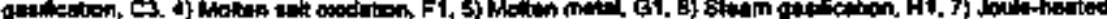

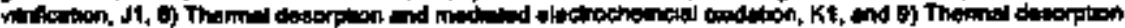
and muperchites waw obdetion, Lt

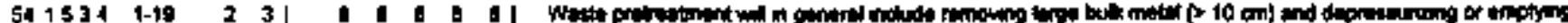

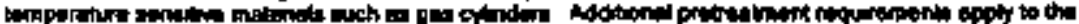

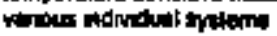

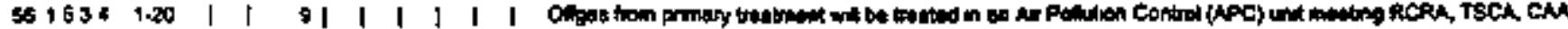

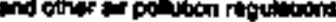

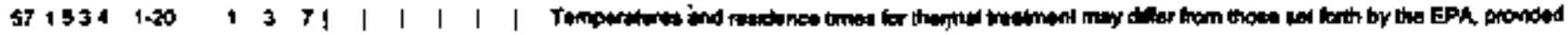




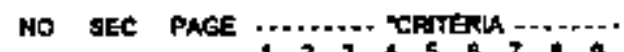

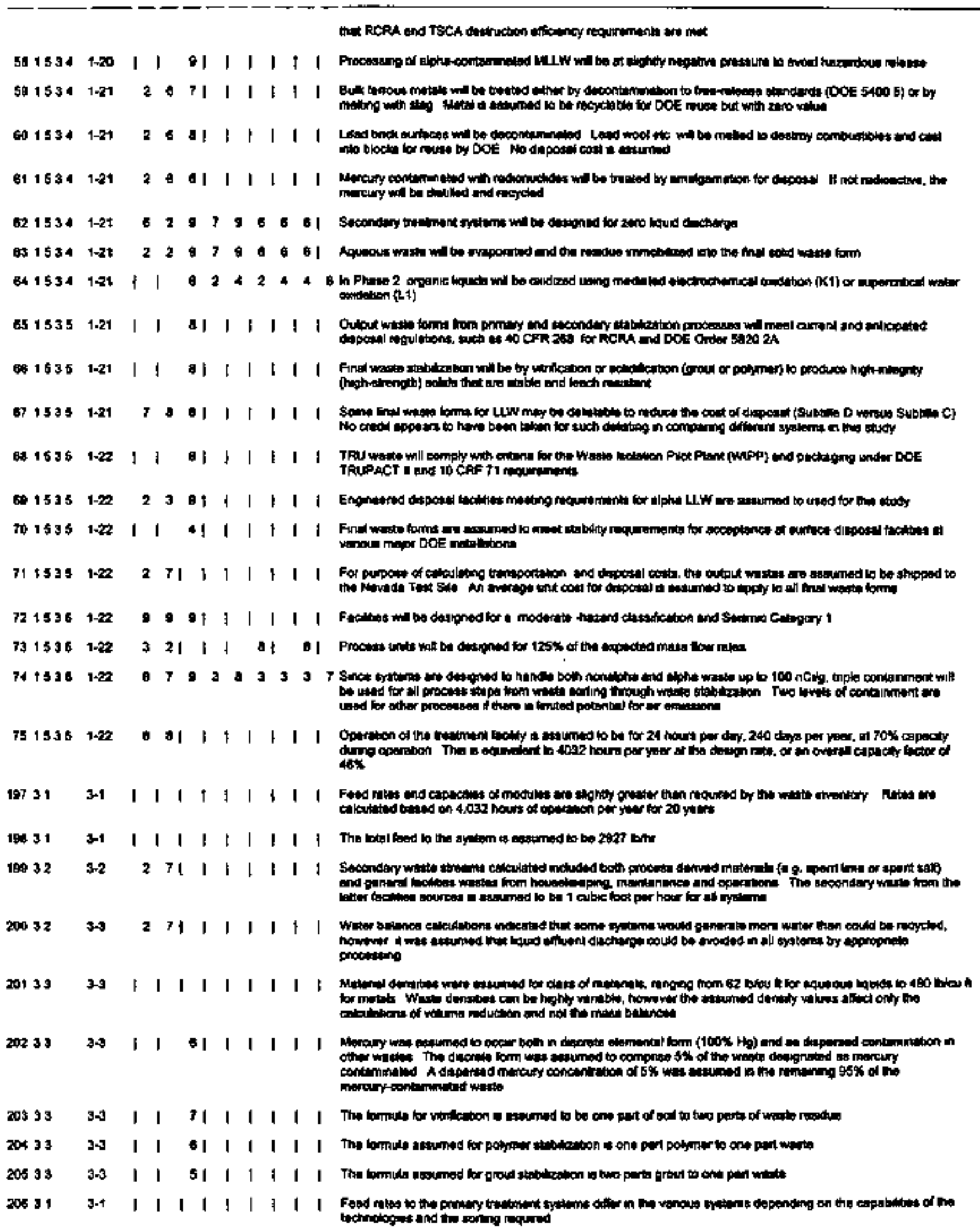




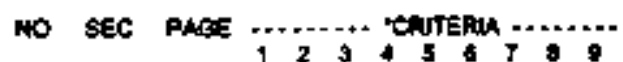

NSSUMPTONS ON OESGN FEATURES

- - - - - - - - - -

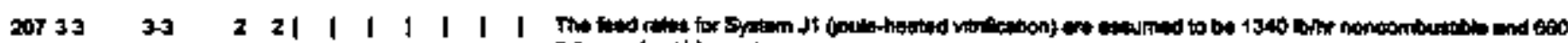
Panr combunable wate

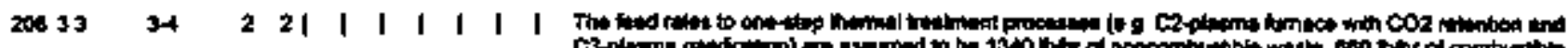

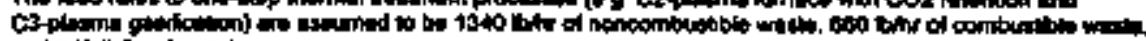
cold 149 tht of mot

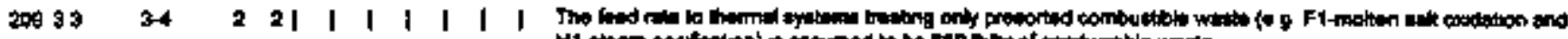

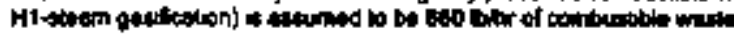

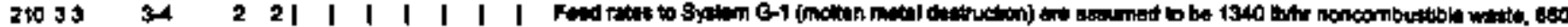

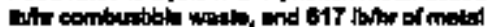

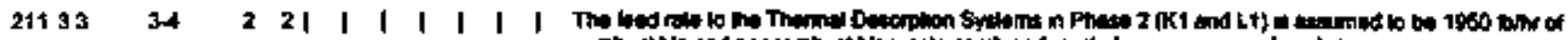

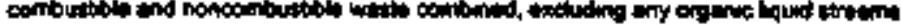

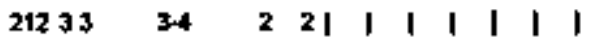

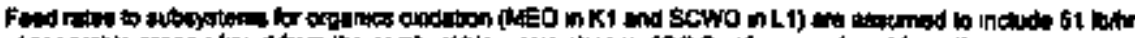

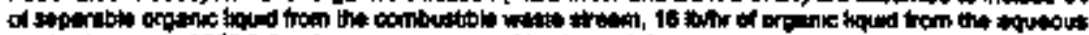

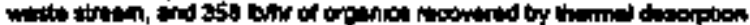
213 3 $34 \quad 2$ a 5 |

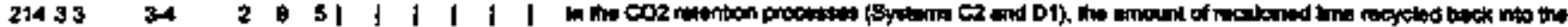

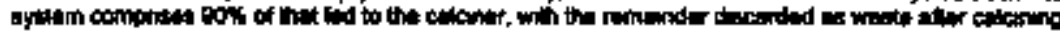

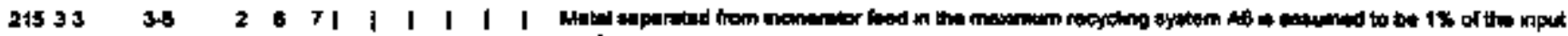

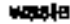

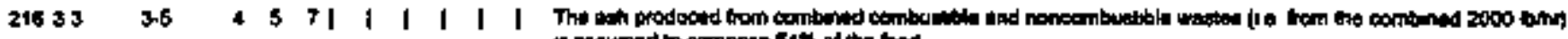

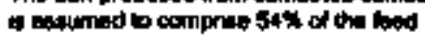

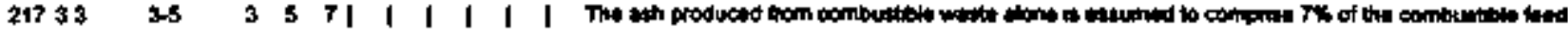

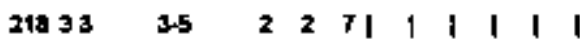

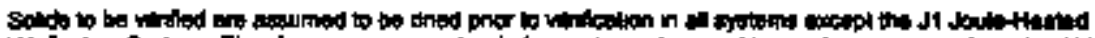

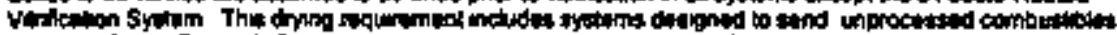

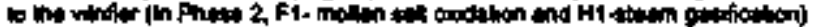

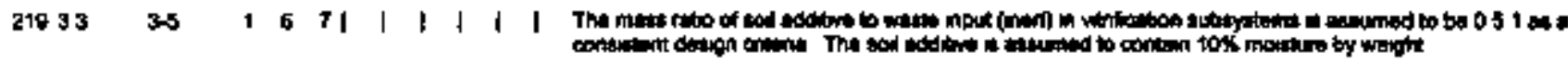

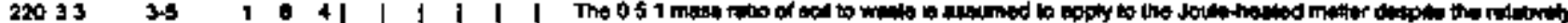

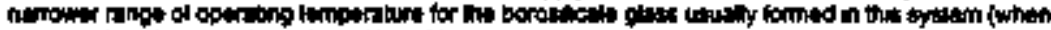

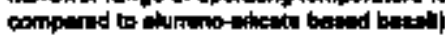

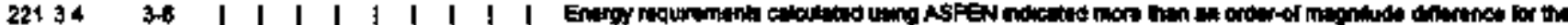

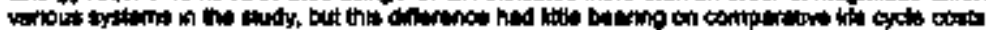

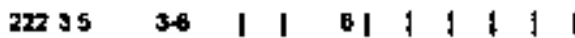

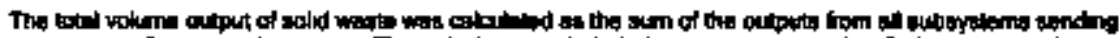

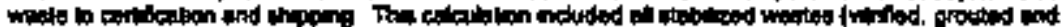

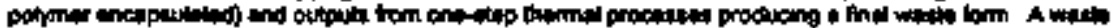

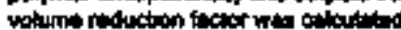

$223353.5141|1| 1 \mid$

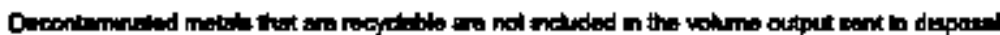

22436 35 I I 7 I

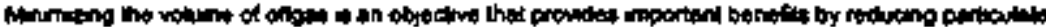

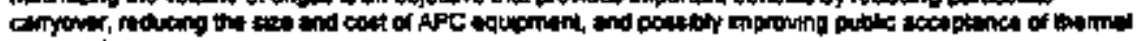

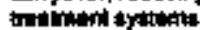

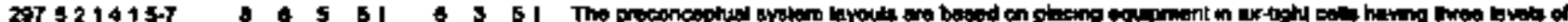

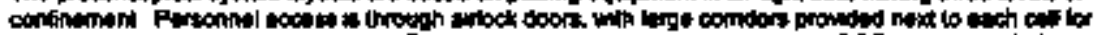

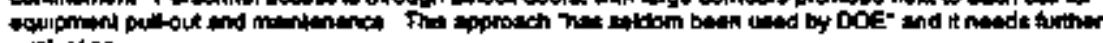
eraten

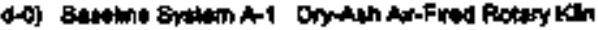

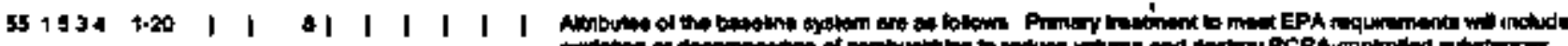

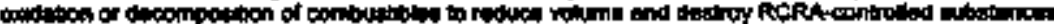

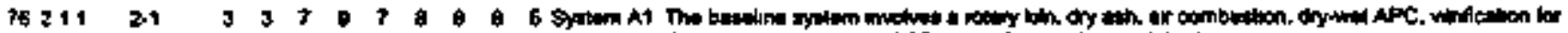

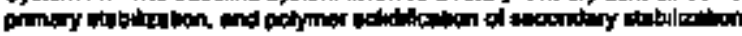

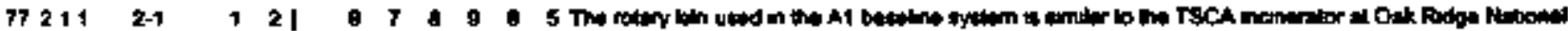
Ladory (ORNA)

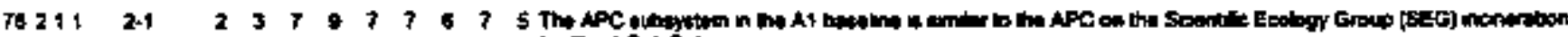

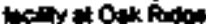

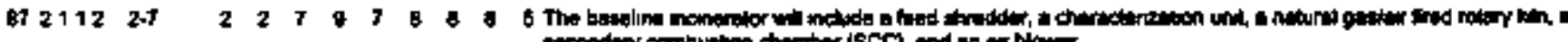

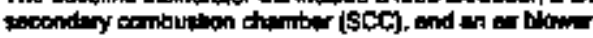

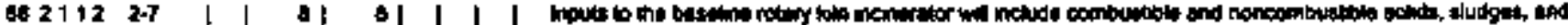

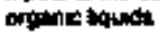




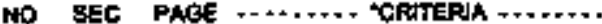

$123+56780$

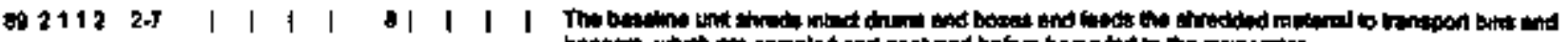

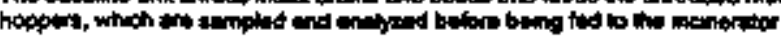

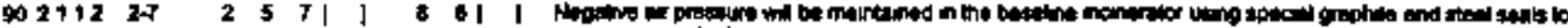

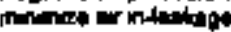

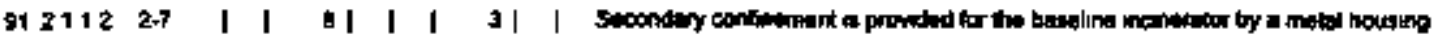

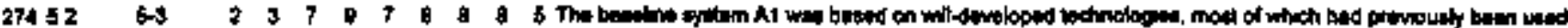

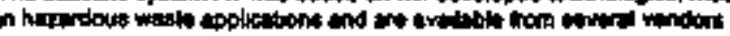

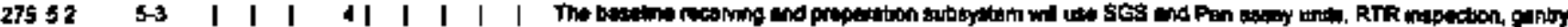

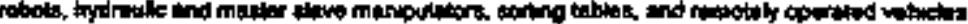

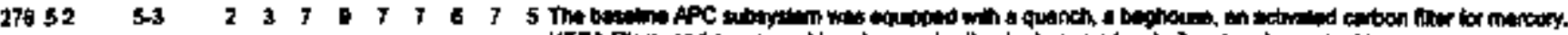

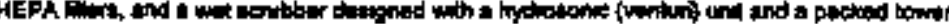

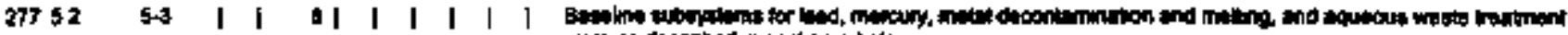

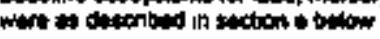

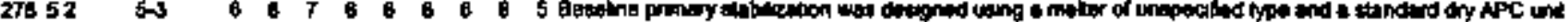

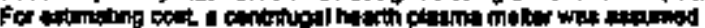

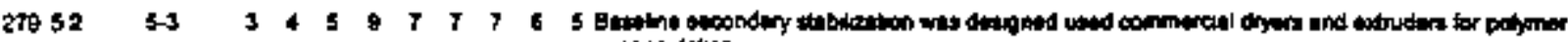
onctiofution

d.1) Slagging Rotary Kn A-T

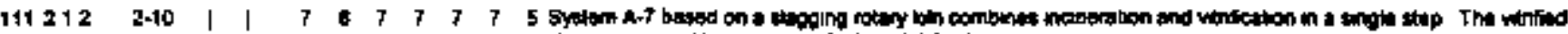

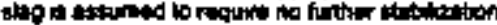

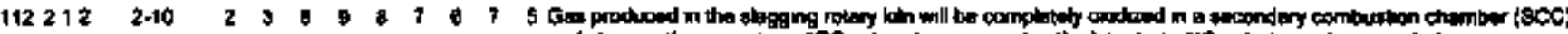

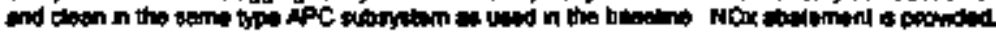

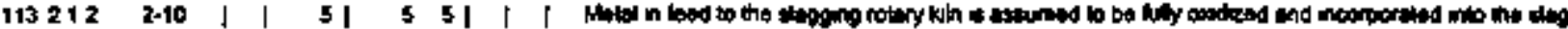

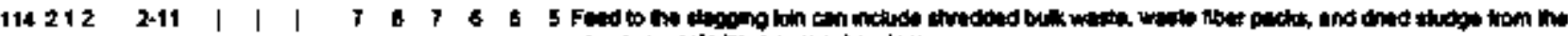

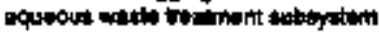

115212 2-11 | |

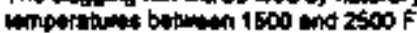

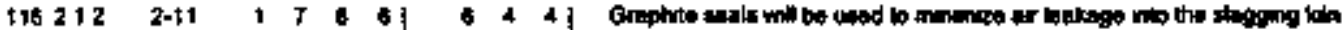

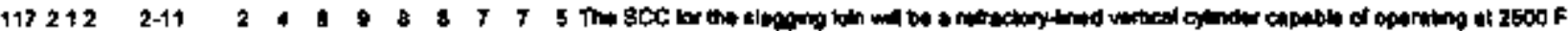

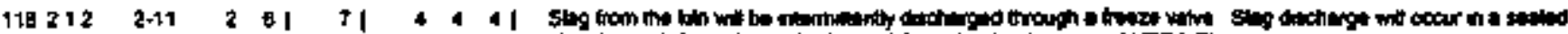

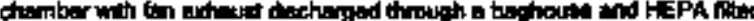

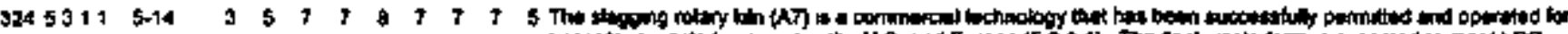

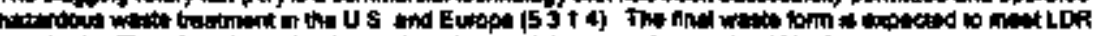

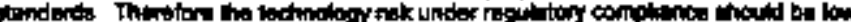

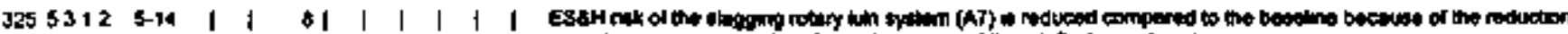

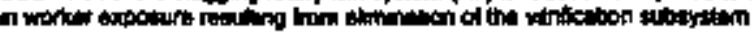

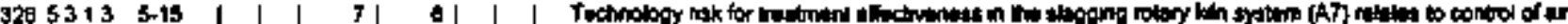

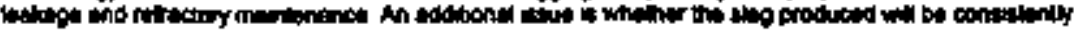

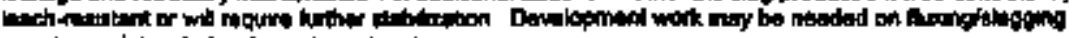

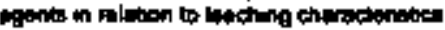

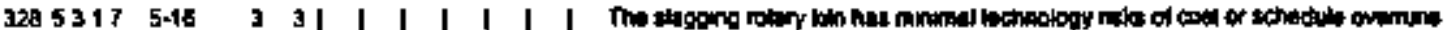

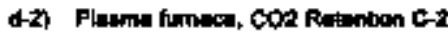

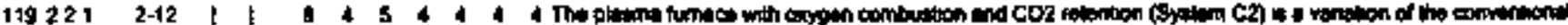

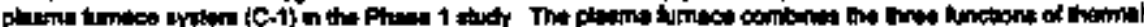

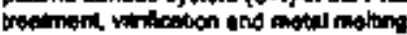

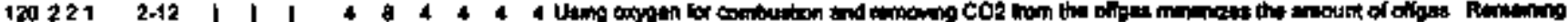

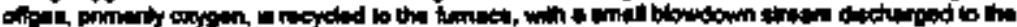
inosphere

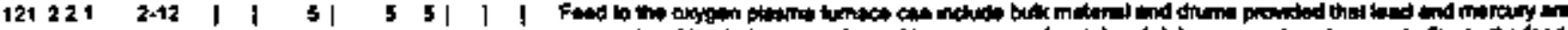

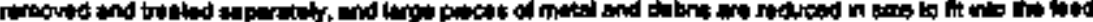
tythen

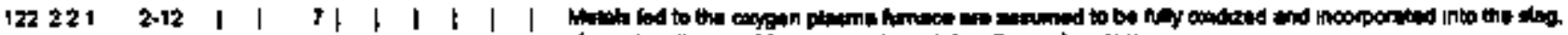

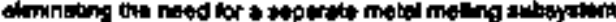

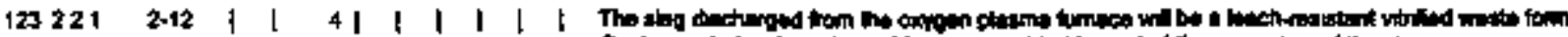

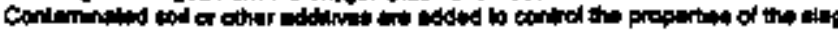


NO SEC PACE ......... "CRITERIA ........

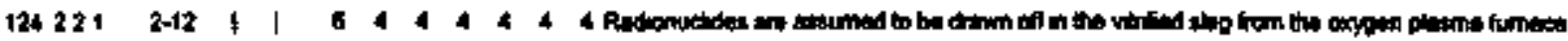

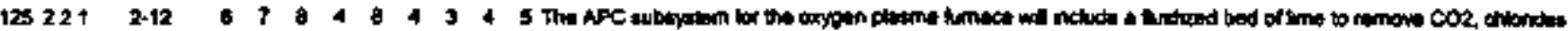

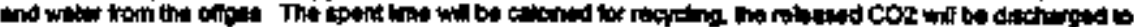
the wornosphere

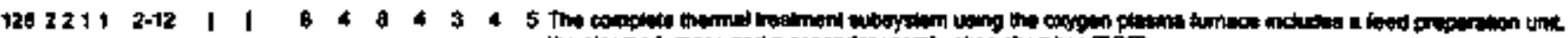

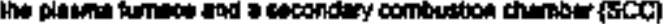

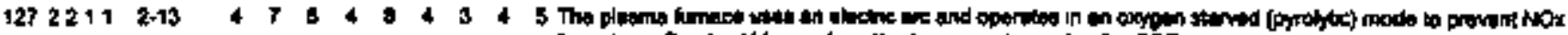

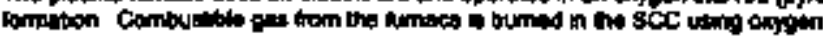

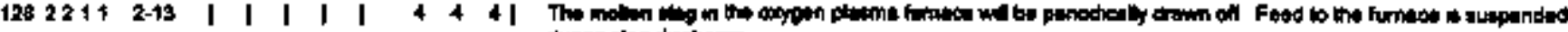

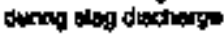

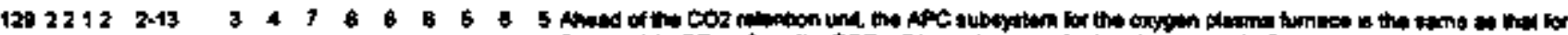

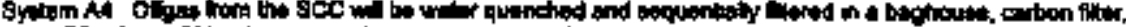

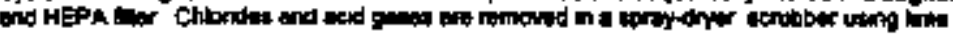

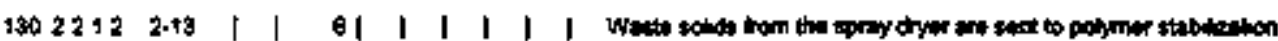

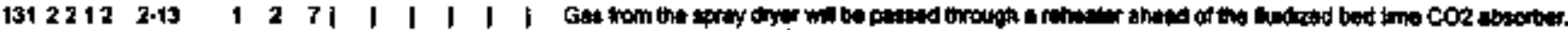
which doperatiod an $650 \mathrm{C}$.

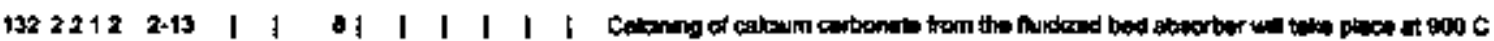

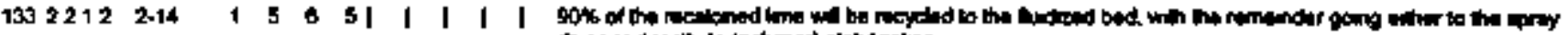

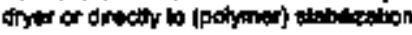

5342212 2-13 2 2 3 S

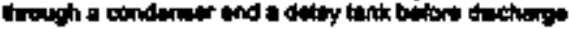

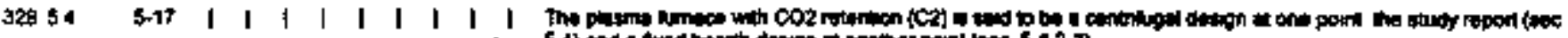

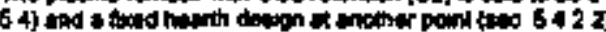

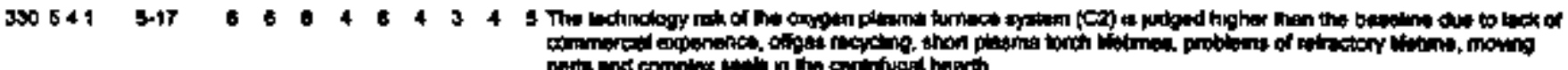

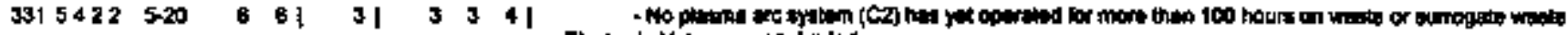

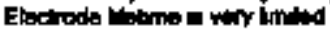

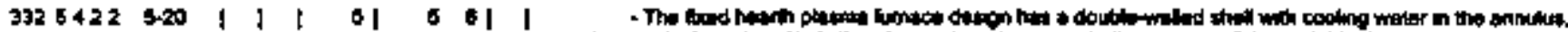

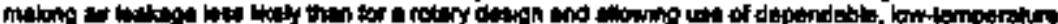
mationata

$39554115-17$ i 1 : | | | | | |

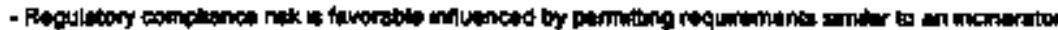

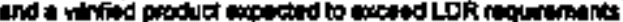

$33454125-17|| 5||||||$

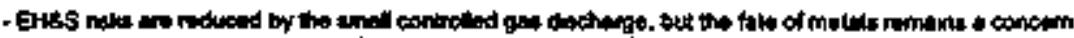

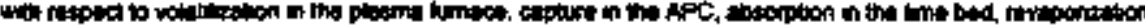

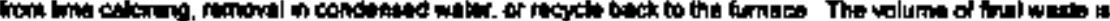
matomed

\begin{tabular}{|c|c|c|c|c|c|c|c|c|}
\hline 3956493 & 5-10 & ] & 1 & | & 31 & 31 & 41 & 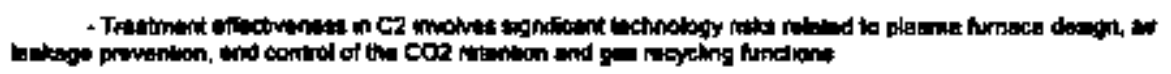 \\
\hline 3365414 & S-10 & 6 & $\theta$ & 1 & 31 & 31 & 41 & 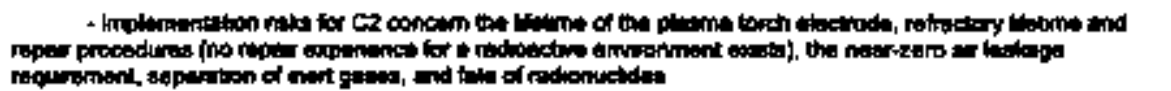 \\
\hline 3375415 & 54 & I & $\mathbf{I}$ & 31 & I I & 11 & $\mathbf{I}$ & 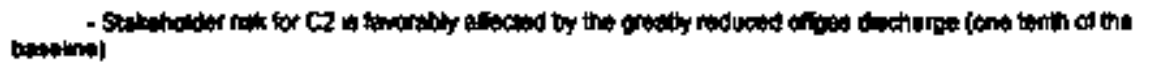 \\
\hline $930 \$ 410$ & 5-10 & B & $\theta$ & 1 & I & I I & b & 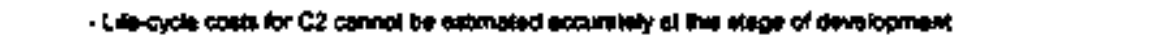 \\
\hline 3495417 & $6-10$ & 8 & & 1 & $\mathbf{I}$ & I I & I & 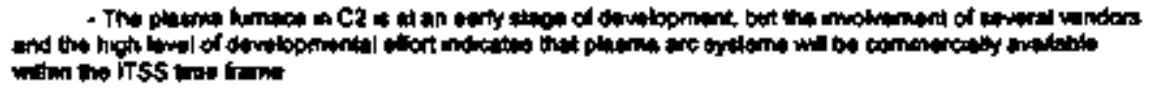 \\
\hline 3405117 & $5-10$ & I & 1 & 1 & I & I I & 1 & 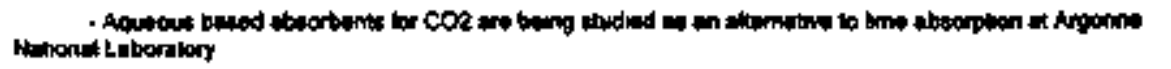 \\
\hline 3415421 & $5-19$ & I & I & I & 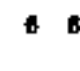 & 86 & 141 & 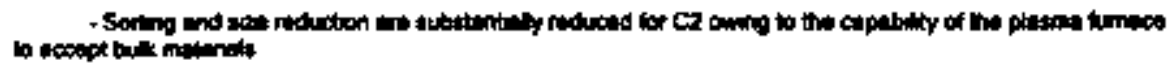 \\
\hline 185423 & $5-20$ & 1 & 1 & 4 & 21 & 21 & I & 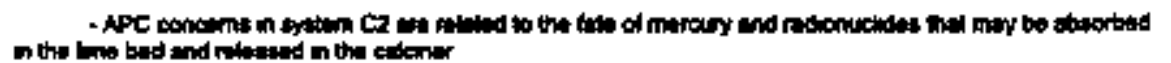 \\
\hline
\end{tabular}

d-3) Phand Gentration C-3

135222 2-14 1 | 

pisim

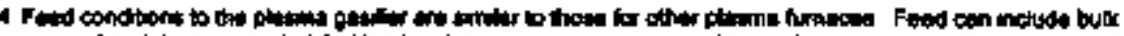

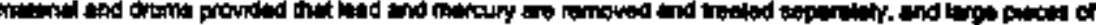

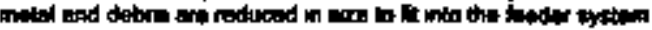

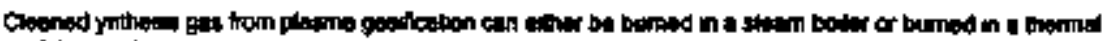
ordawon init

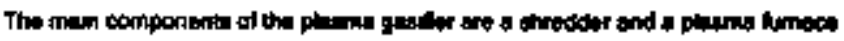

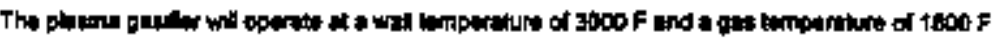

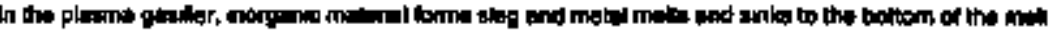

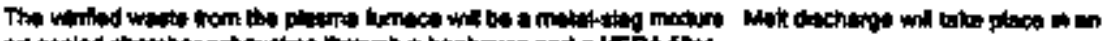

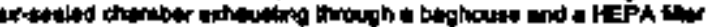

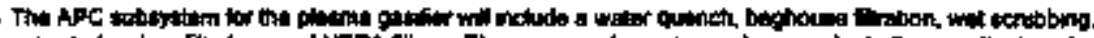

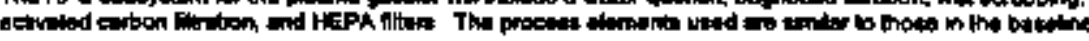

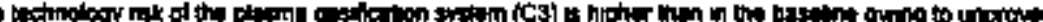

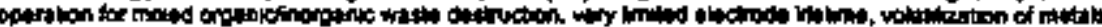

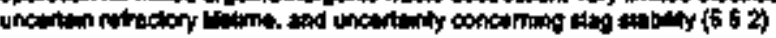

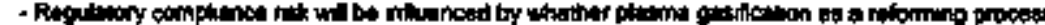

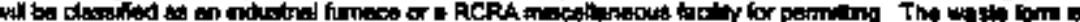

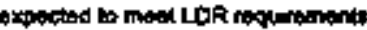

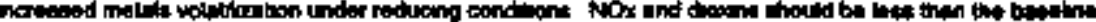

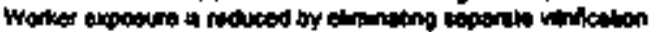

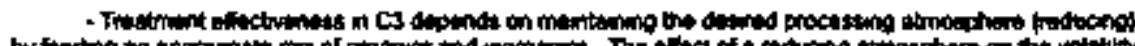

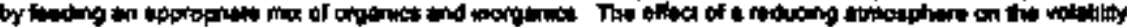

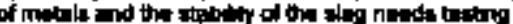

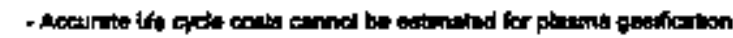

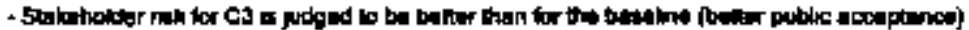

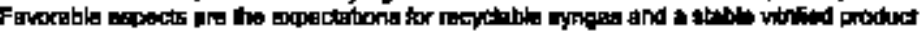

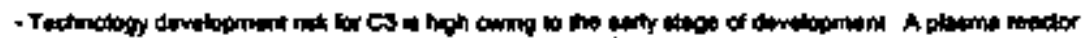

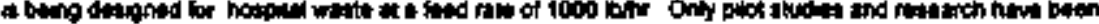

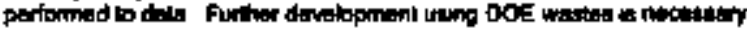

d-4) Hower Sel Orodition $F+1$

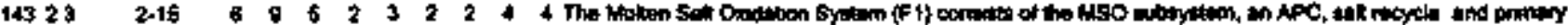

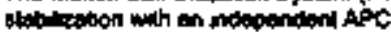

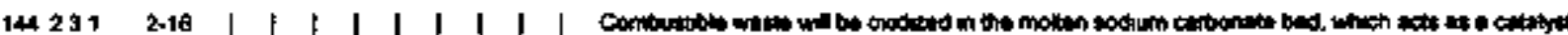

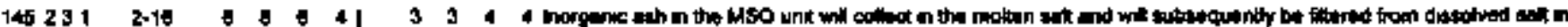

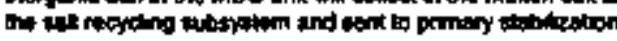

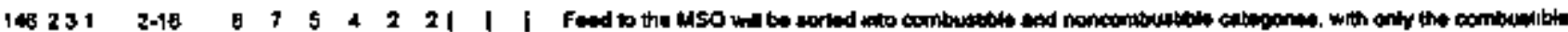
gong to the inso unt

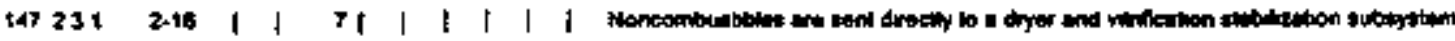

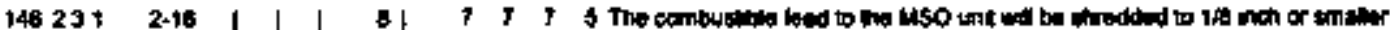

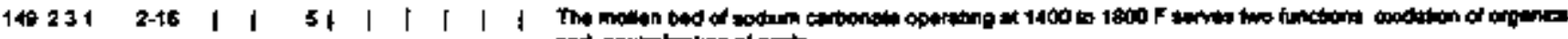

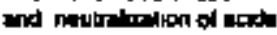

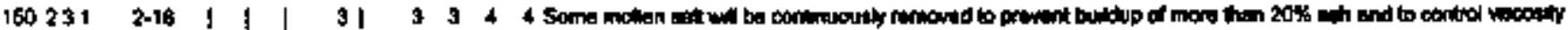

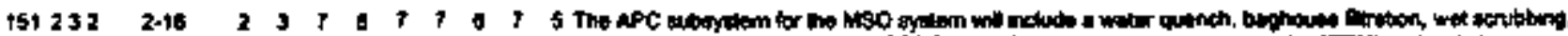

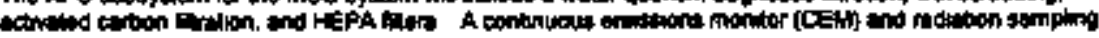

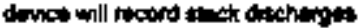

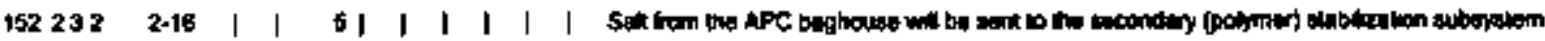

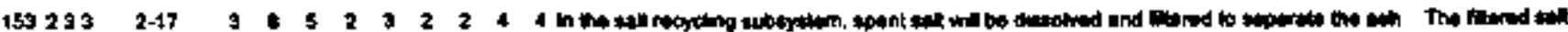

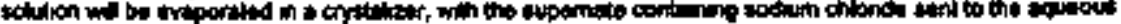

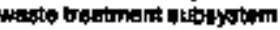

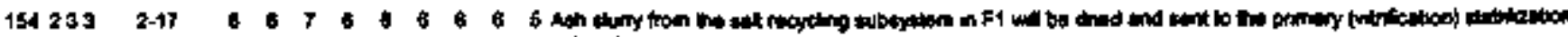
totytyotion

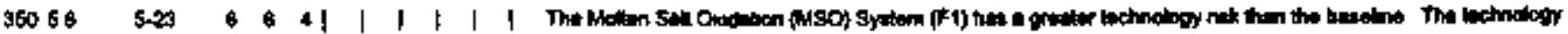




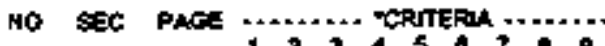

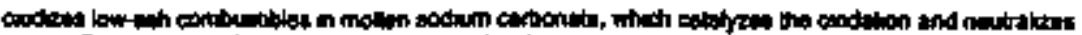

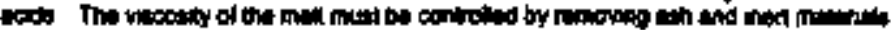

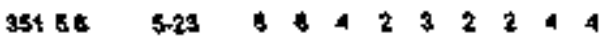

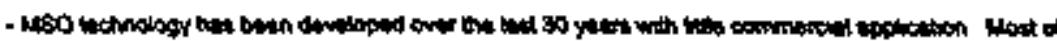

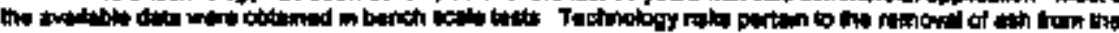

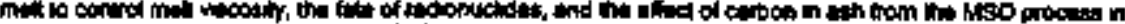

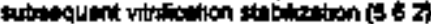

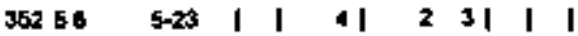

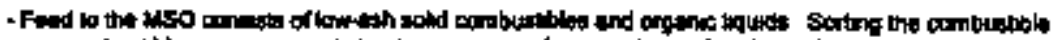

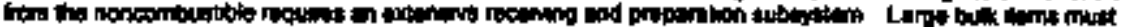

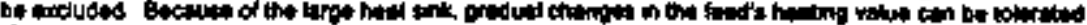
$156 \mathrm{~A}$

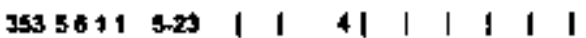

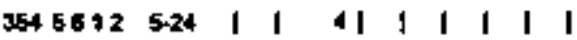

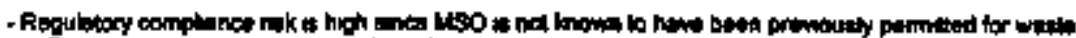

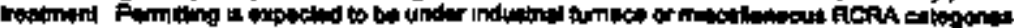

- EHAs nita t

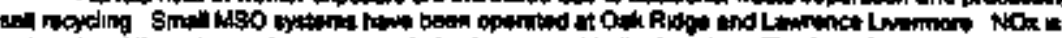

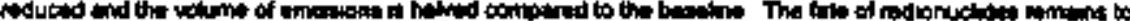
Berentutend

$35556135-246 \div 42221 \mid$

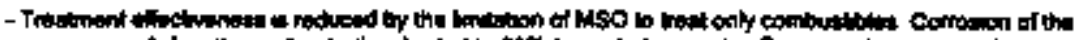

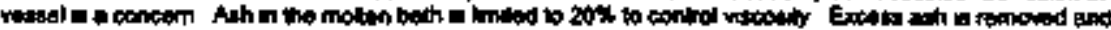

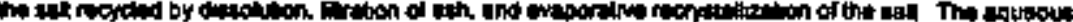

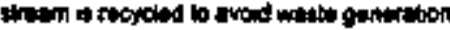

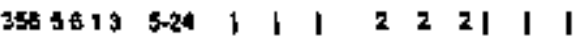

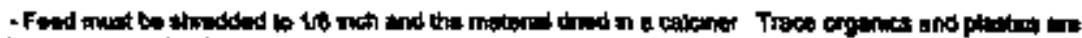

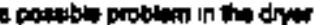

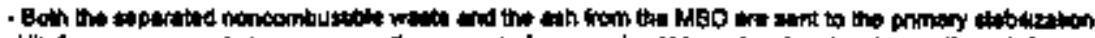
$3575195-25 \mid$ I 454 | I I

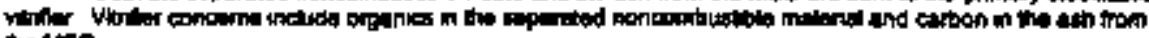
the Has

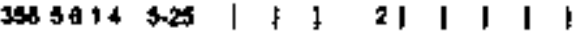

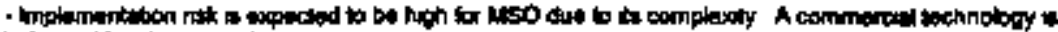

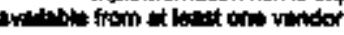

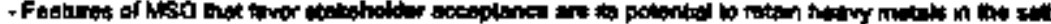

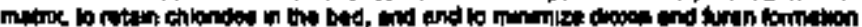

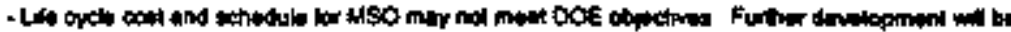

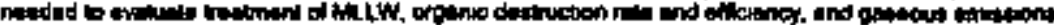

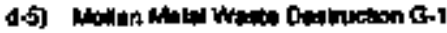

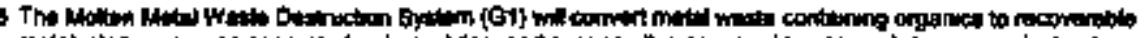

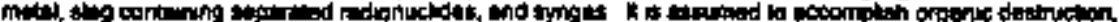

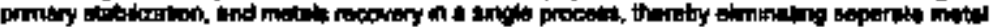

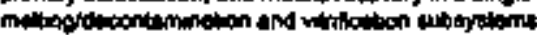

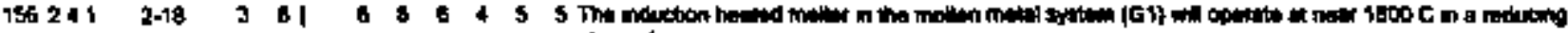
unowatern

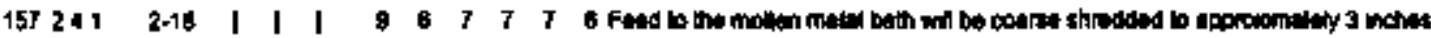

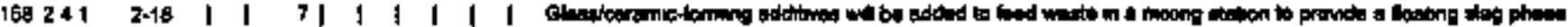

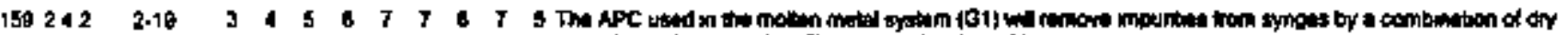

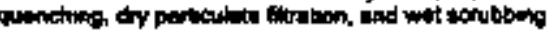

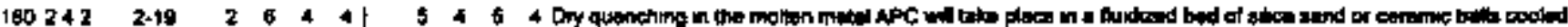

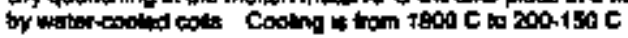

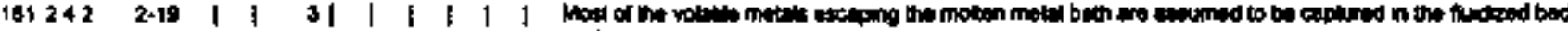
colont

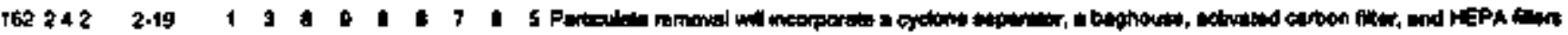

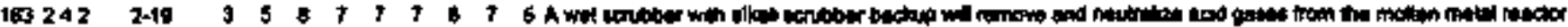

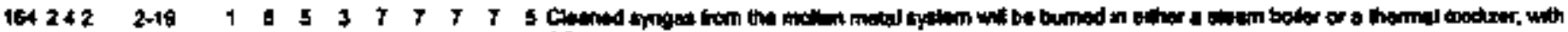

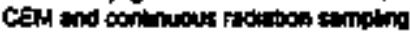

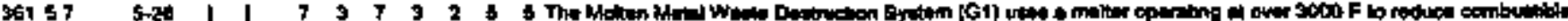

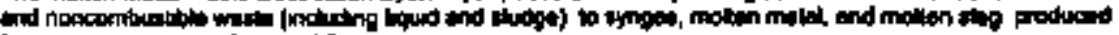

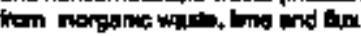

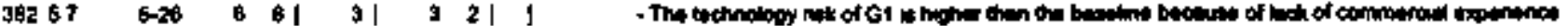

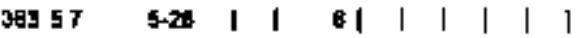

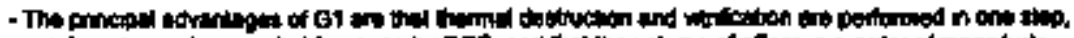

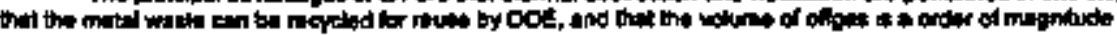

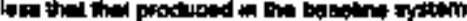

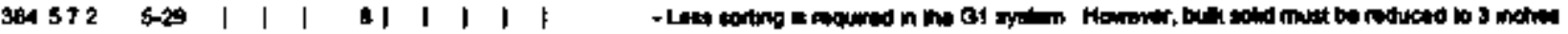




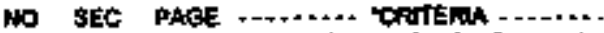

3855726206131321

385725.296 a 5 3

$\begin{array}{lllllllllll}30757 & 511 & 5.27 & \mid & \mid & 71 & 1 & \mid & \uparrow & \mid & 1\end{array}$

$3057125-27 \quad|\quad 7|$

$\operatorname{seg} 57125-27 \quad 1 \quad 1 \quad 7 / \quad 5 \quad 1 \quad 1 \quad 1$

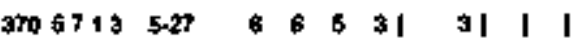

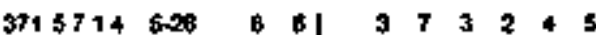

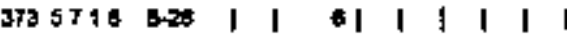

$37457175-28 * 11|1| 1 \mid$

$3757185.24 \mid$\begin{tabular}{lllll|}
$\mid$ & 3 & 3
\end{tabular}

d-6) Slam Gasiteabon H-1

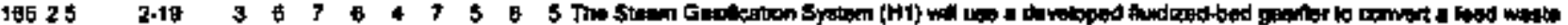

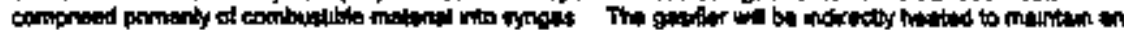

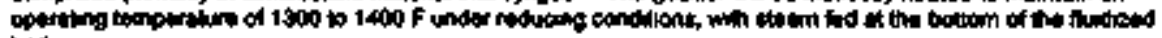
bets

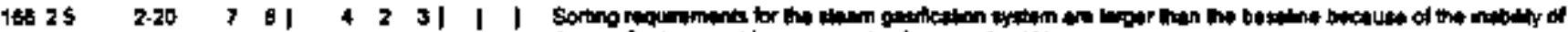

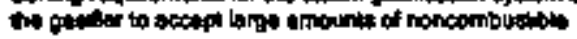

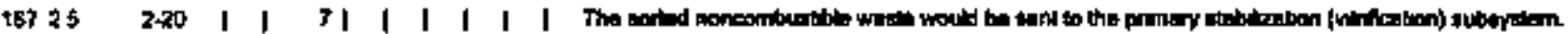

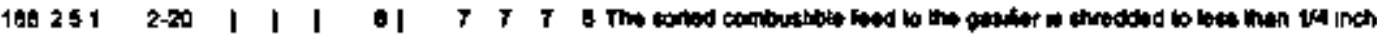

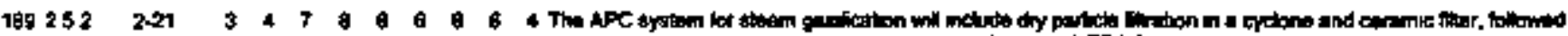

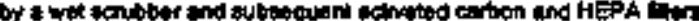

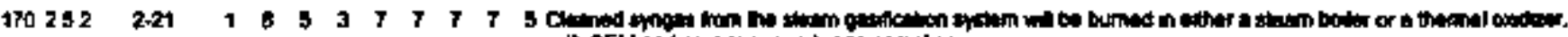

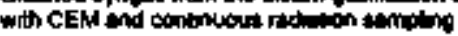

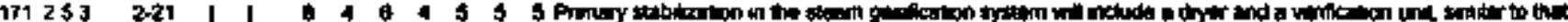

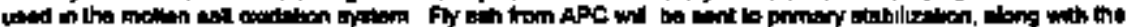

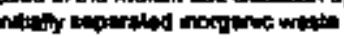

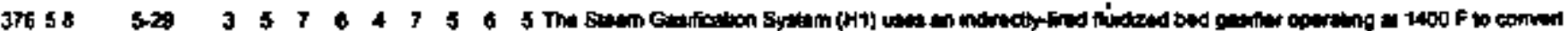

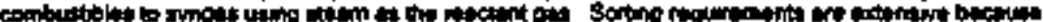

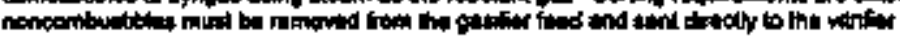

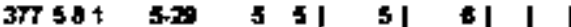

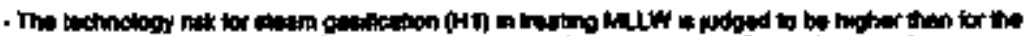

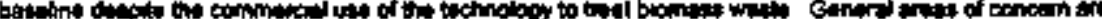

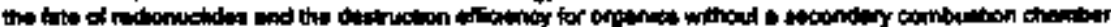

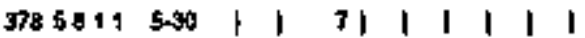

$3785012530 \quad 1 \quad 151 \quad 1 \quad 1 \quad \mid$ ingatione

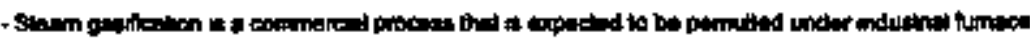

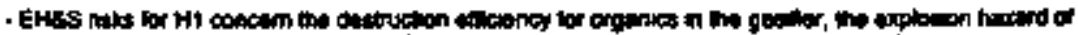

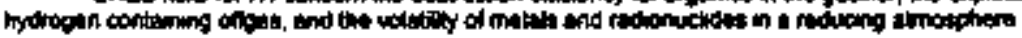

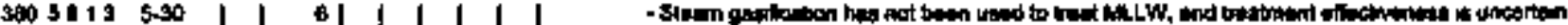

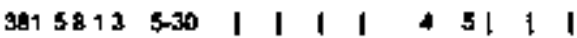

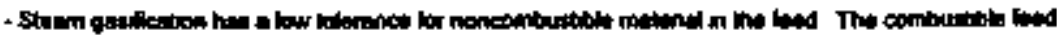


MO SEC PASE +......... TritERA ........

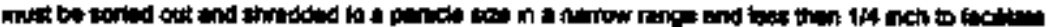

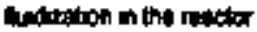

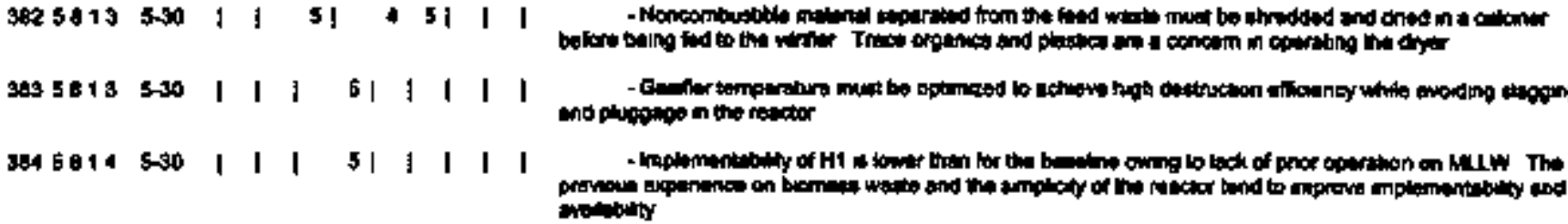

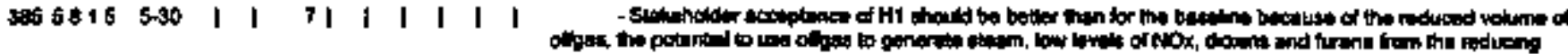

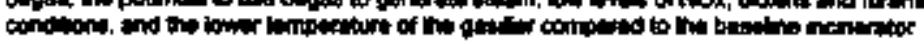

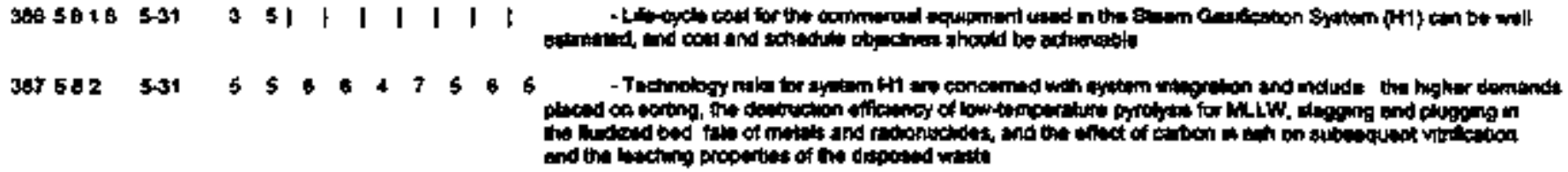

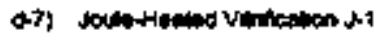

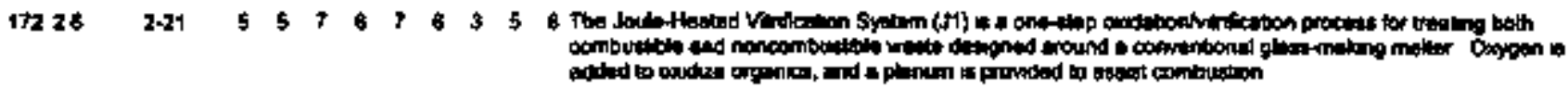

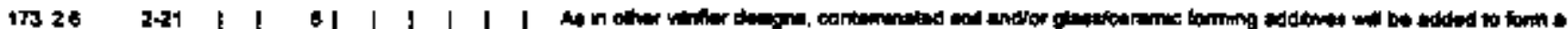

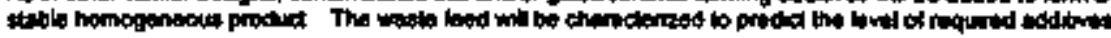

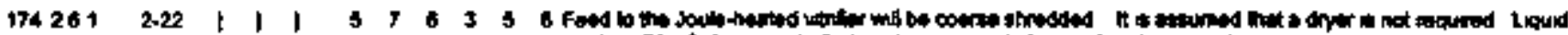

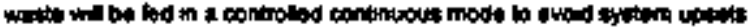

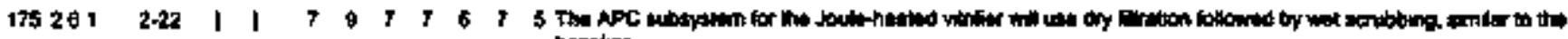
bosaina

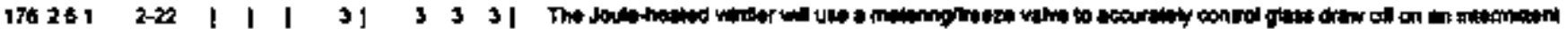
batat

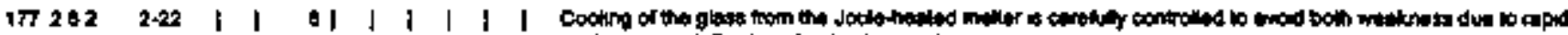

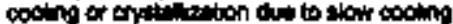

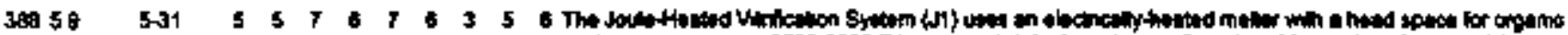

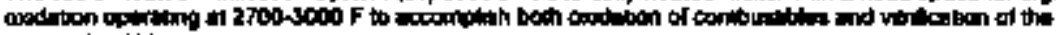
noncermbutatela wo:te

3059115039 | 16 |

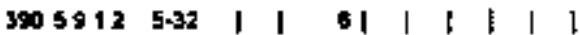

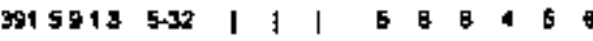

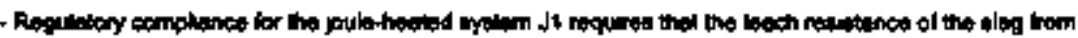

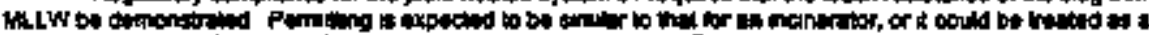

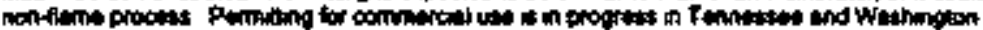

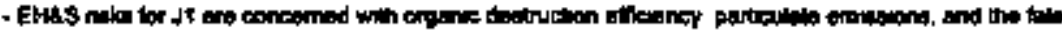

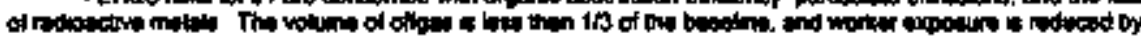

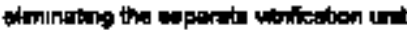

\begin{tabular}{|c|c|c|c|c|c|c|c|}
\hline 3925913 & $\$ \$ 2$ & I & I & $1 \mathrm{~J}$ & I & 5 & 31 \\
\hline 3905913 & 5032 & I & \lceil & 1 & 71 & I & I \\
\hline 3045614 & 5-32 & 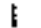 & I & I & I & 4 & 31 \\
\hline 3056014 & $5 \cdot 33$ & I & I & I & 1 & I & I \\
\hline 3965015 & $5-30$ & | & I & 71 & I & 1 & 1 \\
\hline 3975016 & $5-33$ & 4 & & 311 & | & I & i \\
\hline 304517 & $5-33$ & & & & & & \\
\hline
\end{tabular}

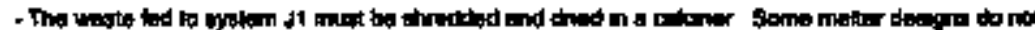

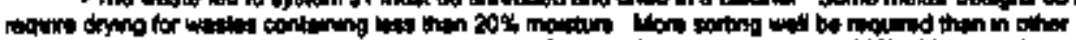

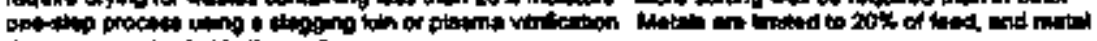

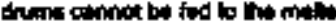

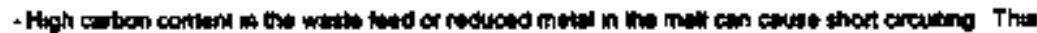

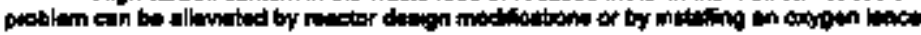

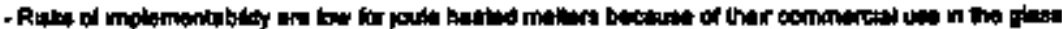

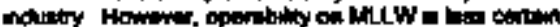

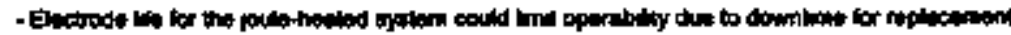

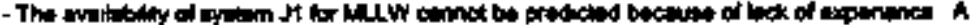

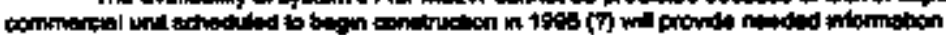

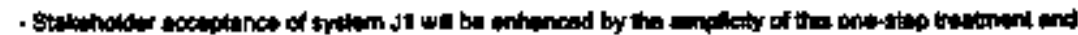

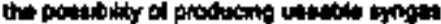

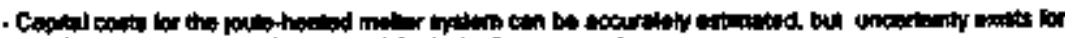

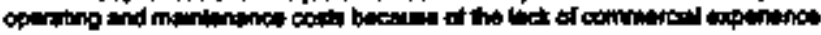

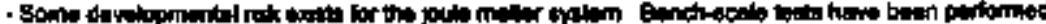

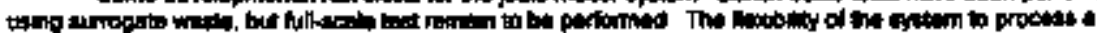

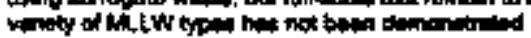




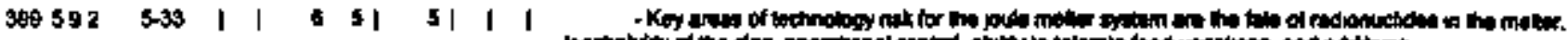

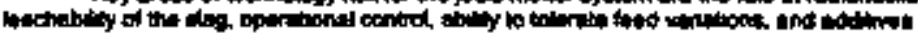

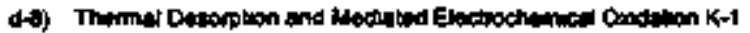

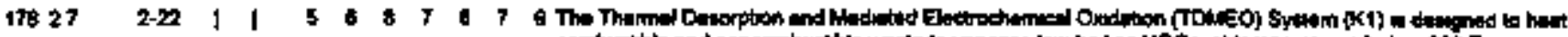

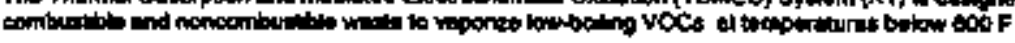

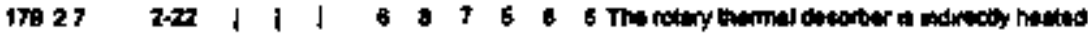

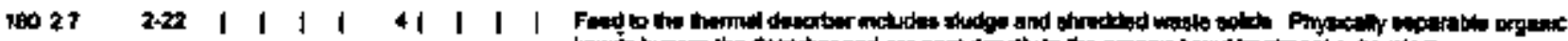

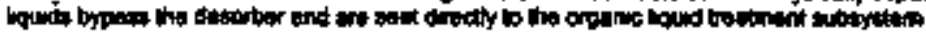

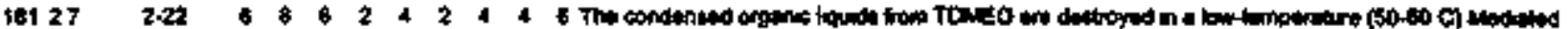

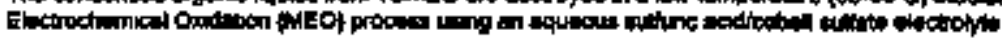

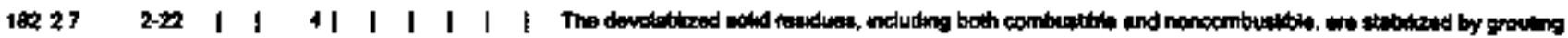

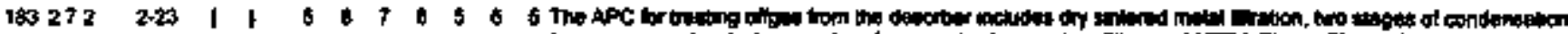

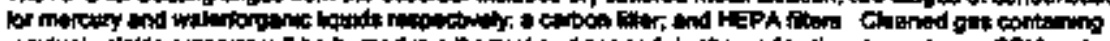

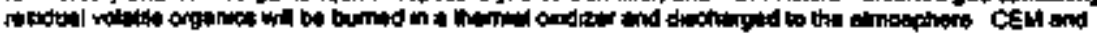

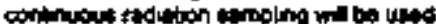

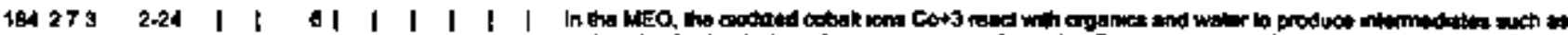

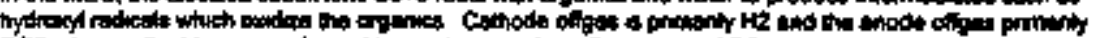

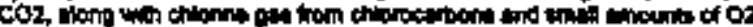

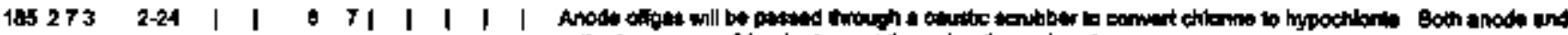

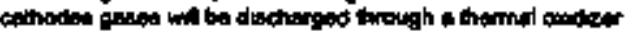

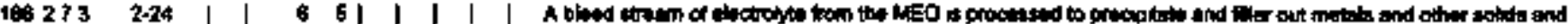

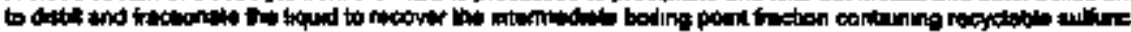
and

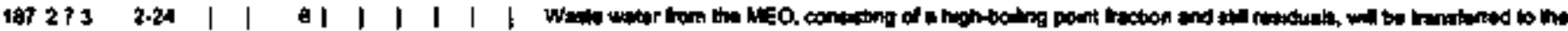

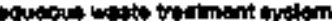

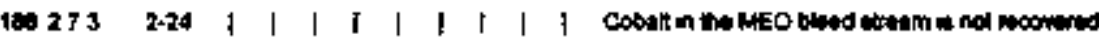

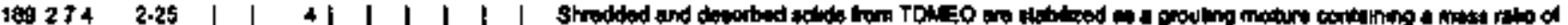

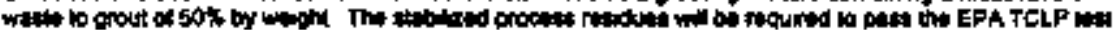

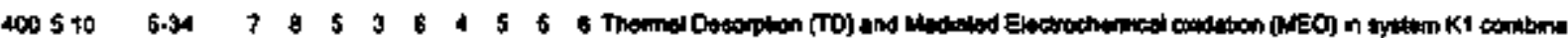

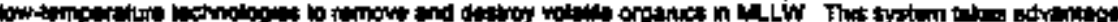

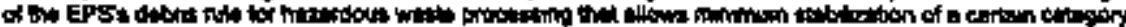
antw worto

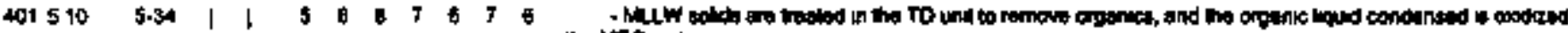
in thin NiteO on

$\begin{array}{llllllllll}402510 & 5-34 & \mid & \mid & 4 ! & \mid & \mid & \mid & \mid & \mid \\ 4035101 & 6 & 54 & 7 & 7 & 3 & 3 & 5 ! & \mid\end{array}$

$40451011534|+4|$ I I I I

$405510125-36 \quad \mid \quad 71-1 / 1 / 1$

$406 \$ 1013 \$-36$ | $|\$ 3| \$ 1 \mid$

$40751021536|154| 4||$

$40510215-30|154|$

$40950 \% 455+7|3| 1|1|$

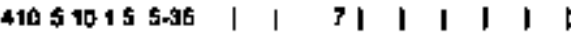

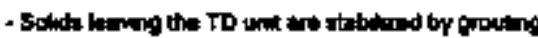

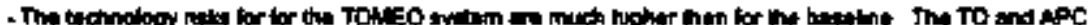

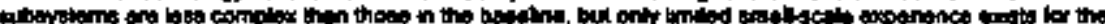

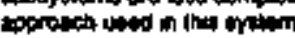

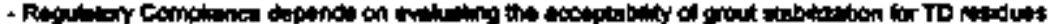

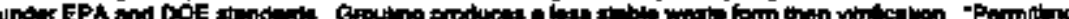

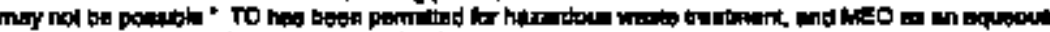

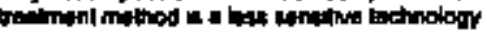

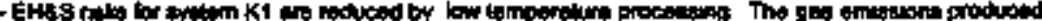
ot in $\mathrm{Hz}$ oflom.

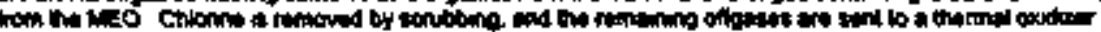

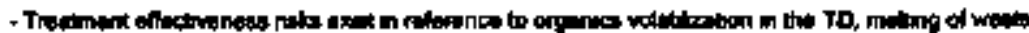

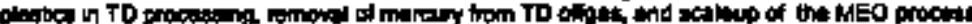

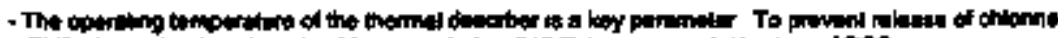

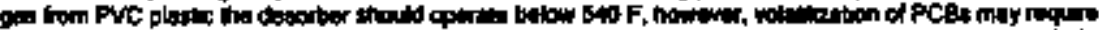

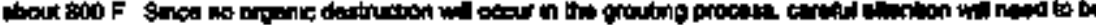

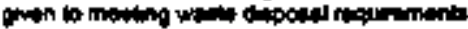

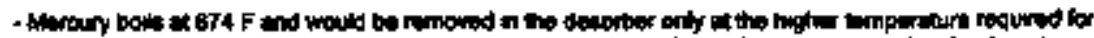

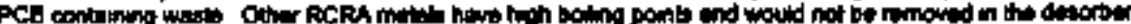

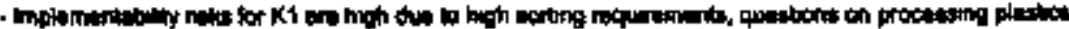

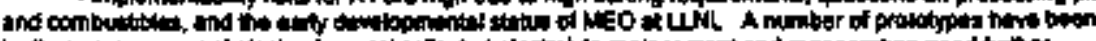

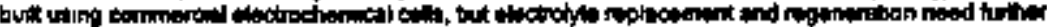
dervelopment is 1022

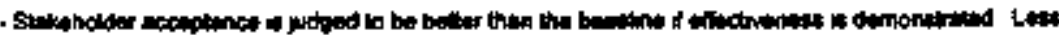



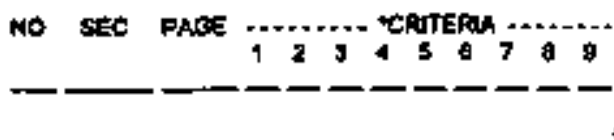

$41510165.36 \quad 77$ I I I I I I

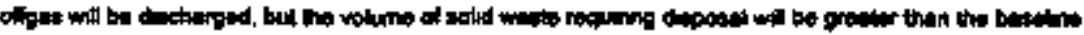

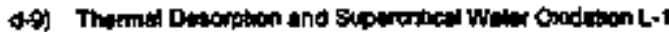

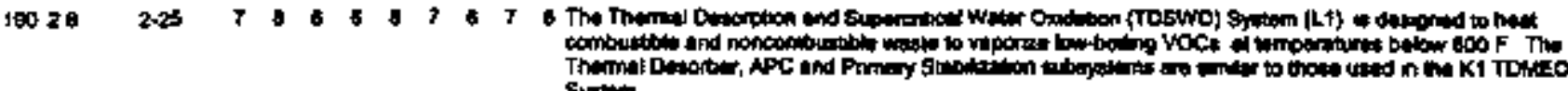
Syath

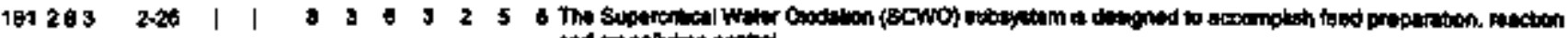
and al polution mantol

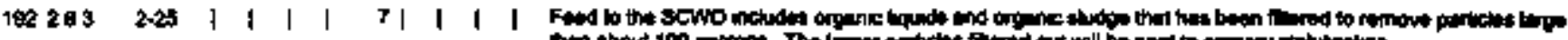

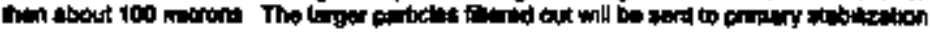

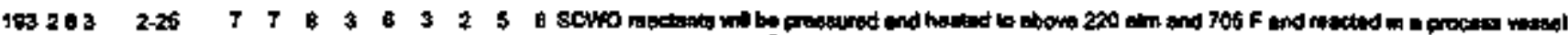

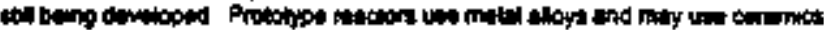

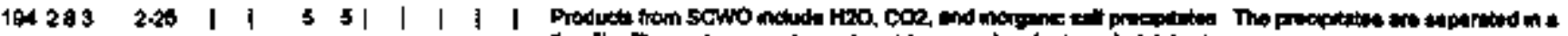

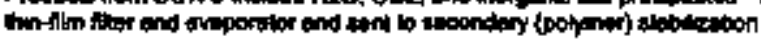

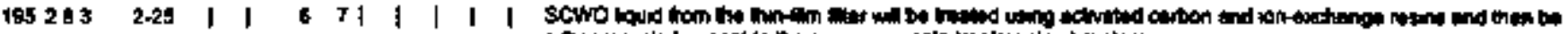

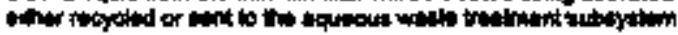

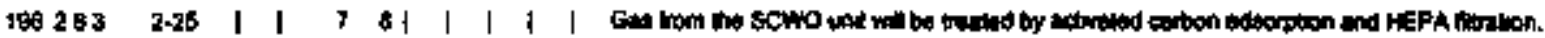

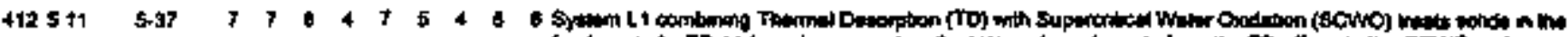

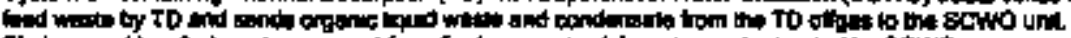

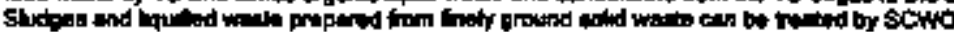

$413511153077|3154|$

$\$ 1451111598$ | 14||||||

$415511125-39 \quad|\quad| 6||||||$

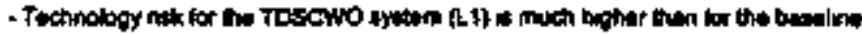

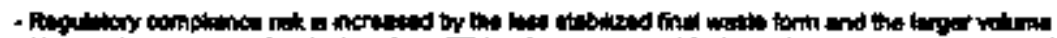

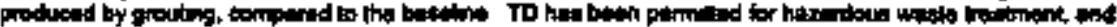

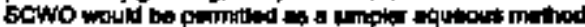

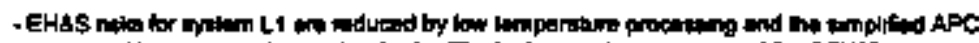

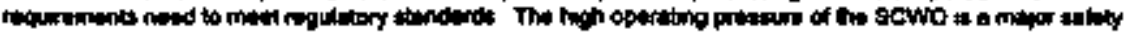
-

$45511135-39$ I $11|1| 1 \mid$

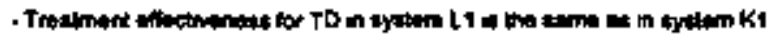

$417511495-39$ | I 7 a 5325

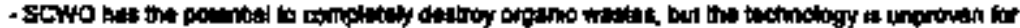

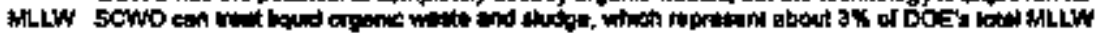

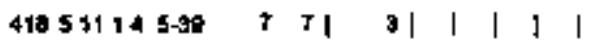

$419+11225-10+742 \mid 9131$

$420511955-39$ | I 7 | | | | | |

$421519+65-30 \quad 7 \quad 7|\quad| \quad|\quad| \quad \mid$

$4225112254077 \mid 367271$

-1) Rectoving and Properpon

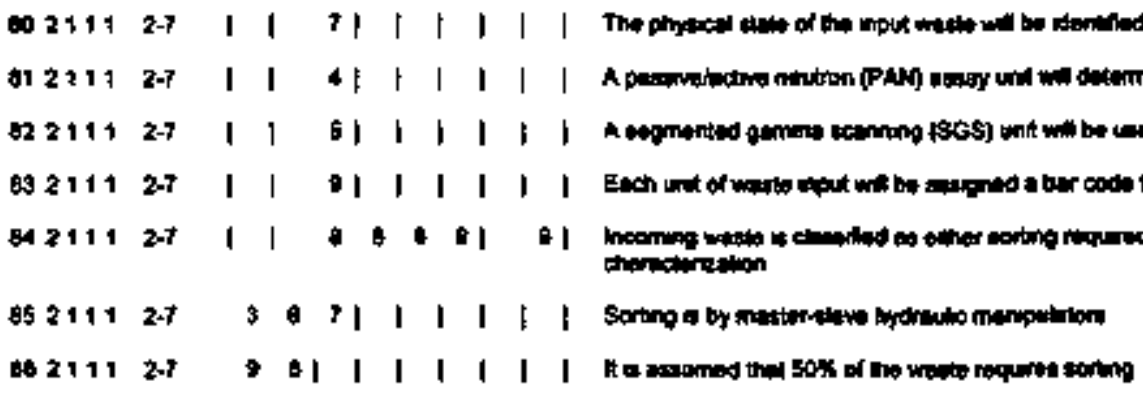

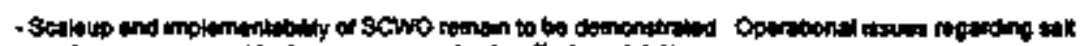

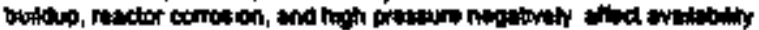

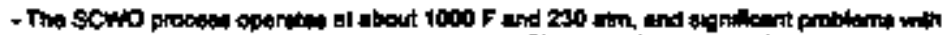

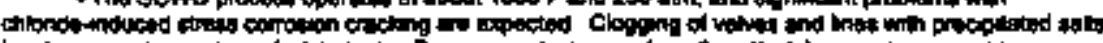

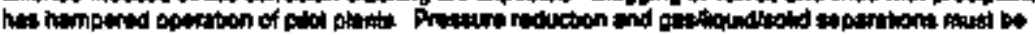
optentad

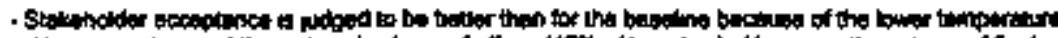

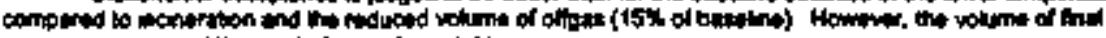

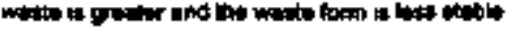

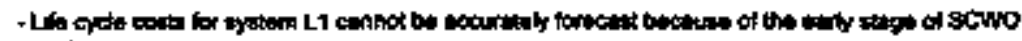
dowlopinent

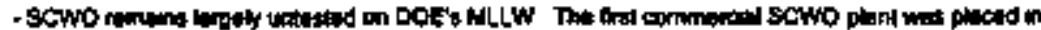

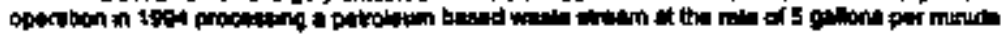


NO SEC PAEE -....... TCRITERH +.+2++4

123456700

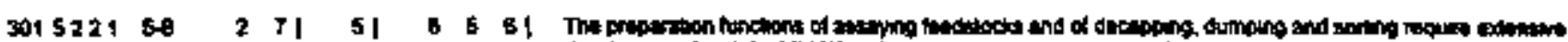

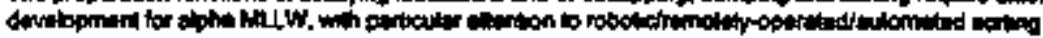

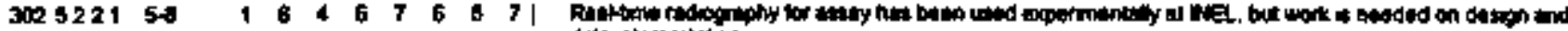

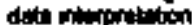

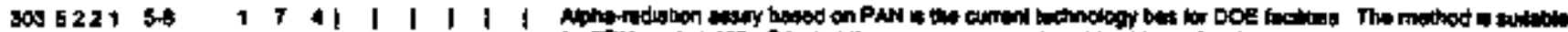

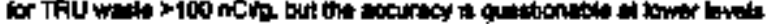

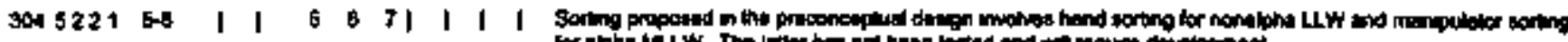

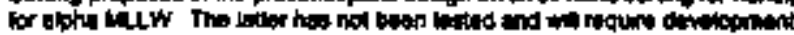

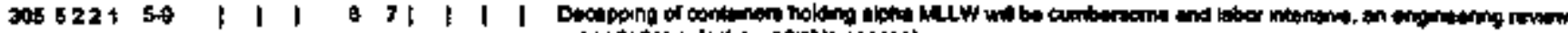

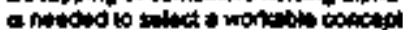

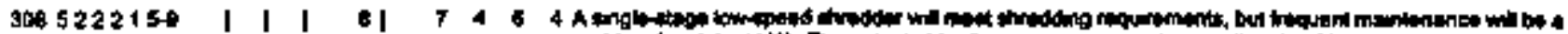

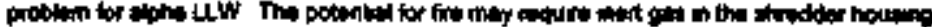

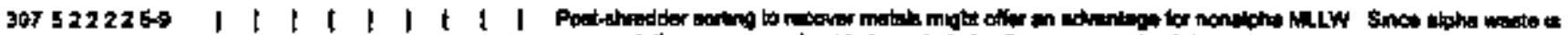

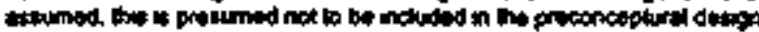

4.2) Phmery Treininand

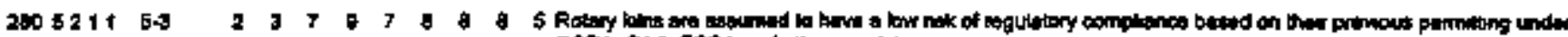
RCRA, CAA, TSCA and oingr nouletion:

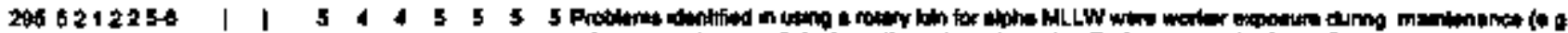

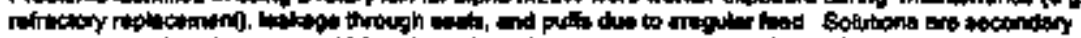

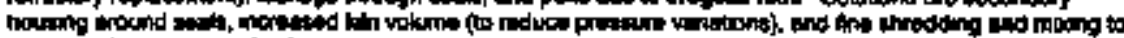

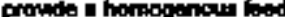

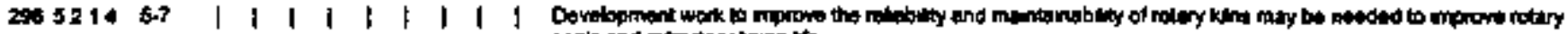

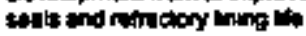

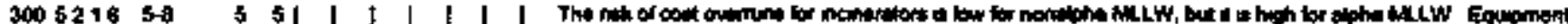

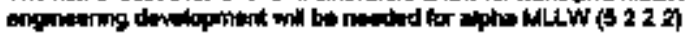

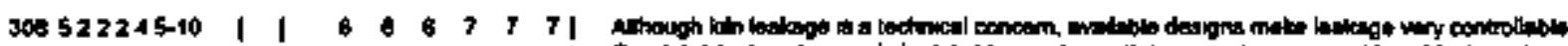

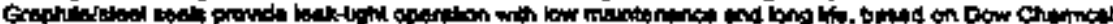
Corp enpenonces

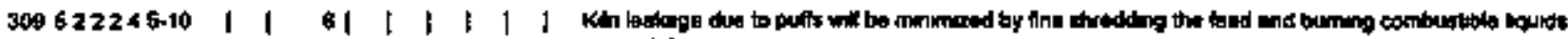
Ioparabity

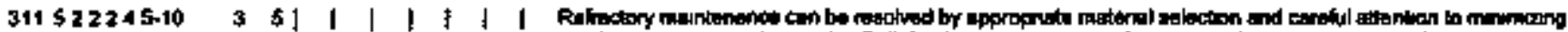

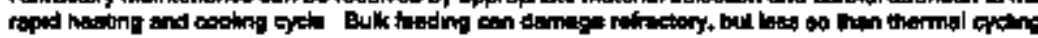

e-3) Ar Pribon Contol

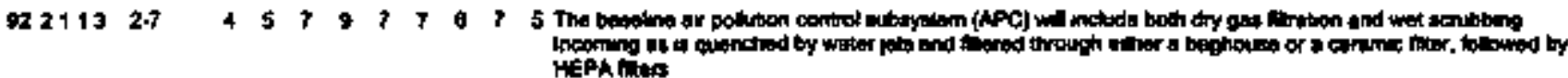

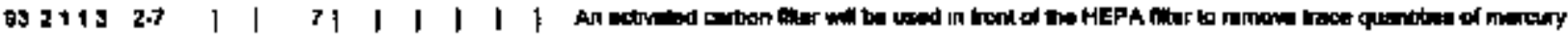

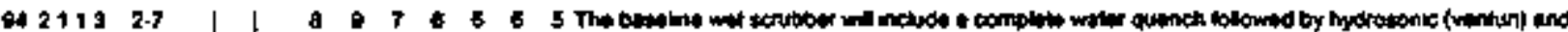

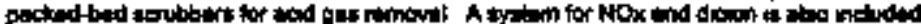

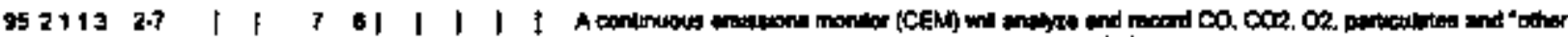

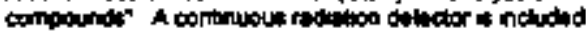

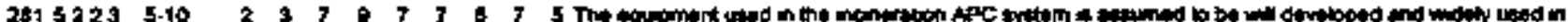

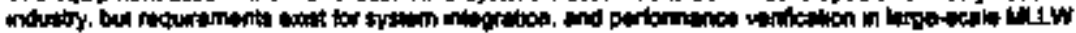
tranimatrinte

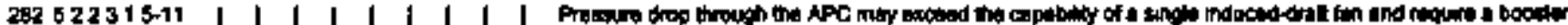

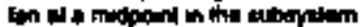

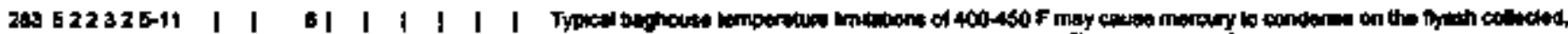

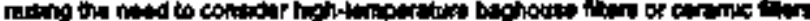

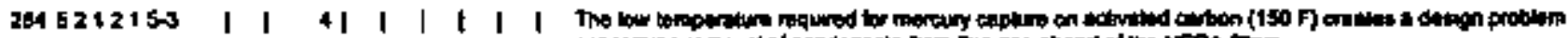

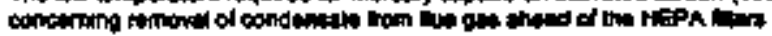

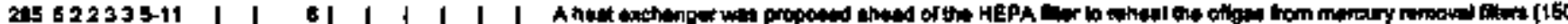

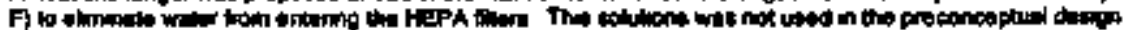

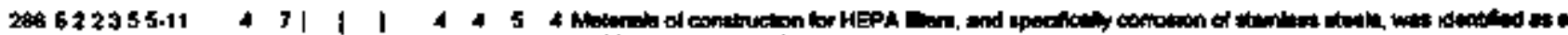

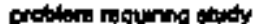

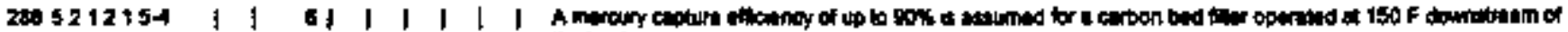
the bitionis 
NO SEC PACE ........ GATEFA ...... $12345 \% 7$ 自

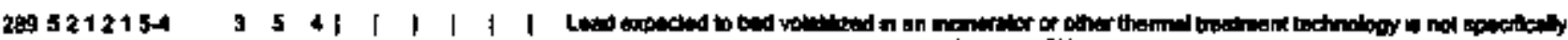

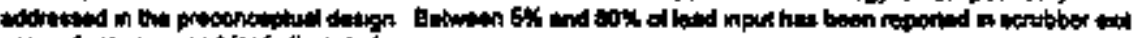

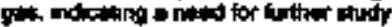

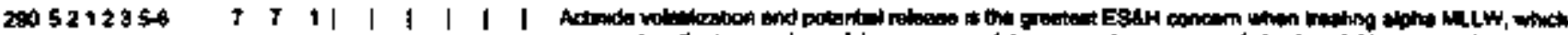

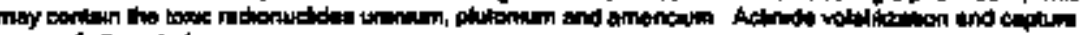

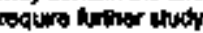

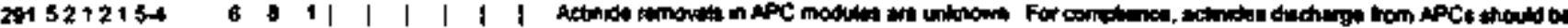

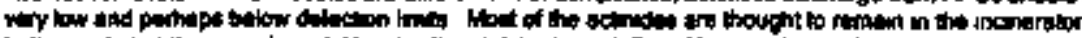

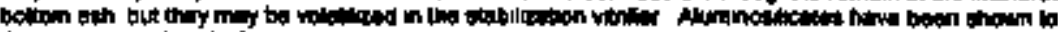

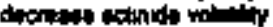

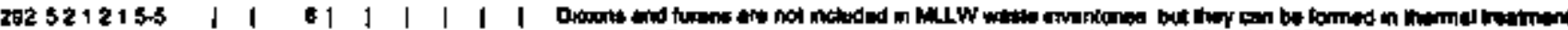

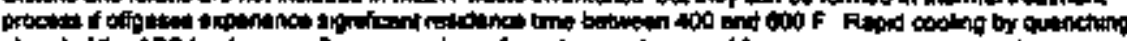

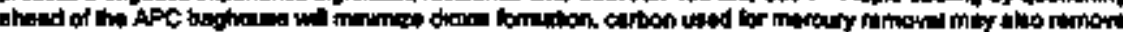

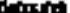

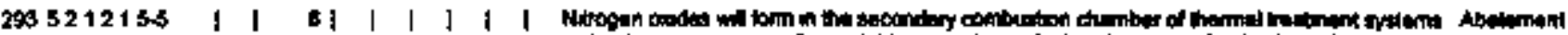

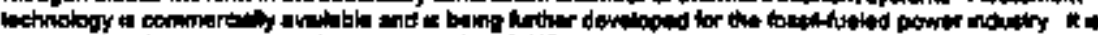

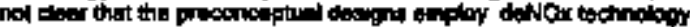

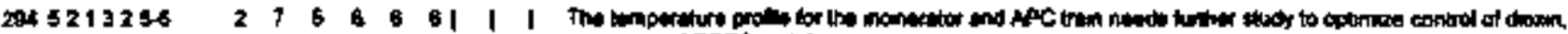

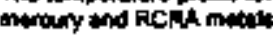

-4) Pumily Stablegotom

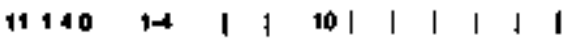

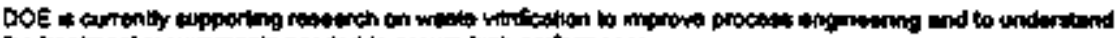

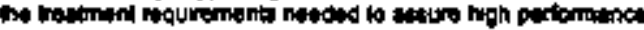

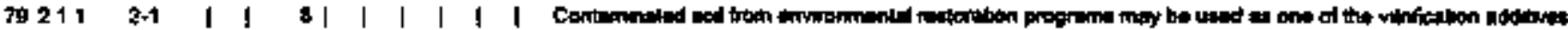

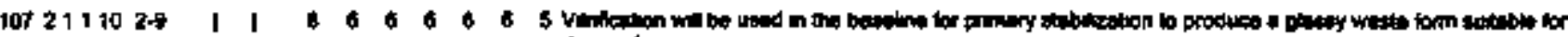
dipoint

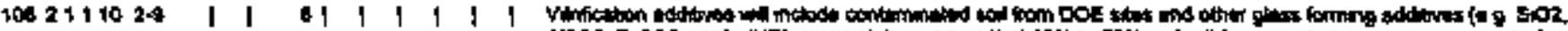

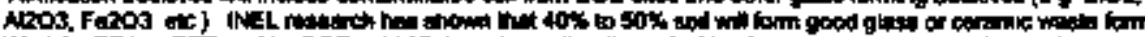

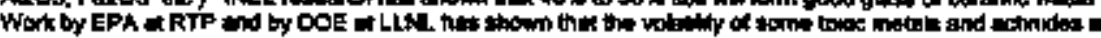

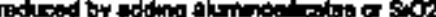

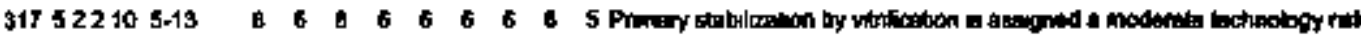

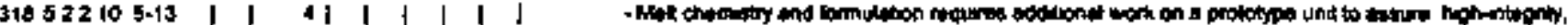

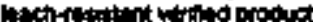

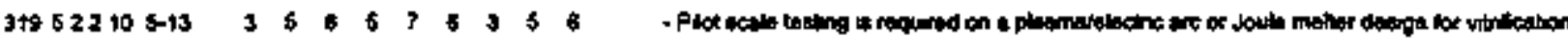

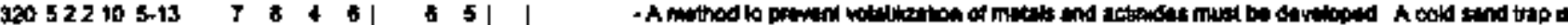

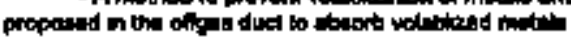

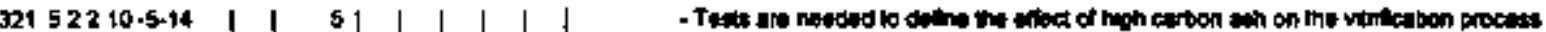

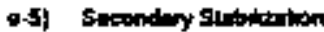

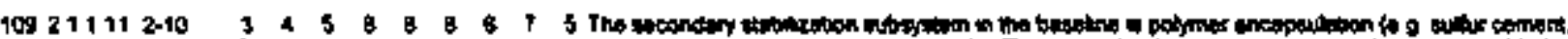

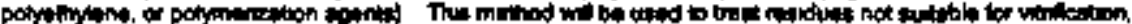

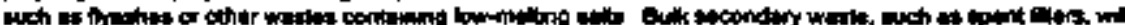

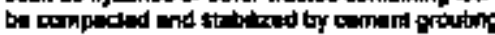

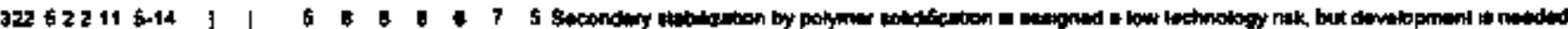

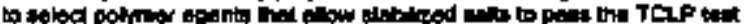

-8) Hatel Decomammition

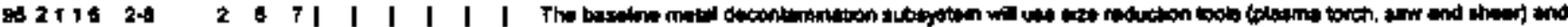

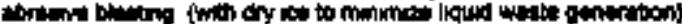

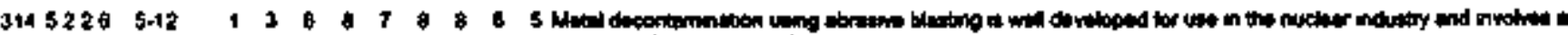

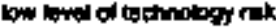

a) Whind Whitho

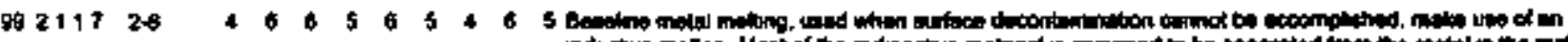

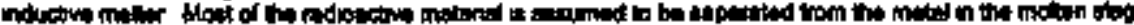

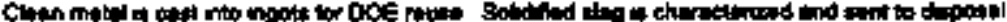

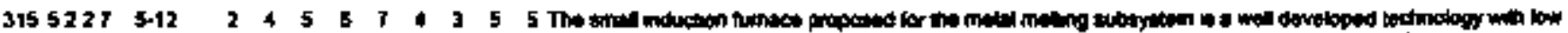

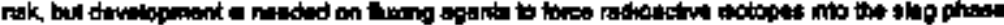

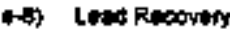

ag $1 \div 42-6$ $263 \mid$ | 11

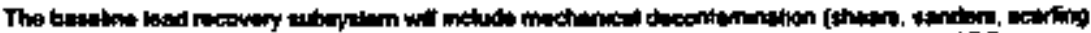

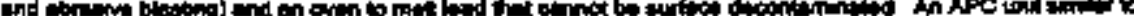




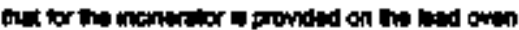

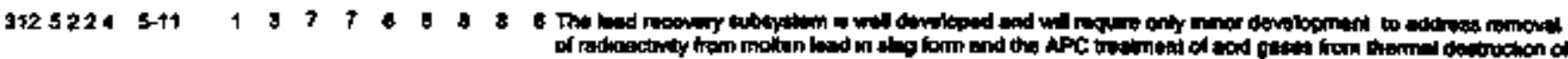
cynthere nober of lad ollonts

-9 Aquava Weis Trosimant

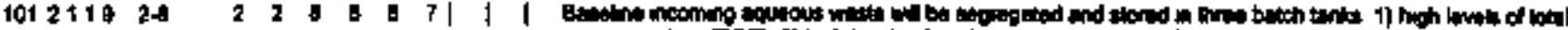

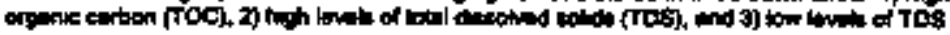

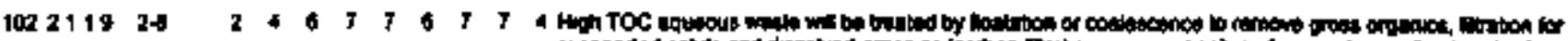

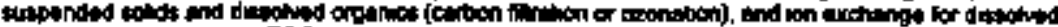

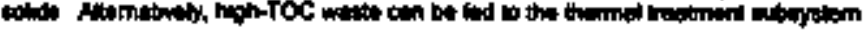

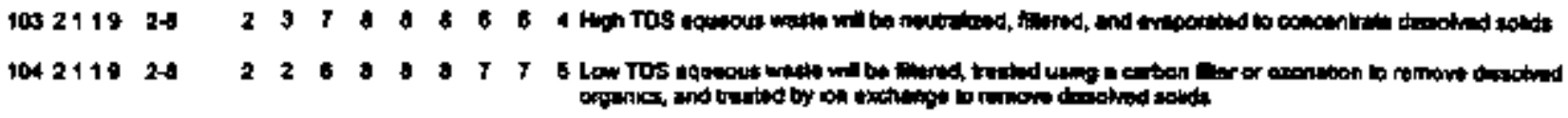

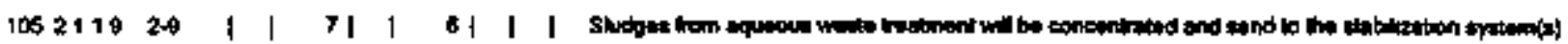

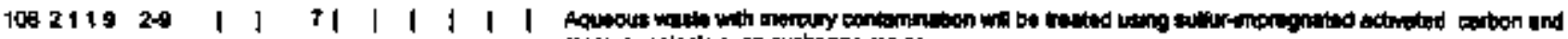

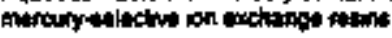

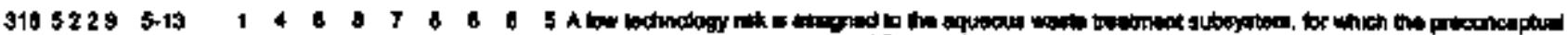

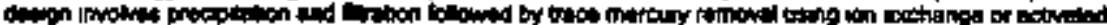

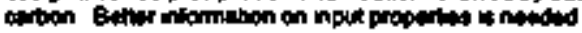

0-80) Warty Amalopmation

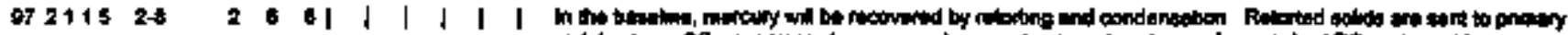

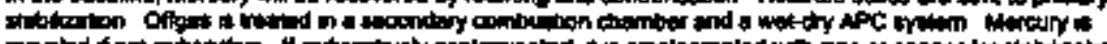

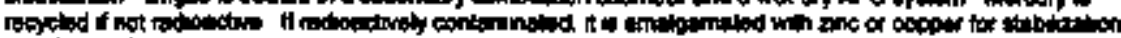
and depoun:

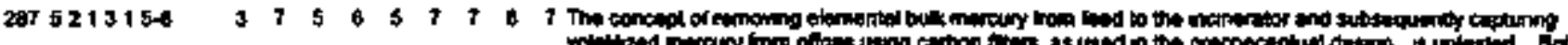

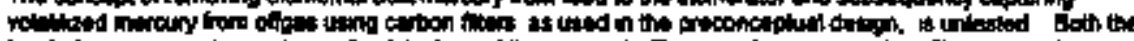

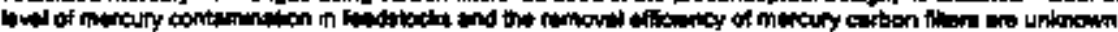

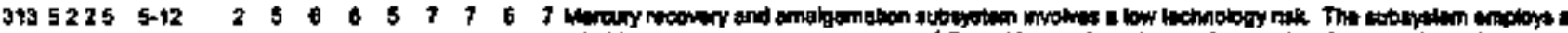

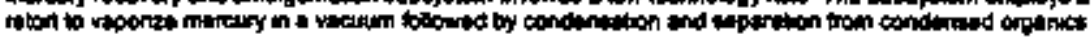

-11) Specal Wuate Tregtmart

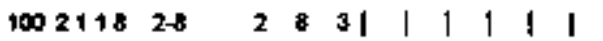

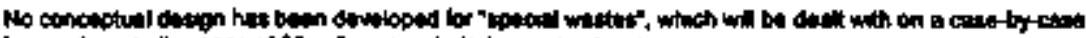

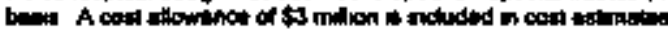

-12) Caritr and stap

$110211122-1022$ of 1 | 11 |

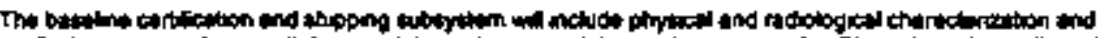

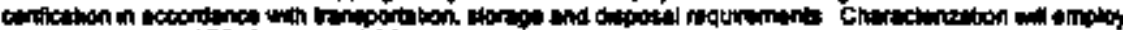

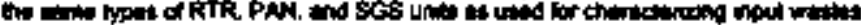

$3252212 \$ 14 \quad 125 \mid$ | 14 | 1

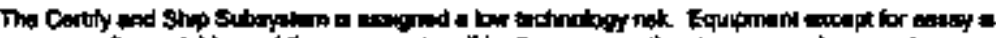

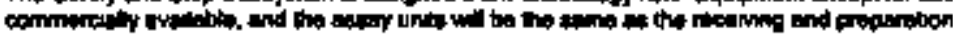

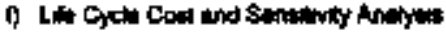

\begin{tabular}{|c|c|c|c|c|c|c|c|c|c|c|}
\hline 22540 & 41 & $\mathbf{s}$ & $\mathbf{5}$ & 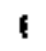 & r & I & $b$ & I & 1 & 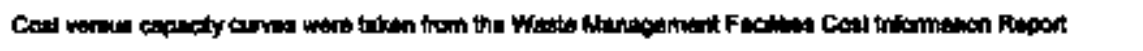 \\
\hline 22040 & $4-1$ & 7 & a ! & 1 & $\mathbf{I}$ & ! & $\mathbf{I}$ & I & 1 & 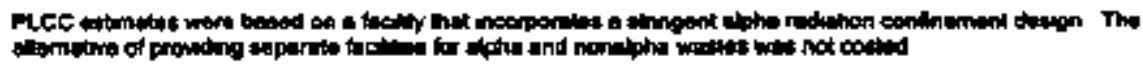 \\
\hline $227+1$ & 41 & 6 & 71 & 1 & I & I & $\mathbf{I}$ & $\mathbf{I}$ & $\mathbf{I}$ & 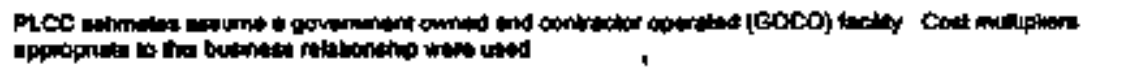 \\
\hline 22840 & $4-1$ & 3 & 31 & I & 1 & $\mathbf{I}$ & $\mathbf{i}$ & I & $\mathbf{I}$ & 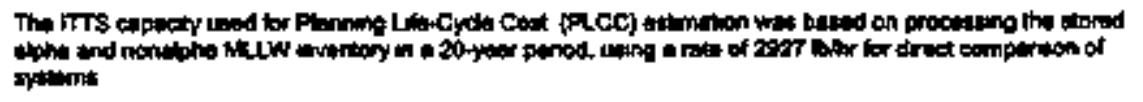 \\
\hline 22041 & 41 & $\mathbf{i}$ & 11 & I & I & 1 & I & I & $\mathbf{I}$ & 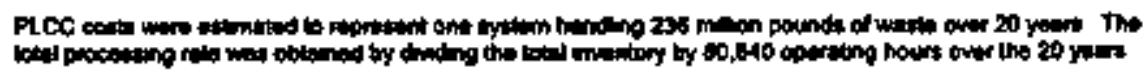 \\
\hline 23042 & $4-1$ & 1 & I & I & I & I & I & i & I & 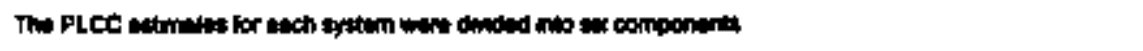 \\
\hline 231421 & 41 & 1 & 11 & I & 1 & I & I & 1 & $\mathbf{I}$ & 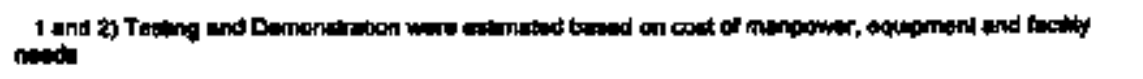 \\
\hline 232422 & 42 & 1 & 11 & 1 & 1 & I & I & I & $\mathbf{I}$ & 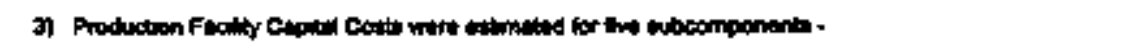 \\
\hline 2334221 & $4-2$ & $\boldsymbol{7}$ & 8 & I & I & r & I & $\mid$ & 1 & 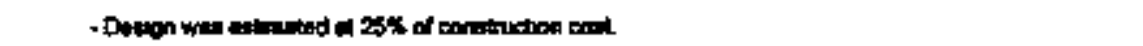 \\
\hline
\end{tabular}




- - - - - - - -

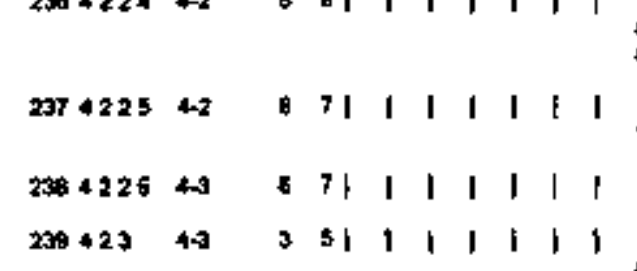

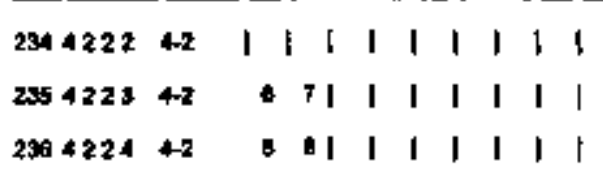

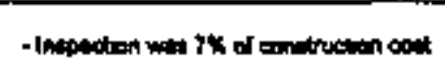

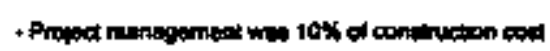

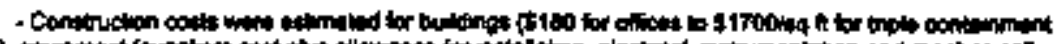

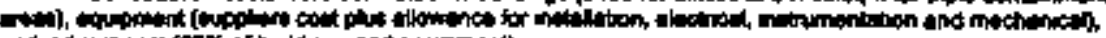

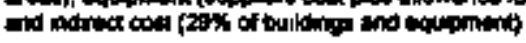

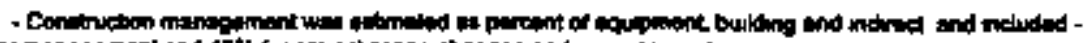

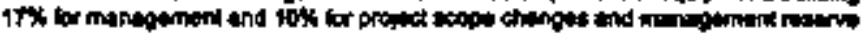

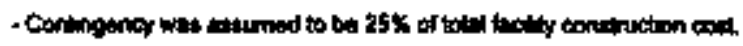

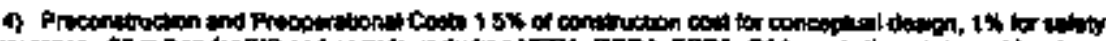

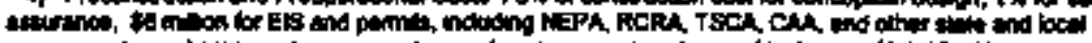

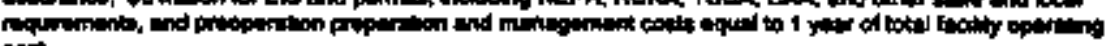
cont.

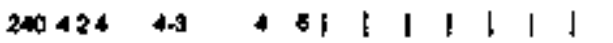

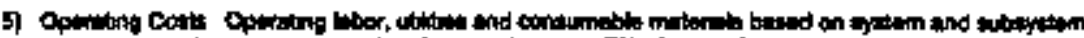

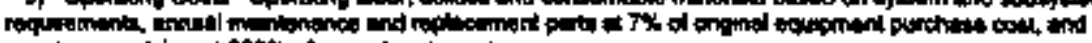

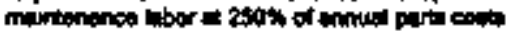

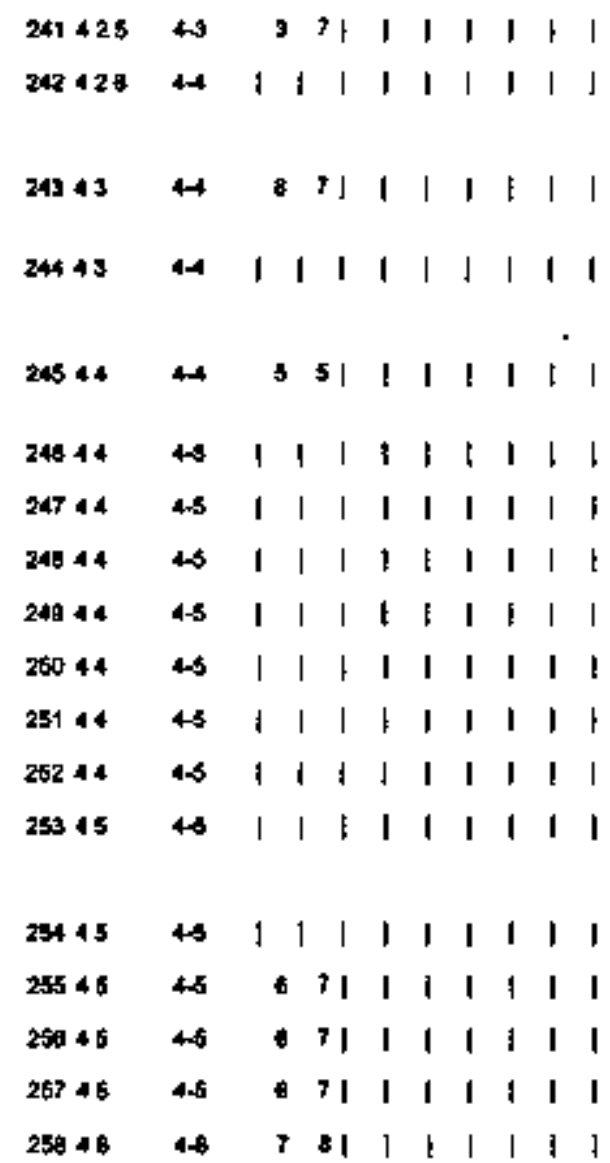

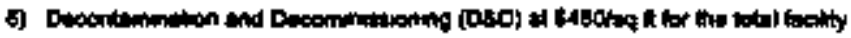

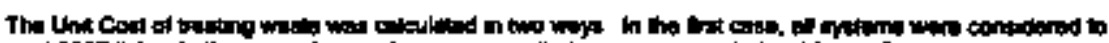

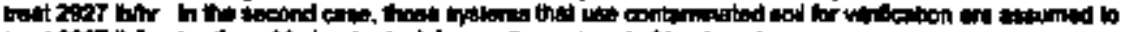

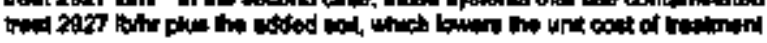

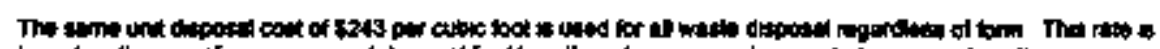

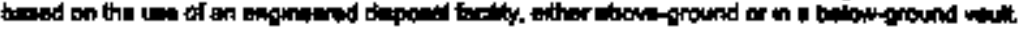

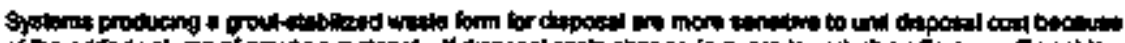

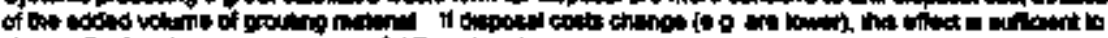

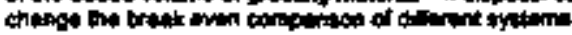

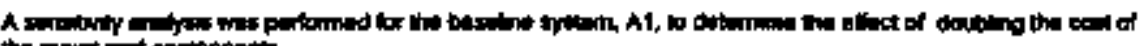

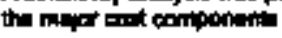

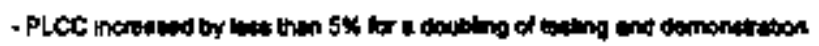

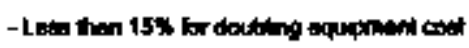

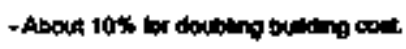

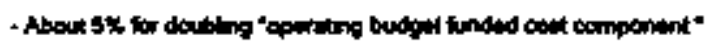

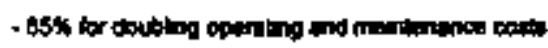

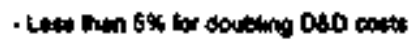

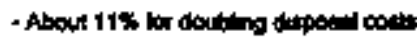

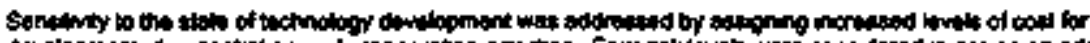

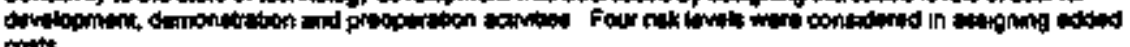
citus

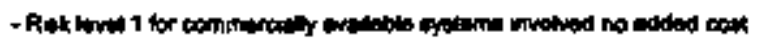

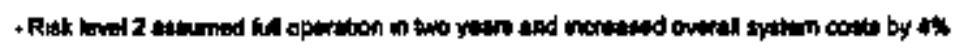

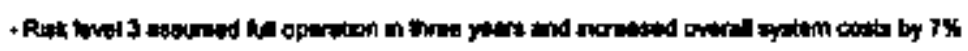

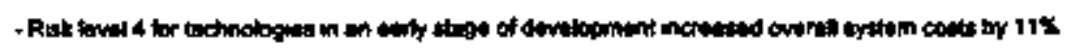

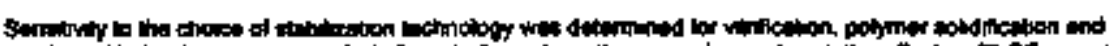

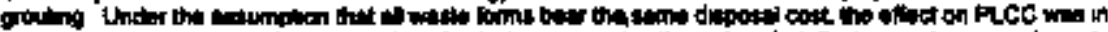

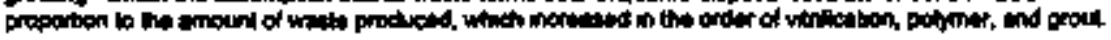

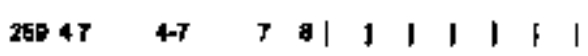

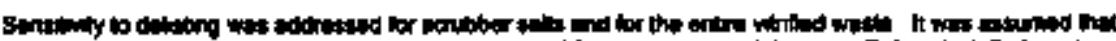

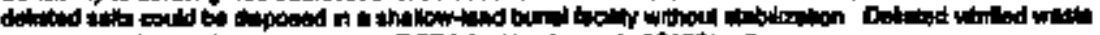

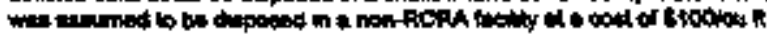

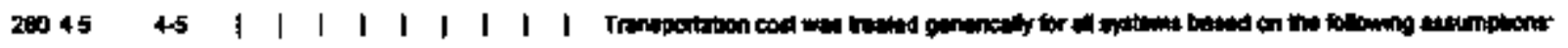

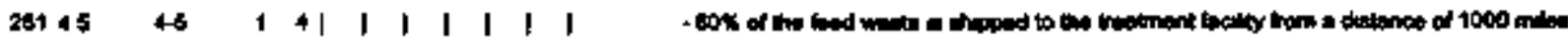

2425 is $1 * 111$ | 1 I I I

$203454.5 \quad 241 \quad 1 \quad 1 \quad 1 \quad 1 \quad 1 \quad 1$

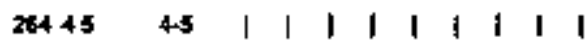

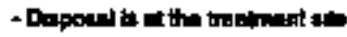

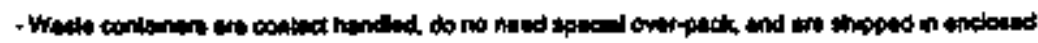
ratom

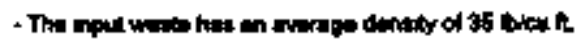




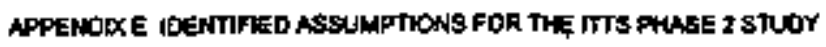

$P=\mathbf{E}-17$

No

SEC

PAGE

ceaterase

ASSUMPTIONS OR DESHRNFEATUATS

255

4

$+25156700$

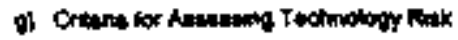

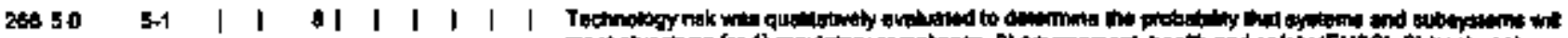

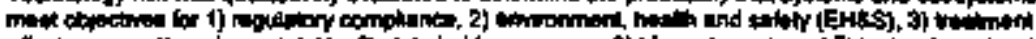

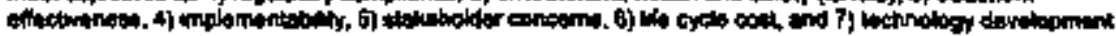

267511 5-4 I I a | | | | | |

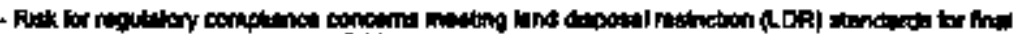

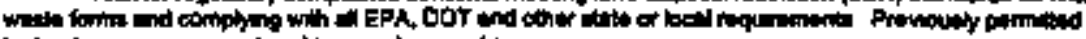

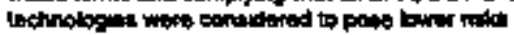

209525.2||$\quad|||| \mid$

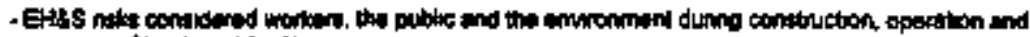

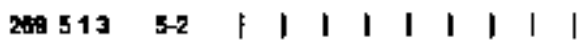

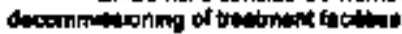

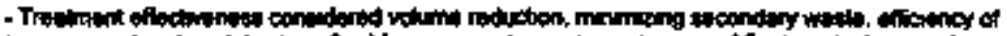

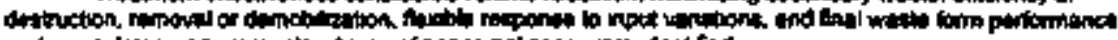

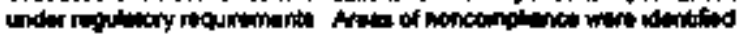

$2705145-255|1| l|l| l \mid$

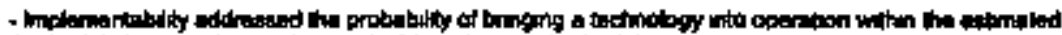

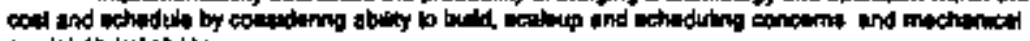

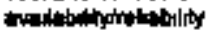

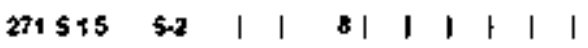

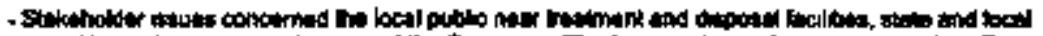

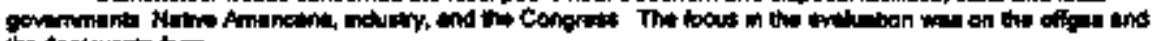

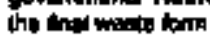

$272 \$ 18$ 5-2 1 1 $\mid$ |

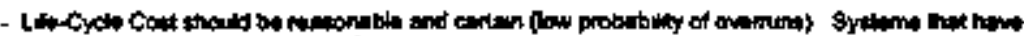

$2735: 75-2 \quad 1|1||1|||$

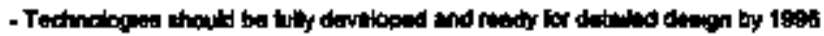

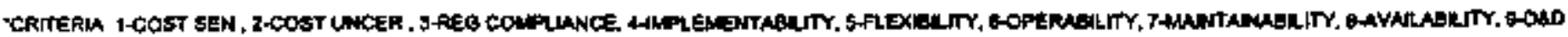


APPENDIX F

\section{IDENTIFIED ASSUMPTIONS FOR THE INTS STUDY}




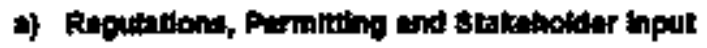

\begin{tabular}{|c|c|c|c|c|c|}
\hline 1 & $1,8 . t$ & 5 & 2 & 6 & 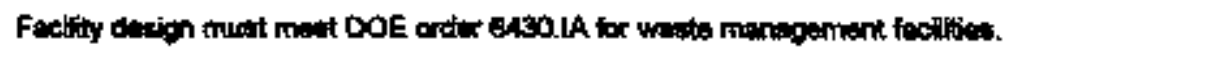 \\
\hline 2 & 1.9 .1 & 15 & 1 & 4 & Factity desion must meet RCRA tecility striderds. \\
\hline 3 & 1.9 .1 & 15 & 7 & $\mathbf{6}$ & Factitios are pleced in siamic celtegory 1. \\
\hline 4 & 1.9 .1 & 粕 & 1 & $\mathbf{3}$ & 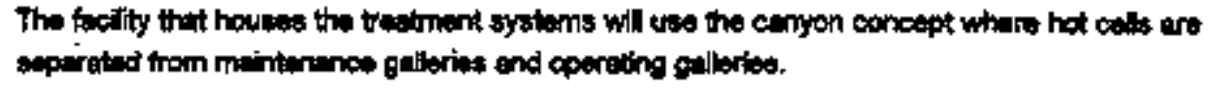 \\
\hline $\mathbf{s}$ & 1.9 .1 & 16 & 1 & 3 & 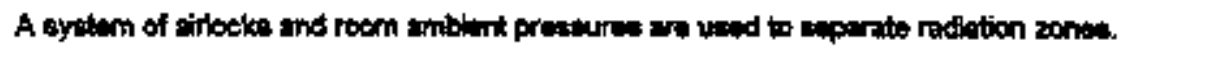 \\
\hline 6 & 1.9 .1 & 16 & 1 & 1 & Hot colls ent doelgrad ae dpha hot ceiler. \\
\hline 7 & 7.9 .1 & 16 & 日 & $\mathbf{6}$ & 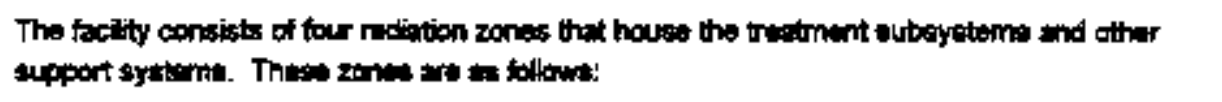 \\
\hline 8 & t.9.1 & 18 & 6 & $\mathbf{6}$ & 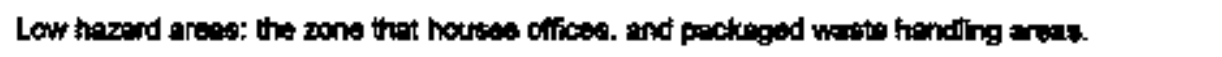 \\
\hline 9 & $1,9.1$ & 16 & a & $\mathbf{B}$ & 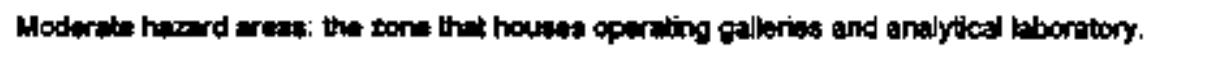 \\
\hline 10 & 1.9 .1 & 16 & 6 & 6 & 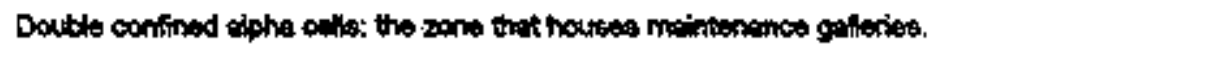 \\
\hline 11 & 1.9 .1 & 18 & B & 6 & 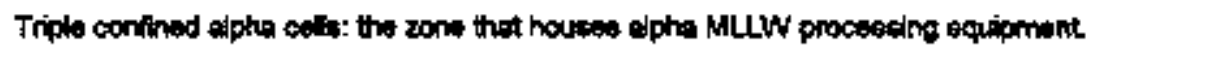 \\
\hline 12 & 1.9 .1 & 16 & $\mathbf{2}$ & (5) & 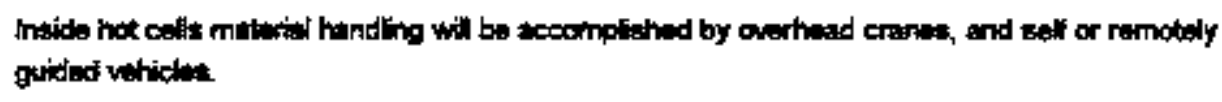 \\
\hline 13 & 1.9 .1 & 18 & 2 & 6 & 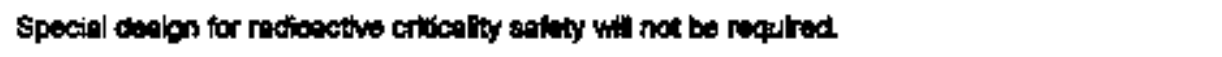 \\
\hline 14 & 1.9 .1 & 15 & 1 & $\$$ & 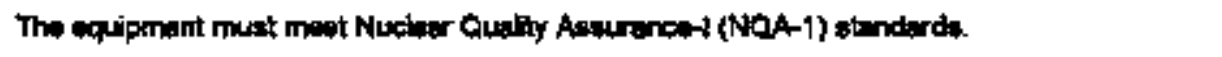 \\
\hline 15 & 1.8 .2 & 17 & 3 & s & 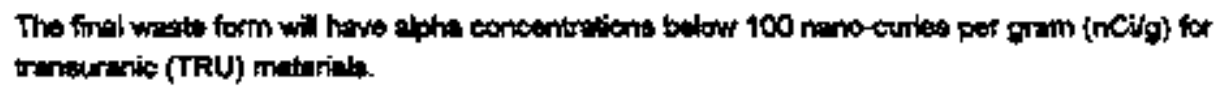 \\
\hline 16 & $1.9 Z$ & 17 & 3 & 7 & 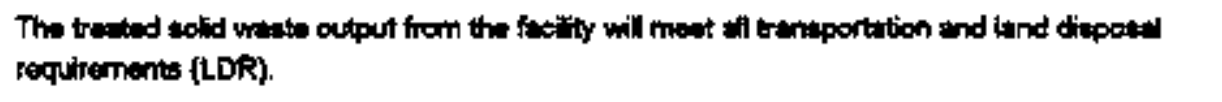 \\
\hline 17 & 1.9 .2 & 17 & 2 & 4 & 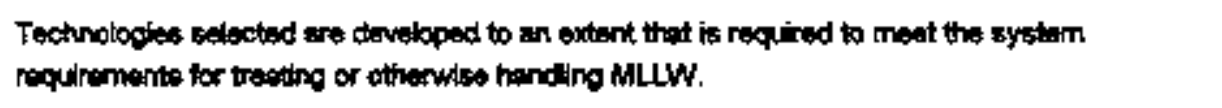 \\
\hline 18 & 1.9 .2 & 17 & 4 & 4 & 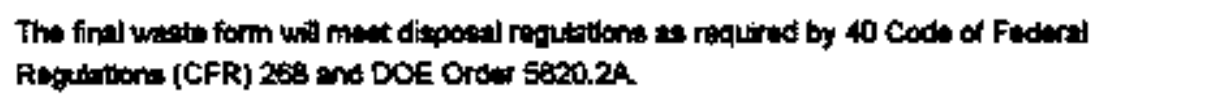 \\
\hline 19 & 1.9 .2 & 17 & 2 & 3 & There is no radiological trangformation of waite from one rodiation frapory to another. \\
\hline 70 & 1.83 & 18 & ร & 5 & 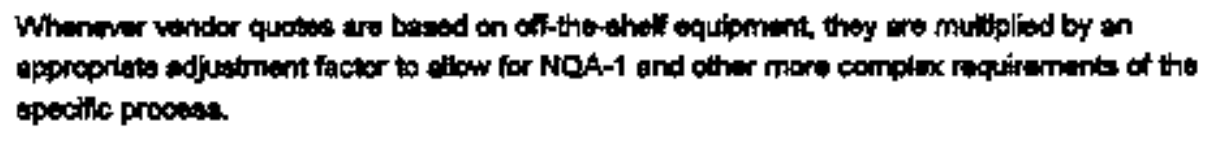 \\
\hline 21 & 1.10 .1 & 20 & $\mathbf{2}$ & 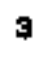 & 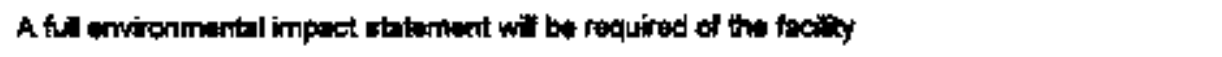 \\
\hline 22 & T.10.1 & 20 & 8 & 9 & 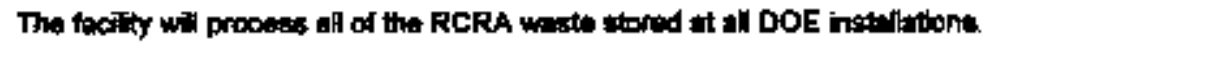 \\
\hline $\mathbf{2 3}$ & t.10.1 & 20 & $\mathbf{Z}$ & 3 & 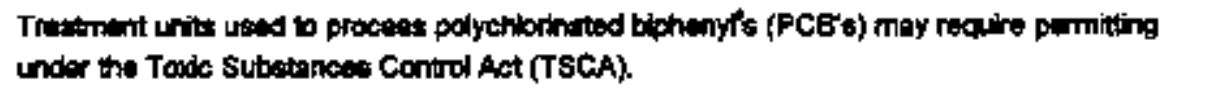 \\
\hline 24 & 1.10 .1 & $\mathbf{2 0}$ & 1 & 5 & 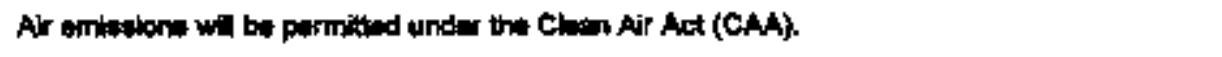 \\
\hline 25 & 1.10 .1 & 20 & 4 & a & 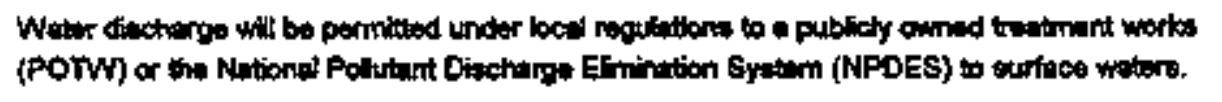 \\
\hline 25 & 1.10 .1 & 20 & 3 & 6 & 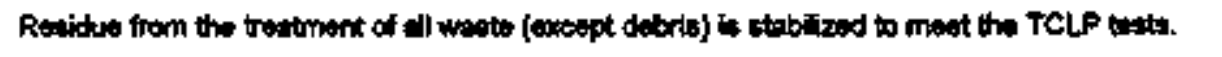 \\
\hline 27 & 1.10 .3 & 21 & 2 & $\mathbf{B}$ & 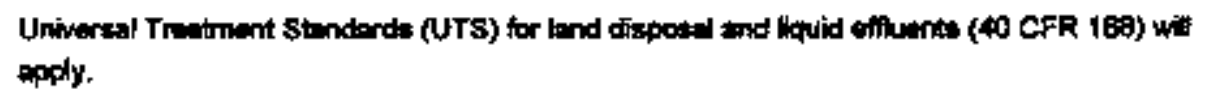 \\
\hline
\end{tabular}




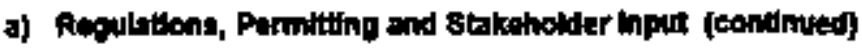

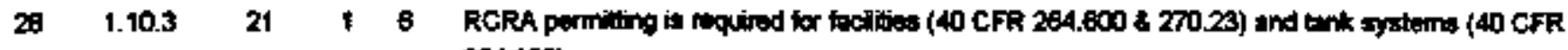
264.190)

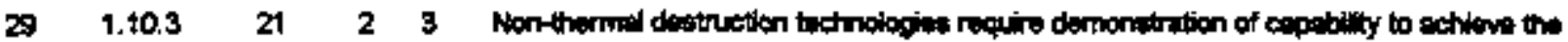

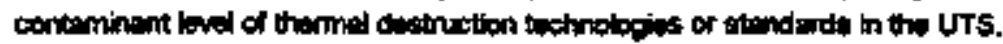

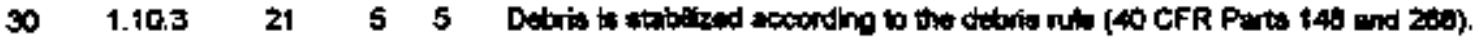

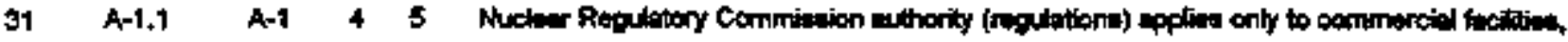
thentore this foclity would be exempt.

32 A-12 A-1 1 \$

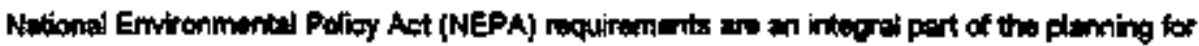

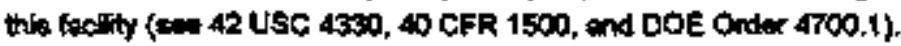
PCB waste should be treated in accontence with eperabing requiremente (40 CFR 761 .80-70).

The feclity wil process onty lmited quentitless of the waste covered by the Comprehenesive

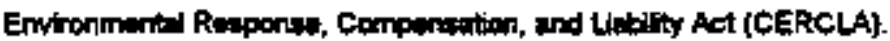

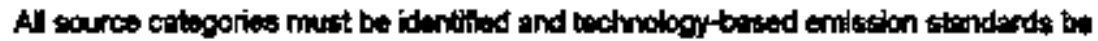
promulgated (CAA Section 112c).

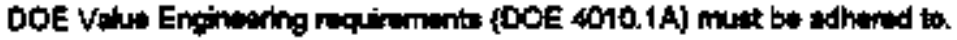

39 A-1.B A-6 34

DOE Hazrdous Matertal Patkaging ior Traneport - Administritive Procadures (DOE 1540.2) must be achered $\mathbf{m}$.

DOE Otcament Reporting and Processing of Optrattens Informetion requiramemts (DOE 600.39) must be adhard ta.

DOE Conduct of Oparatons Requkements for DOE Facilies (DOE \$4EO. 19) must be adhered to.

41 A-1.8 A-B 34

DOE Quinty Assurance requirements (DOE 5700.4C) muat be adhered to.

DOE Heardous and Rediontivu Niond Wath Proyrem nequirements (DOE 5400.3) must be atheried to.

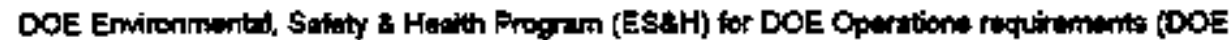
5480 13) mist be whoned to.

$\begin{array}{rrrrr}44 & \text { A-t.B } & \text { A.7 } & 3 & 5 \\ 45 & \text { A-1.6 } & \text { A.7 } & 3 & 2 \\ 46 & \text { A-1.B } & \text { A.7 } & 3 & 2 \\ 47 & \text { A-t.8 } & \text { A-B } & 3 & \text { B } \\ 48 & \text { A-1.8 } & \text { A-8 } & 3 & 3 \\ 49 & \text { A-1.8 } & \text { A-B } & 3 & \text {. }\end{array}$

DOE Ceneral Ervironmented Protection Progum requimmitt (DOE 5400.1) thut bo adhered to.

50 A-1.B A-B 32

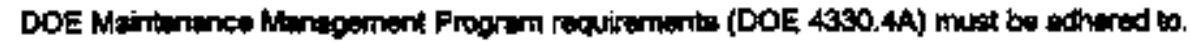

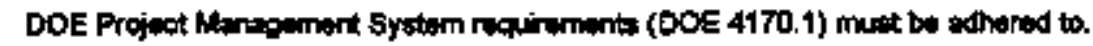

DOE Ervironmented Protection, Sofety, and Hewith Protecion Standirda (DOE 5490.4) mast be whered to.

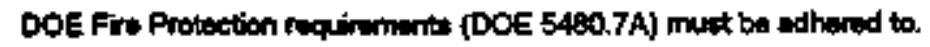

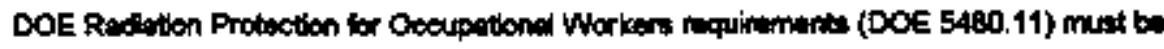
thered to.

$\begin{array}{lllll}51 & \text { A-1.8 } & \text { A-9 } & 3 & 2 \\ 52 & \text { A-1.日 } & \text { A-9 } & 3 & \text { A } \\ 53 & \text { A-1.日 } & \text { A-9 } & 3 & 4\end{array}$

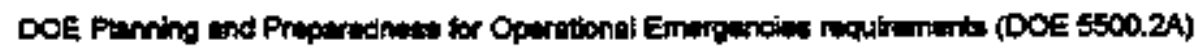
mutt be achered to.

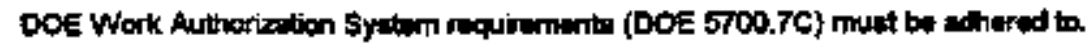

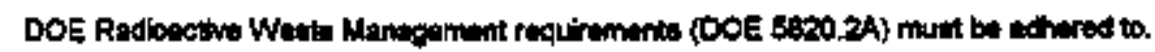

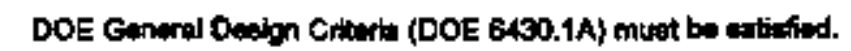




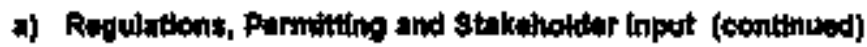

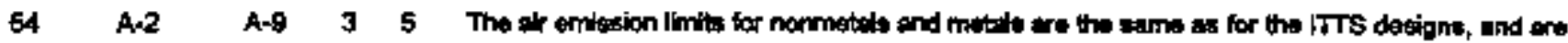

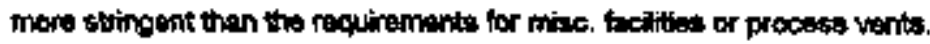

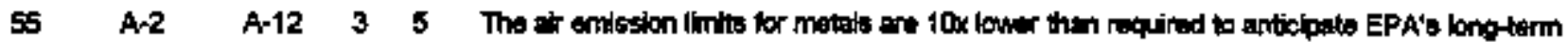
preficrenca for edopting more klowoun tochnology-baged standards.

b) Input wistio Charactiorstics

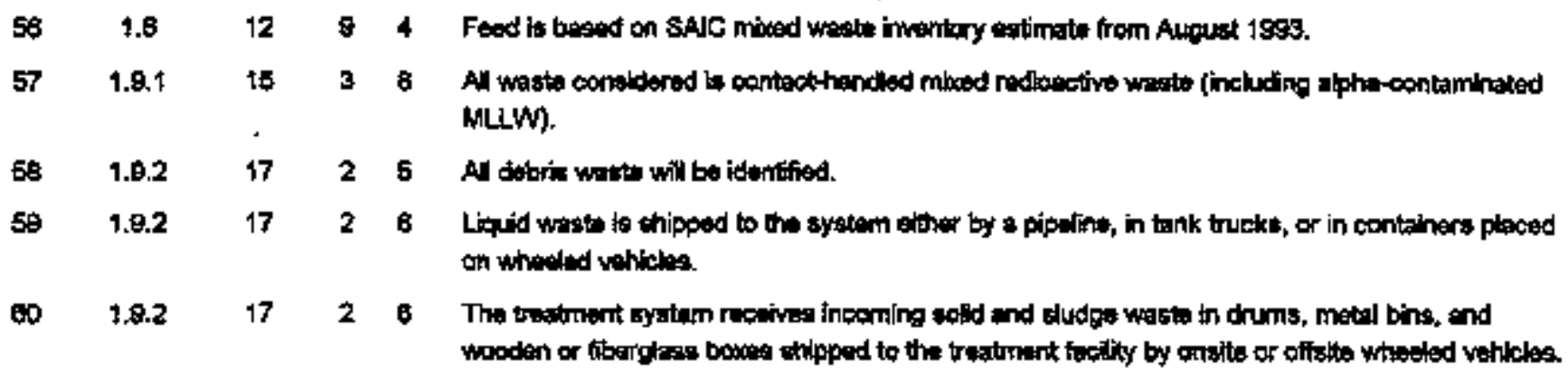

c) Whatio Charapteritzition

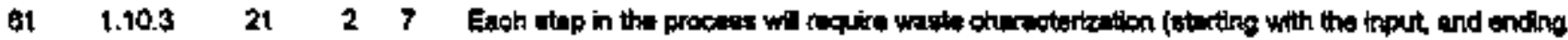 with the find waste, oflpes, ind corutber tolits).
G 1920327

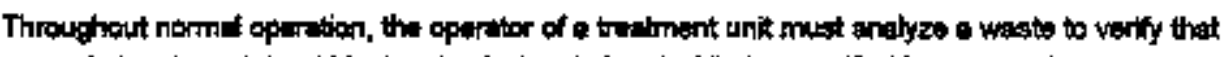 weste fod to the unit is within the physlcal and cherriced limito aposifiod ith the pertit.
03

$\begin{array}{llll}1.10 .3 & 22 & 2 & 6\end{array}$
No thempt was made to provide elhiolding in any unik cperation.

d) Gentra Desion and Operating Assumptions

\begin{tabular}{|c|c|c|c|c|c|}
\hline 64 & 1,3 & 4 & 3 & $\mathbf{8}$ & 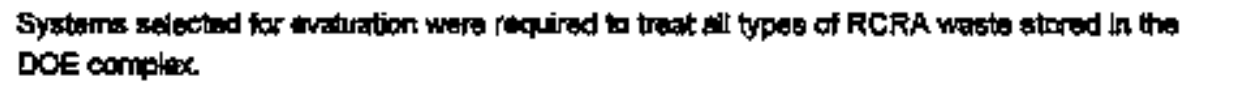 \\
\hline 65 & 1.7 & 12 & $\mathbf{9}$ & $\theta$ & 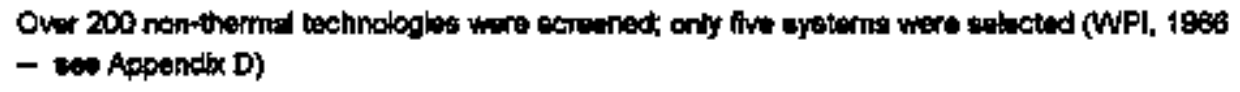 \\
\hline 66 & 1.9 .1 & 16 & 3 & 3 & 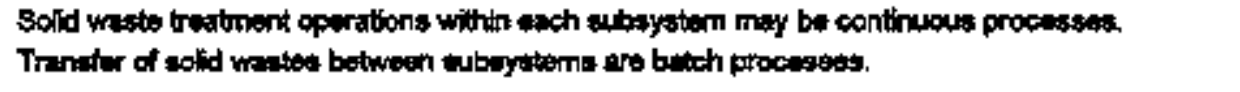 \\
\hline 自 & 1.5 .1 & 96 & $\mathbf{5}$ & $\mathbf{2}$ & 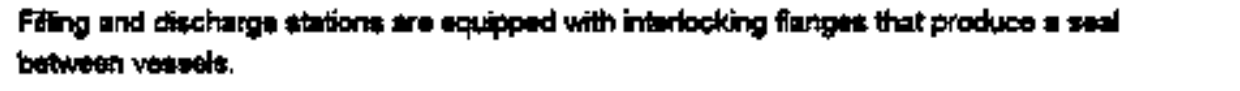 \\
\hline 68 & 1.9 .1 & 10 & 5 & 3 & Liquld and gaseous matorials handing prosossas are continuous operations. \\
\hline 69 & 1.9 .1 & 16 & 3 & 2 & 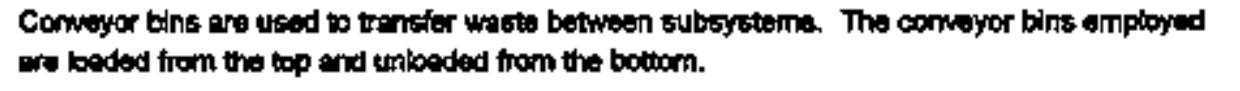 \\
\hline 70 & 1.8 .2 & 17 & - & B & 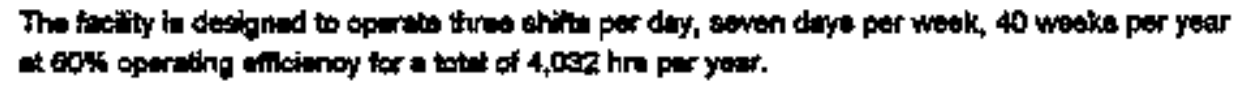 \\
\hline 71 & 1.9 .2 & 17 & 7 & 2 & 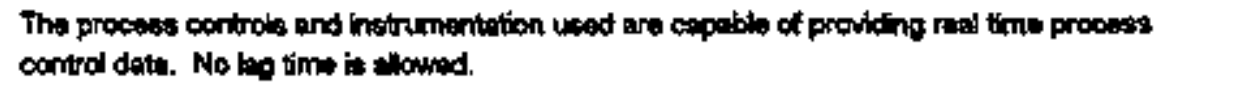 \\
\hline & 1.9 .2 & 17 & 7 & 2 & 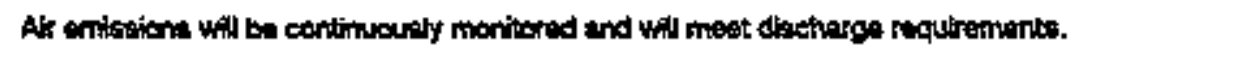 \\
\hline
\end{tabular}


No. Sect. Page U* S*

d) Gonerel Dodpon and Operaling Aatumptions (oontinued)

\begin{tabular}{|c|c|c|c|c|c|}
\hline 73 & 1.10 .3 & 26 & 5 & 3 & 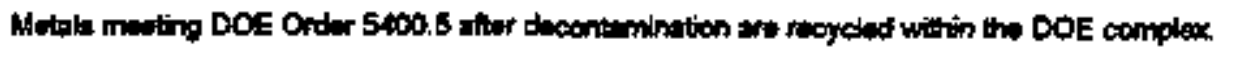 \\
\hline 74 & 1.10 .3 & 25 & 2 & 3 & Lesd that eennct undergo aurfece deconsmination is grouled. \\
\hline 70 & 1.10 .3 & 28 & 2 & 7 & 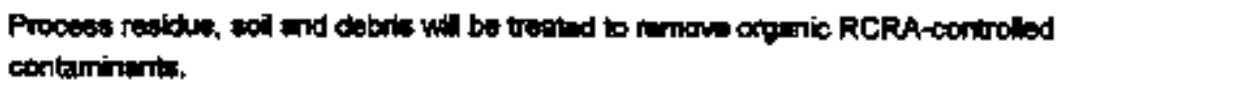 \\
\hline 76 & 1.10 .3 & 25 & 2 & $\mathbf{B}$ & 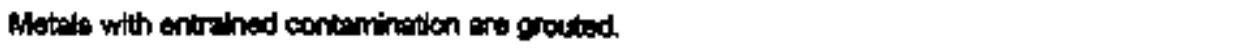 \\
\hline 77 & 1.10 .3 & 26 & 3 & s & Trapted sol and debrie will be stebilized in grout. \\
\hline 79 & t.10.3 & $\mathbf{2}$ & $\mathbf{3}$ & 8 & 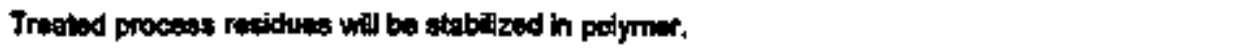 \\
\hline 79 & $1,70.3$ & 25 & 2 & 7 & 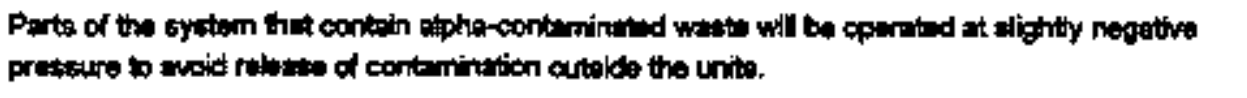 \\
\hline 60 & 1.10 .3 & $\mathbf{2 5}$ & 3 & 4 & 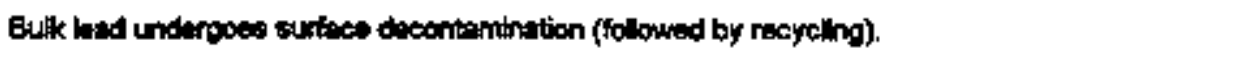 \\
\hline 61 & 1.10 .3 & $\mathbf{2 B}$ & 3 & 8 & 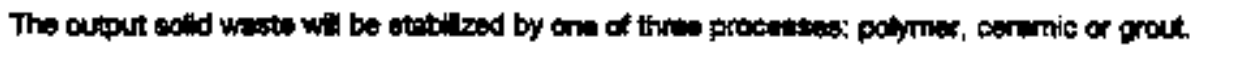 \\
\hline 82 & $1,10.3$ & 28 & 3 & 7 & 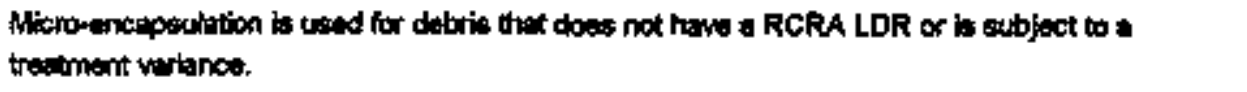 \\
\hline 3 & 1.10 .3 & 27 & s & 4 & 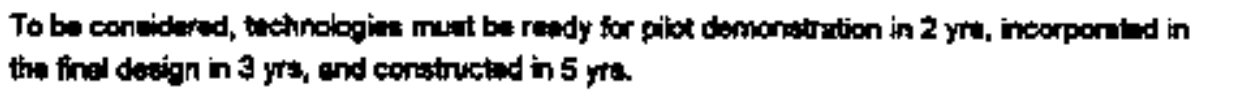 \\
\hline 4 & 1.10 .3 & 27 & 5 & 4 & The opertitiog pariod is 20 youre. \\
\hline & 1.10 .3 & 27 & B & 6 & 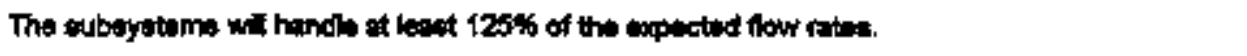 \\
\hline & $\$ .10 .3$ & 27 & $\mathbf{s}$ & 3 & 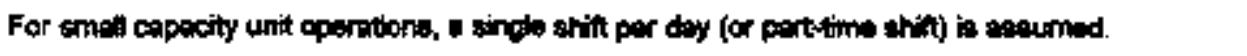 \\
\hline$\theta$ & 1.10 .3 & 27 & $\mathbf{s}$ & 6 & 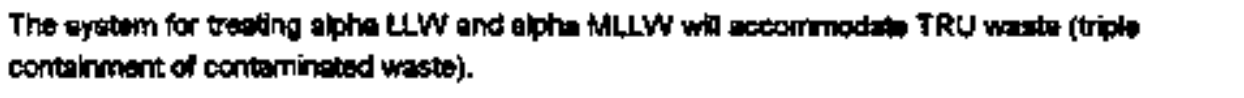 \\
\hline 89 & $\$ .10 .3$ & 29 & 5 & (1) & 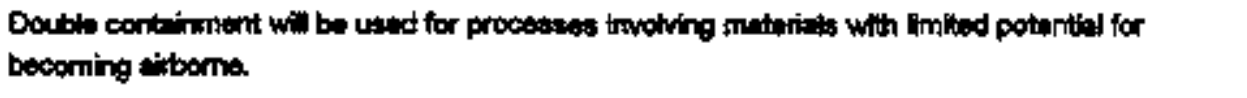 \\
\hline 6 & 3 & 97 & 4 & 3 & 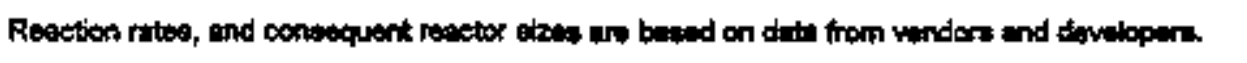 \\
\hline 9 & 3.1 & 97 & 5 & 4 & 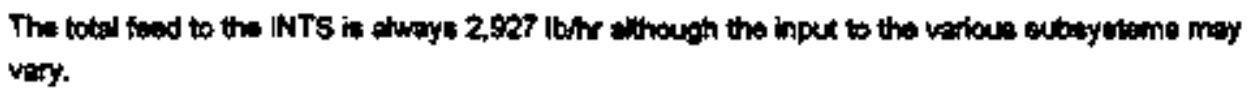 \\
\hline & 3.2 & s & 3 & $\$$ & 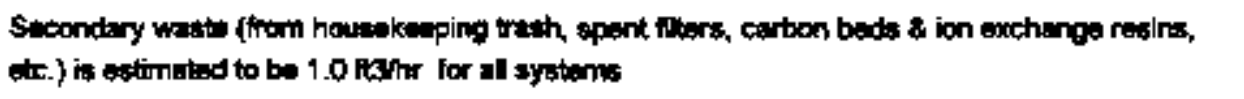 \\
\hline & 3.3 & $\$ 9$ & 3 & 3 & 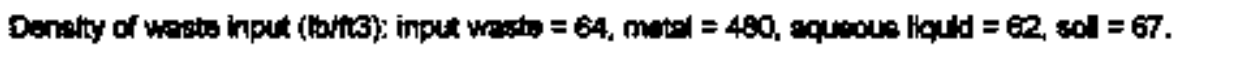 \\
\hline & $\mathbf{3 . 3}$ & 8 & 3 & $\mathbf{s}$ & 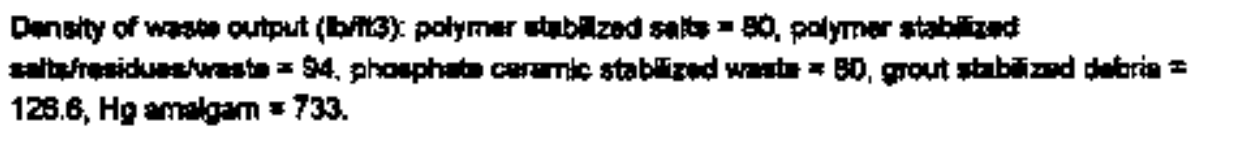 \\
\hline & 3.3 & $\$ 0$ & a & 3 & 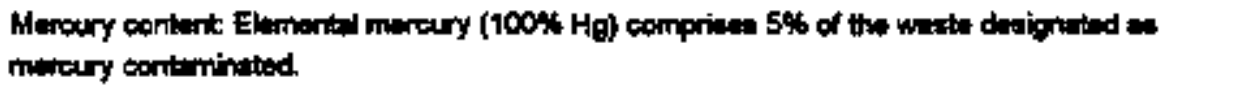 \\
\hline & 3.3 & 99 & $\mathbf{8}$ & 3 & 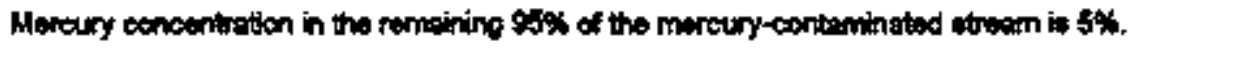 \\
\hline & 3.3 & 100 & 帛 & B & 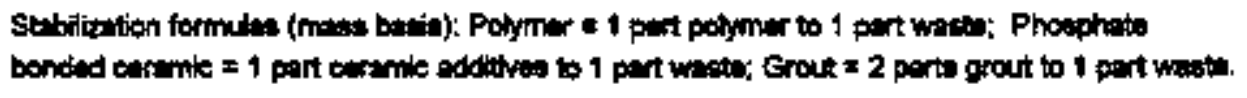 \\
\hline & 3.4 & 100 & 7 & 2 & 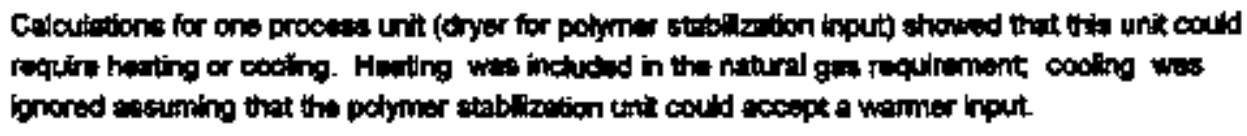 \\
\hline
\end{tabular}


d) Geikeral Design and Operating Astomptions (continuad)

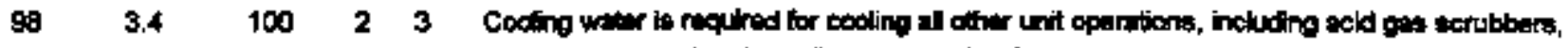

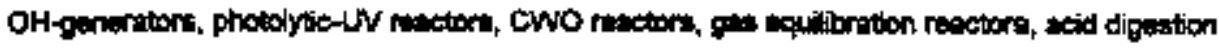
riturers, and HWO2 recevery reacers.

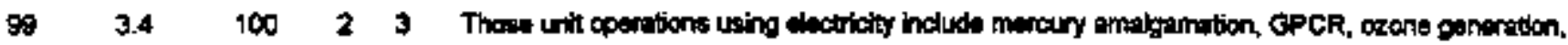
solt concentrator, and the MEO cells.

$100 \quad 3.4 \quad 100$

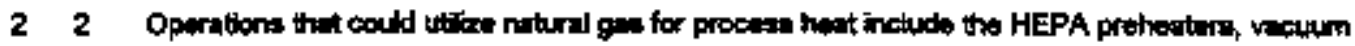

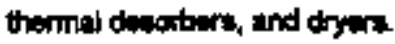

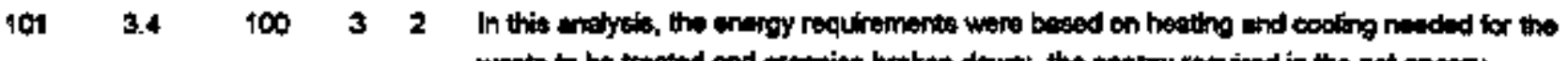
wate to be troeted end orgatice broken down; the worgy required ia the net energy.

$102 \quad 3.4 \quad 100 \quad 3 \quad 2 \quad$ Calculetions made with ASPEN provided oversil energy requirements ke ell of the unit operations within the modale for the five systems.

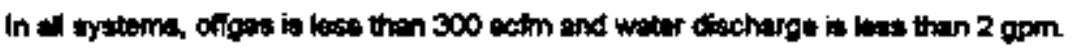

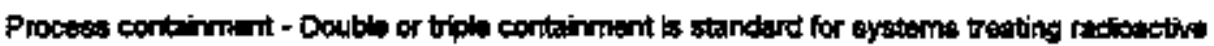
wasto end is not a rigifigant discrimirator between systertis.

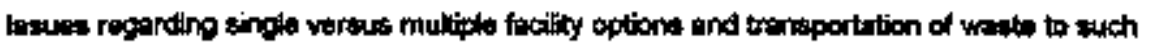

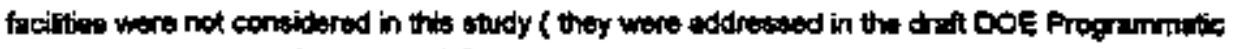
Emironanentel Impost Stutement (PEIS)].

Henford tank wantes and Rocky flots ponderotos).

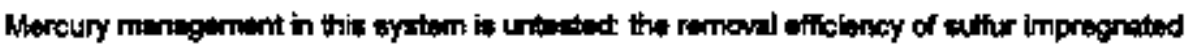

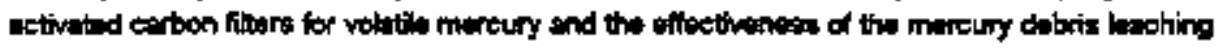
procosts are unknowr at this tims.

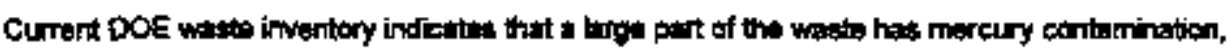

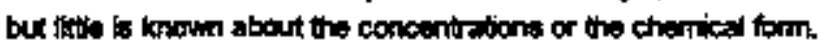

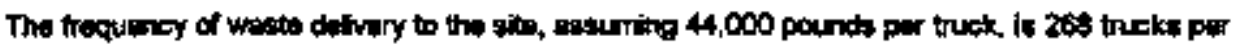
yaner.

The INTS atudy asoungtion is that wastes wall be treated on-site and disposed of or-site.

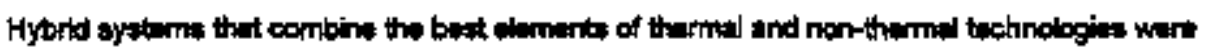
not conaidered.

d-1) Syotion 1 - Grout Debrits

\begin{tabular}{|c|c|c|c|c|c|}
\hline 112 & $\mathbf{z}$ & 31 & 7 & $B$ & 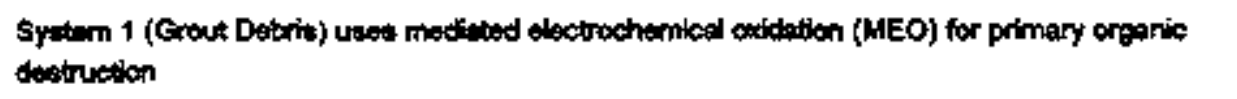 \\
\hline 113 & 2 & 31 & 7 & B & 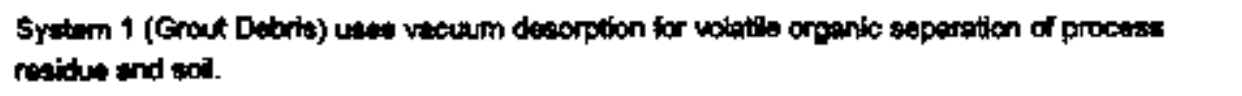 \\
\hline 114 & 2 & 31 & 3 & 3 & 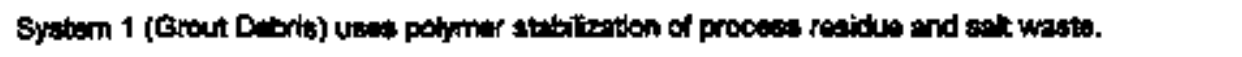 \\
\hline 115 & 2 & 31 & 3 & 3 & 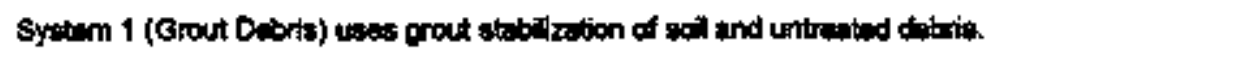 \\
\hline 196 & 6.2 & 184 & 5 & 3 & 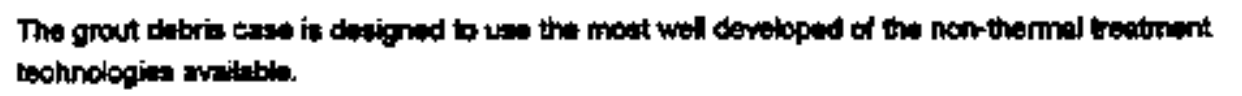 \\
\hline 117 & $\mathbf{6 . 2}$ & 195 & $\mathbf{8}$ & 4 & 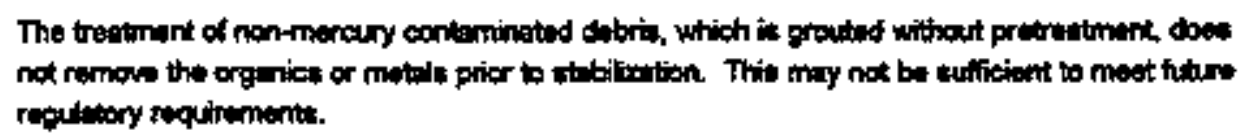 \\
\hline
\end{tabular}




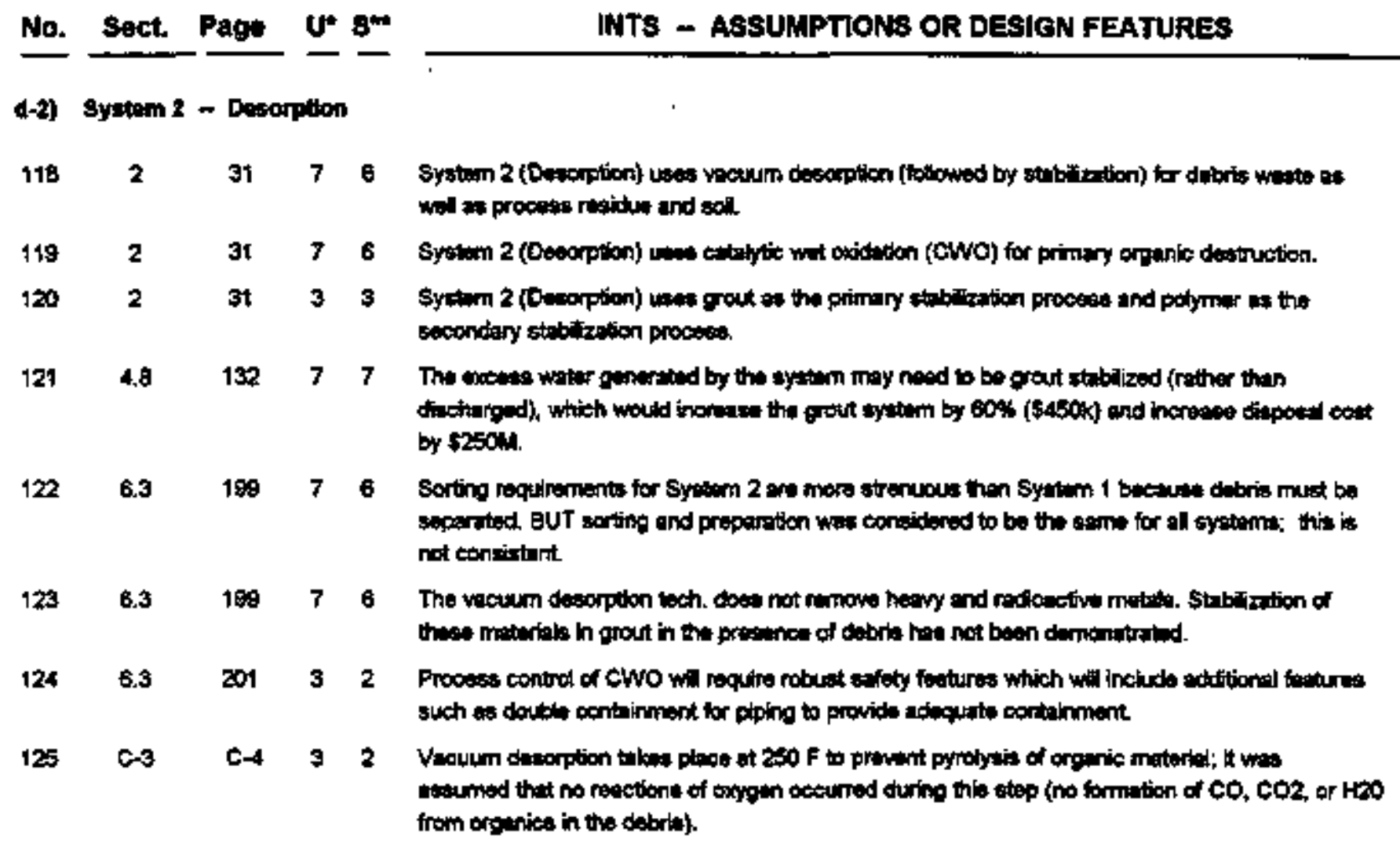

d-7) Syztom 3 - Whath

\begin{tabular}{|c|c|c|c|c|}
\hline 126 & 32 & 7 & 6 & 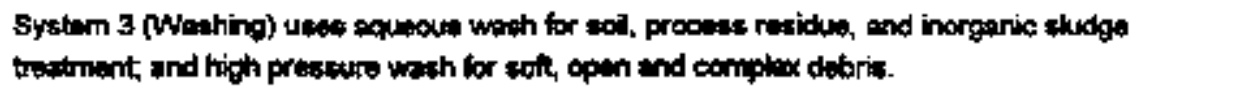 \\
\hline 127 & 31 & 3 & 2 & 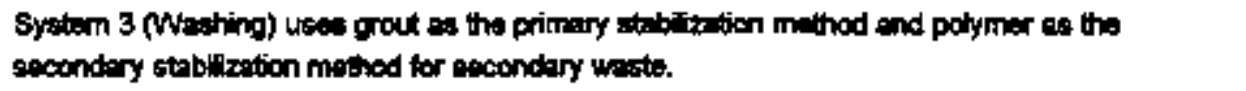 \\
\hline 129 & 3t & 7 & 6 & 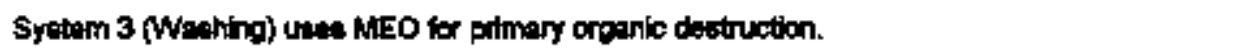 \\
\hline 2.3.1 & 49 & $\mathbf{2}$ & 2 & 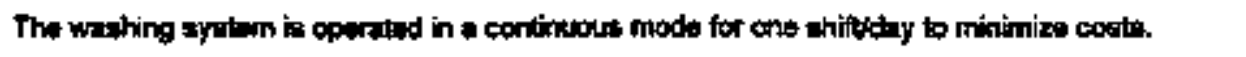 \\
\hline 2.3 .1 & 50 & $\mathbf{3}$ & $\mathbf{5}$ & 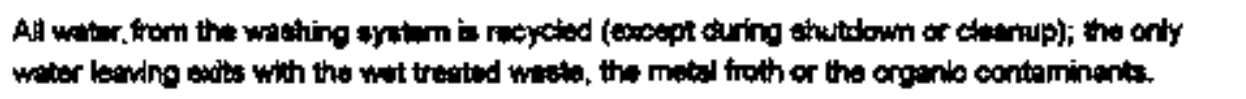 \\
\hline 2.3 .1 & $\$ 1$ & 3 & $\mathbf{2}$ & 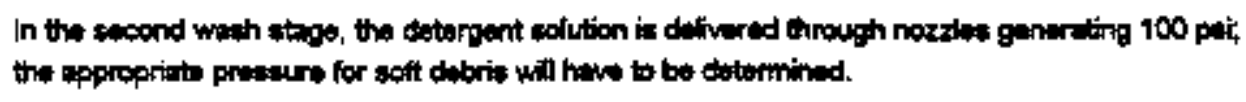 \\
\hline 231 & $\mathbf{5 1}$ & 3 & $\mathbf{Z}$ & 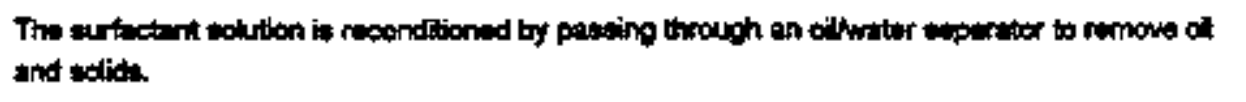 \\
\hline 2.3 .1 & 51 & $\mathbf{3}$ & 4 & 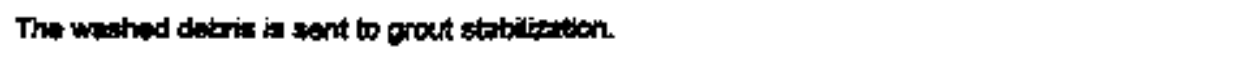 \\
\hline$\$ .4$ & 203 & 4 & 3 & 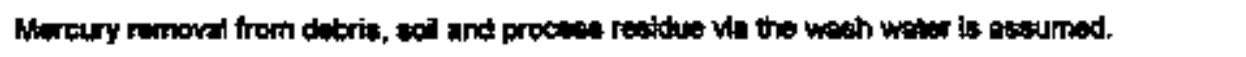 \\
\hline 84 & 200 & 4 & 6 & 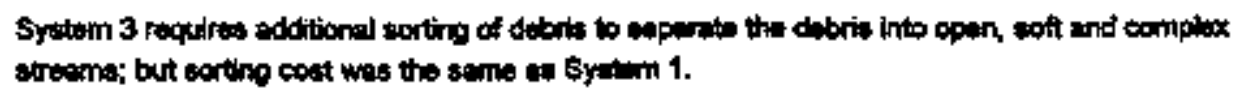 \\
\hline 6.4 & 207 & 6 & 6 & 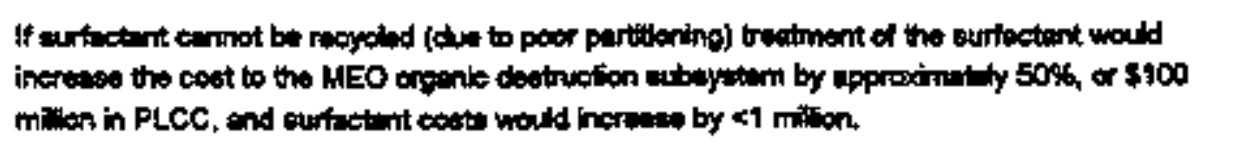 \\
\hline
\end{tabular}

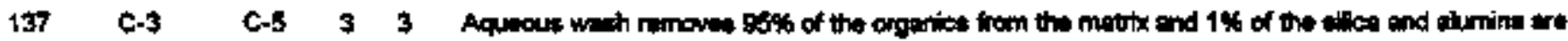

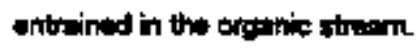


No. Soct Page U:

d-4) Syoum 4 - Ackd Dipustica

$\begin{array}{ccccc}138 & 2 & 31 & 7 & 6 \\ 139 & 2 & 31 & 3 & 2 \\ 140 & 2 & 31 & 7 & 6 \\ 141 & 2 & 31 & 3 & 2 \\ 142 & 2 & 31 & 7 & 6 \\ 143 & 2 & 31 & 7 & 6 \\ & & & & \\ 144 & 2 & 31 & 7 & 6 \\ 145 & 24.1 & 52 & 3 & 4\end{array}$

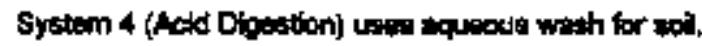
dobris.

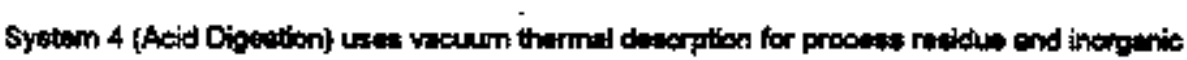
oludga.

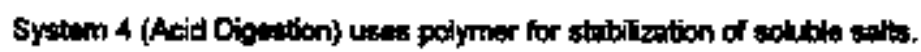

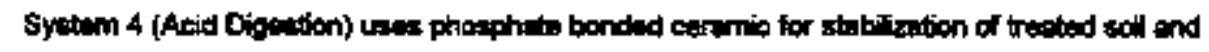
insoltols residues.

System 4 (Acld Digestion) uses phosphoricalite actd digesion for primery orgenic destruction and soft debris tratument.

\$ywem 4 (Aoid Digution) uses hith pressure spray wesh for open debrit.

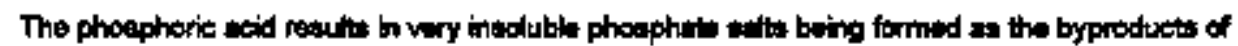
the organic destruction procese; these sabs ene eesly removed and become pert of the phospliats bonded oncmic.

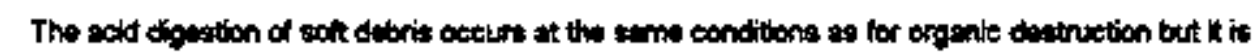

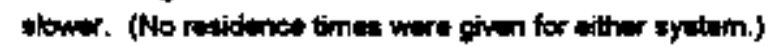

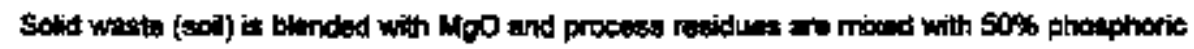

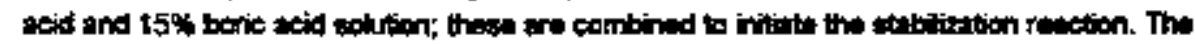

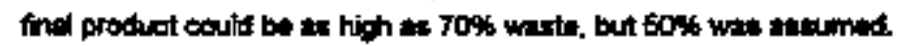

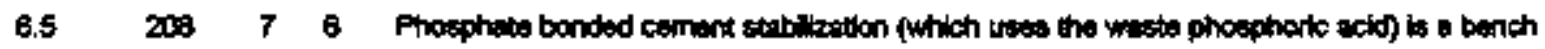

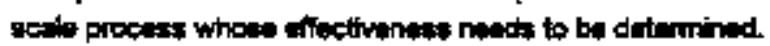

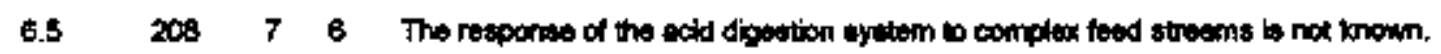

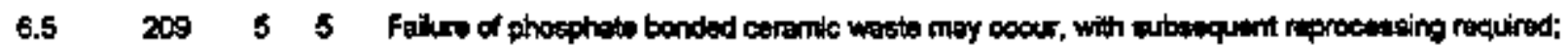

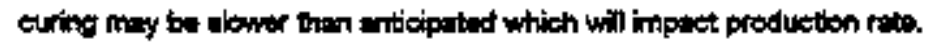

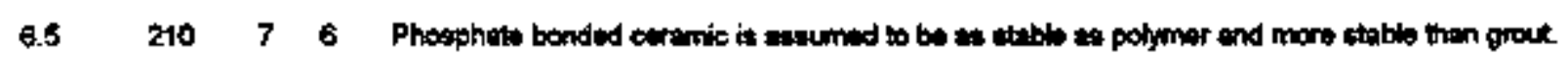

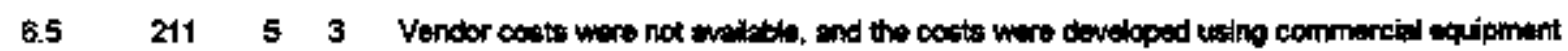

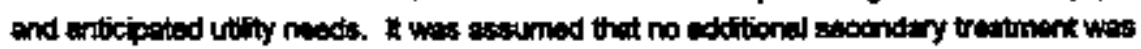
neaded.

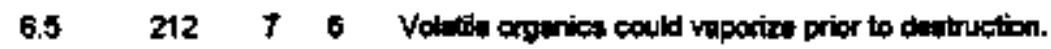

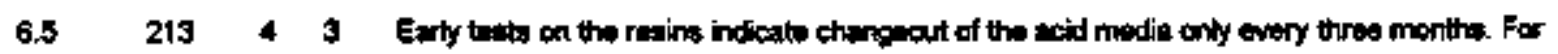

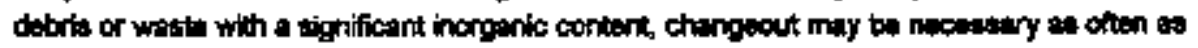
wholdy.

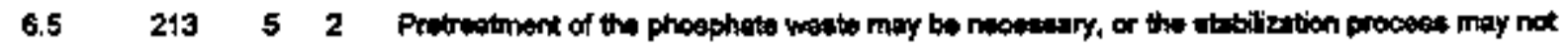
work.

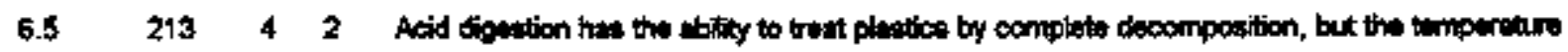

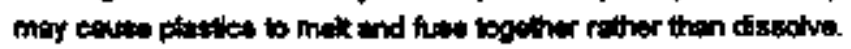

Systiem 5 - Catrbyat wat Oxidetion

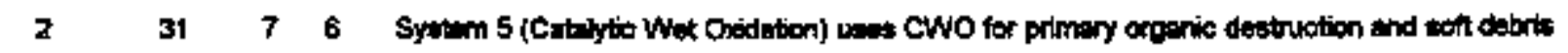
treptument.

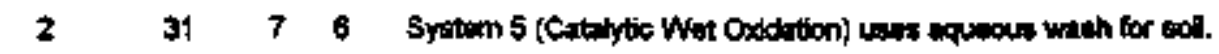


d-5) system a - Cetnlyzed Wet Oxidalion (contiaued)

\begin{tabular}{|c|c|c|c|c|c|}
\hline 150 & 2 & 31 & 3 & 2 & Syatem 5 (Cetelytic Wot Oxdetion) uses grout for stab" 20 tan of tratided deries and sol. \\
\hline 160 & 2 & 31 & $\mathbf{7}$ & 6 & 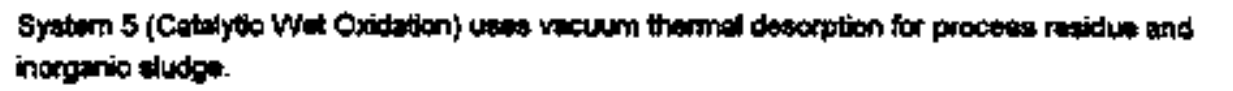 \\
\hline 161 & $\mathbf{2}$ & 31 & 7 & 6 & 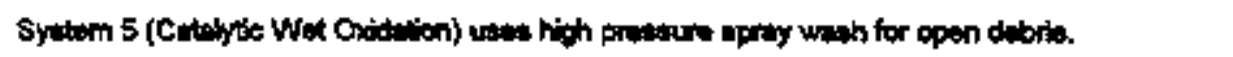 \\
\hline 162 & 2 & 31 & 3 & $\mathbf{z}$ & 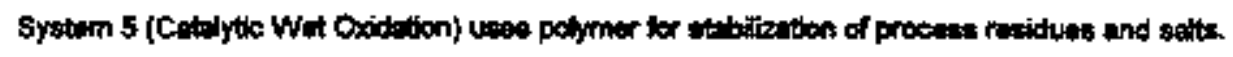 \\
\hline 163 & $\mathbf{2 5 . 3}$ & 55 & 7 & 6 & 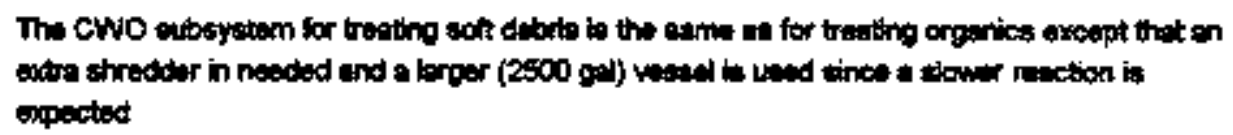 \\
\hline
\end{tabular}

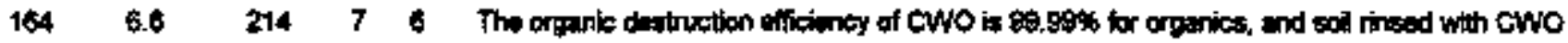

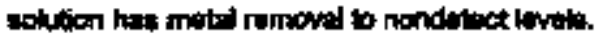

a) Subrystam Deslgn and Optraind Asaumptions

\begin{tabular}{|c|c|c|c|c|}
\hline 165 & 30 & 3 & 5 & 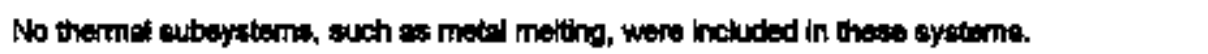 \\
\hline 168 & 30 & 3 & 3 & 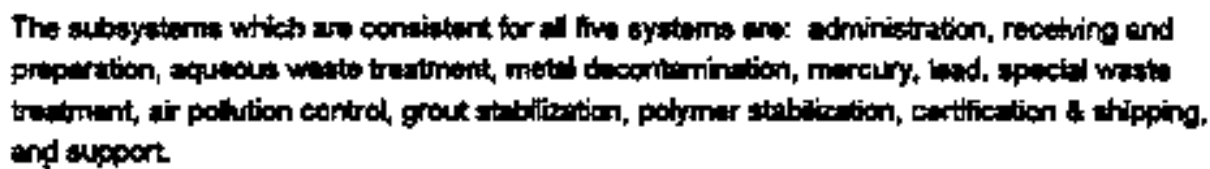 \\
\hline
\end{tabular}

-1) Reowiving and Proparation

\begin{tabular}{|c|c|c|c|c|c|}
\hline 167 & 1.10 .3 & 24 & $\mathbf{5}$ & 8 & 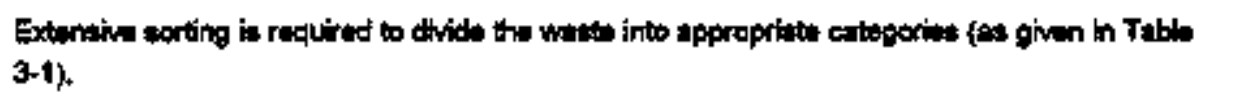 \\
\hline 168 & 2 & 30 & 5 & 8 & 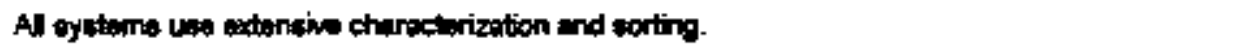 \\
\hline 169 & 2.1 .2 & 34 & 6 & 8 & 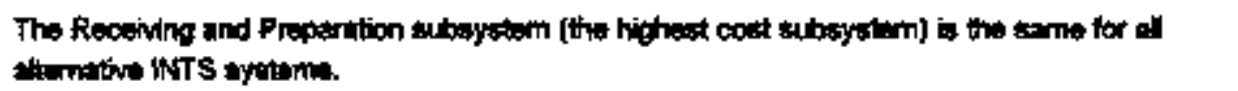 \\
\hline 170 & 1.9 .2 & 17 & $\mathbf{6}$ & 息 & 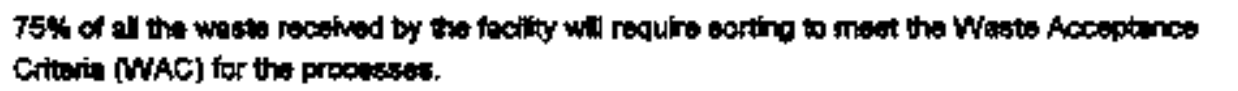 \\
\hline 171 & 1.9 .2 & 17 & $\mathbf{6}$ & 㤩 & 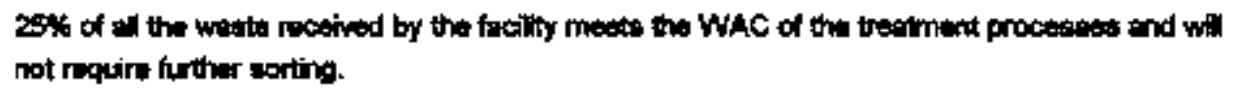 \\
\hline 172 & 6.2 & 187 & a & 6 & 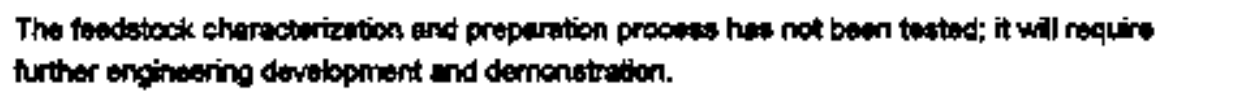 \\
\hline 173 & 6.2 & 204 & 8 & $\mathbf{B}$ & 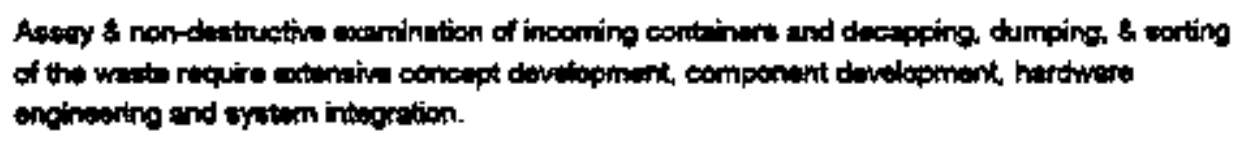 \\
\hline
\end{tabular}

4-2) Organk Destrueton

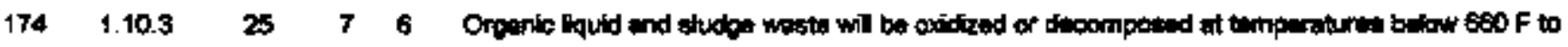

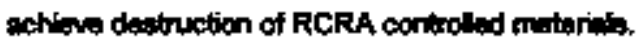

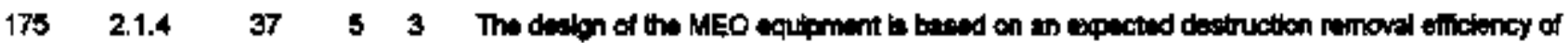 gow for each poent trough the MEO tow.

$175 \quad 2.1 .4 \quad 37 \quad 9 \quad 3$

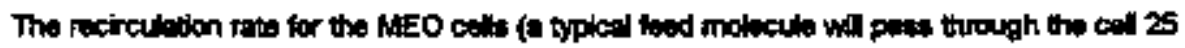

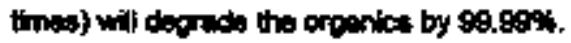


-2) Orativis Dentrition (cominuned)

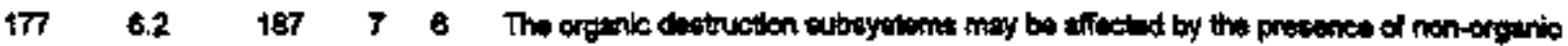

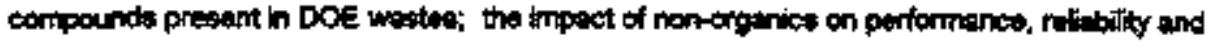
swillability mutat be eddressed. uned for the otudy.

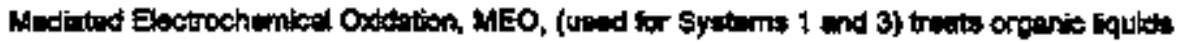

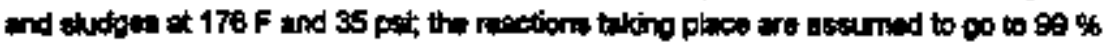

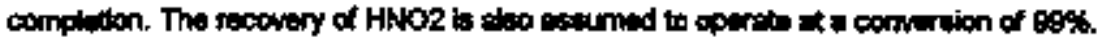

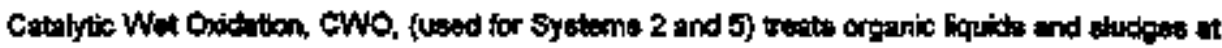

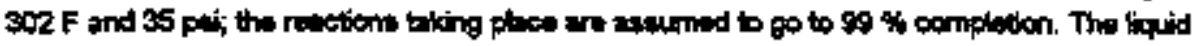

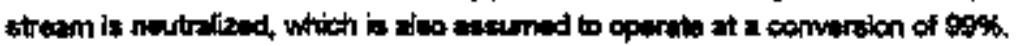

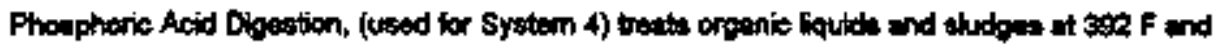

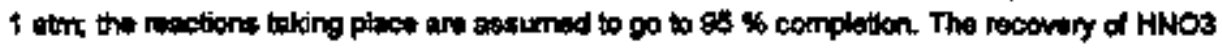
is aloo asoumed to operita at a comverion of $0 \% \%$.

-3) Ar Polutiton Control

\begin{tabular}{|c|c|c|c|c|c|}
\hline 182 & 2.1.13 & 42 & $\mathbf{5}$ & 3 & 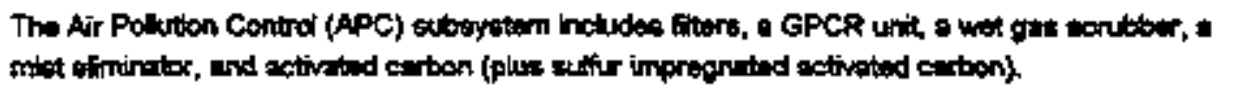 \\
\hline 183 & $\mathbf{2}$ & 30 & 7 & 3 & 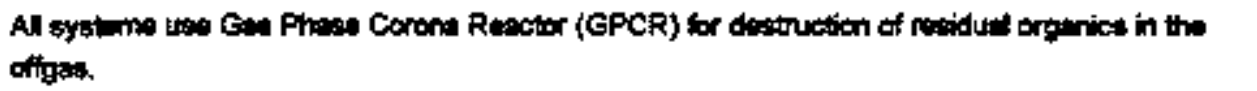 \\
\hline 184 & 2.1.13 & 49 & 8 & $\mathbf{2}$ & 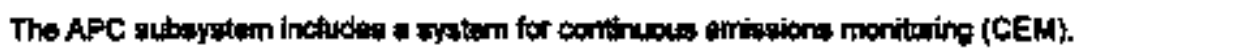 \\
\hline 18S & $\mathbf{6 . 2}$ & 188 & 7 & 4 & 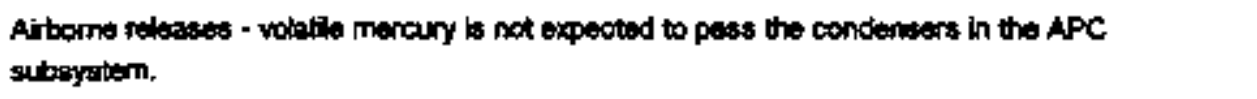 \\
\hline 168 & A-2 & A-9 & $\mathbf{8}$ & 3 & 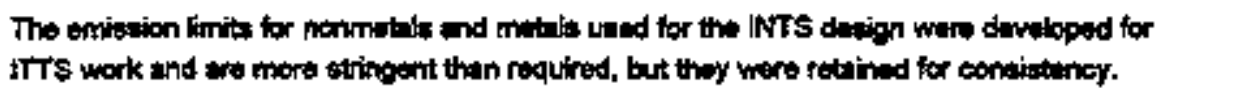 \\
\hline 167 & $A-3$ & A-18 & 8 & 3 & 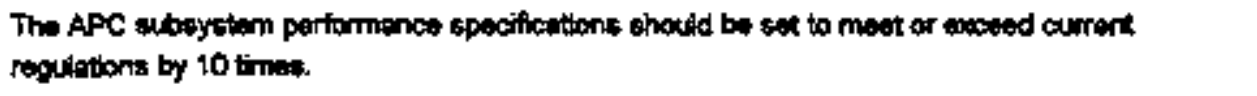 \\
\hline $18: 8$ & C-2 & $c-1$ & 日 & 4 & 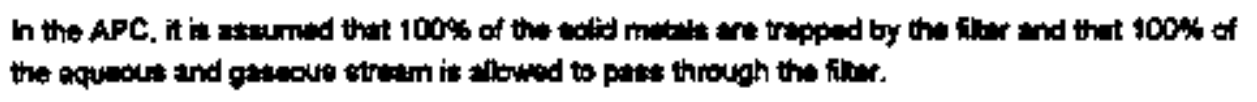 \\
\hline 189 & $c \cdot 2$ & c.1 & 4 & 3 & 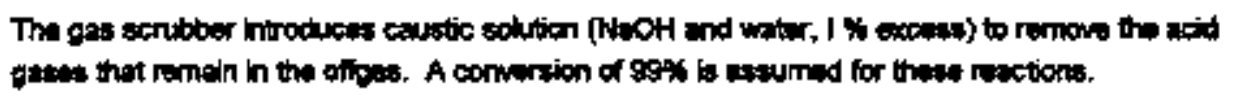 \\
\hline 190 & $c-2$ & $c-1$ & 8 & 4 & 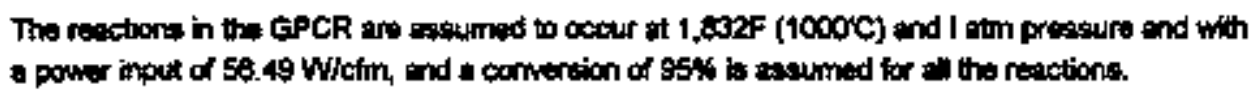 \\
\hline 191 & $c-2$ & $\mathbf{c - 2}$ & 7 & 3 & 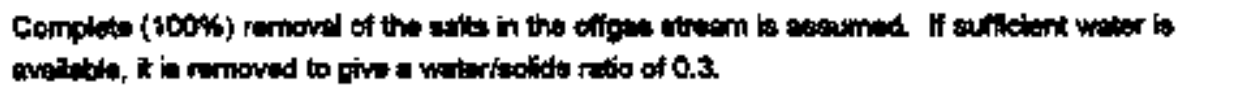 \\
\hline e-4) & \multicolumn{5}{|c|}{ Primury 9tabilzedion (Crout) } \\
\hline 192 & $\mathbf{2}$ & 30 & 3 & 2 & 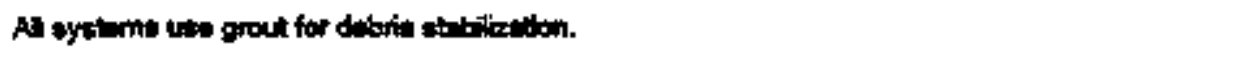 \\
\hline 193 & Z.1.14 & 43 & $\mathbf{8}$ & $\mathbb{\theta}$ & 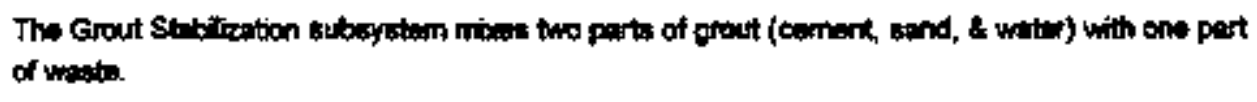 \\
\hline 194 & 6.2 & 180 & 7 & 4 & 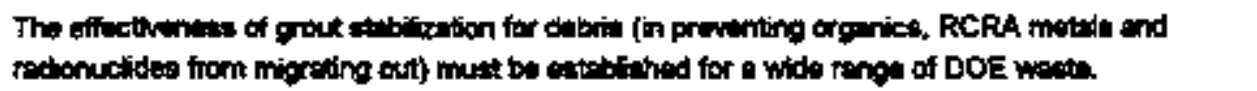 \\
\hline
\end{tabular}


No. Satt. Page $\underline{\text { set }}$

-4) Primery stabilization (Croug pondinuth)

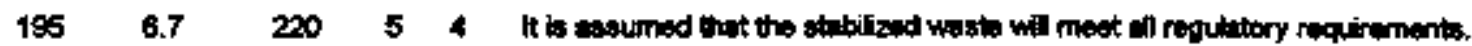

-8) Secondery stabilzation (Polymer)

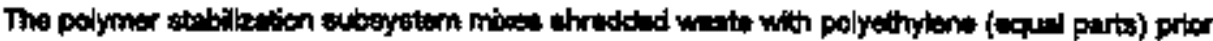
to extrueion

\section{-6) Metid Decontaniantion}

\begin{tabular}{|c|c|c|c|c|}
\hline 1.10 .3 & 25 & 3 & 3 & 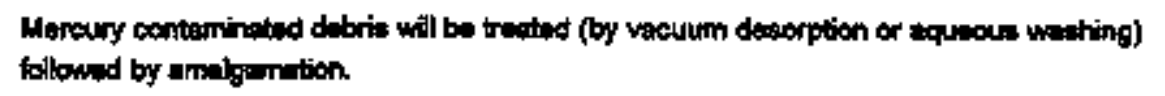 \\
\hline 2 & 30 & 3 & 2 & 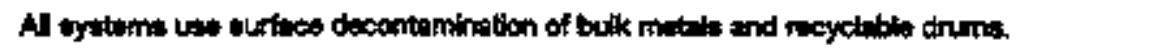 \\
\hline 2.1 .8 & 40 & 3 & $\mathbf{2}$ & 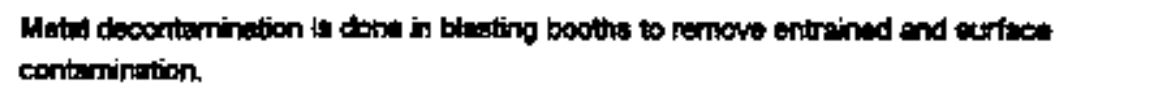 \\
\hline$c-2$ & C-3 & 4 & 2 & 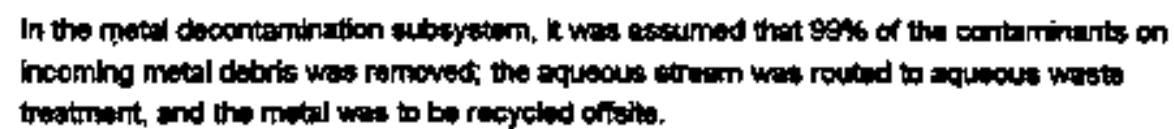 \\
\hline
\end{tabular}

-7 Motal Melting (Hot used in INTS's)

e-6) Lead Recovery

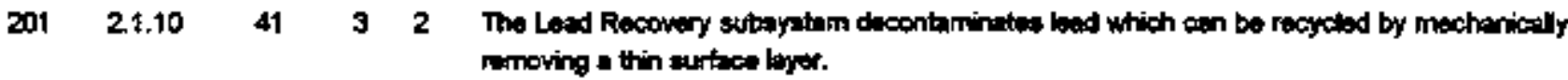

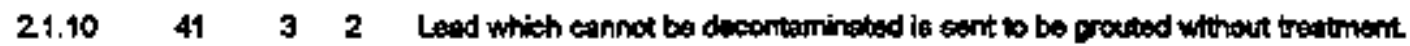

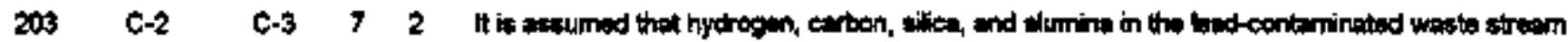

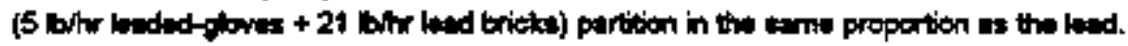

\section{Q-9) Aqueous Wast Treatuent}

\begin{tabular}{|c|c|c|c|c|c|}
\hline 204 & 1.10.3 & 28 & 4 & $\mathbf{8}$ & 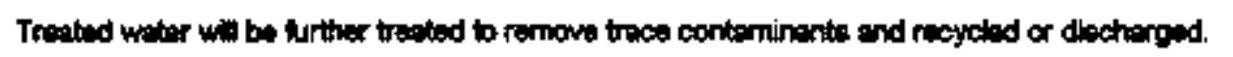 \\
\hline 205 & 1.10 .3 & $\mathbf{2 8}$ & 6 & 3 & 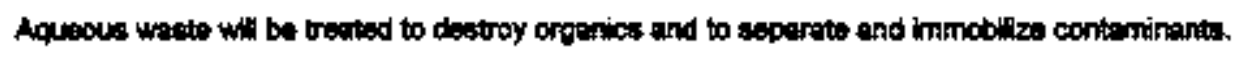 \\
\hline 2008 & 2 & 30 & 6 & 4 & 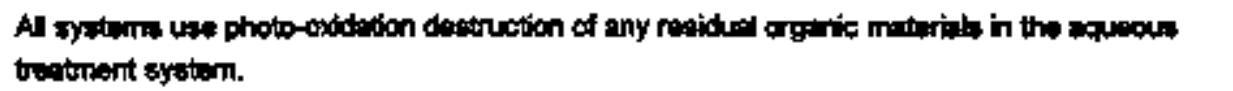 \\
\hline 207 & 2 & 30 & 6 & 4 & 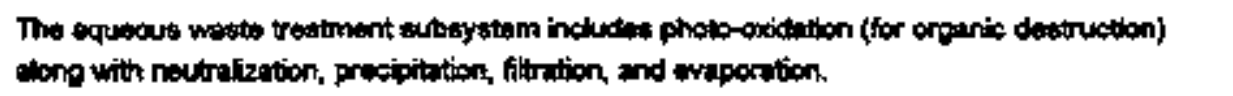 \\
\hline $\mathbf{2 0 8}$ & 2.1.3 & 35 & 4 & 4 & 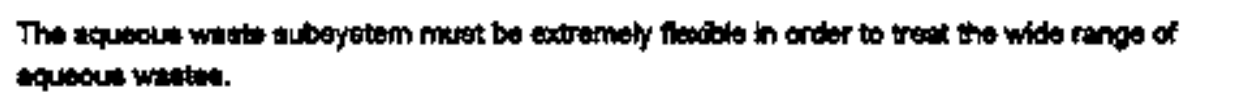 \\
\hline $\boldsymbol{x}$ & 2.1.3 & 35 & $\boldsymbol{B}$ & 4 & 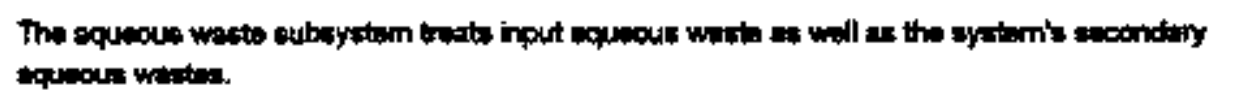 \\
\hline 210 & 2.1 .3 & 35 & 6 & 3 & 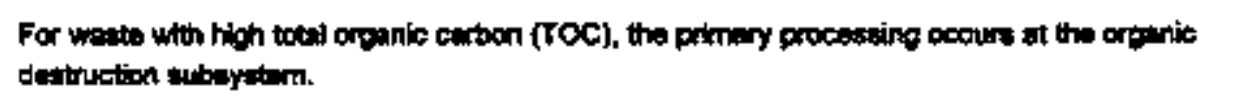 \\
\hline 11 & 2.1 .3 & 38 & 7 & 3 & 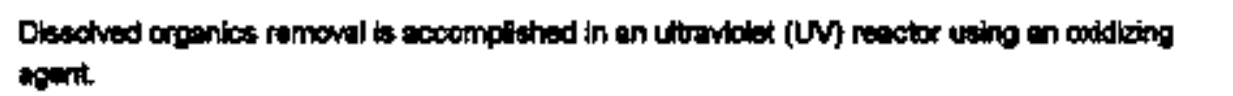 \\
\hline
\end{tabular}




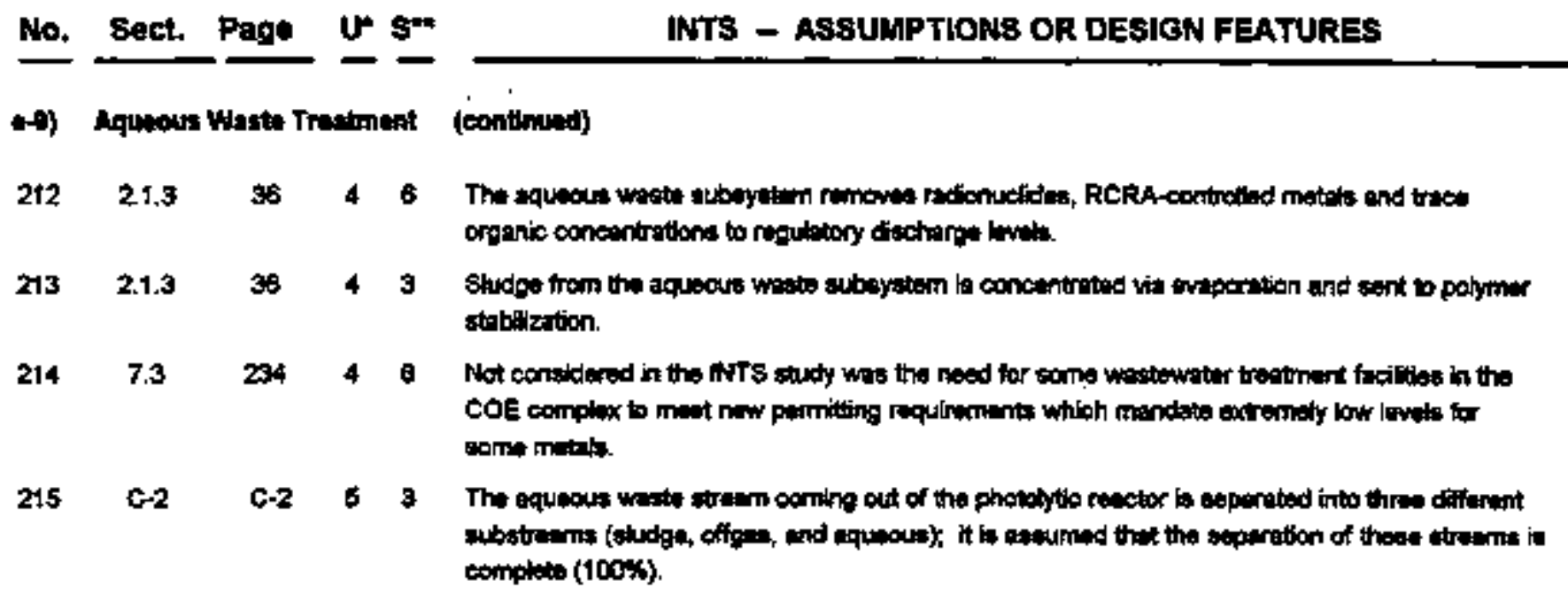

e-10) Mercery Amalasmation

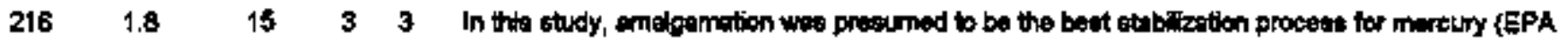 Finiad an aDT).

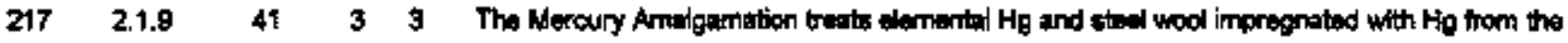

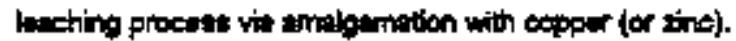

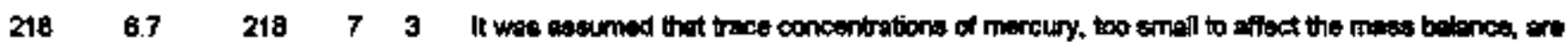

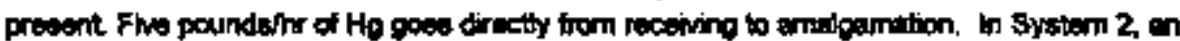

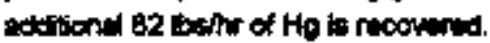

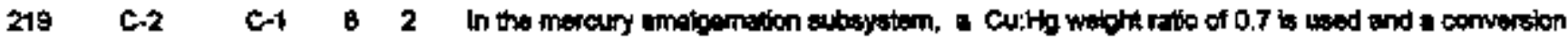 of 100\% is asommd.

-11) Specind Wato Trentimant
200 2.1.14

$\begin{array}{lll}41 & 4 & 4 \\ 41 & 4 & 4\end{array}$

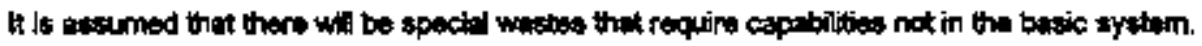
$221 \quad 2.1 .1 \mathrm{t} \quad 41 \quad 4$
226 C $-2 \quad 4 \quad 4$

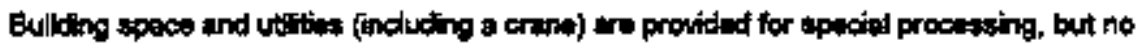 eqpipmank.

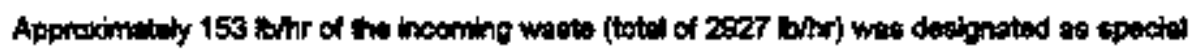

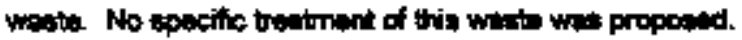

4-12) Certily and ship

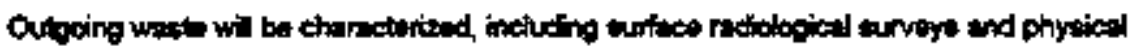 sinvers.

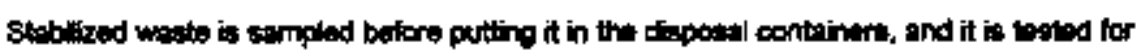 locing.

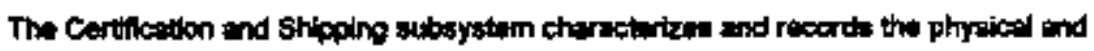 redologicet propertes of the peckeged wiste.

(19) Administration 
No. Sect. Page $\mathbf{u}^{*} \mathbf{8}^{* *}$

-14) Process Residue and lnorganis sindge

\begin{tabular}{|c|c|c|c|c|c|}
\hline 227 & 2.1.5 & 3 & 7 & $\mathbf{B}$ & 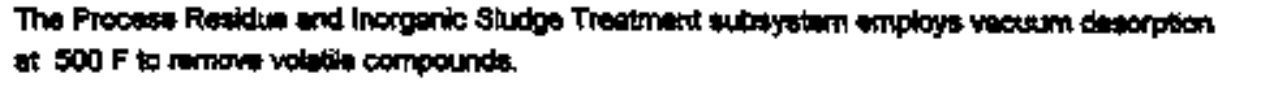 \\
\hline 228 & 2.15 & 40 & $\mathbf{B}$ & $\mathbf{3}$ & 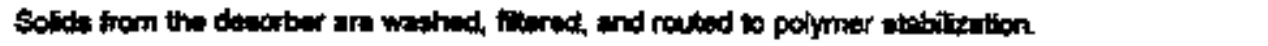 \\
\hline 229 & 2.1 .5 & 40 & 6 & 3 & 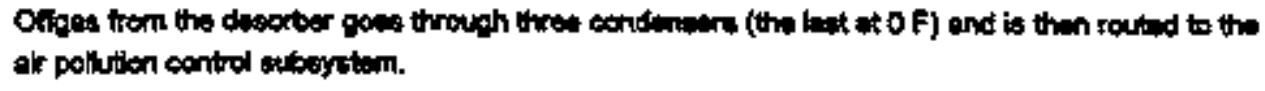 \\
\hline 230 & 8.2 & 195 & 3 & $\mathbf{S}$ & 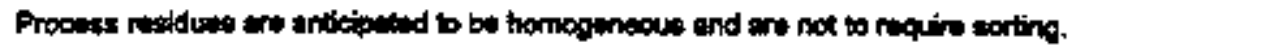 \\
\hline
\end{tabular}

6-15) Bufik soil

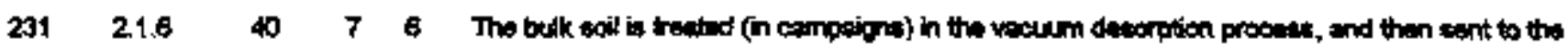 grout otabilization oxhosystom.'

(-18) Dibris

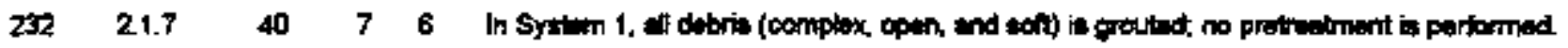

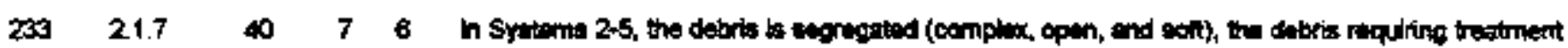 ts ohnedded, and then the debrie ia treictad prior to grouthg.

6-17) support

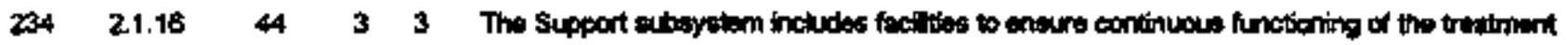

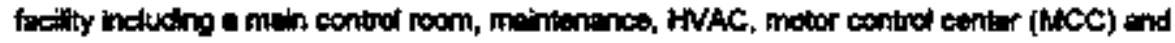 electitad ropris.

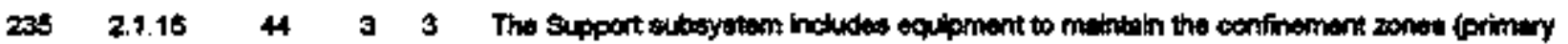

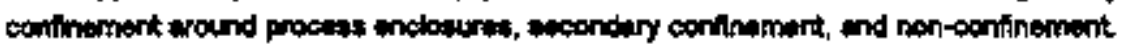

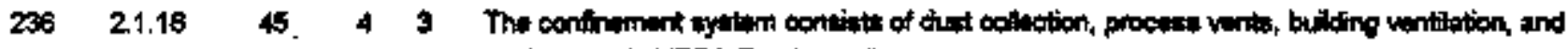 nucles grado HEPA fitrotion unito.
-183 Disposts
$\begin{array}{lll}237 & 1.10 .3 & 27\end{array}$
72

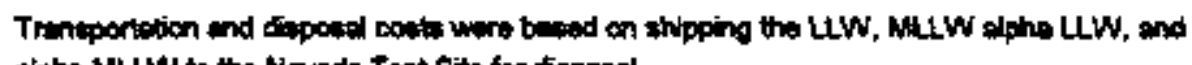

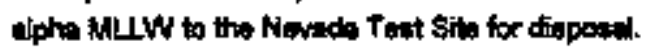

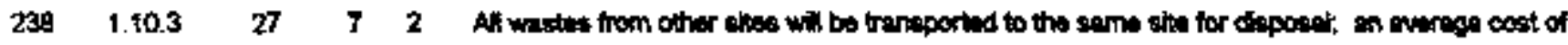 diaposal it uted bor all ehipments.

$2090 \quad 1.10 .3 \quad 27$

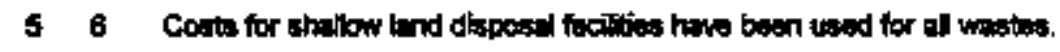
$240 \quad 21.17 \quad 40$
50

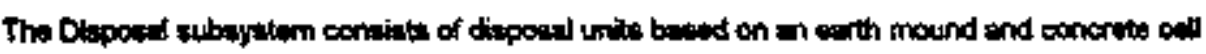 concest.

7 Le Cyche Cost and sensithity Anvyots
$241 \quad 1.8 \quad 15$

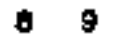

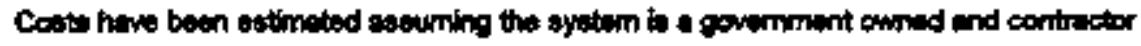 operatied (GOCO) tacky.

$242 \quad 1.9 .3 \quad 18 \quad 8$

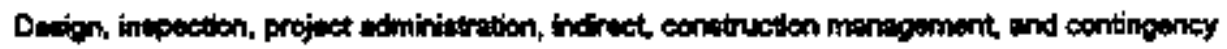

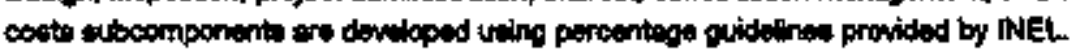




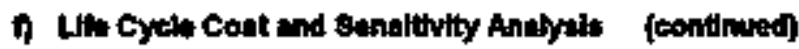

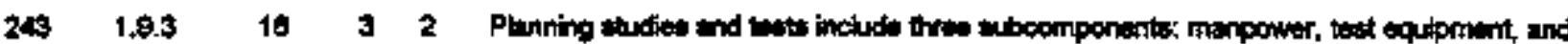

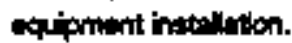

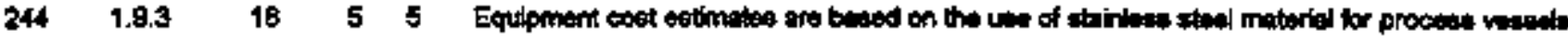

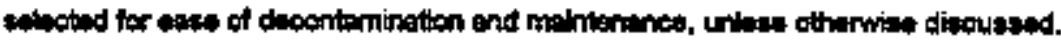

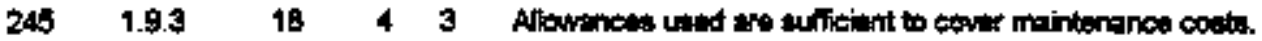

$246 \quad 1.9 .3 \quad 18 \quad 74$ Pro-operations betiog ond otortup will be scosmplithed in ons yent.

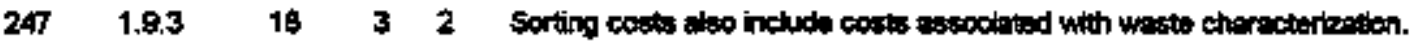

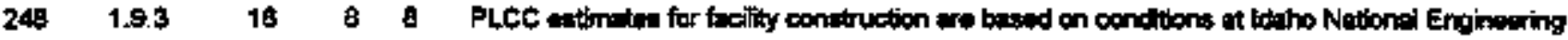

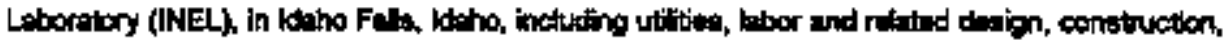
operoitan, end maneament factors.

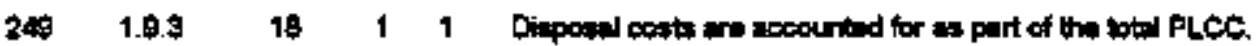

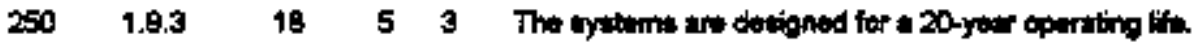

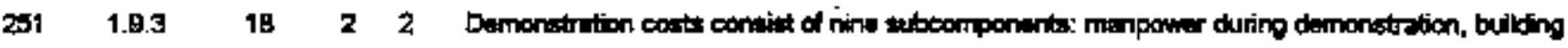
structurs, equpment, design, inepection, project adrinistrotion, indinect, construction mantornate (CM), and contingandy.

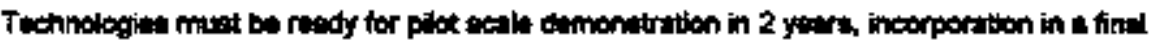
design in 3 yeore, and construction in 5 yeers.

The costs tor each focity are divied into these six components: shdies and bench scalo tests.

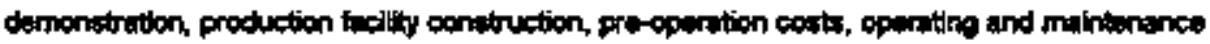

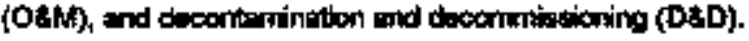

The ellowence percenteges ere historical averages experienced by OOE contractors at INEL

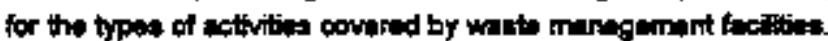

The mointenteres cos eubcomponent to divided into metntenance bace and maintenence reptacement equipment cost The emnud maintenance eqpipment cout to 74 of the original equipment capited coct for most aubeystems. The annul meintenance bobor cost is 250\% of the mintimpnce equipment cont.

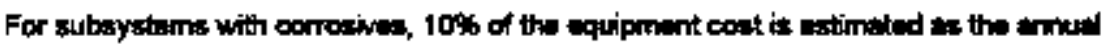

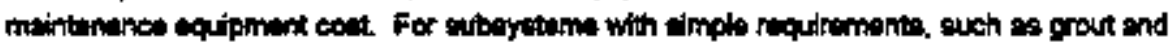

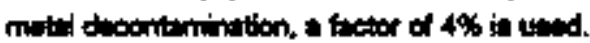

\begin{tabular}{|c|c|c|c|c|c|}
\hline 247 & 3.4 & $\mathbf{2 7}$ & 2 & 2 & 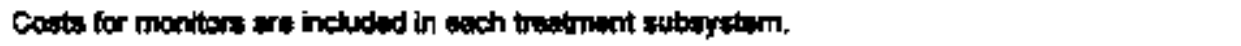 \\
\hline 250 & 3.4 & 100 & 4 & 1 & 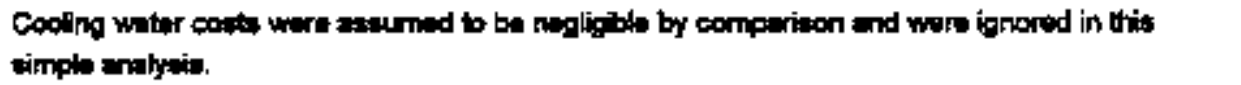 \\
\hline 250 & 3.4 & 100 & 5 & 2 & 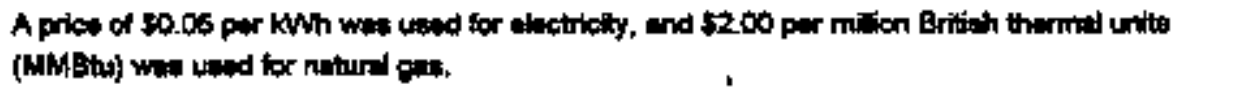 \\
\hline 260 & 4 & 125 & 8 & 6 & 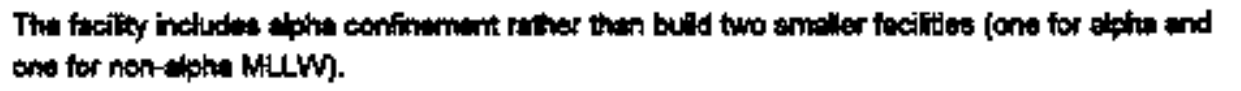 \\
\hline 21 & 4 & 126 & 4 & 3 & 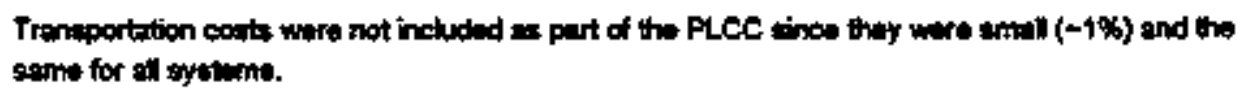 \\
\hline $2 \pi$ & 4.1 & 124 & $\mathbf{B}$ & 㝵 & The time value of money was ignored in this notypie. \\
\hline 263 & 4,1 & $12 \theta$ & 7 & 2 & Coot information obsined during awcond helf of 1985 . \\
\hline
\end{tabular}


1) Whe Cyob Cost and senitivity Analysts (continued)

\begin{tabular}{|c|c|c|c|}
\hline 284 & 4.21 & 128 & 3 \\
\hline 285 & 4.22 & 129 & 8 \\
\hline 286 & 422 & 128 & 8 \\
\hline 267 & 4.2 .2 & $12 \mathrm{~s}$ & 1 \\
\hline 268 & 4.2 .2 & 128 & B \\
\hline 269 & $\mathbf{4 . 2 . 2}$ & 128 & 1 \\
\hline 270 & 4.2 .2 & 126 & 6 \\
\hline 271 & 4.2 .2 & 126 & 6 \\
\hline 272 & 4.2 .2 & 128 & 6 \\
\hline 273 & 4.2 .2 & 126 & 5 \\
\hline 274 & 4.2 .2 & 127 & 2 \\
\hline 275 & 4.22 & 127 & $\mathbf{Z}$ \\
\hline
\end{tabular}

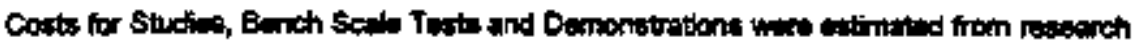

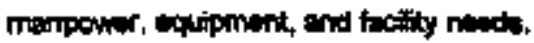

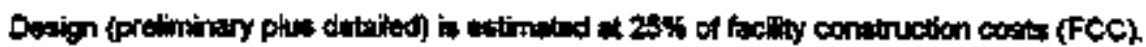

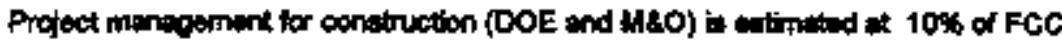

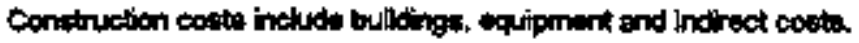

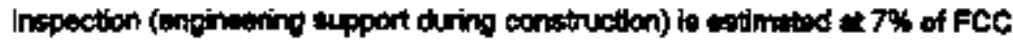

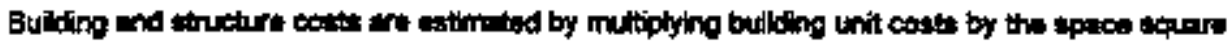

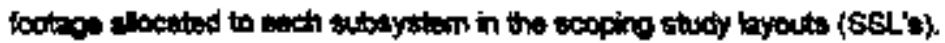

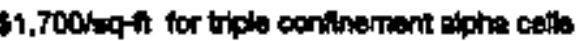

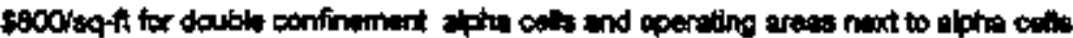

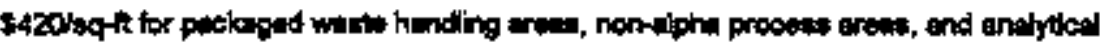
umboratorien

5180hereft we sifice topece

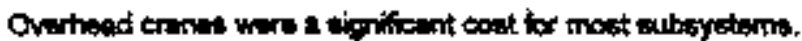

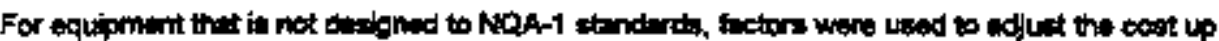

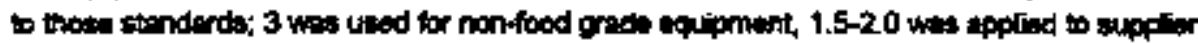
co:t.

$278 \quad+22 \quad 127 \quad 1 \quad 1$

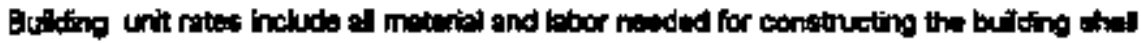

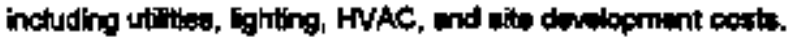

$27 \quad 4.22 \quad 127 \quad 1$

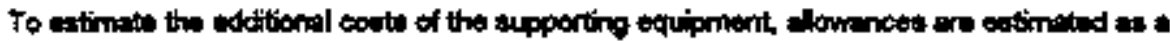

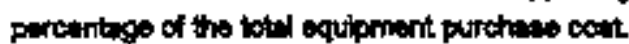

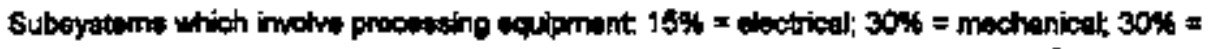
instumentition'

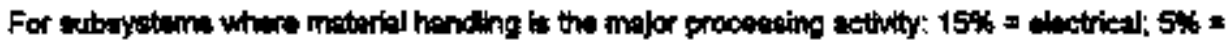
mechonical; $\mathbf{5 \%}=$ ingtrumentation.

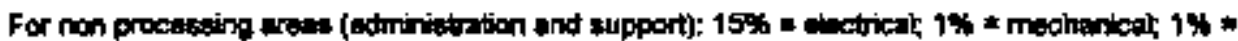
instrumertiotion.

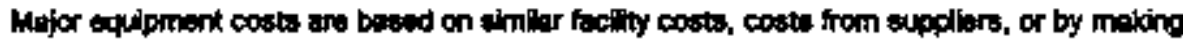

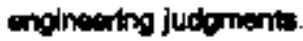

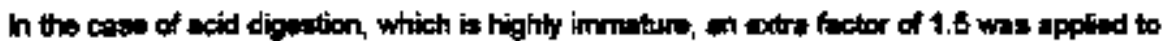

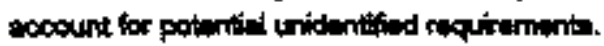

$293 \quad 4.22 \quad 127 \quad 3 \quad 3$

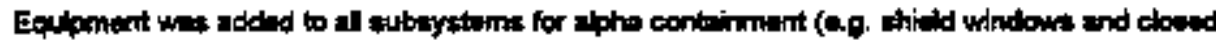
sircult bitriaion).

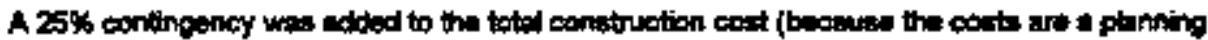
lavil atimatol).

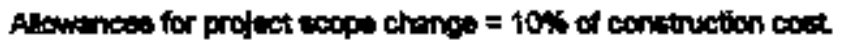


No. Sect. Page Us 8*

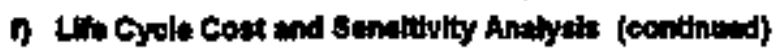

\begin{tabular}{|c|c|c|c|c|c|}
\hline 286 & 4.22 & 123 & 1 & 1 & 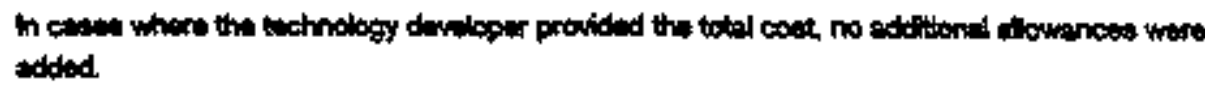 \\
\hline 260 & 4.23 & 128 & $\mathbf{a}$ & 3 & Concepheal deaign is estumated at $1.5 \%$ of construetion cost. \\
\hline 290 & 4.2 .3 & 128 & 4 & 6 & 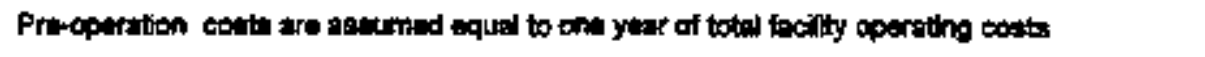 \\
\hline 291 & 4.2 .3 & 120 & 7 & 4 & 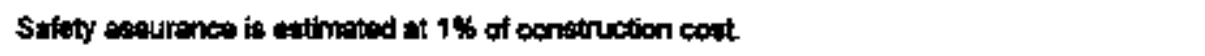 \\
\hline 292 & 4.2 .3 & 128 & 7 & $\mathbf{3}$ & $\$ 7$ milian is the extimpind cont for al permith. \\
\hline 293 & 4.2 .4 & 120 & 3 & 7 & 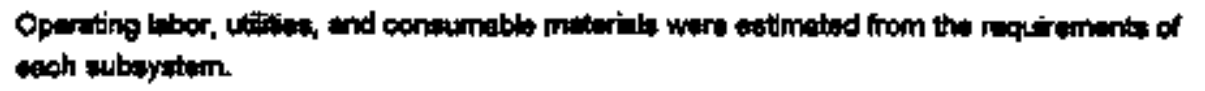 \\
\hline 294 & 4.2 .4 & 129 & 4 & 6 & 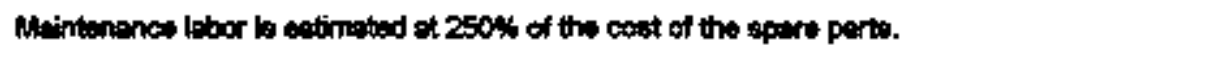 \\
\hline 285 & 4.2 .4 & 129 & 4 & 4 & 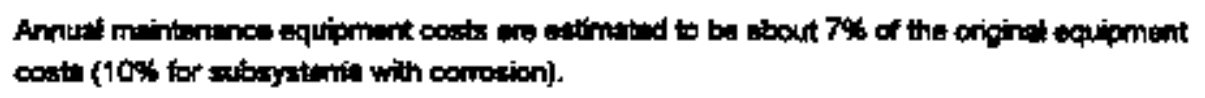 \\
\hline 296 & 4.25 & 129 & 7 & 4 & 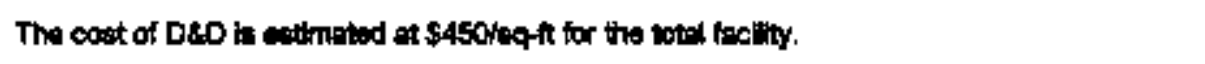 \\
\hline 297 & 4.2 .6 & 129 & 1 & 1 & The PLCC cost estimate in the sum of the component costs. \\
\hline 299 & 4.3 & 729 & 8 & 6 & 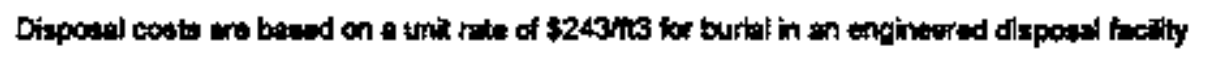 \\
\hline 29 & 4.4 & 128 & 1 & 1 & Total PLCC is the PLCC phe the ditpoul costs. \\
\hline 300 & 4.5 & 130 & 1 & 1 & 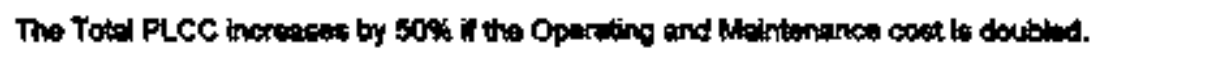 \\
\hline 301 & $4 . \$$ & 130 & t & 1 & The Totol PLCC inereates by 23\% if the DAepossal coet is docteled. \\
\hline 302 & 4.6 & 131 & 8 & 6 & 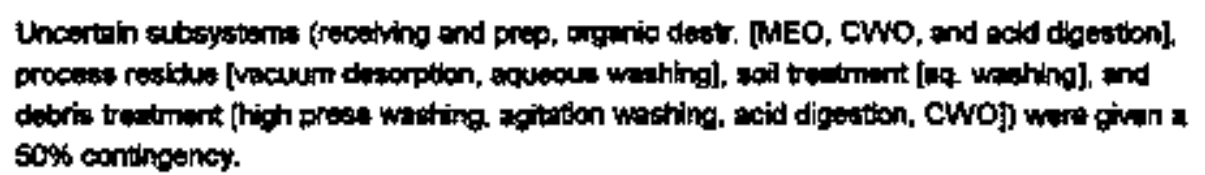 \\
\hline
\end{tabular}

\begin{tabular}{|c|c|c|c|c|c|}
\hline 300 & 4.6 & $\{31$ & 1 & 1 & 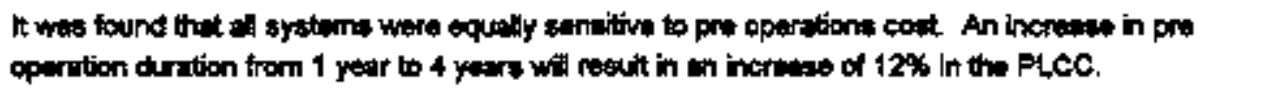 \\
\hline 304 & 4.7 & 132 & 1 & 1 & 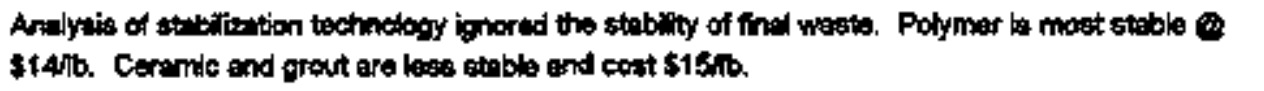 \\
\hline 305 & 4.8 & 132 & 3 & $\mathbf{2}$ & Trensiportation costs have not been inctured in the PLCC. \\
\hline 300 & 4.9 & 134 & $\mathbf{3}$ & 2 & 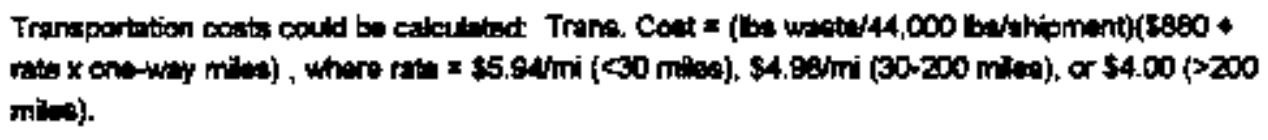 \\
\hline 307 & 4.2 .4 & 135 & • & $\$$ & 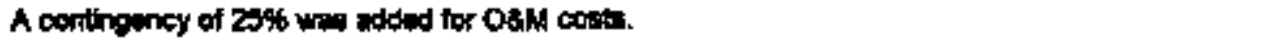 \\
\hline 308 & 5.1 .4 & 160 & 3 & 2 & 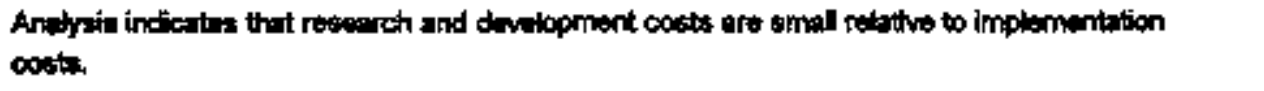 \\
\hline 309 & $\$ 1.4$ & 94 & 8 & 1 & 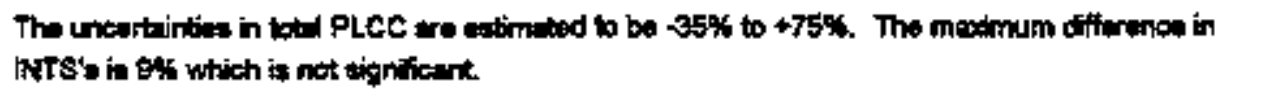 \\
\hline 310 & 5.1.5 & Ies & 8 & 3 & 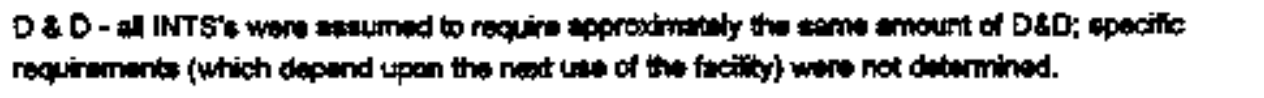 \\
\hline 311 & 5.1 .5 & 165 & 6 & 3 & 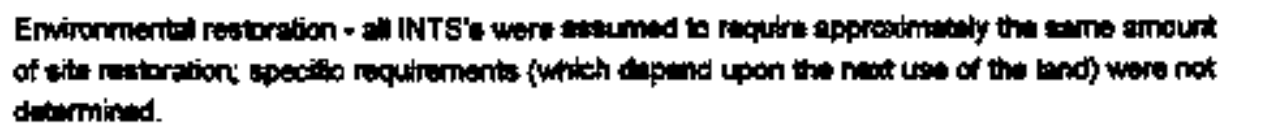 \\
\hline
\end{tabular}


No. sect. Page Un ses

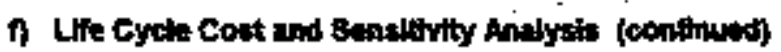

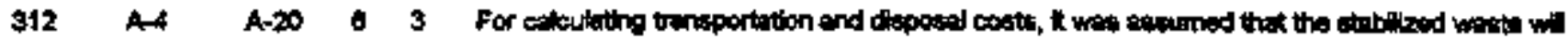

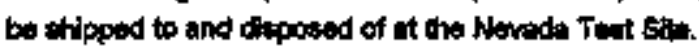

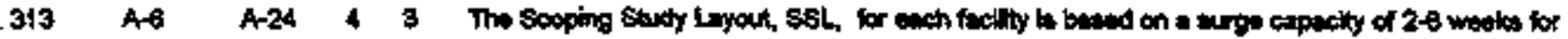

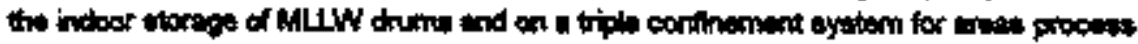 alpha-contaminated MLLW.

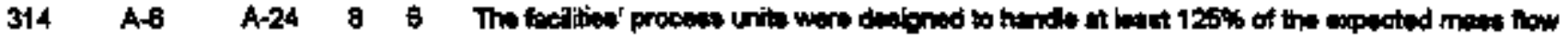 roted.

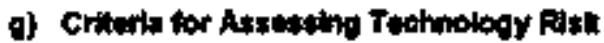

\begin{tabular}{|c|c|c|c|c|c|}
\hline$\$ 16$ & 5.1 .1 & 159 & 2 & 2 & 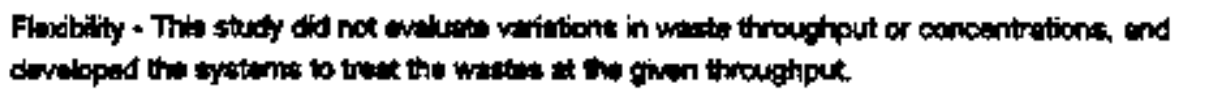 \\
\hline 310 & 5.1 .1 & 159 & 2 & 2 & 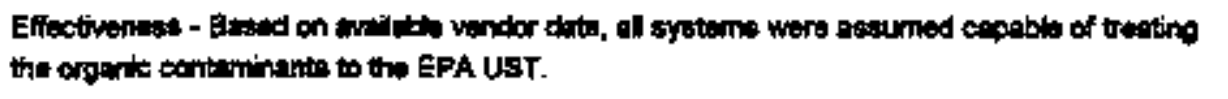 \\
\hline 317 & $5.1 . t$ & 159 & 2 & 2 & 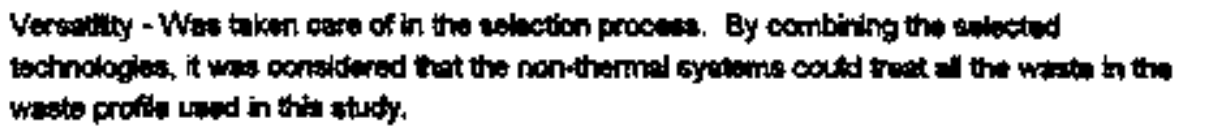 \\
\hline 316 & $5.1+1$ & 100 & 2 & 2 & 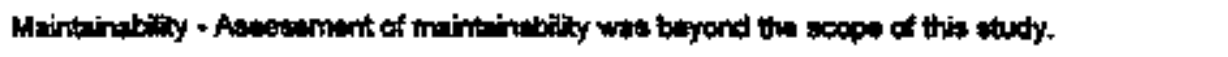 \\
\hline 319 & 5.1.t & 160 & 2 & 2 & 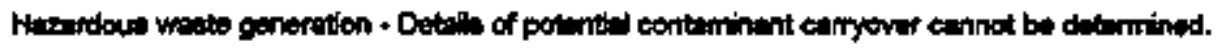 \\
\hline 320 & \$.1.1 & 160 & 2 & 2 & 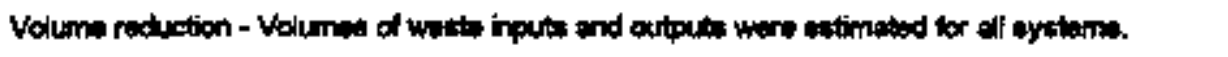 \\
\hline 321 & $5.1,1$ & 160 & 2 & 2 & 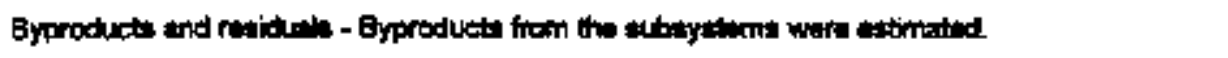 \\
\hline 322 & $\$ .1 .1$ & 160 & 2 & 2 & 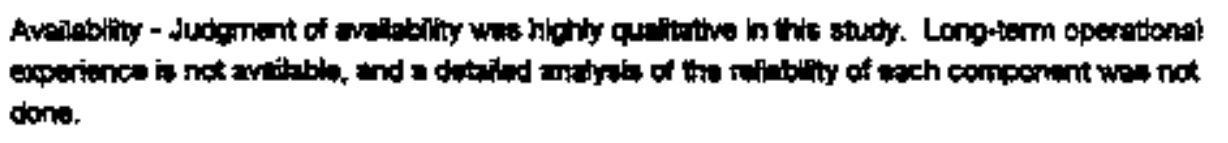 \\
\hline 323 & $5.1 . t$ & 160 & $\mathbf{2}$ & 2 & 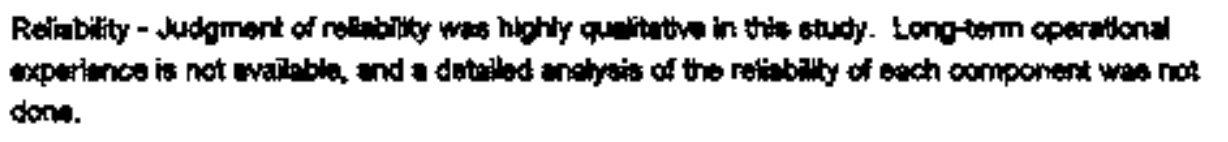 \\
\hline 324 & 5.1 .1 & 160 & $\mathbf{2}$ & 2 & 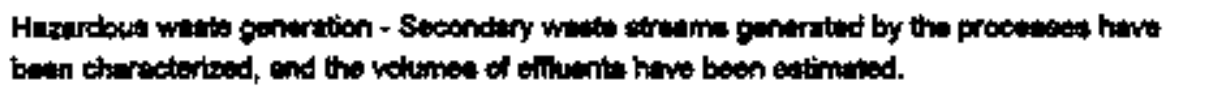 \\
\hline 325 & 5.1 .1 & 161 & 2 & 2 & 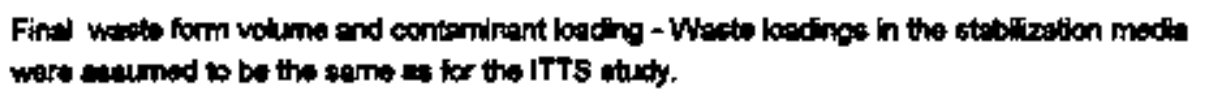 \\
\hline 328 & 5.1 .2 & 161 & 2 & 2 & 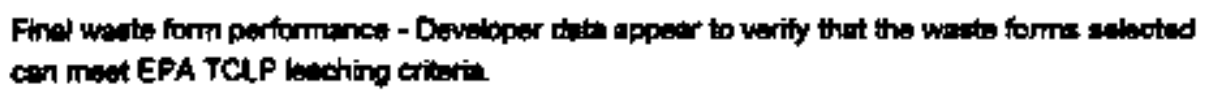 \\
\hline 327 & 5.1 .2 & 161 & 2 & 2 & 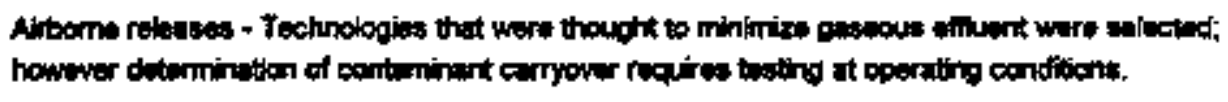 \\
\hline 328 & $\mathbf{5 . 1 . 2}$ & $16 t$ & 2 & 2 & 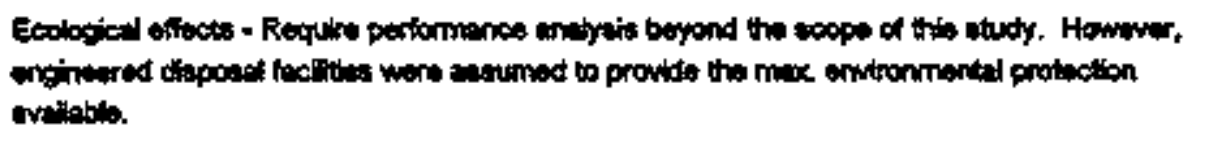 \\
\hline 329 & 5.1 .2 & 191 & 2 & 2 & 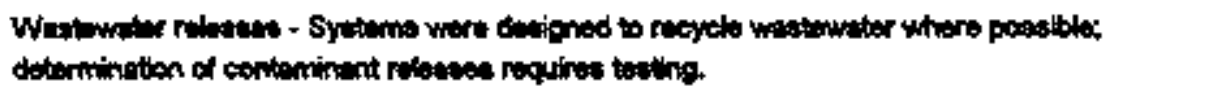 \\
\hline 330 & 5.1 .3 & 1ez & 2 & 2 & 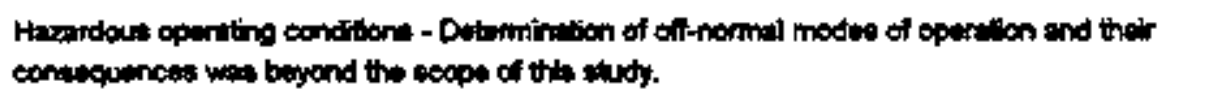 \\
\hline
\end{tabular}




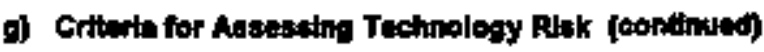

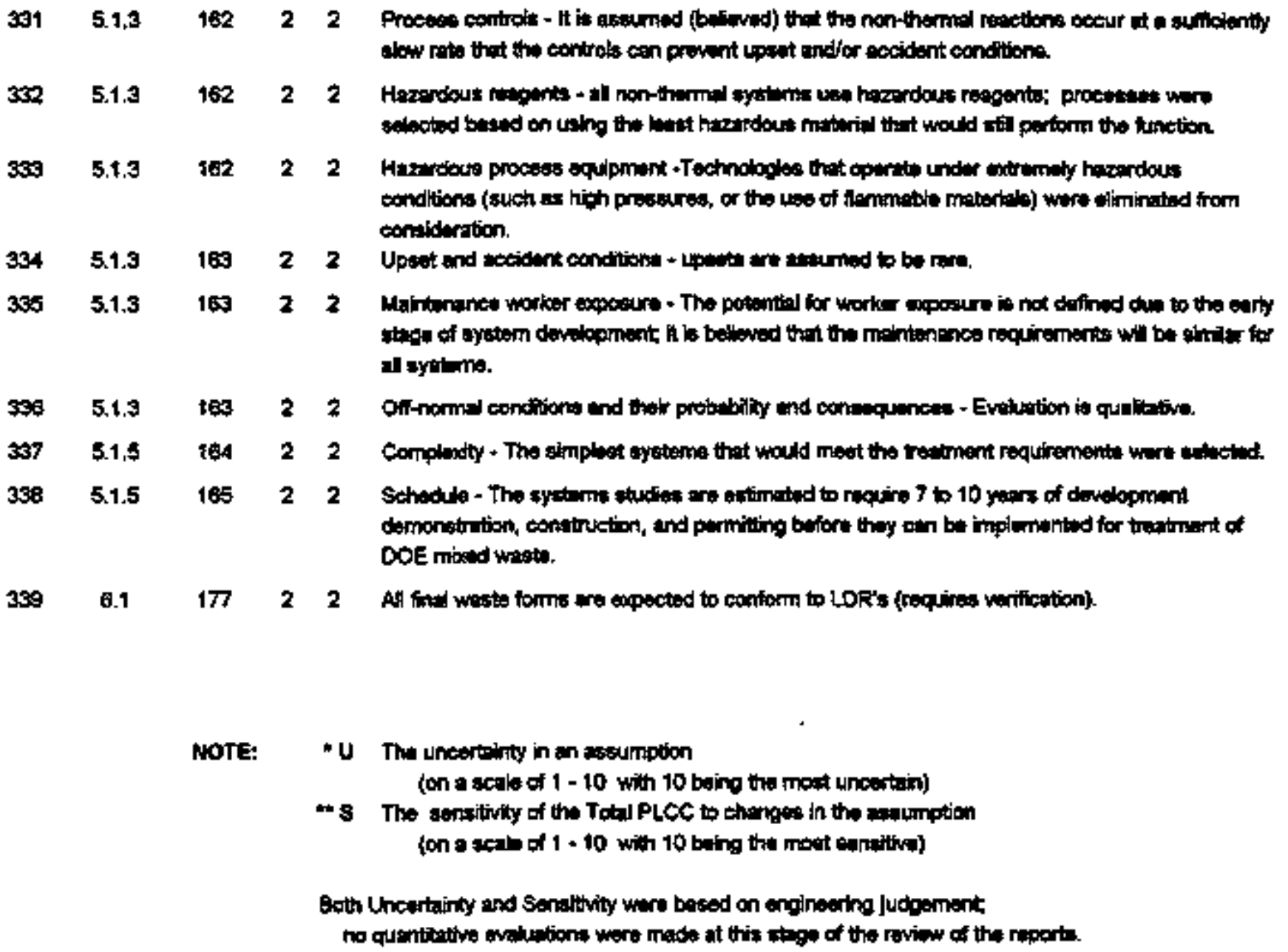




\section{APPENDIX G}

\section{ASSUMPTIONS FROM THE ITTS PHASES 1 AND 2 REPORTS AND THE INTS REPORT WITH HIGH COST SENSITIVITY AND UNCERTAINTY}


App D

No. Ho. 8ect Page U* gm

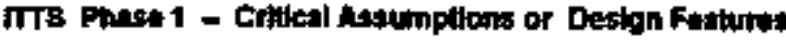

a) Regulatoms, Permitting and Stakehoider inquit

$\begin{array}{llllll}1 & 11 & \text { A.1.5.4 A.7 } & 9 & 7\end{array}$

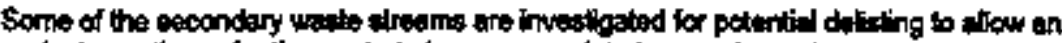

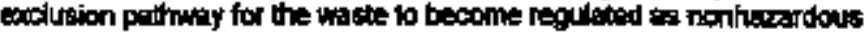

$\$ \quad 100$ A-4.4.2 A.31 $7 \quad 7$

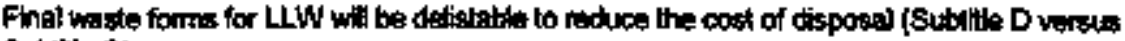
Sublite C).

b) Inpux Wioste Characieristics

\begin{tabular}{|c|c|c|c|c|c|}
\hline 108 & 3.3 & 58 & 8 & 8 & 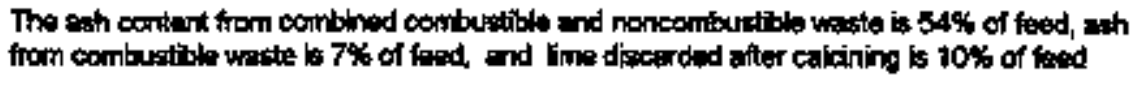 \\
\hline 271 & 2.1 .1 & 17 & 6 & 8 & 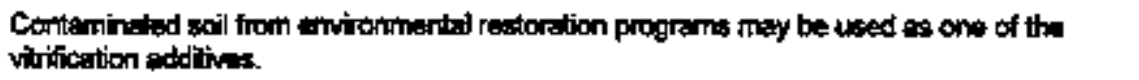 \\
\hline 374 & 2.1.10 & 21 & 7 & 7 & 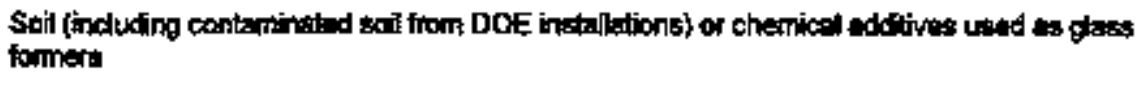 \\
\hline 38 & A-5.1 & A-19 & 8 & 7 & The ITTS shall thent the wask typa dascribed in Toble A-4 of Phase 1 report \\
\hline
\end{tabular}

d) General Design and Operaling Assumptions

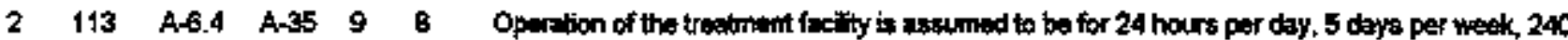

days per year, at $70 \%$ sapecty duriog oparition. This is equivalent to 4032 hours per year.

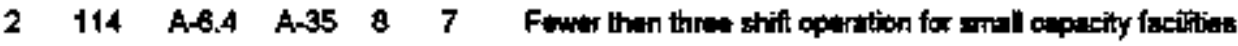

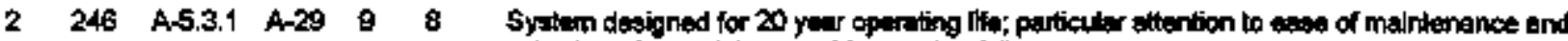

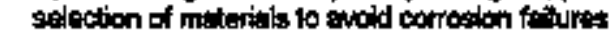

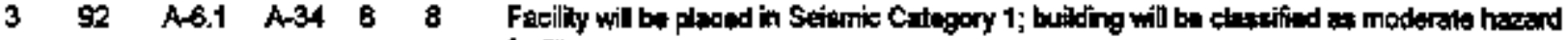
faclity

$\begin{array}{llllll}4 & 91 & 1.3 .2 & 10 & 8 & 7\end{array}$

$5 \quad 265 \quad$ A.5.3.2 A.30 $7 \quad 7$

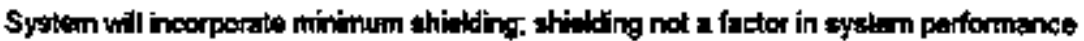

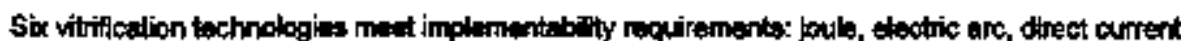

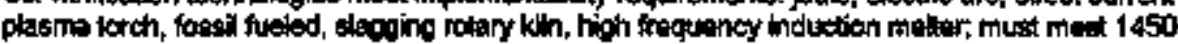

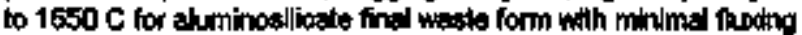

$\begin{array}{rrrrr}- & 103 & 3.3 & 58 & 9\end{array}$

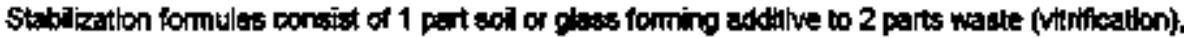
1 part polymer to i part wate (polymer stablization), 2 perts grout to 1 part witste (Gout stabizizat|on)

d-5) System AS - Rolary Kan wilh AIr and Polymer \$tabileation

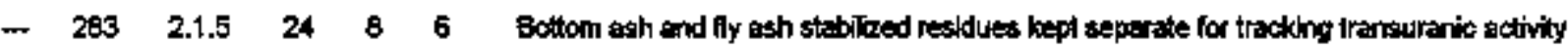

d-7) 8ystem 81 - Indlreetty Hoated Pyolyzer with Oxyoen and Dryhtht APC

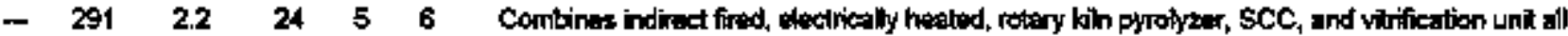

fred on woygen

1. $340 \quad 2.1 .1 .2 \quad 25 \quad 5 \quad 6$

Pyrclyzer, SCC. ding are intedraded with vitification unlt

Q-1) Recetwing and Preparation

$\begin{array}{llllll}6 & 325 & 2.1 .1 & \text { 18 } & 9 & 6\end{array}$

Systems Af - A6 and C1: it is sesumed thet 51\% of the wette requirs sorting (Tabla 3-9 Phane 2 report?

$\begin{array}{lllll}727 & 2.1 .1 .1 & 18 & 9 & 8\end{array}$

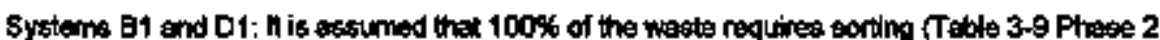
reporit)

$\begin{array}{lllll}- & 328 & 2.1 .1 & 18 & 9\end{array}$

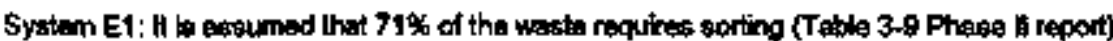

(-3) Ar Poilition Control (APC)

$\begin{array}{llllll}8 & 104 & 3.3 & 58 & 7 & 8\end{array}$

CO2 absorption, Ene recycting is $90 \%$ and rejection is $10 \%$

$\begin{array}{llllll}9 & 370 & 21.1 .4 & 19 & 7 & 7\end{array}$

$\begin{array}{llllll}B & 371 & 21.1 .4 & 19 & 7 & 7\end{array}$

Lime or dolomite recycded up to ten times in caleining line zecowery system

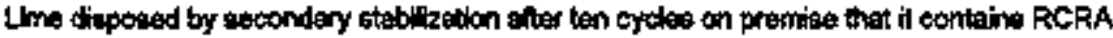
metals and is subiect to dipposal restriction:

$\begin{array}{llllll}8 & 278 & 2.1 .4 & 20 & 7 & 7\end{array}$

$\begin{array}{llllll}8 & 279 & 2.1 .4 & 23 & 7 & 7\end{array}$

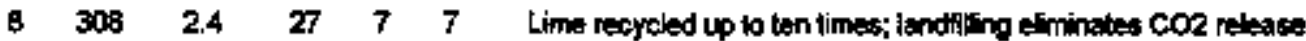

e-4a5) Stabtitiation (Primary and Secondary)

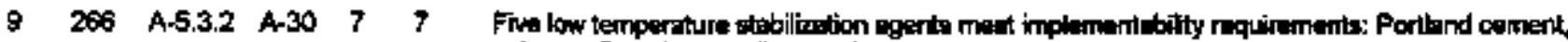

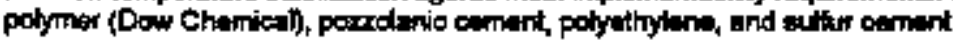




\begin{tabular}{|c|c|c|c|c|c|c|}
\hline Ho. & $\operatorname{mp}_{\text {M. }} D$ & sect. & Poge & tr & s. & 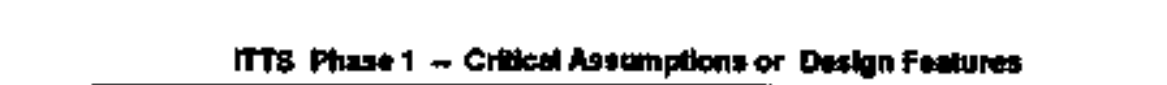 \\
\hline ㄷA미 & OH:py & |atal & & & & \\
\hline 1 & 462 & 4.3 & $\mathbf{8 2}$ & $\mathbf{9}$ & $\theta$ & 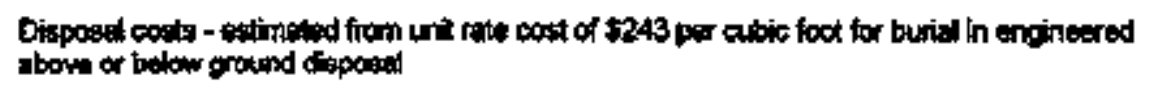 \\
\hline 1 & 85 & A.4,4.1 & A.30 & $\mathbf{a}$ & 9 & 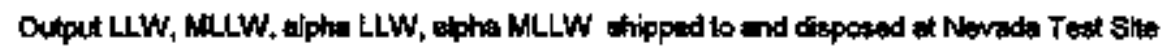 \\
\hline 1 & 84 & & & $\mathbf{8}$ & $\mathbf{8}$ & 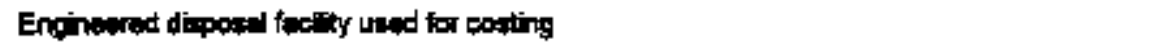 \\
\hline 1 & $\infty$ & A-4.4.2 & A-31 & $\mathbf{5}$ & 7 & 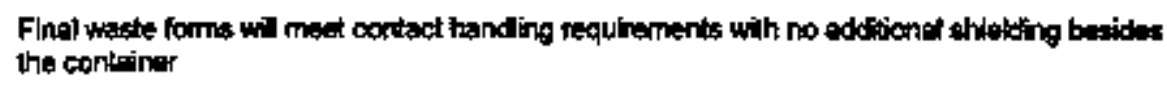 \\
\hline
\end{tabular}

i Lita Cycie Cost and Sensittrity Anabysis

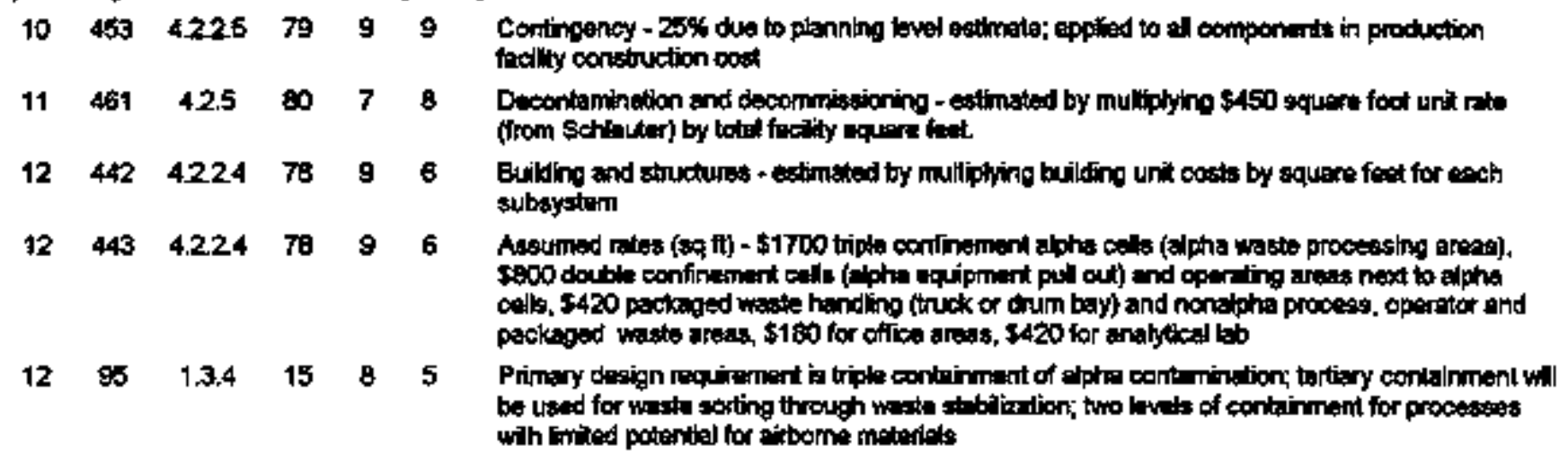


a) Regulations, Perminting and Siakeholder input

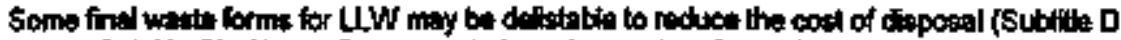

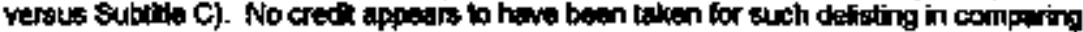
difierent myetem: in this study.

\begin{tabular}{|c|c|c|c|c|c|c|}
\hline 1 & 243 & 43 & $4-4$ & 8 & 7 & 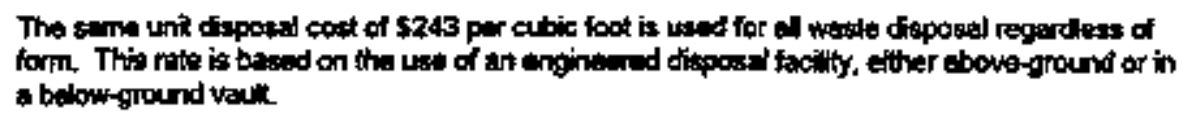 \\
\hline 1 & 208 & 4.6 & 4.6 & 7 & 8 & 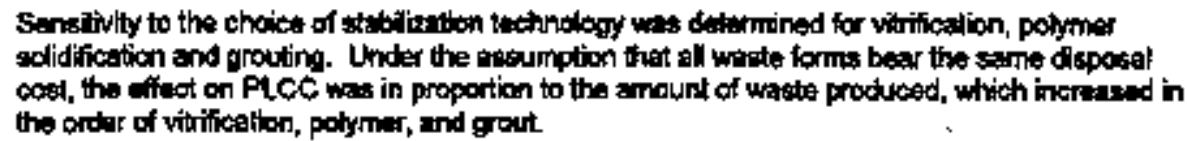 \\
\hline & 250 & 4.7 & 4.7 & 7 & 8 & 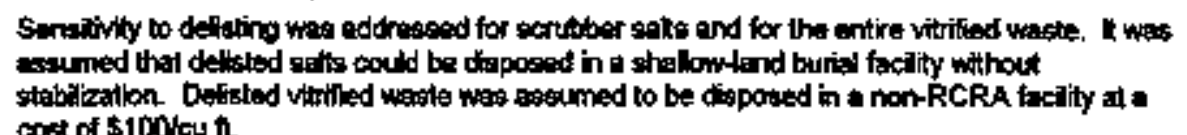 \\
\hline
\end{tabular}

d) Goneral Desion and Dperating Assumpilon*

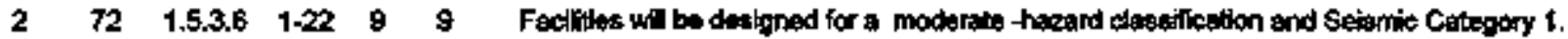

$\begin{array}{llllll}3 & 75 & 1.5 .3 .8 & 1.22 & 6 & 8\end{array}$

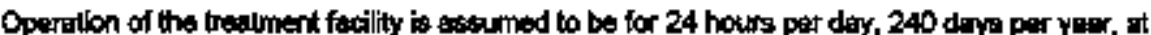
70\% cepotity duing operstion. This is aquivient to 4032 hours per your at the destan rate, or on overall capacky factor of $46 \%$.

$\begin{array}{llllll}4 & 74 & 1.5 .3 .6 & 1.22 & \text { B } & 7\end{array}$

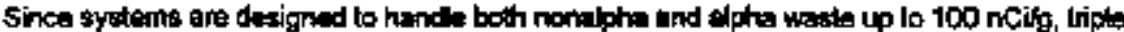

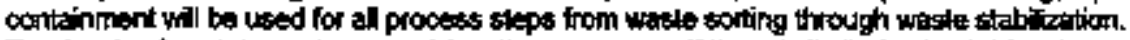

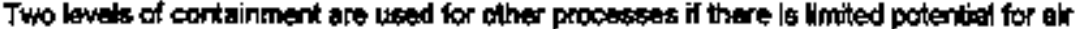
emissions.

$\begin{array}{llllll}4 & 297 & 5.2 .1 .4 .1 & 5.7 & \text { B } & 6\end{array}$

The preoonceptul system layouts are based on plecing equipment in airtight cells having 1hne?

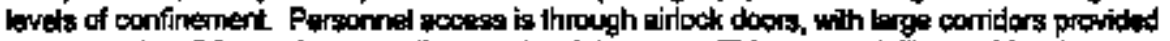

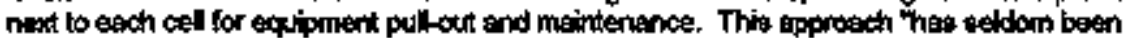
used by DOE" and it needs further evaluation.

FS $\quad 226 \quad 4 \quad 41 \quad 7 \quad 9$

PLCC eqtimates wero based on o factily that incorpoxales a shingent alphe radetion

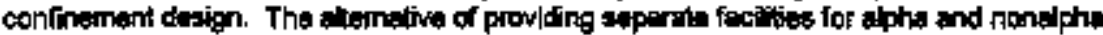
wastes was ret oosted.

d-2) Syatem C2 * Plasma Fumace with CO2 Rtiention

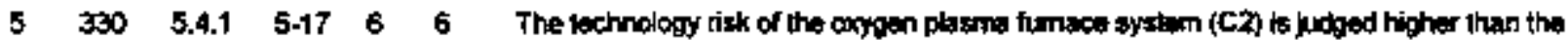

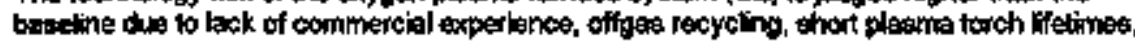
problems of refractory lifelime, moving parls and complex seads in the centritugal heath.

$\begin{array}{llllll}5 & 331 & 5.4 .2 .2 & 5-20 & 6 & 6\end{array}$

$5 \quad 336 \quad 5.4 .1 .4 \quad 5-18 \quad 6 \quad 6$

$\begin{array}{llllll}5 & 339 & 5.4 .1 .7 & 5-19 & 6 & 6\end{array}$
No plasma are system has yeit operaled for more than 100 hours po vaste or sumrogate waste. Electrod Fietina is very linited.

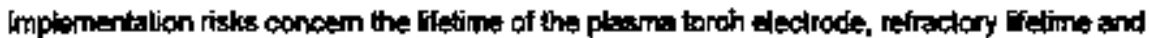
repair procedures (no repeir experience for a radoactive ervironment exisk), the near-zero ais

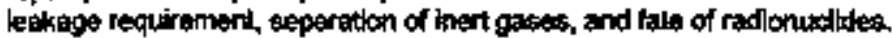

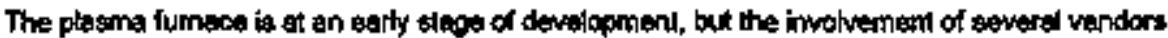
and the high lovel of developmentel effort indieates thet plasma arc systems will be commercially arribable within the ITss time trame.

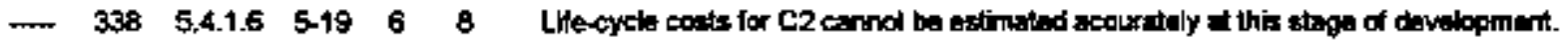

d-3) Syatem C3 - Punsma Gasification

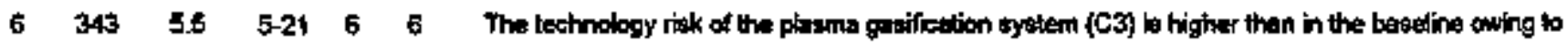

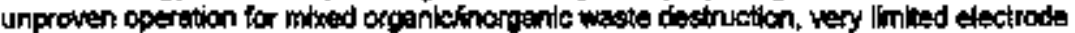

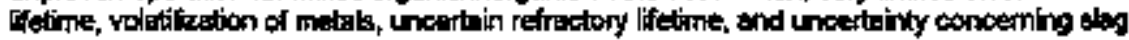
stablity (5.5.2).

$6 \quad 349 \quad 5.5 .1 .7 \quad 5-22 \quad 6 \quad 6$

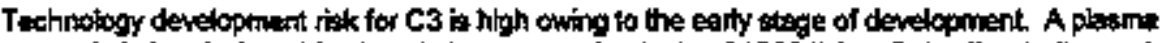
resutor is being deasioned for hosptal waste at a feed talle of $1000 \mathrm{bm}$. Only pilat shudies end research heve been performed to date. Futher developmeth using DOE wastes is necossury.

- $\quad 347 \quad 5.5 .1 .5 \quad 5.22$ \& 6

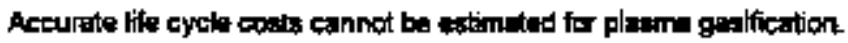




\begin{tabular}{|c|c|c|c|c|c|c|}
\hline No. & App E & sect. & Page & $\mathbf{U}^{*}$ & $s$ & ITT8 Phase 2 - Crition Assumptions of Desłon Featunes \\
\hline -4) & systen & nf1 - & Molten & sal & & \\
\hline 7 & 143 & 23 & 2.15 & 6 & $\mathbf{9}$ & 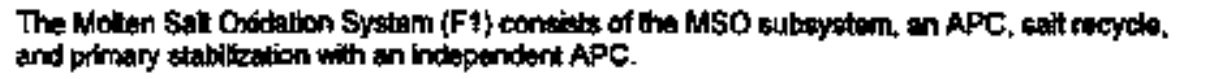 \\
\hline 7 & 145 & 2.3 .1 & 2-16 & 6 & 6 & 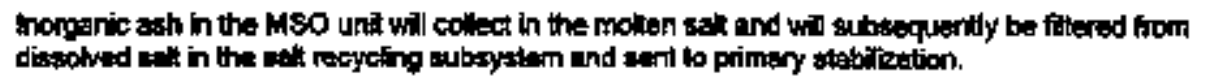 \\
\hline 7 & 146 & 2.3 .1 & 2-16 & 6 & 7 & 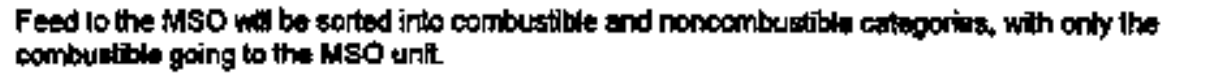 \\
\hline 7 & 954 & 23.3 & $2-17$ & 6 & 6 & 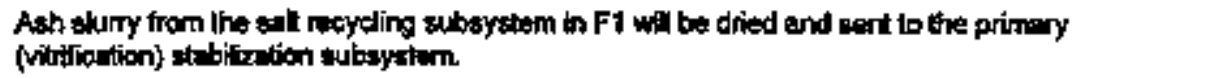 \\
\hline 7 & 350 & 5.8 & $5-23$ & B & 5 & 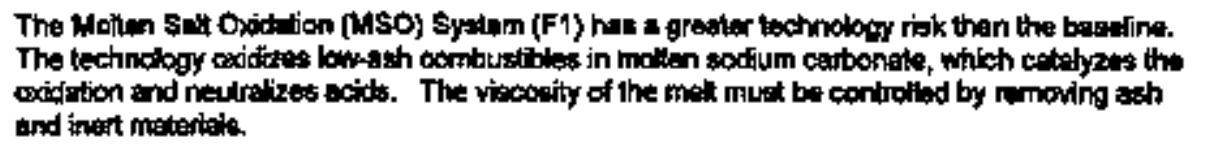 \\
\hline 7 & 351 & 5.6 & $5-23$ & 6 & 6 & 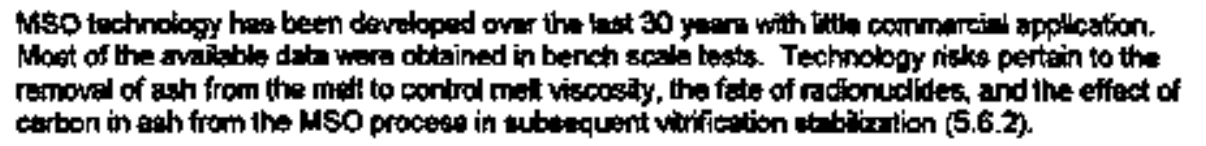 \\
\hline 7 & 355 & 5.6.1.3 & $5-24$ & 6 & 6 & 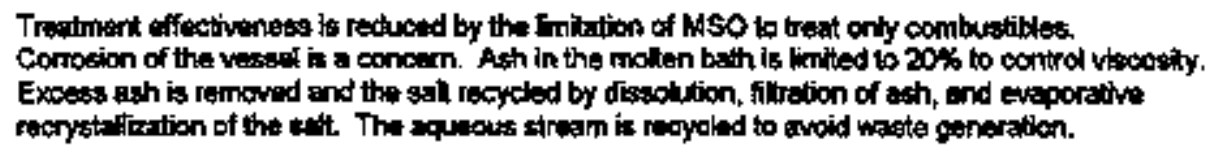 \\
\hline 7 & 360 & 5.6 .1 .6 & $5+25$ & 7 & 8 & 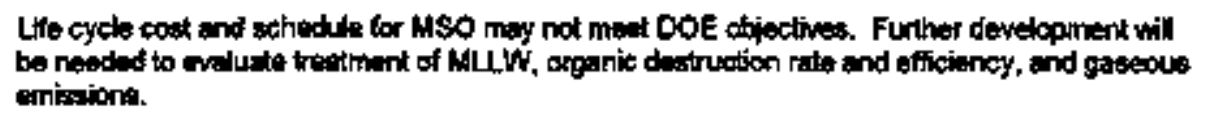 \\
\hline
\end{tabular}

d-5) System G1 - Mollen Metal Watse Destruction

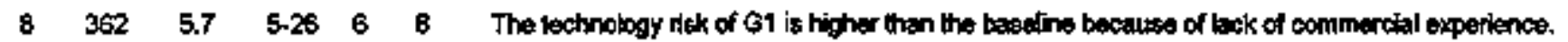

$\begin{array}{lllllll}B & 365 & 5.7 .2 & 5-29 & 6 & 6 & T\end{array}$

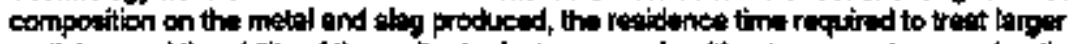
partiekes, and the ability of the melter to destroy organic wishout a becondery combustion chamber.

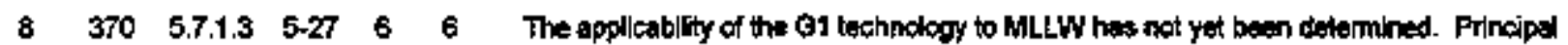

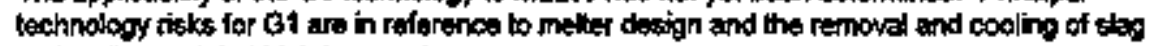
and motten metel at high ternpurelumas.

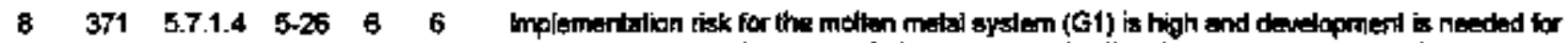

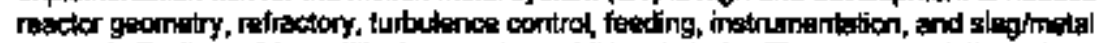

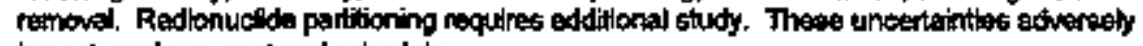
tmpect scaleup, cost and sochedule.

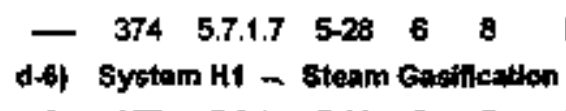

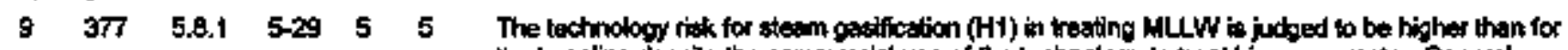

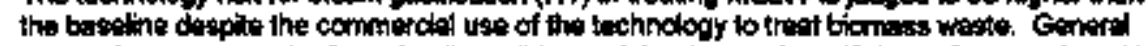

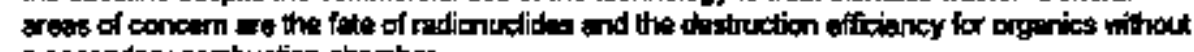
a secondary combustion charibu.

$\begin{array}{llllll}9 & 387 & 5.8 .2 & 5-31 & 5 & 5\end{array}$

Technology risks for system $\mathrm{H} 1$ are concerned with system folegration end Include: the higher demands placed on apting: tha destuction efficiency of lowtemparature pyrobyeis for MLLW.

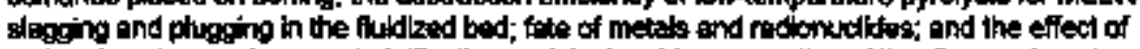

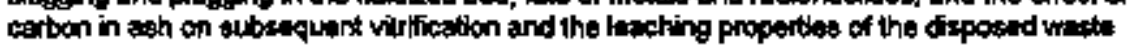

$\begin{array}{llllll}\text { Set } & 166 & 25 & 2+20 & 7 & 6\end{array}$

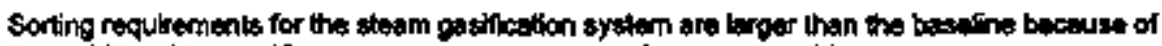 the inabify of the gatifie to accept larga amounts of nonooribustibla.




\begin{tabular}{|c|c|c|c|c|c|c|}
\hline No. & $\begin{array}{c}\text { App E } \\
\mathrm{No} .\end{array}$ & sect & Page & $\mathbf{u}$ & st & ITTS Phase 2 - Gitaleal Assumptiont of Deiph Feutures \\
\hline & Broter & $\mathbf{n} \mathbf{J 1}$ & Jousle & הת & & Ificenton \\
\hline 10 & 398 & 5.9 .1 .7 & $5-35$ & $\mathbf{5}$ & $\mathbf{5}$ & 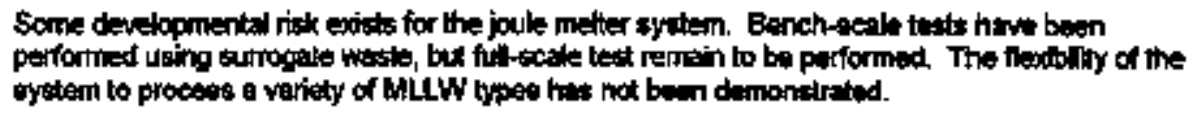 \\
\hline & 172 & 2.6 & $2-21$ & $\mathbf{5}$ & 5 & 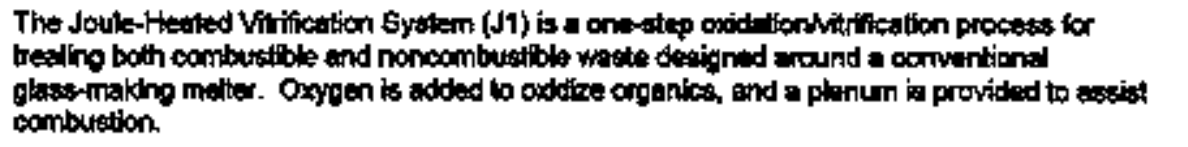 \\
\hline 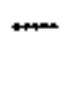 & 388 & 5.9 & $5-31$ & $\mathbf{s}$ & 5 & 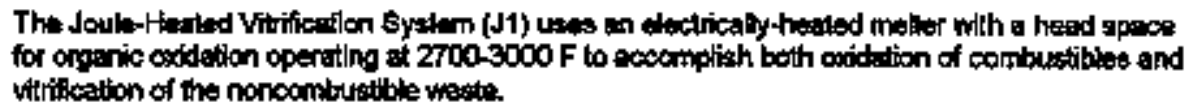 \\
\hline
\end{tabular}

d-8) System K1 - Thermal Desorption and Medlated Electrochemical Oxidation

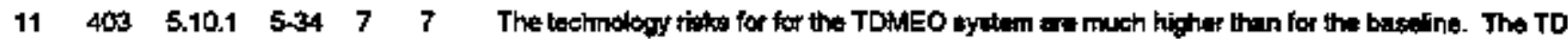

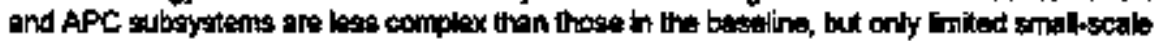
experience exists for the approach lused in this syedem.

$\begin{array}{llllll}11 & 409 & 5.10 .1 .4 & 5-35 & 7 & 7\end{array}$

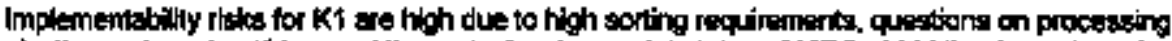
plastios and combustibles, and lin early dmwlopmental stahus of MEO at UNL. A number of

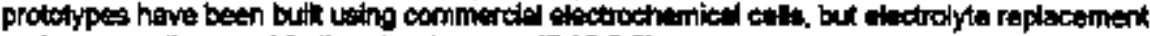
and regeneration need further development $\$ 5.10 .22$.

\begin{tabular}{|c|c|c|c|c|c|c|}
\hline & 400 & 5.1 & $5-34$ & 7 & B & 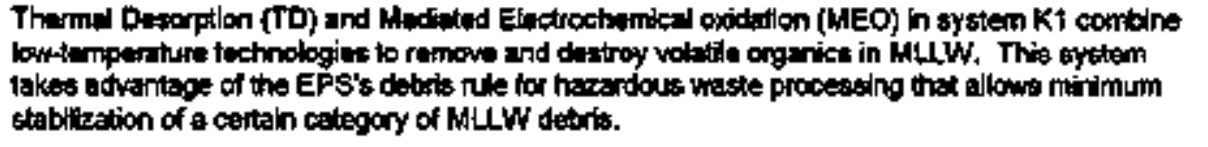 \\
\hline$m$ & 411 & 5.10 .1 .6 & 5-35 & 7 & 7 & 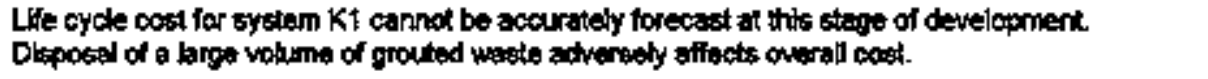 \\
\hline (-9) & \multicolumn{6}{|c|}{ System L1 - Themal Desorption and 8upercritical Water Oxidation } \\
\hline 12 & 190 & 2.8 & $2-25$ & 7 & 8 & 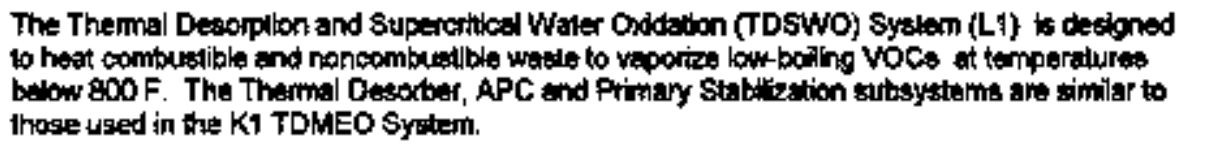 \\
\hline$\$ 2$ & 193 & $\mathbf{2 . 6 . 3}$ & $2-25$ & 7 & 7 & 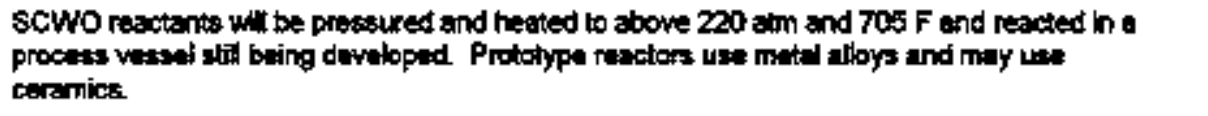 \\
\hline 12 & 413 & 6.11 .1 & 6.30 & 7 & 7 & Techndegy risk for the TDSCWO syztem (L1) is meh higher than for the banstine. \\
\hline 12 & 418 & $5,11.1 .4$ & $5-39$ & 7 & 7 & 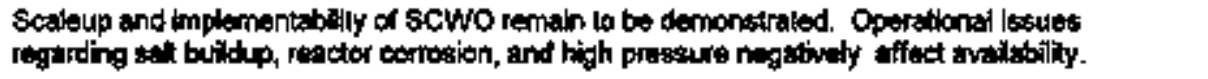 \\
\hline 12 & 419 & 5.11 .2 .2 & $5-40$ & 7 & 7 & 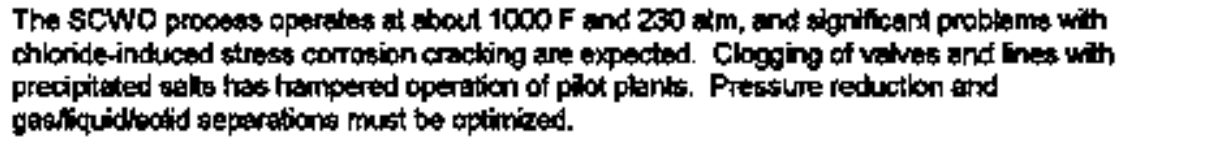 \\
\hline 12 & 421 & $\mathbf{5 . 1 1 . 1 . 6}$ & $5-39$ & 7 & 7 & 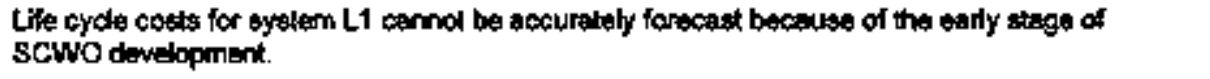 \\
\hline 12 & 422 & 5.11 .22 & $5-40$ & $\overline{7}$ & 7 & 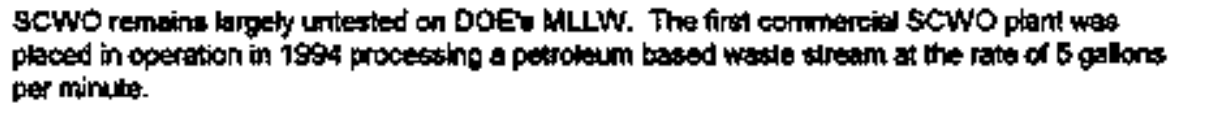 \\
\hline & 412 & 5.11 & $5-37$ & 7 & 7 & 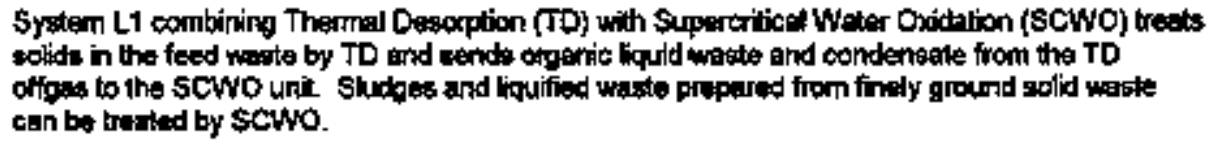 \\
\hline (-1) & \multicolumn{6}{|c|}{ Recolving and Preporatiba } \\
\hline 13 & Ba & $2 . \pm .1 .1$ & $\mathbf{2 - 7}$ & 9 & 8 & 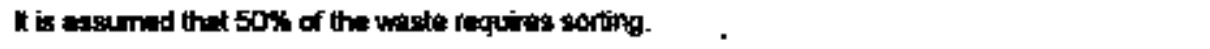 \\
\hline-2 & \multicolumn{6}{|c|}{ Primetry Fratimint } \\
\hline 14 & 300 & 5.2.1.6 & $5-8$ & $\mathbf{5}$ & $\mathbf{5}$ & 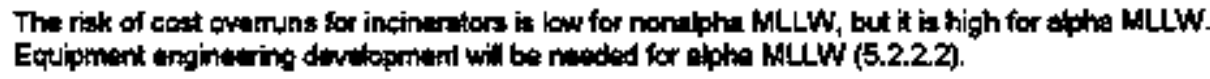 \\
\hline
\end{tabular}

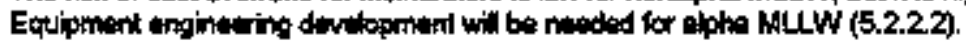




\begin{tabular}{|c|c|c|c|c|c|c|}
\hline No. & Ape. & sect. & Part & $U^{*}$ & 8w & TT8 Fhase 2 - Cittos Assumptions or Dualon Fentures \\
\hline$-3 \mid$ & \multicolumn{6}{|c|}{ Air Polution Control (APC) } \\
\hline 15 & 290 & 521.23 & 66 & 7 & 7 & 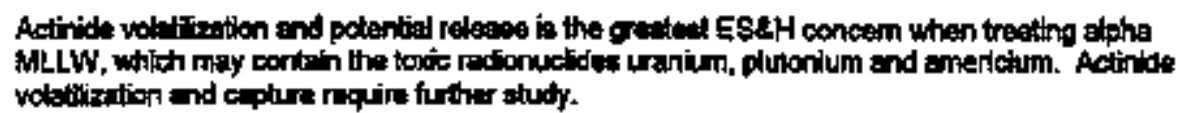 \\
\hline 15 & 291 & 5.2.1.2.t & $5-4$ & 6 & 8 & 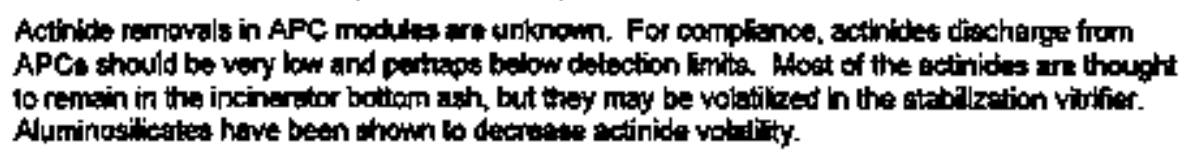 \\
\hline 15 & 320 & 5.2210 & 5.13 & 7 & 8 & 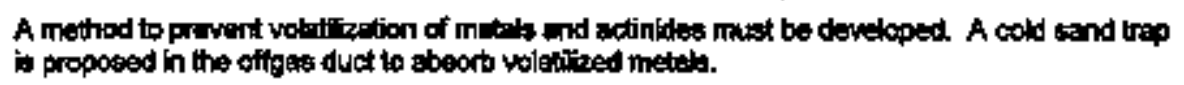 \\
\hline$\omega$ & 125 & 2.2 .1 & 2-12 & $\mathbf{6}$ & 7 & 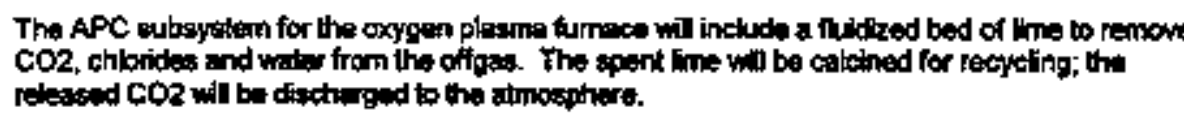 \\
\hline & 366 & 5.72 & $5-29$ & $\mathbf{6}$ & 8 & 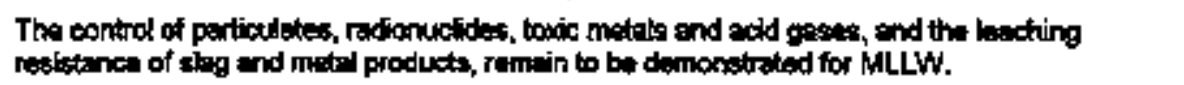 \\
\hline-4$)$ & \multicolumn{6}{|c|}{ Primary Stabitization } \\
\hline & 270 & 5.2 & $5-3$ & 6 & $\mathbf{5}$ & 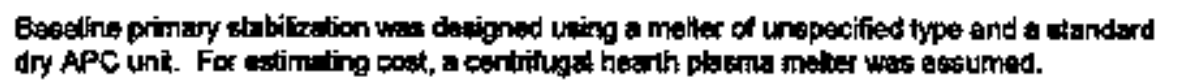 \\
\hline ب⿻ & $\mathbf{3 9 7}$ & 5.2 .210 & $5-13$ & $\mathbf{6}$ & 6 & 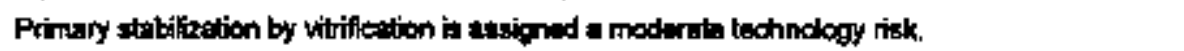 \\
\hline e-9) & \multicolumn{6}{|c|}{ 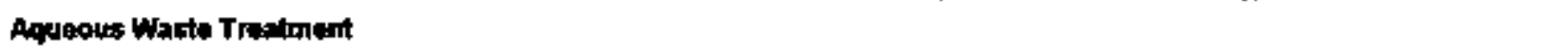 } \\
\hline$\underline{\cdots}$ & 194 & 2.7 & 2.22 & 6 & $\mathbf{B}$ & 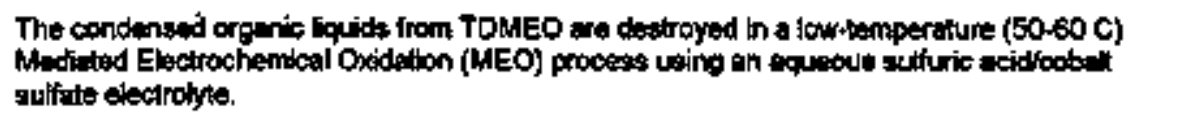 \\
\hline \multicolumn{7}{|c|}{ n) Lit: Cycis Cost and sansitivity Anolysis } \\
\hline 16 & 227 & 4.1 & $4-1$ & 6 & 7 & 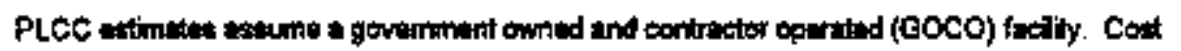 \\
\hline 16 & 2033 & 422.1 & 4-2 & 7 & 8 & Design was estinated at $25 \%$ of conetruction eost \\
\hline 16 & 235 & 4.2 .2 .3 & 42 & 6 & 7 & 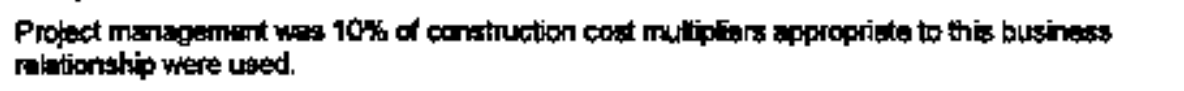 \\
\hline 15 & 234 & 4.2.2.4 & 4-2 & 6 & $\mathbf{8}$ & 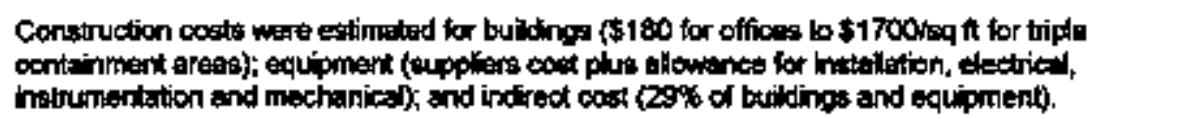 \\
\hline 16 & 237 & 4.2.2.5 & 4-2 & 6 & 7 & 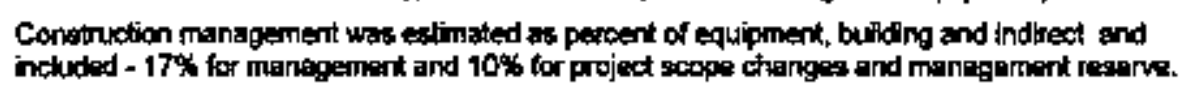 \\
\hline 15 & 238 & 4.2 .2 .5 & $4+3$ & 6 & 7 & 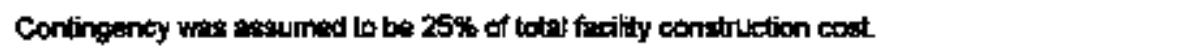 \\
\hline & $x-255$ & 4.5 & 4-5 & 6 & 7 & 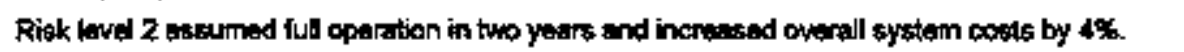 \\
\hline$\vec{m}$ & $x-256$ & 4.5 & 45 & 6 & 7 & Risk level 3 gesumed fill operation in three years and increased overel ayalem costs by $7 \%$. \\
\hline & $x-257$ & 4.5 & 4-5 & 6 & 7 & $\begin{array}{l}\text { Risk level } 4 \text { for lechnologies in an early steye of developmem thereased cural system costs } \\
\text { by } 11 \% \text {. }\end{array}$ \\
\hline
\end{tabular}


$\operatorname{App} F$

No. Ho. Sect. Page U* 5*

a) Regulationif, Pamiling and strituholdar laput

\begin{tabular}{|c|c|c|c|c|c|}
\hline 3 & 1.9 .1 & 15 & 7 & $\mathbf{B}$ & 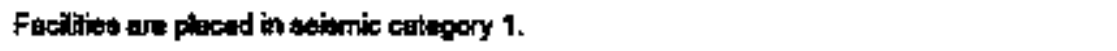 \\
\hline 7 & 1.9 .1 & 16 & 6 & 6 & $\begin{array}{l}\text { The faciny constats of four radiation zones that hoves the treatment aubsydteme and other } \\
\text { sapport systems. These zones are as follows: }\end{array}$ \\
\hline 8 & 19.1 & 16 & 6 & 6 & Low hazand areas; the zone that houses ofloces and packeged waste handing areas. \\
\hline 9 & t.9.1 & 16 & 6 & $\mathbf{b}$ & 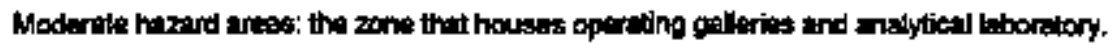 \\
\hline 10 & 1.9 .1 & 16 & 6 & 6 & 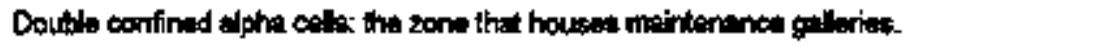 \\
\hline 11 & $\mathbf{1 . 9 . 1}$ & 16 & 6 & \$ & 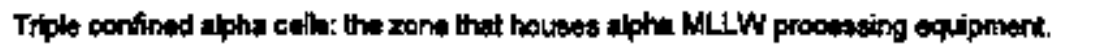 \\
\hline
\end{tabular}

d) Gringral Design and Operating Assumptions

\begin{tabular}{|c|c|c|c|c|c|c|}
\hline $\mathbf{F S}$ & $\boldsymbol{2}$ & 1.10 .1 & 20 & 9 & 9 & The facirty will process all of the RCRA wate tored at af DOE installations. \\
\hline FS & 105 & 6.3 & 166 & 量 & 9 & 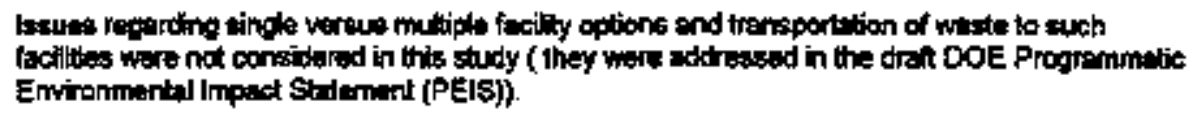 \\
\hline FS & 105 & 5.3 & 156 & 8 & $\mathbf{B}$ & 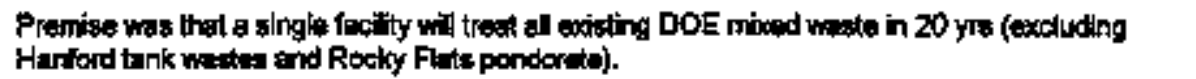 \\
\hline Fs & 200 & 4 & 125 & 8 & $\mathbf{B}$ & 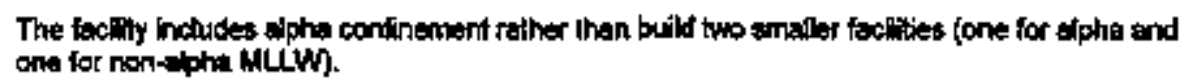 \\
\hline Fs & 111 & 6.7 & 224 & $\$$ & 7 & $\begin{array}{l}\text { Hyluid systems that combine the best elements of theirnal tund nen-themnal technologies were } \\
\text { not considered. }\end{array}$ \\
\hline$=$ & 65 & 1.7 & 12 & 9 & 9 & 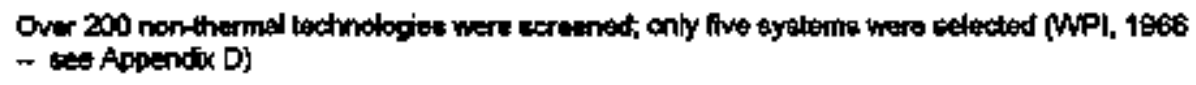 \\
\hline 2 & 87 & 1.10 .3 & 27 & 5 & 6 & 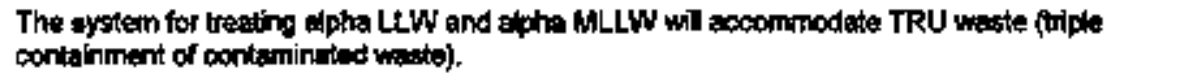 \\
\hline 2 & 88 & $1,10,3$ & 28 & 5 & 6 & 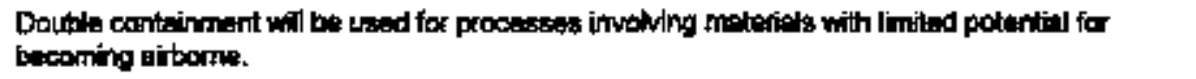 \\
\hline 2 & 104 & 5.1 .3 & 153 & 5 & 6 & 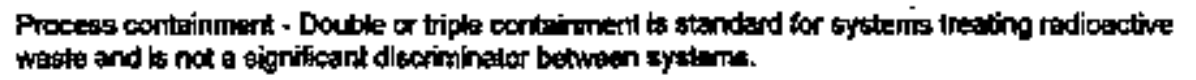 \\
\hline 3 & 70 & 1.92 & 17 & 8 & B & 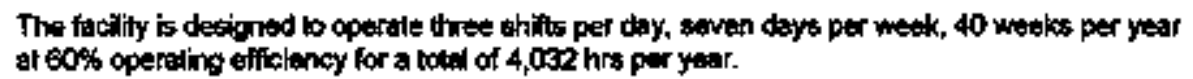 \\
\hline 3 & 85 & 1.103 & 27 & 8 & 6 & The subsyotems will handle et least $125 \%$ of the expexted fiow rales. \\
\hline 4 & 96 & 3.3 & 100 & 6 & $\mathbf{B}$ & 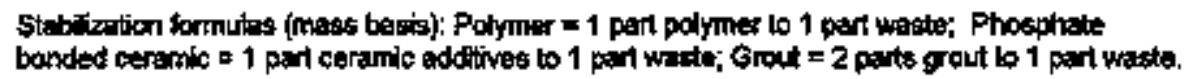 \\
\hline
\end{tabular}

d-1) System 1 - Groul Debits

$\begin{array}{llllll}5 & 112 & 2 & 31 & 7 & 6 \\ 6 & 113 & 2 & 31 & 7 & 6\end{array}$

System 1 (Grou Debris), uses medlated electrochernical axidation (MEO) for primary arganlc desturation

d-2) System 2 - Desorpation

$\begin{array}{cccccc}6 & 118 & 2 & 31 & 7 & 6 \\ 6 & 123 & 6.3 & 199 & 7 & 6 \\ 7 & 119 & 2 & 31 & 7 & 8 \\ 11 & 121 & 4.8 & 132 & 7 & 7\end{array}$

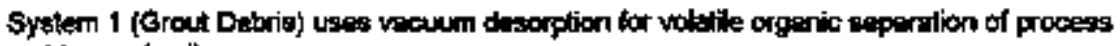
rasidue and soil. wall as procests residue and soll.

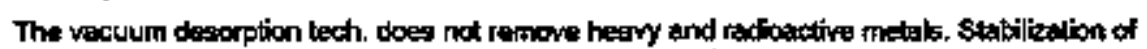
these maleriats in groul in the presence of debris has nol bean demcnstraled.

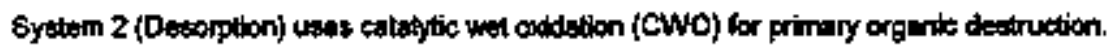

The eccess water generaled by the system may need to be grout stebized (riather thrn

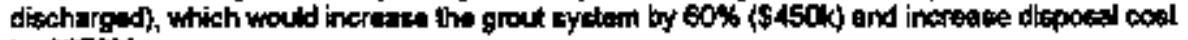
by $\$ 250 \mathrm{M}$.

$\begin{array}{llllll}12 & 122 & 6.3 & 199 & 7 & 6\end{array}$

Sorting requirementa for System 2 are mere stronuous than System 1 becalde debris must be

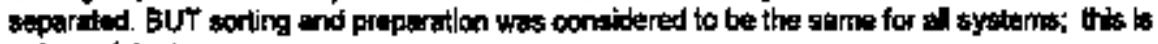
not convingtent. 
App F

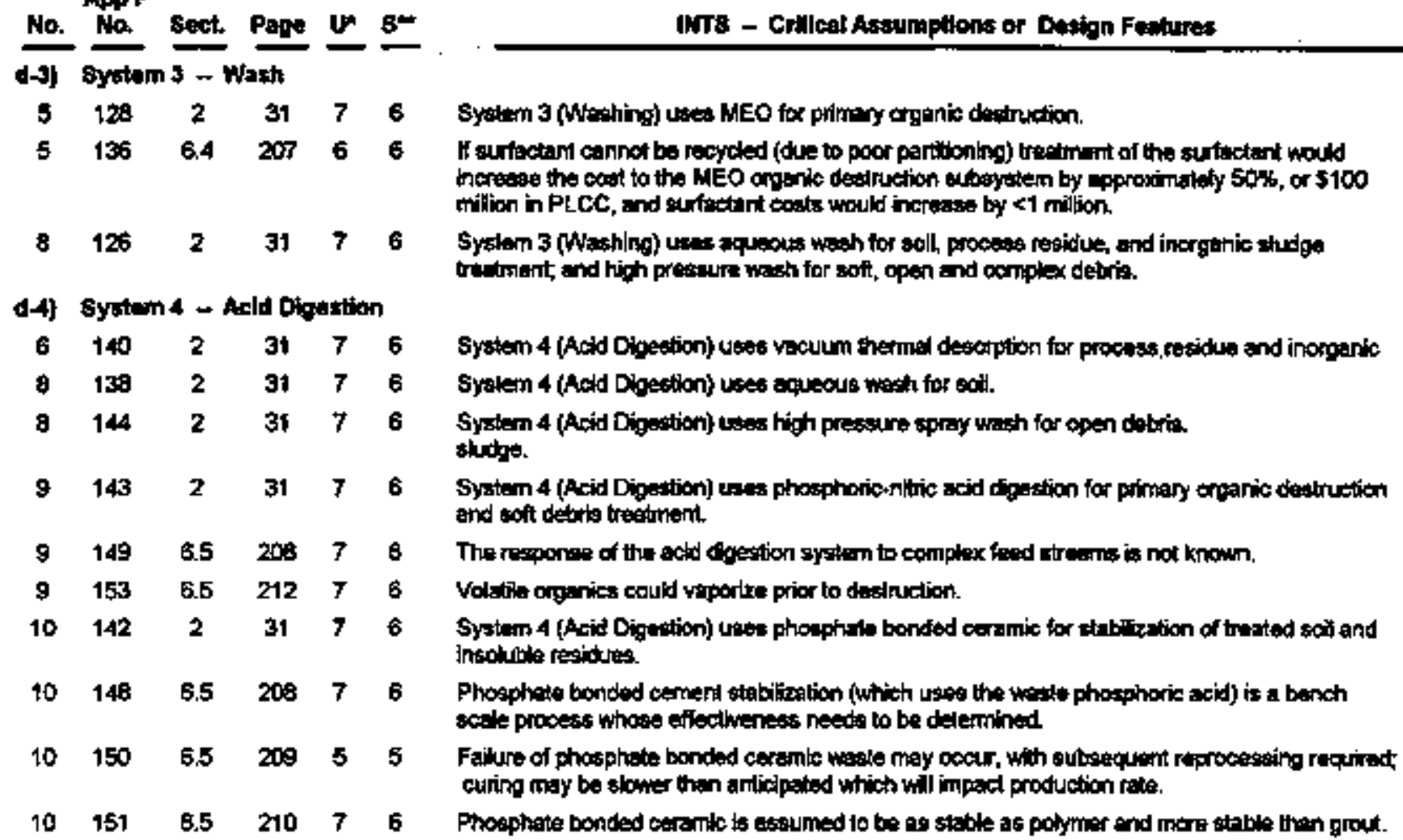

d.6] Syshem of - catalyzed Wat Oxpdation

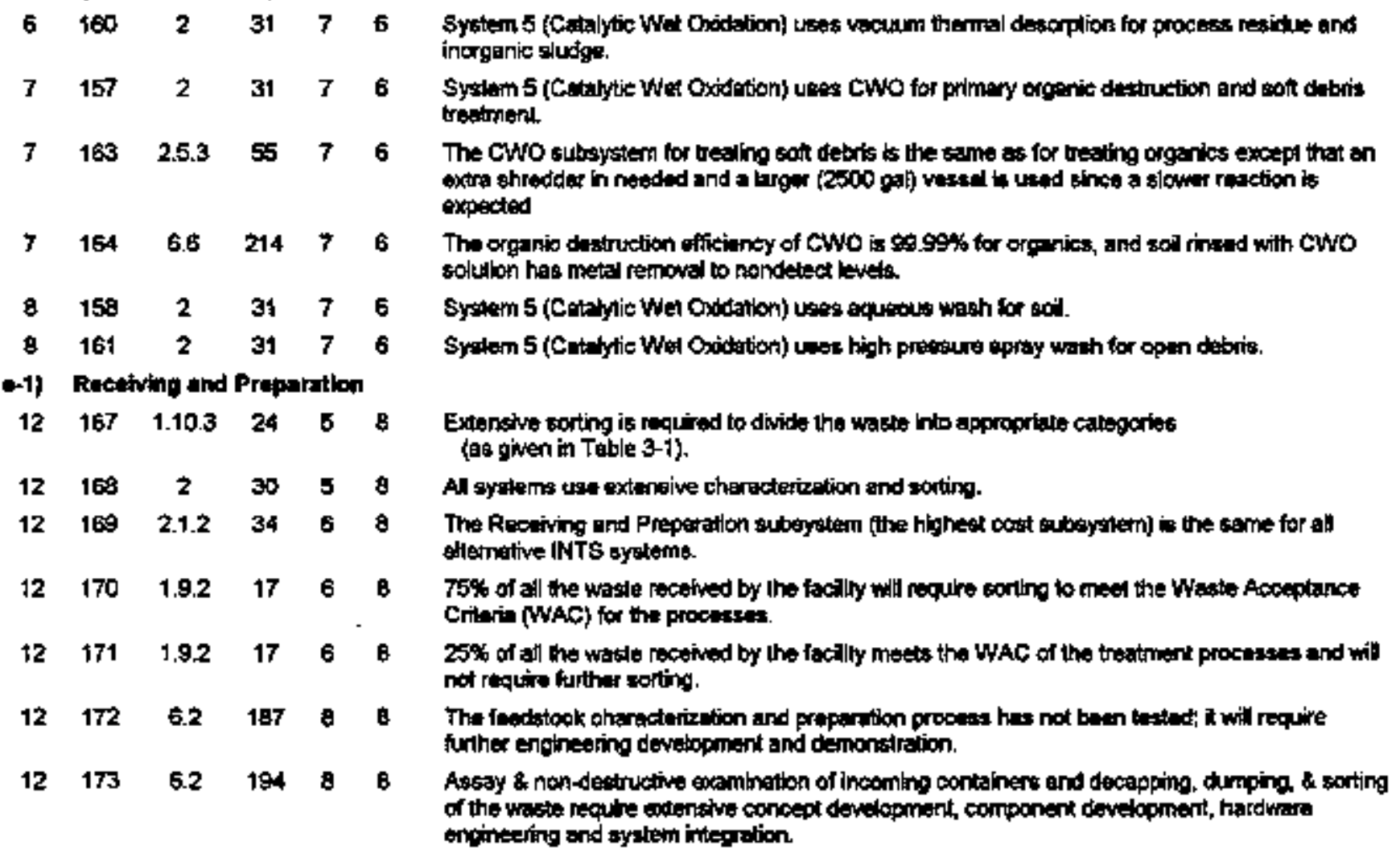




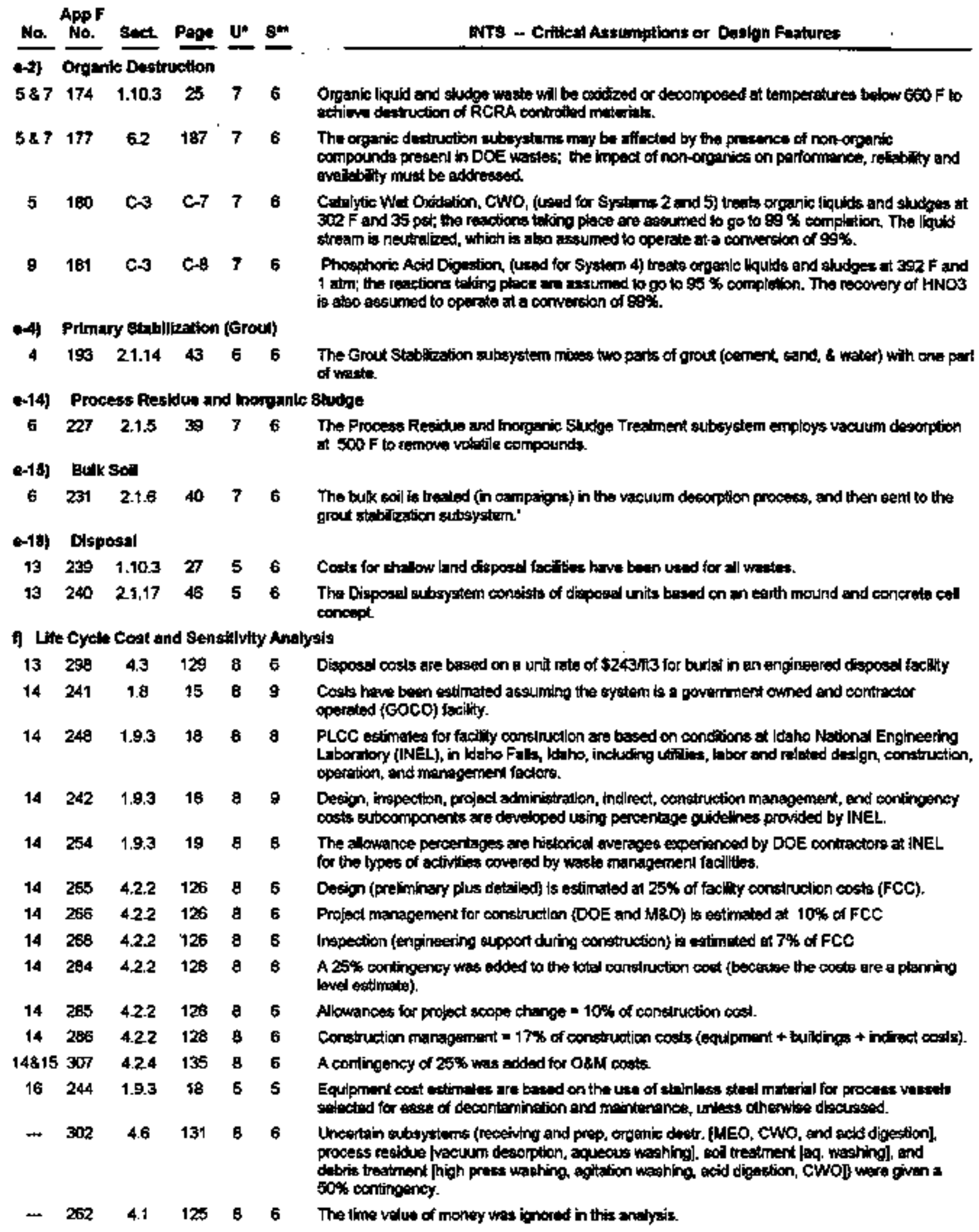

Nokt: $* U$ The uncertainty In an pastmption (on z seale of 1 - 10 with 10 being the most urxertain)

- 8 The senolitiky of the Totol PLCC to changes in the assumption (on a ecale of 1 - 10 with 10 being the most sensilive) 


\section{APPENDIX H}

\section{ASSUMPTIONS OF INTEREST FROM THE ITTS PHASE 2 ANALYSIS OF PERFORMANCE MEASURES}




$\begin{array}{llllllllll}-401533 & 1-18 & 1 & 1 & 1 & 1 & 1 & 1 & 1 & 1 \\ 2805212356 & 7 & 7 & 11 & 1 & 1 & 1 & 1 & 1\end{array}$
* 11 I $\$ 1$ I I

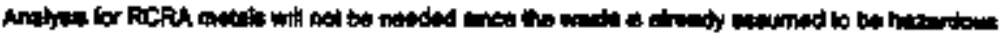

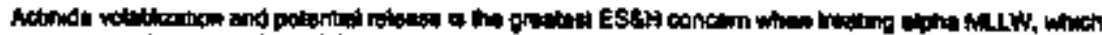

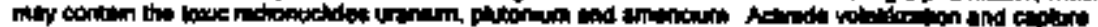
require firtiter shoty
2916212154

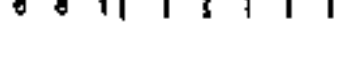

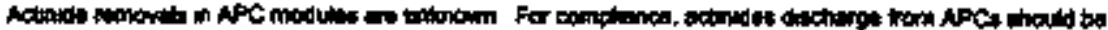

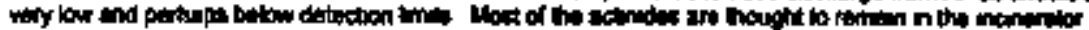

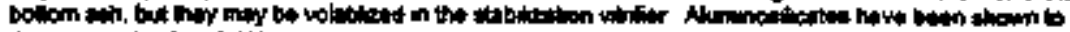

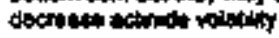

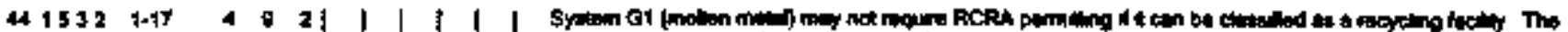

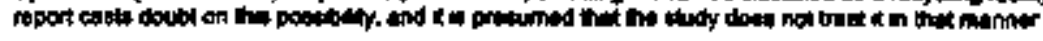

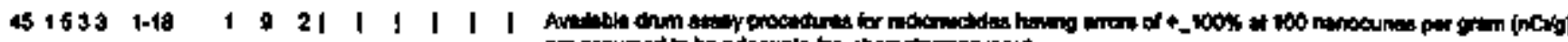

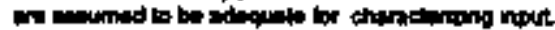

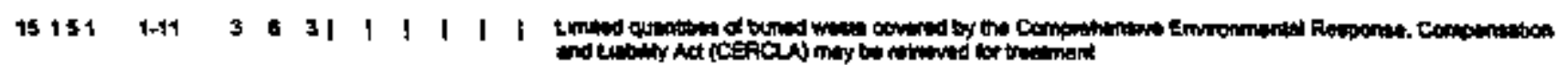

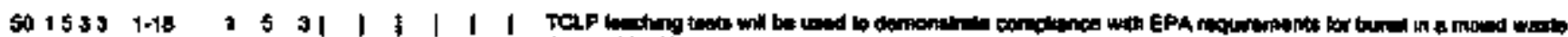

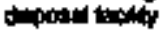

$10021192822 \cdot 31+1 / 1$ I

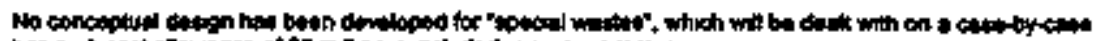

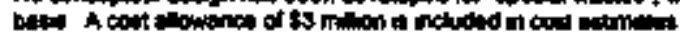

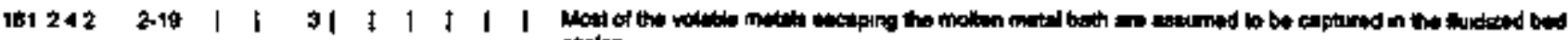
moler

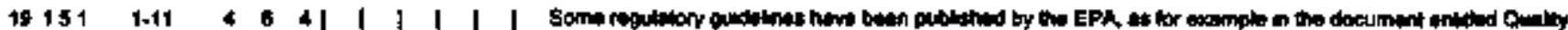

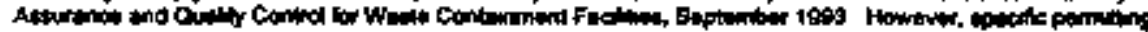

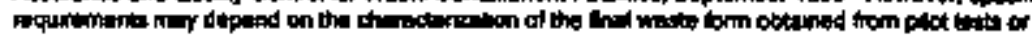
demontatrotion

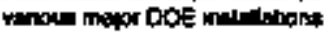

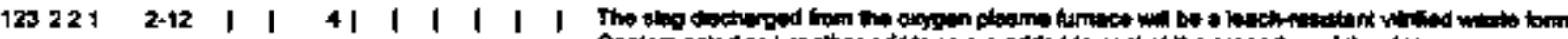

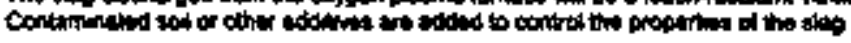

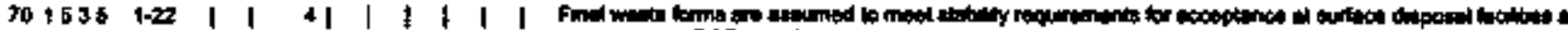

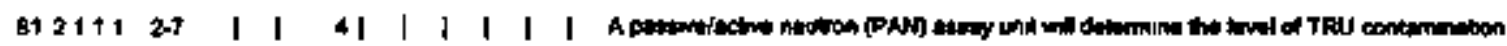

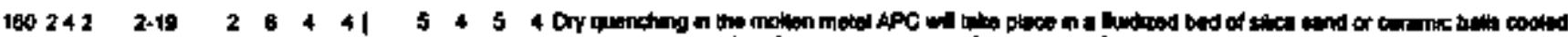

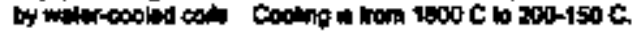

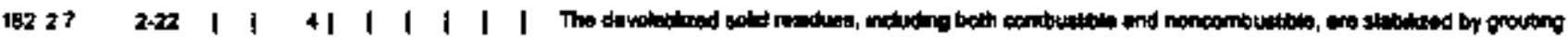
$109242-25$ I 1 | I I I I I

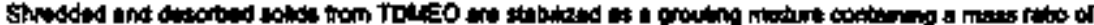

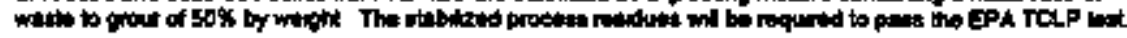

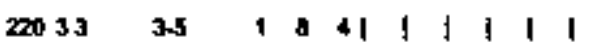

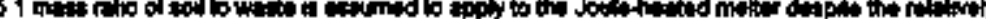

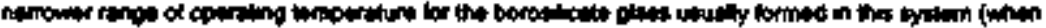

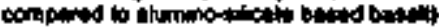

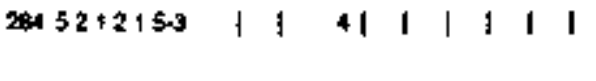

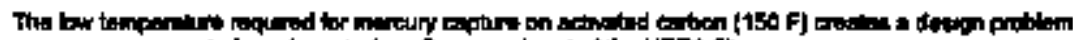

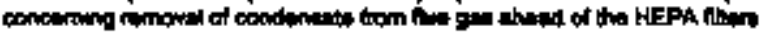

$289521216-4$

3541 I 1 I 1 |

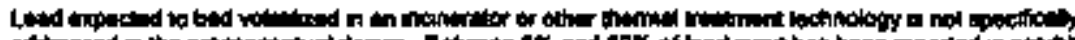

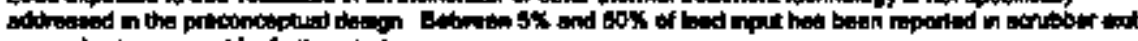

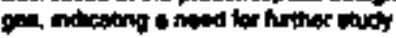

$30252215-1640767$

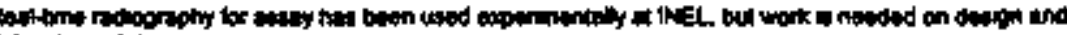

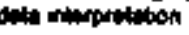

$303 \$ 22100$

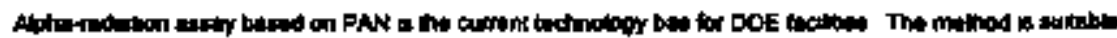

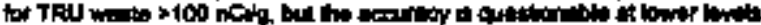

319 522106053 | $|4||| l|l|$

320522705770401

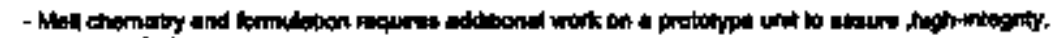

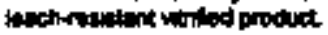

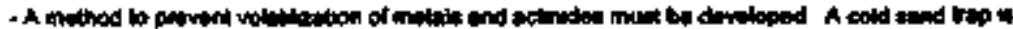

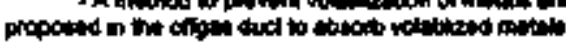

$34254235-20|1| 2|2|||$

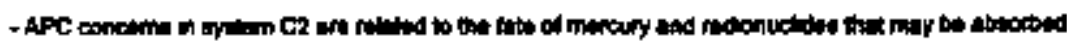

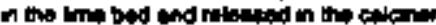

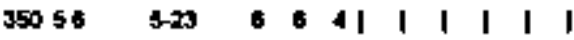

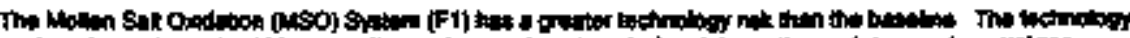

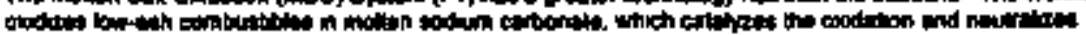

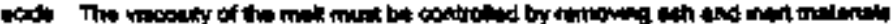

$351585-23644232244$

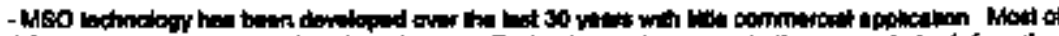

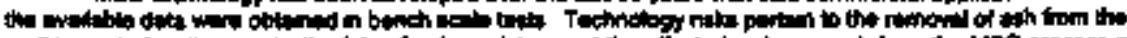

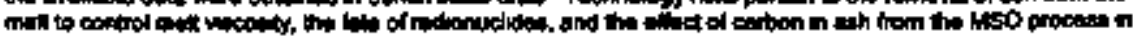




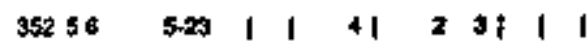

$35356115-23 \quad 1 \quad 1 \quad 41 \quad 1 \quad 1 \quad 1 \quad 1$

\$54 \$612 5-24 I $|4| 1|1| 1 \mid$

$35556135-24 \quad 6 \quad 6 \quad 422214$

$35758135-25$ I I 45 B 41

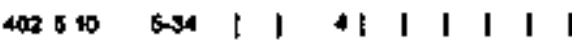

$4045101+5-34$ I I I I

41451111530 | 141 | 1 | 1

119511225407742 (2)

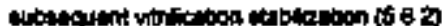

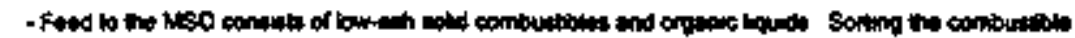

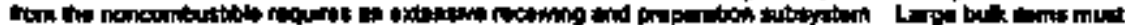

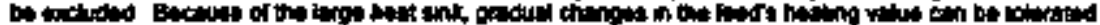
(562)

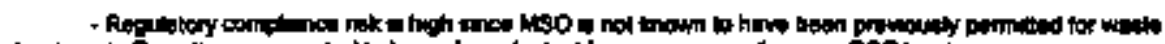

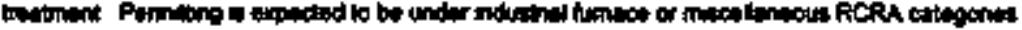

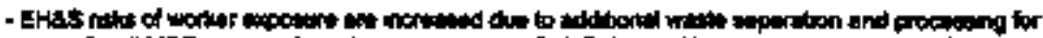

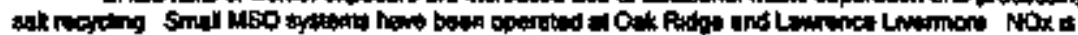

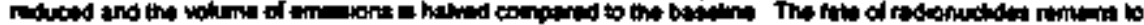
be writuind

\section{1}

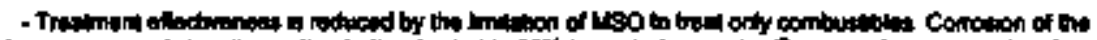

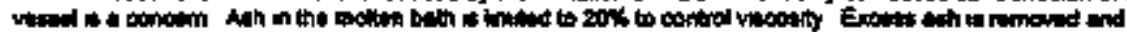

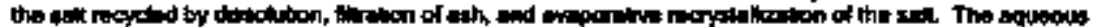

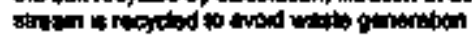

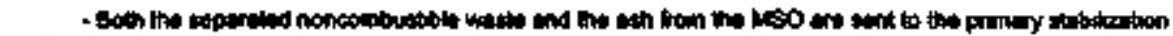

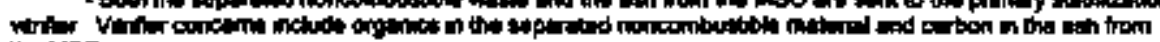
thaso

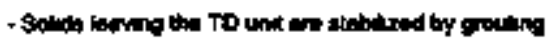

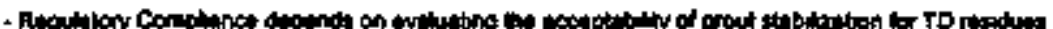

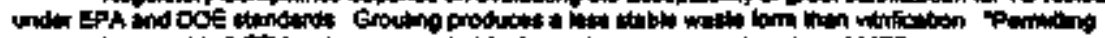

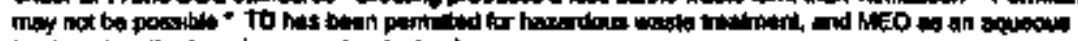

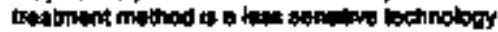

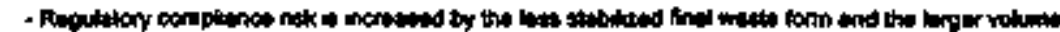

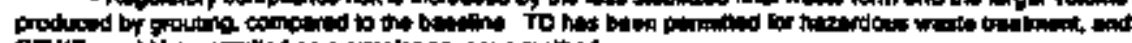

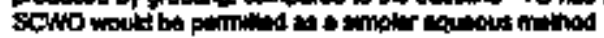

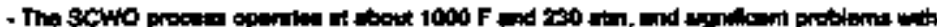

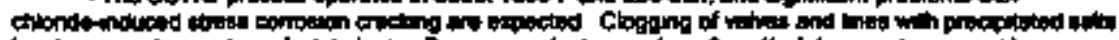

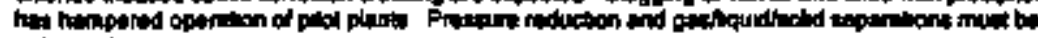
contried 


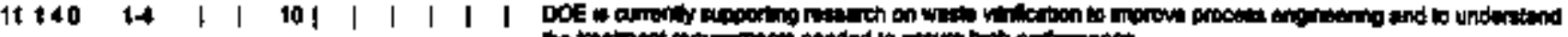

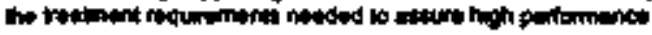

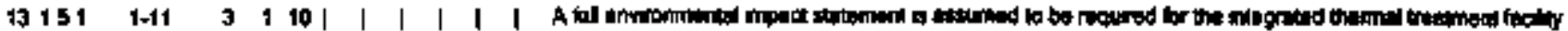

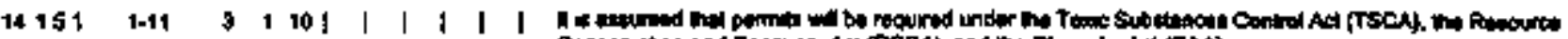

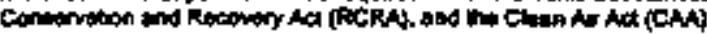

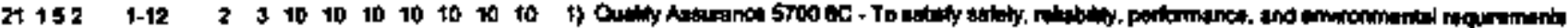

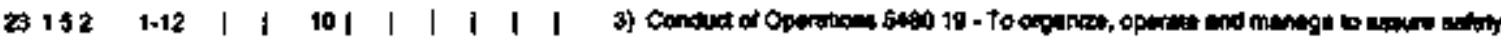
$24152 \quad 1-12$ i 1010 |

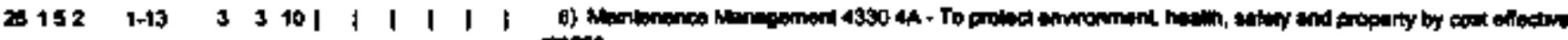 nitents

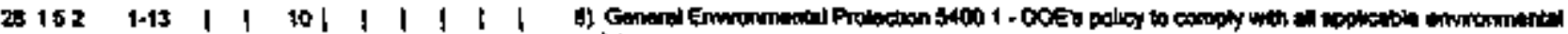
regutionat

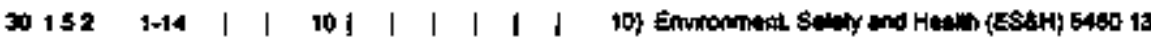

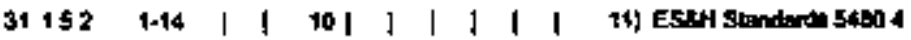

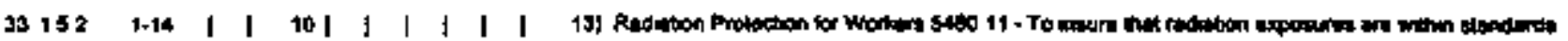

$36152 \quad 1-15 \quad 3 \quad 310 \mid$ |

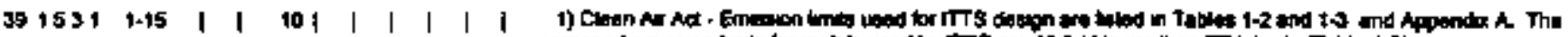

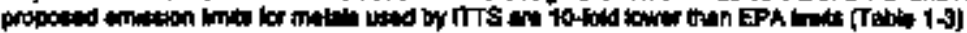

409532 1-15

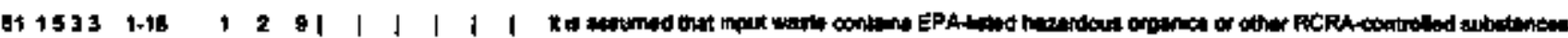

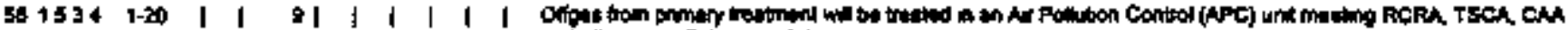
and other at polition requewion

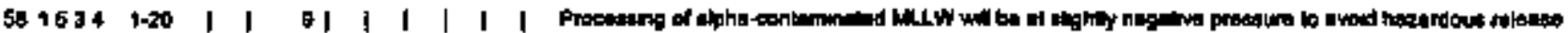

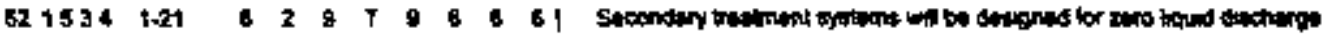

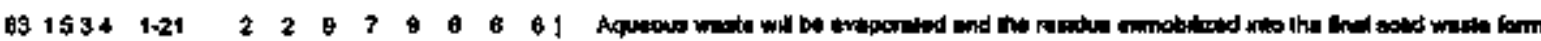

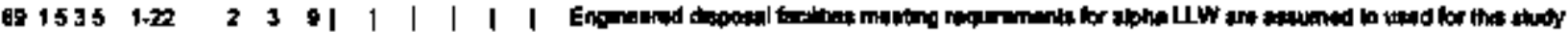

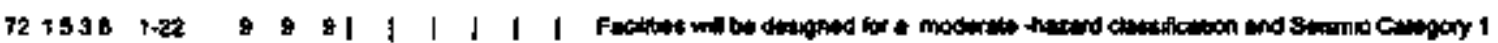

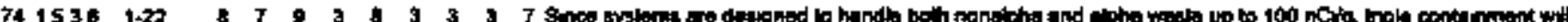

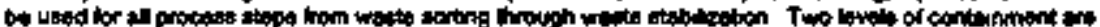

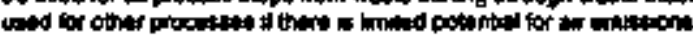

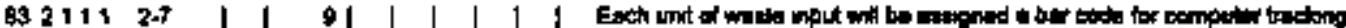

$1+0211522-10 \quad 2251|1| 1 \mid$

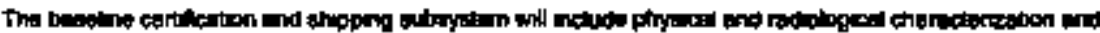

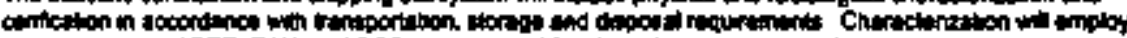

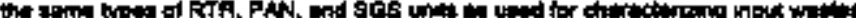

1342212 2.13 230 a

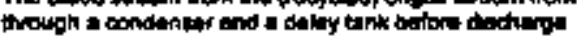


I. Assumptions with Low Regulatory Compliance Scores

II. Assumptions with High Regulatory Compliance Scores 


\section{EXAMPLE}

\section{APPENDIX I}

\section{EXAMPLE OF EVALUATION OF PERFORMANCE (ITTS PHASE 2 SYSTEMS)}




\section{EXAMPLE OF EVALUATION OF PERFORMANCE (ITTS PHASE 2 SYSTEMS)}

The method used is an adaptation of the Kepner-Tregoe approach applied to the 422 regulatory and design assumptions for Phase 2 technologies listed in Appendix E. Ratings on a scale of 1 to 10 were assigned to applicable assurmptions relating to nine cost and petformance criteria: 1) cost sensitivity, 2) cost uncertainty, 3) regulatory compliance, 4) implementability, 5) flexibility (to treat a variety of imput waste), 6) operability, 7) maintainability, 8) availability, and 9) decommissioning and decontamination. The ratings were assigned in a once-through manner by a senior chemical engineer with process experience, based on engineering judgement applied to the information presented in the Phase 2 study report. The assumptions, with their respective scores, can be traced back to the related page in the LITCO Phase 2 stidy report by consulting Appendix $\mathrm{E}$.

To facilitate comparison, ratings were sorted according to system and criteria using readily available spreadsheet software. The Lonus spreadsheet used for the analysis which follows is available for traciag or extending the analysis. Table J-1 presents averaged rating scores on nine criteria for ten treatment systems (the baseline and nine Ptase 2 systems, including all subsystems). and these summary data are used to compute the weighted comparison factors in the table that take into account both cost and performance. Table I-2 presents a similar set of averaged rating scores for the primary thermal subsystems alone, which serves to accentuate differences that are masked by averaging over all of the subsystems in each system. Selected data from these tables have been graphed for illustrating the points that follow.

Observations can be derived from the rating summaries at different levels of detail, as illustrated by the following examples:

Anahsis of Cost Assumptions. Out of the total of $\mathbf{4 2 2}$ design and regulatory assumptions identified from the Phase 2 report, 199 were rated for cost effect. The overall distributions of ratings for cost sensitivity and cost uncertainty were bimodal, with peaks at rating levels of 2-3 and 6-7, reflecting in part the proclivity indicated in Table I-2 for certain thermal subsystems to have either high or low cost ratings for both sensitivity and uncertainty (e.g., high ratings for systems K-I and L-1 based on thermal desorption with special oxidation systems and a low rating for the baseline rotary kiln system). In Figure I-1, only the two kiln-based systems, A-1 and A-7, evidence a lower cost sensitivity for the thermal subsystem (the kiln) than for the total system, including air pollution control, waste stabilization, and other subsystems. The kess fully developed thermal subsystems, such as K-1, L-1, and F-I (F-1 uses molten salt oxidation), were characterized by high scores for both cost sensitivity and uncertainty (Table I-2), reflecting a tendency in rating to assume that the costs associated with implementing unproven technologies, although not well known, will probably be high. As discussed in the previous section of this review, cost assumptions that are rated high on both sensitjvity and uncertainty require careful review. Out of the 199 assumptions rated for cost effects in the Phase 2 report, the 69 assigned ratings above 5 for both sensitivity and cost were iscorporated with the eritical cost assumptions in Appendix G.

Analysis of Regulatory Complionce Assumptions. The averaged ratings for regulatory compliance in Tables I-1 and I-2, respectively representing overall systerns and thermal subsystems 
alone, show relatively small differences, in the range of 5 to 7 . Slightly lower average scores were observed for the less developed thermal treatment subsystems (F-1, K-1 and L-1) and for the systems relying on grouting instead of vitrification (K-1 and $\mathrm{L}-1)$. However, the more important differences affecting regulatory compliance are found at the level of the individual assurnptions. In Figure I-2, a histogram for the 265 assumptions rated for regulatory compliance indicates that most of the ratings are in a central range of 5 to 8, where it is assumed that they have little particular effect. Subsets of assumptions having low or high regulatory compliance ratings are listed separately in Appendix $\mathrm{H}$. The low scores, from 1 to 4 , are of special importance because of their appraised potential to interfere with achieving compliance. Examples include assumptions concerning: 1) waste characterization using drum assay procedures accurate to only $\pm 100 \%$, 2) the adequateness of the TCLP (toxicity characteristic leaching procedure) leaching test to demonstrate U.S. Environmental Protection Agency (EPA) compliance entailing long-term stability, and 3) the lack of information on themal release of actinides in primary thermal treatment subsystems and their capture in air pollution modules, and 4) the untested designs used for recovering bulk mercury from the feed waste and subsequently capturing thermally volatilized mercury on carbon filters. Further review of all assumptions with low regulatory compliance scores is recommended. At the high end of the distribution, scores of 9 or 10 may indicate that costly measures are being used to achieve unneeded overcompliance; a possible example is the assumption that metals ernissions will be controlled at levels that are one tenth of the EPA limits.

Anahysis of Implementability Rating. Averaged ratings for implementability presented in Figure I-3 and Tables I-1 and I-2 indicate the highest scores for the kiln-based systems, A-1 and A-7. In these two cases alone, the implementability ratings for the thermal stubystems are higher than those for the tota! system, indicating that the kilns themselves are appraised as posing less difficulty than the related air pollution control and vitrification subsystems, All other thermal subsystems have implementability scores that are lower than those for the corresponding total system. The Joule-heated vitriffer (J-1), patterned after glass melter technology, was assigned the next highest score after the kiln-based systems. The lowest subsystem scores were assigned to plastala gasification and molten salt oxidation, followed by mediated electrochemical oxidation and supercritical water oxidation. Implementability was downgraded for a variety of process-related reasons that are documented in the assumption listings in Appendix E, which are organized by system and subsystem. Some of the principal reasons for downgrading themal technologies were 1) an early stage of development, 2) high sorting requirements, 3) sensitivity to feed variations or system upsets (e.g., the potential for excess offgasing), 4) containment problems complicated in some cases by high pressure, 5) problems with seals for preventing leakage, 6) excessively high temperatures of $3000^{\circ} \mathrm{F}$ and higher, 7) limited lifetime for components such as plasma torches and refractory linings, 8) the effect of reducing conditions on construction materials and on the thermal volatility of nuclides, 9) complex flowsheets such as those involved in offgas recycling after $\mathrm{CO}_{2}$ retention or salt separation and recycling, and 10) conditions such as unburned carbon after primary thermal treaconent that could gdversely affect downstream vitrification.

Rating for Flexibility. The ratings on flexibility to treat a variety of input waste shown in Figure I-4 and Tables I-1 and I-2 indicate low scores for the molten salt oxidation system (F-1) and the steam gasification system (H-1) because of the inability to treat wastes containing appreciable inorganic content and the consequent requirement for a high degree of sorting. 
Operabilty, Maintainability, and Availability. The ratings on these three criteria shown in Figures I-5 through I-7 tend to parallel each other for most of the systems, except that the appraised differences are smatler in the case of availability. Again, the differences among the systems as a whole are small, but they are amplified for the thermal subsystems alone. Many of the reasons given above for downgrading implementability apply atso to the criteria discussed here. Operability was particularly downgraded fot component and materials problems and complexity, applying most prominently to systems involving plasma gasification (C-3), molten salt oxidation (F-1), and supercritical water extraction (L-1), and to a slightly lesser degree to the plasma furnace with $\mathrm{CO}_{2}$ retention (C-2) and molten metal waste destruction (G-1). Maintainability was downgraded for similar reasons, with the supercritical water extraction system (L-1) receiving the lowest score because of the difficulty of maintaining seals at high pressures. The lowest score for availability was given to the plasma furnace with $\mathrm{CO}_{2}$ retention ( $\mathrm{C}-2$ ) because of the appraised difficulties involved in the combination of the plasma hearth and the gas recycle system.

Ratings for Decommissioning and Decontamination. The ratings for this criterion were perhaps the most difficult to judge based on general engineering experience. The scores shown in Figure I-8 are similar for most of the systems and their corresponding thermal subsystems. The systems given the highest scores were the two thermal desorption systems, K-1 and L-1, that did not involve vitrification in either the primary thermal subsystem or in a separate vitrifier, and which therefore did not involve adherent slag residues. The virrification system given the highest score was the Joule-heated melter because of its relative simplicity, involving fewer processing units.

Weighted Performonce Scores. The weighted performance scores (WPS) shown in Figure I-9 were calculated for each of the systems and for their respective thermal subsystens (WPTSS) using the weighting factors shown in Table 1-1. It should be noted that the weighting considered only the seven performance criteria and not the two cost criteria. The highest weighting factor anong the seven criteria considered was given to regulatory compliance, which was $25 \%$. Implementability, flexibility, and operability were each weighted at 15\%; and maintainability, availability and deconmissioning/decontamination were each weighted at $10 \%$. Combining the criteria, even with weighting, served to average out some of the differences among systems. As in the case of the implementability criteria, the two kiln-based systems rank highest, and for these two alone, the thermal subsystem scores are higher than those for the total system. The ranking of systems suggested by the weighted scores will be discussed below in relation to life-cycle cost.

Ranking Based on Performance Ratings and Cast. The primary purpose of this review is not to rank the systems under study. However, for sake of illustration and perhaps to shed some light on the merit of the systems, the following observations are offered:

- First of all, certain critical regulatory or design assumptions need to be considered individually, since their effect will be lost in averaging and combining scores across subsystems and criteria. For example, if the capure of volatile nuclides and mercury from high-temperature thermal systems cannot be adequately resolved, then most of the Phase 2 systems would be eliminated, with the possible exception of steam gasification $(\mathrm{H}-1)$ and the two thermal desorption systems (K-1 and L-1), which operate at lower temperatures. Or, if grouting proved to be environmentally inadequate, then K-1 and L-1 would be the systems eliminated. Similarly, if the problems of implementing some of the 
more complex or intensive systems proved unresolvable at reasonable time and cost, then systems such as $\mathrm{CO}_{2}$ with gas recycle (C-2), molten salt oxidation with salt recycle (F-1), or high-pressure supercritical water oxjdation (L-1) might be ruled out. The comparisons that follow take account of these individual critical criteria only by assigning them low scores that bring the weighted score down marginally.

- Ranking based on averaged and weighted perfomance scores is useful where it can be assumed that all systems will meet minimum criteria and the question is only which is better, assuming sumilar cost. In order to focus on important differences, it appears preferable to compare systems based on the weighted performance of their thermal subsystems alone (WPTSS in Table I-1 and Figure I-9), which avoids averaging across less critical subsystems. This is warranted by the indication that the themal subsystems scoted lower (more critical) than the corresponding total system in alt cases except the kitn-based systems. The three thermal subsystems with the highest weighted performance scores are the kiln systems A-1 and A-2 followed by the Joule-heated vitrifier J-1. The three therrial subsystems with the lowest ranking are molten sali oxidation (F-1), the plasma furnace with $\mathrm{CO}_{2}$ retention (C-2), and supercritical water oxjdation (L-1), which are the systems that were downgraded for complexity and high pressure.

- Ranking would normally be performed on the basis of both performance and cost, which is sometimes accomplished by ratioing. The ratios of normalized cost to performance in Table I-1 identify the same rankings either with or without the added uncertainty factor. which indicates only that the appraised cost uncertainties for the different systems when averaged across all applicable assumptions were too similar to make a difference. By plotting the data, it is possible to visualize three rank groupings of cost versus performance (Figure I-10). In the low-cost grouping, between 0.85 and 0.9 NPLCC, the preferred systems based on performance are the slagging rotary kiln (A-7) and the Jouleheated vitrifier (J-1), which also score among the top three on performance alone.

In the intermediate grouping, between 0.95 and 1.0 , the baseline rotary kiln (A-1) ranks highest, as it did on performance alone. In the high-cost grouping, above 1.15 , the thermal desorption systems L-1 and K-1 received lower performance scores that would not warrant their higher cost.

Reproducibility of Method. The Kepner-Tregoe method as applied in this review has been shown to facilitate the quantitative evaluation of a large body of qualitative technical information on competing systems and to allow objective comparisons to be made that could not otherwise easily be accomplished. The review does not address the important question of the reproducibility of the method, since only one reviewer assigned ratings to the Phase 2 assumptions considered. However, it is at least encouraging that the results expressed in the ranking are easily understandable in terms of certain broad considerations, including in particular the stage of technology development, concerns over regulatory compliance, and implementability in reference to the complexity and intensity of the system. The engineer who was engaged in this rating effort is of the opinion that getzrally similar results would be obtained by any technically competent reviewer using the method, provided that generaliy similar premises were used. The premises used in the current review strongly favored advanced development over early development and 
simplicity over complexity and downgraded significantly for risk of regulatory noncompliaxce. The complete record of the review is available to permit tracing of all ratings in reference to the study reports. 
TABLE I-1

Example of the Comparison of Performance Scores for Total Systems: Baseline and Phase 2 Systems

\begin{tabular}{|c|c|c|c|c|c|c|c|c|c|c|c|c|}
\hline & \multicolumn{9}{|c|}{ Criteria } & \multirow{3}{*}{$\begin{array}{l}\text { Weighted } \\
\text { Performance } \\
\text { Score }\end{array}$} & \\
\hline & & \multicolumn{2}{|c|}{ Cost } & \multicolumn{7}{|c|}{ Performance } & & \\
\hline & & I & 2 & 3 & 4 & 5 & 6 & 7 & 8 & 9 & & \\
\hline \multicolumn{4}{|c|}{ System Description } & \multicolumn{7}{|c|}{ Weighting Factors } & WPS & NPLCC \\
\hline$\overline{A-1}$ & $\begin{array}{l}\text { Rotary Kiln with Air for } \\
\text { Combustion and Dry/Wet APC - } \\
\text { Baseline }\end{array}$ & 2.87 & 4.80 & 6.30 & 7.15 & 6.84 & 6.82 & 6.14 & 6.55 & 5.07 & 6.48 & 1.00 \\
\hline A-7 & Stagging Rotary Kiln & 2.74 & 5.05 & 6.26 & 7.14 & 6.93 & 6.69 & 6.03 & 6.40 & 5.04 & 6.43 & 0.87 \\
\hline $\mathrm{C}-2$ & $\begin{array}{l}\text { Plasma Furnace with } \mathrm{CO}_{2} \\
\text { Retention }\end{array}$ & 3.20 & 5.33 & 6.22 & 5.81 & 6.96 & 5.68 & 5.17 & 5.63 & 4.95 & 5.90 & 0.95 \\
\hline$C \cdot 3$ & Plasma Gasification & 3.00 & 5.11 & 6.09 & 6.21 & 6.96 & 6.00 & 5.32 & 6.26 & 5.05 & 6.06 & 0.86 \\
\hline F-1 & Molten Salt Oxidation & 3.48 & 5.55 & 5.89 & 5.95 & 5.91 & 5.60 & 5.32 & 6.06 & 4.89 & 5.72 & 1.00 \\
\hline G.1 & Molten Metal Waste Destruction & 3.24 & 5.51 & 6.06 & 6.15 & 7.04 & 5.97 & 5.19 & 6.32 & 5.08 & 6.05 & 0.85 \\
\hline $\mathbf{H}-\mathbf{1}$ & Steam Gasification & 2.98 & 5.29 & 6.17 & 6.51 & 6.24 & 6.39 & 5.80 & 6.37 & 5.04 & 6.14 & 0.96 \\
\hline J-1 & Joule-Heated Vitrification & 3.03 & 5.16 & 6.20 & 6.71 & 6.93 & 6.32 & 5.17 & 6.07 & 5.26 & 6.19 & 0.86 \\
\hline K-1 & $\begin{array}{l}\text { Thermal Desorption and Mediated } \\
\text { Electrochemical Oxidation }\end{array}$ & 3.27 & 5.52 & 5.76 & 6.00 & 6.80 & 6.10 & 5.74 & 6.35 & 5.30 & 6.01 & 1.15 \\
\hline L-1 & $\begin{array}{l}\text { Thermal Desorption and } \\
\text { Sypercritical Water Oxidation }\end{array}$ & 3.61 & 5.61 & 5.96 & 5.88 & 6.84 & 5.96 & 4.96 & 6.04 & 5.32 & 5.92 & 1.17 \\
\hline
\end{tabular}

Criteria Definitions on a Scake of 1 to 10 :

1 Cost sensitivity

2 Cost uncertainty

3 Regulatory compliance

4 implementability

Definitions of Weighted Performance Factors:

5 Flexibility

6 Operability

7 Maintainability

8 Availability

9 Decommissioning and

decontamination

WPS - Weighted performance criteria scores for entire systems.

NPLCC - Normalized planning life-cycle costs for systems, from Table 4-6 in the Phase 2 report. 
TABLE I·2

Example of the Comparison of Cost and Performance Scores for Thermal Subsystems: Baseline and Phase 2 Systems

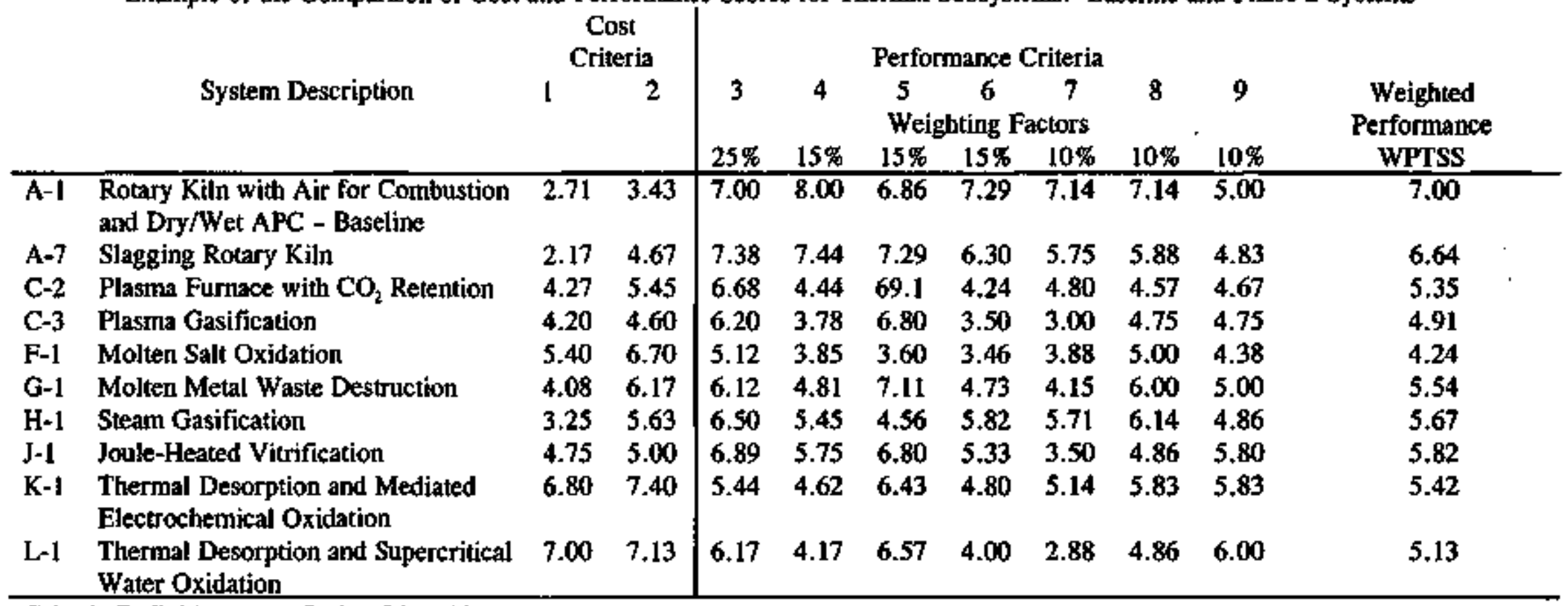

Criteria Definitions on a Scale of 1 to 10:

1 Cost sensitivity

2 Cost uncertainty

3 Regulatory compliance

4 Implementability

5 Flexibility

6 Operability

7 Maintainability

8 Availability

9 Decommissioning and decontamination 


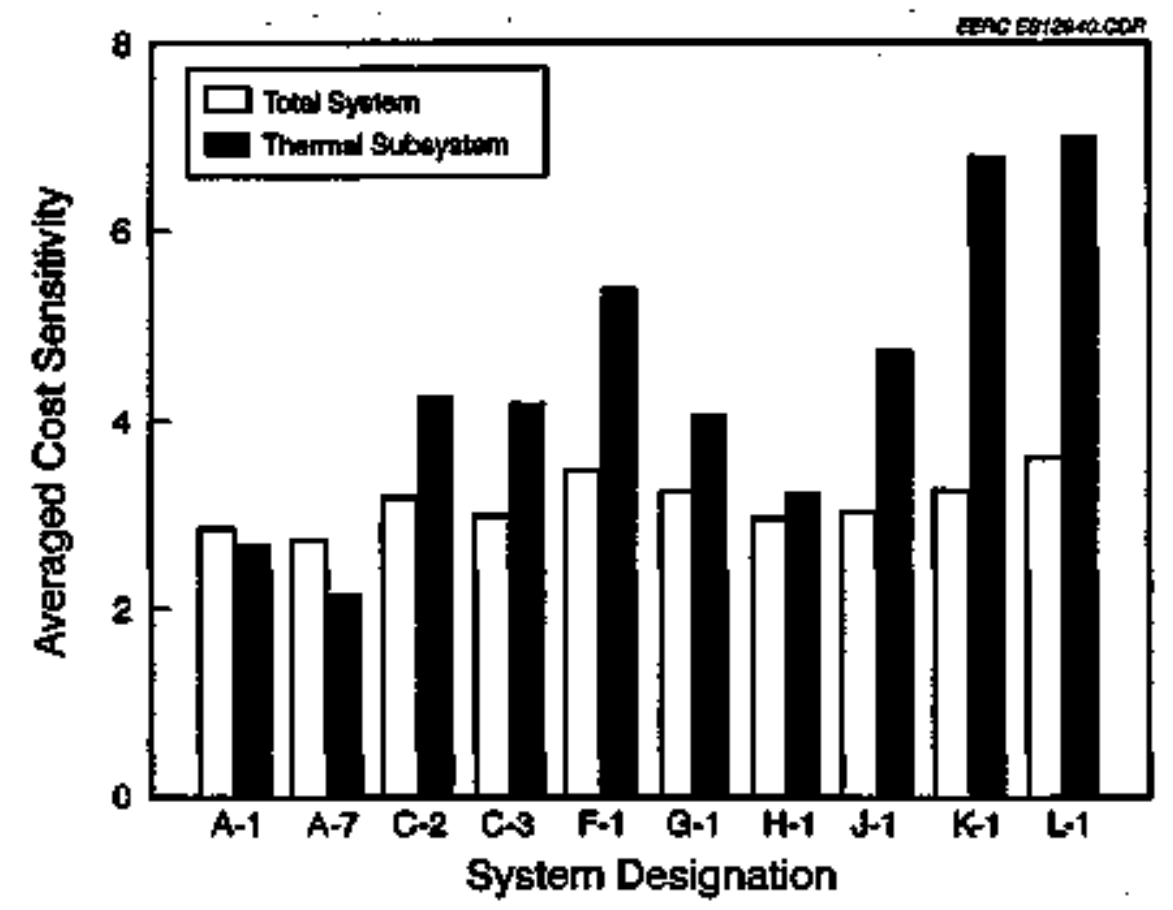

Figure I-1. Example of the comparison of cost sensitivity for Phase 2 systems and themal subsystems.

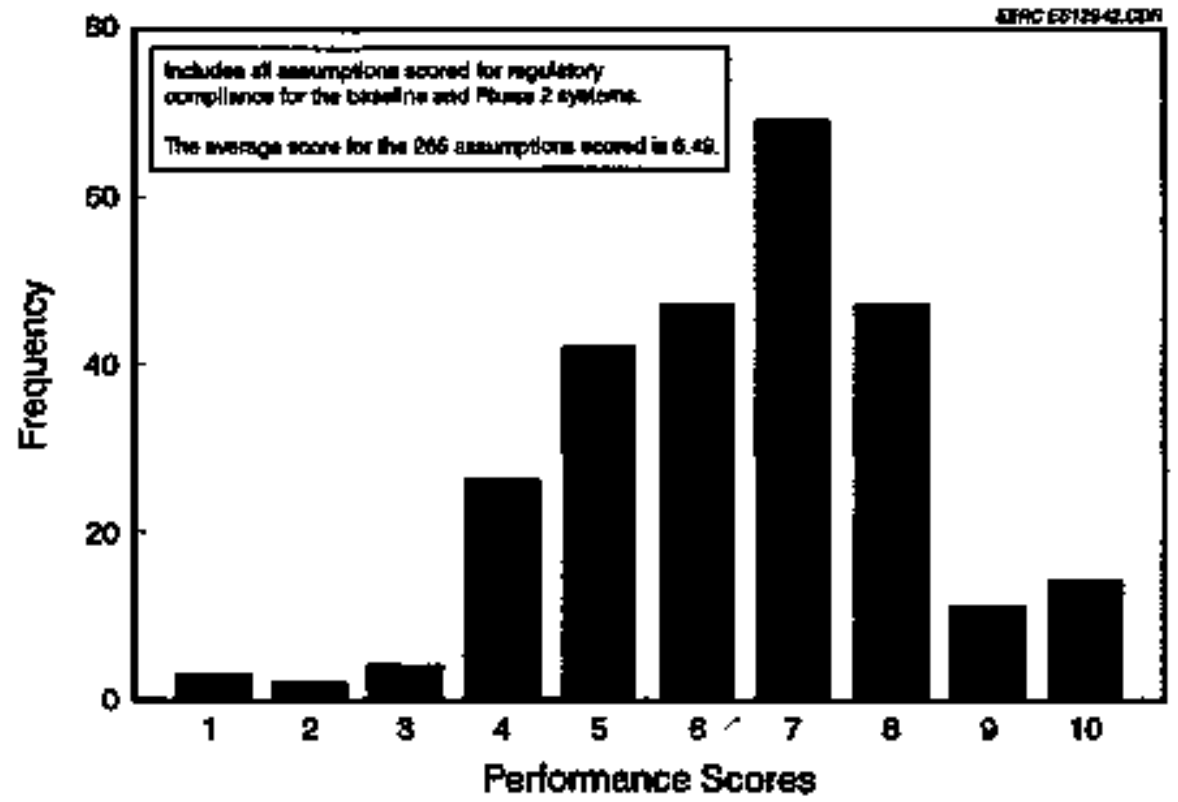

Figure 1-2. Example of the distribution of performance scores for regulatory compliance assumptions. 


\section{EXAMPLE}

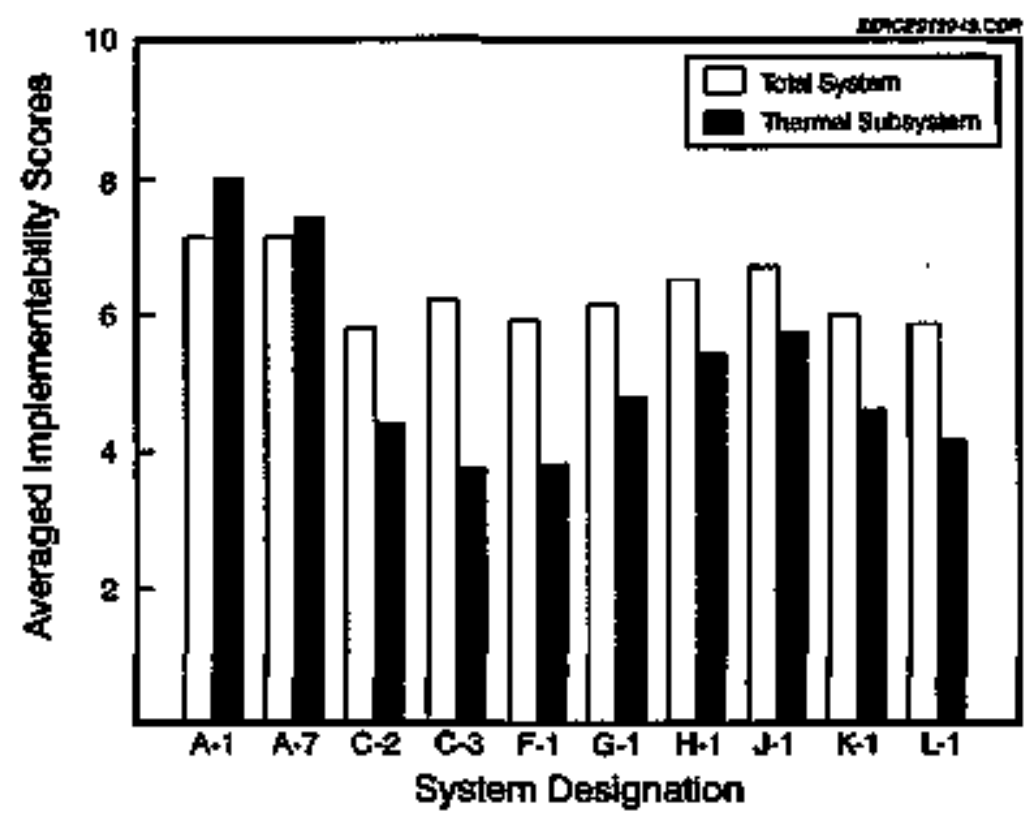

Figure I-3. Example of the comparison of implementability for Phase 2 systems and thermal subsystems.

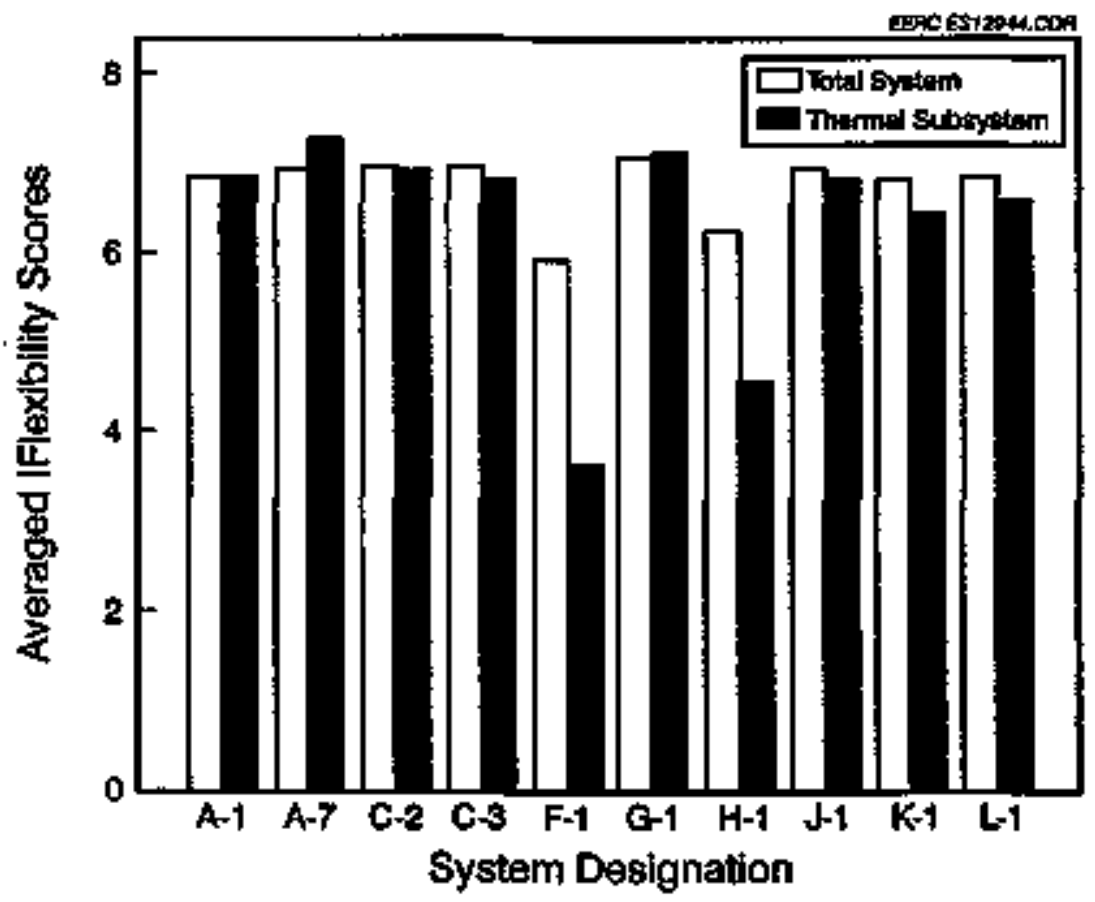

Figure I-4. Example of the comparison of flexibility for Phase 2 systems and thermal subsystems. 


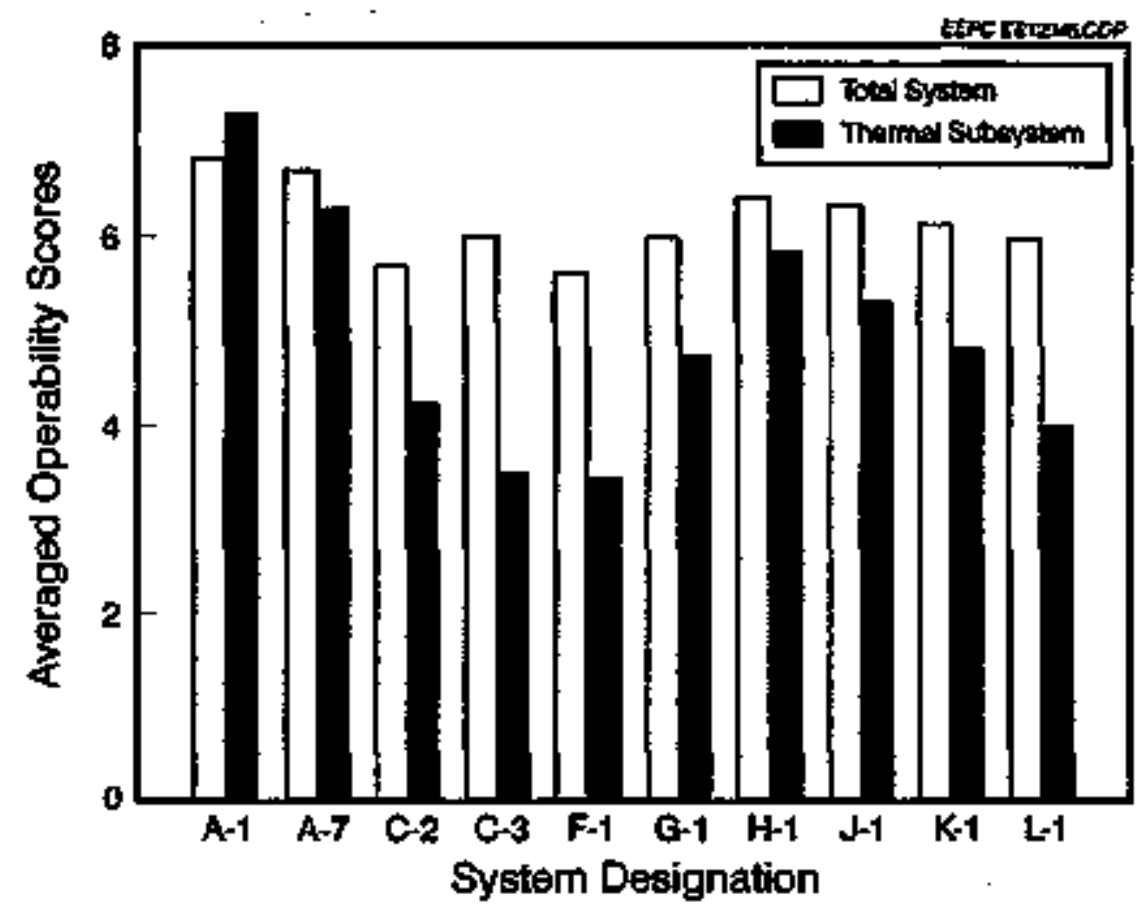

Figure I-5. Example of the comparison of operability for Phase 2 systems and themal subsystems.

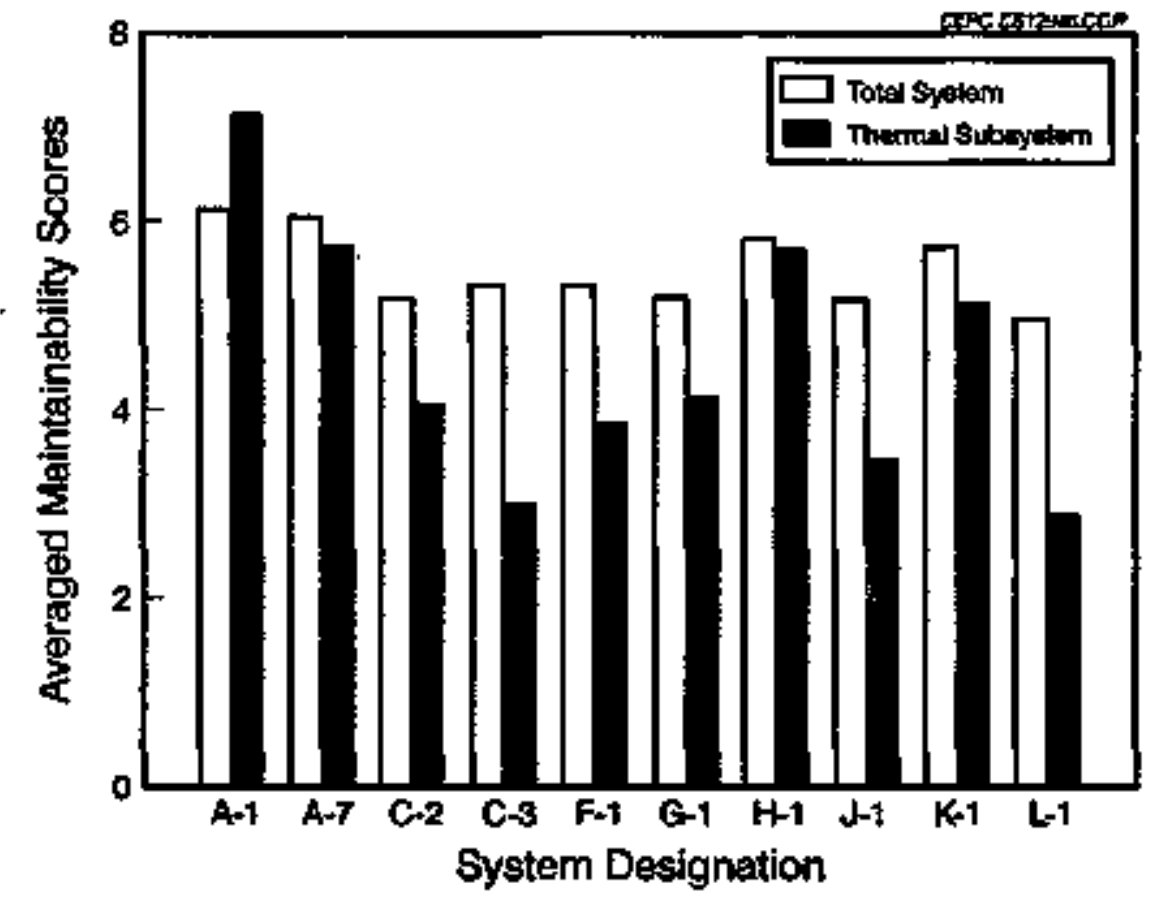

Figure 1-6. Example of the comparison of maintainability for Phase 2 systems and thermal subsystems. 


\section{EXAMPLE}

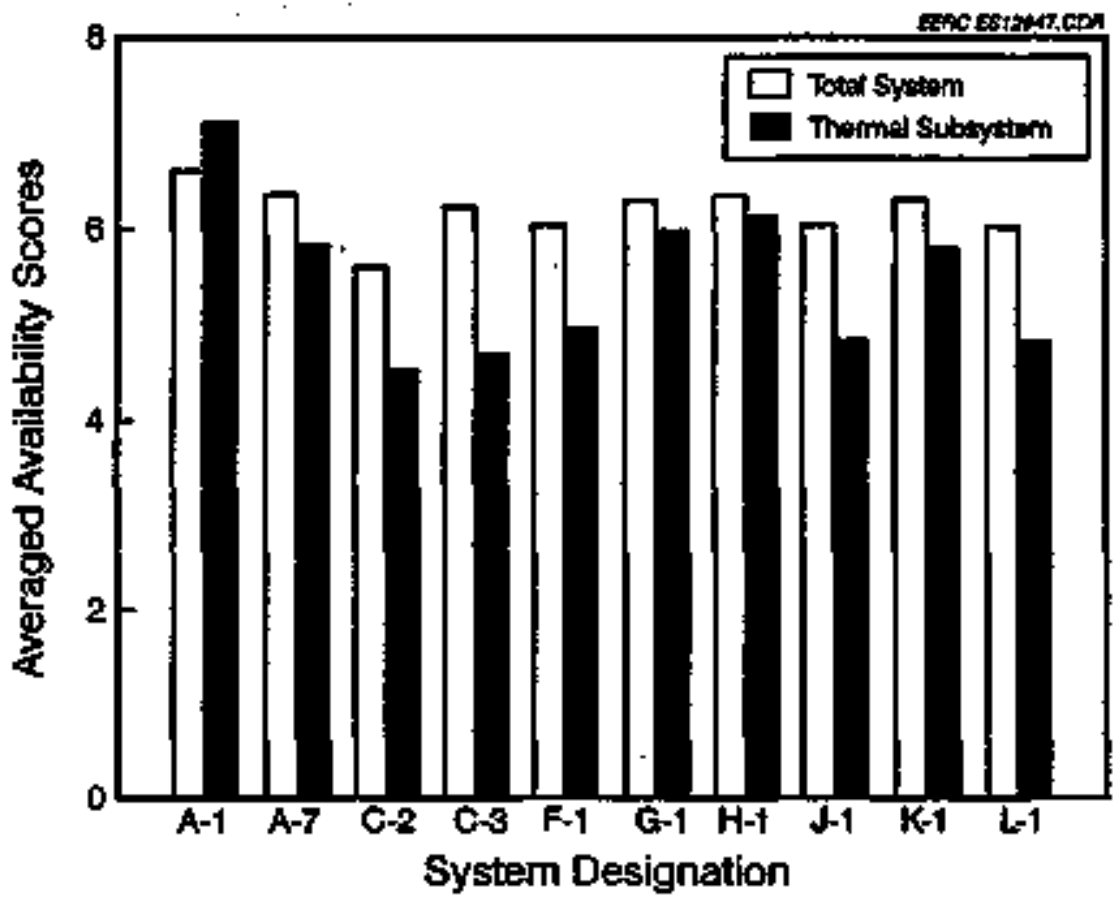

Figure 1-7. Example of the conparison of availability for Phase 2 systems and thermal subsystems.

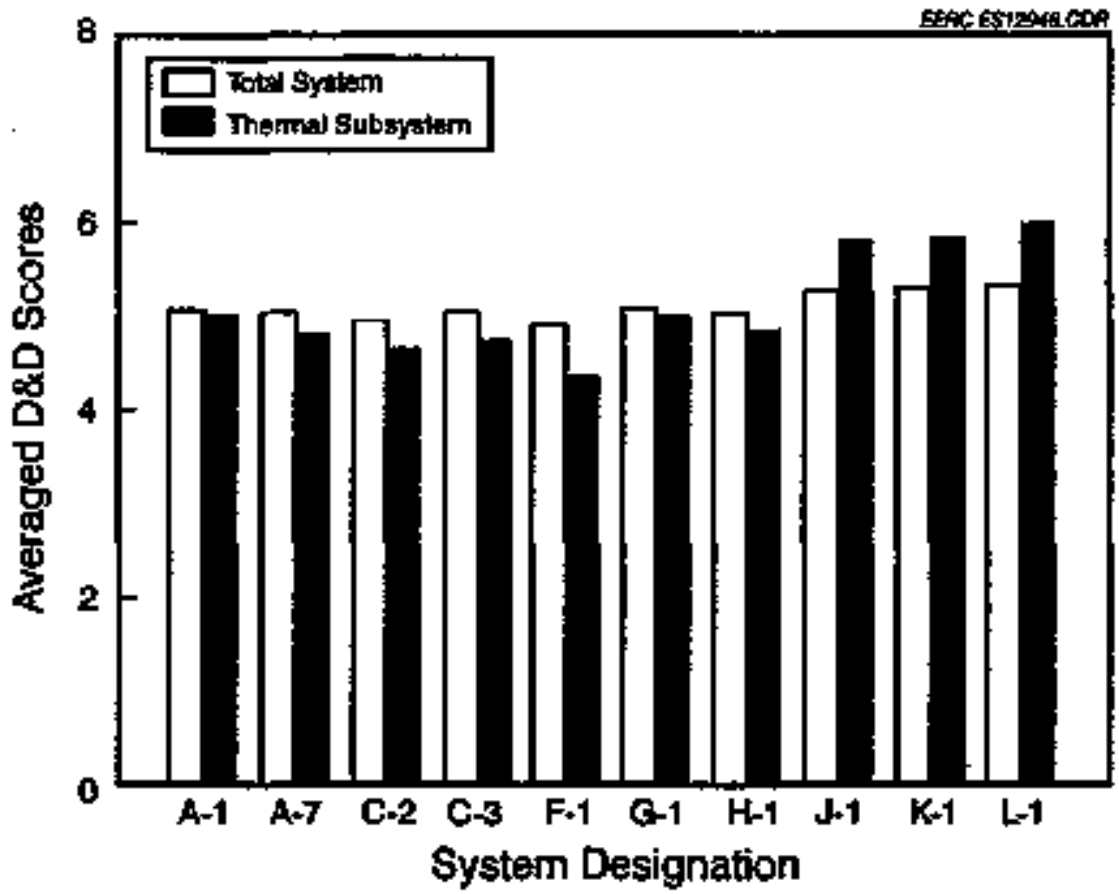

Figure I-8. Example of the comparison of ease of decontarnination and decommissioning for Phase 2 systems and thermal subsysterns. 


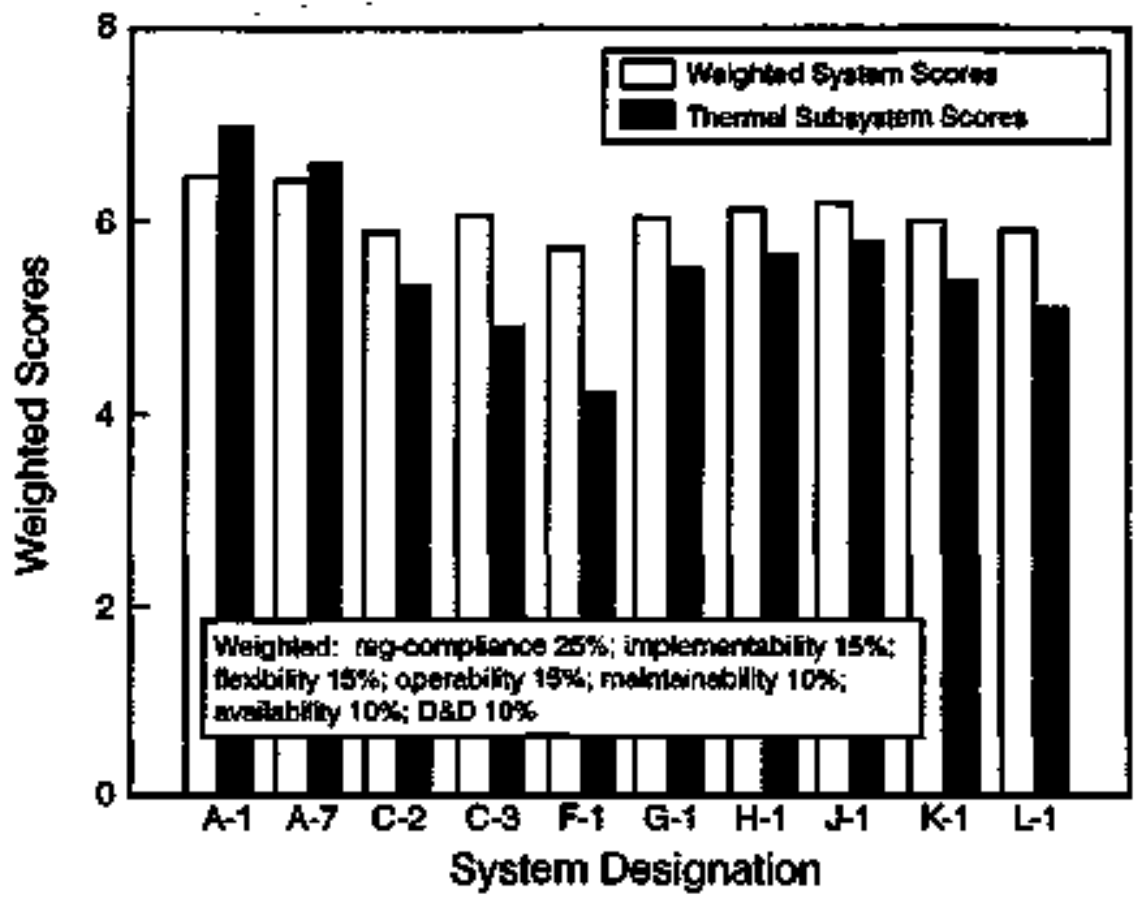

Figure I-9. Example of the comparison of weighted performance scores for Phase 2 systems and thermal subsystems.

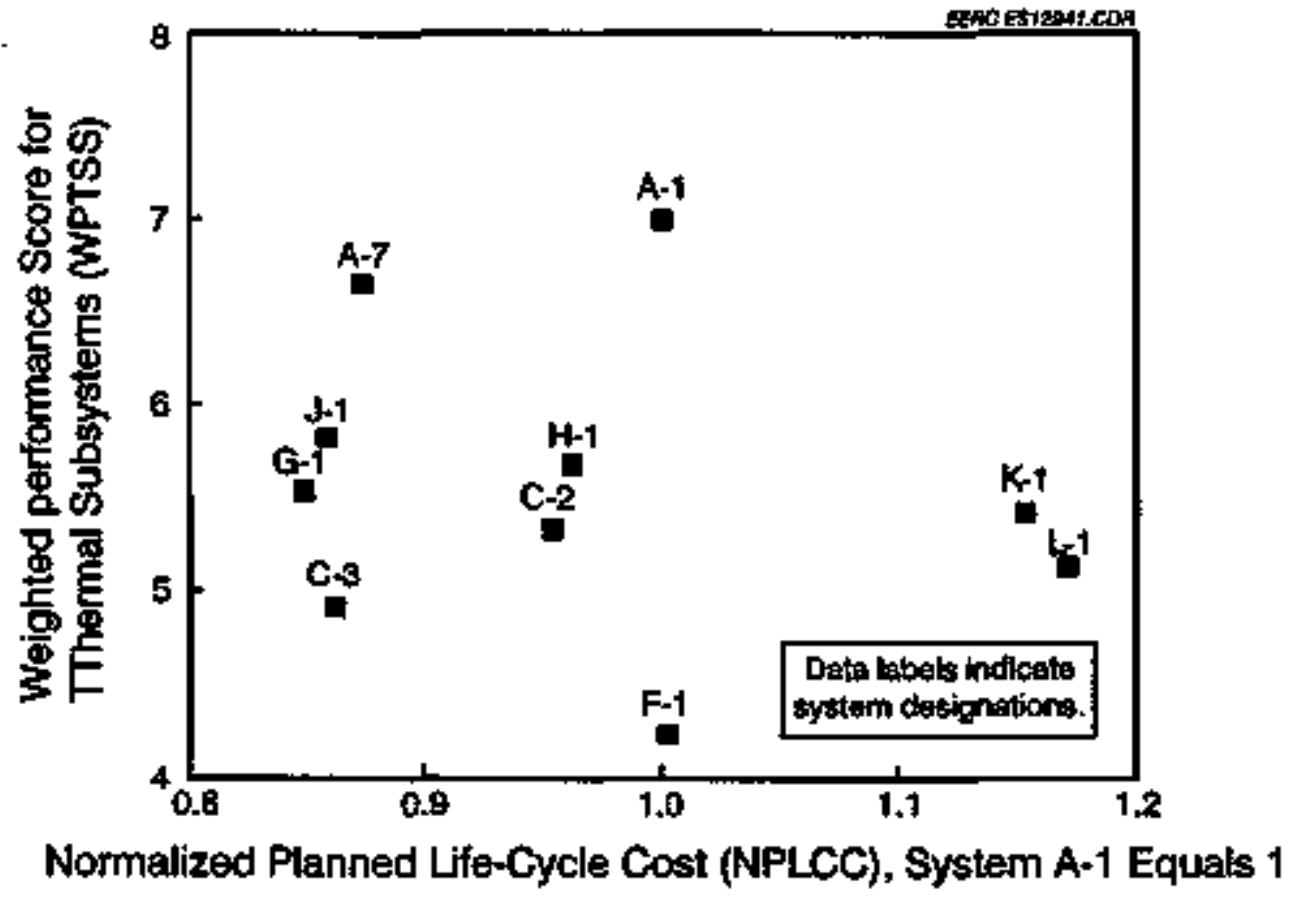

Figure I-10. Example of the ranking of cost and performance for Phase 2 thermat subsystems. 


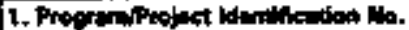
DEfCz1-941C3138日

4. Siame tad Adrats
2. Frop womproinet note

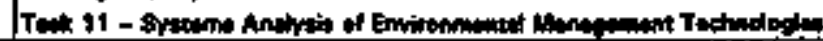

Enoroy \& Environmental fesearch Conter

University of North Dakota

PO Box 0019, Grand Forks, ND 6B202-0018 (701) 777-5000
Pare 1 of 3
3. Nupering Patoed

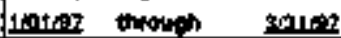
5. Prowtion Btent bas 9/30/94
6. Comptiolon Om
9/29/99

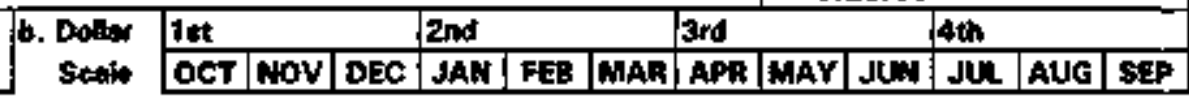

a. Dollurs Exprased in

Thousinds

10. Cont Chart

\begin{tabular}{|c|c|c|c|c|c|c|c|}
\hline \multirow{2}{*}{\multicolumn{2}{|c|}{$\begin{array}{l}\text { Fund } \\
\text { Soures }\end{array}$}} & \multicolumn{4}{|c|}{ Quenter } & \multirow{2}{*}{$\begin{array}{c}\text { Cum. } \\
\text { to } \\
\text { Dete }\end{array}$} & \multirow[b]{2}{*}{$\begin{array}{l}\text { Tot. } \\
\text { Plert }\end{array}$} \\
\hline & & \multirow[t]{2}{*}{ Ist } & \multirow[t]{2}{*}{ Ind } & \multirow{2}{*}{ 38d } & \multirow{2}{*}{ 4th } & & \\
\hline DOE & $\mathbf{P}$ & & & & & 352 & 641 \\
\hline & A & & & 269 & 113 & 392 & \\
\hline & $\mathbf{P}$ & & & & & & \\
\hline & A & & & & & & \\
\hline & $\boldsymbol{P}$ & & & & & & \\
\hline & A & & & & & & \\
\hline & $\mathbf{P}$ & & & & & & \\
\hline & $\mathbf{A}$ & & & & & & \\
\hline & & & & 182 & 170 & 352 & 641 \\
\hline & & & & 269 & 113 & 382 & \\
\hline Vor & & & & $\langle 87|$ & 57 & (30) & \\
\hline & & $P=\mathbf{P}$ & Fned & $\mathbf{A}$ & $=\Delta$ & Iual & \\
\hline
\end{tabular}

Total Pleraned Costs lor Programi/Project \$64t

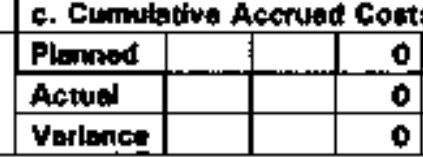

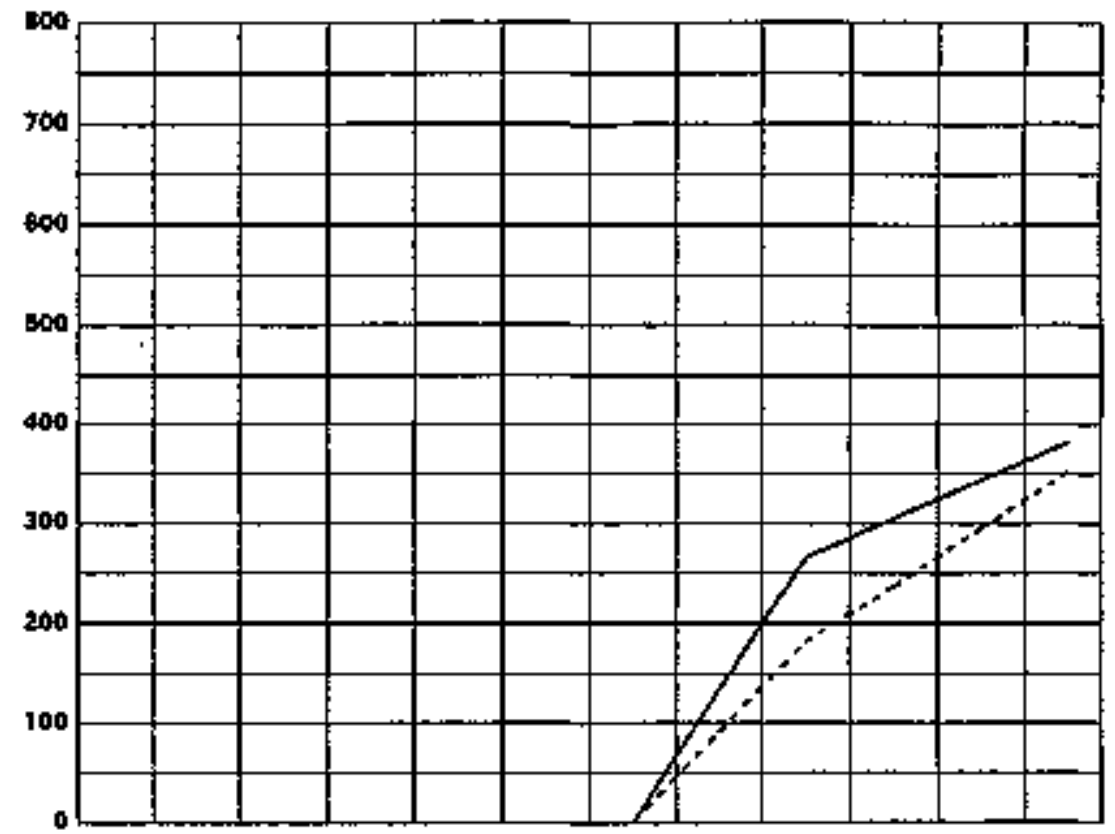

c. Cumulative Accrued Costs

Vorlonce

\begin{tabular}{|l|l|l|l|}
\hline 0 & & & 0 \\
\hline 0 & & & 0 \\
\hline 0 & & & 0
\end{tabular}

\begin{tabular}{|l|l|r|l|l|l|}
\hline & & 182 & & & 352 \\
\hline & & 209 & & & 392 \\
\hline & 187 & & & 1301 \\
\hline
\end{tabular}

\begin{tabular}{|c|c|}
\hline 11. Meior Mrlatona Statle & Unit: Plened \\
\hline & 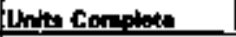 \\
\hline & $p$ \\
\hline 13.1 Srment idenotichion & c \\
\hline & $\mathbf{P}$ \\
\hline 11.2 Systems Eurluation. & $\Leftrightarrow$ \\
\hline & P \\
\hline 17.3 Aopgertang & c \\
\hline 1 1. 4 Compnuadion of Tabk mecorting to WeTC & P \\
\hline Onders & 6 \\
\hline & $\mathbf{P}$ \\
\hline & c \\
\hline & $\mathbf{P}$ \\
\hline & c \\
\hline . & $\mathbf{P}$ \\
\hline & C \\
\hline & $\mathbf{P}$ \\
\hline & $\mathbf{C}$ \\
\hline & $\mathbf{P}$ \\
\hline & $\mathbf{C}$ \\
\hline
\end{tabular}

12. Ramarka

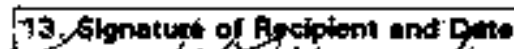

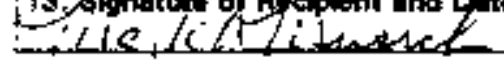




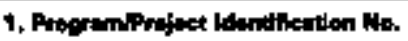
DefC21-94MC51388

4. Nene and Adtrast

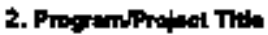

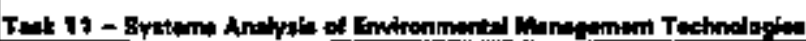
Enwrgy \& Enviranmantal fuseserch Center University of North Dakets PO Box 9018, Grand Forks, ND 58202-9018 (70t) 777-6000
Len 2 if 3

3. Reporting Palod

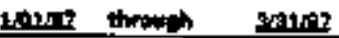

B. Propran Part ow $9 / 30 / 94$

6. Conplotion Onta $\mathbf{9} 29 / 99$

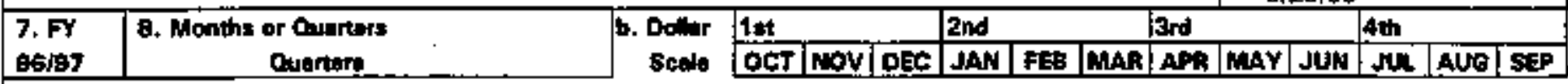
9. Cort
a. Dollore Exprapand in
Strotus:
Thourende

10. Cout Chart

\begin{tabular}{|c|c|c|c|c|c|c|c|}
\hline \multirow{2}{*}{$\begin{array}{l}\text { Fiund } \\
\text { Solnes }\end{array}$} & & \multicolumn{4}{|c|}{ Quatertar } & \multirow{2}{*}{$\begin{array}{c}\text { Cum. } \\
\text { to } \\
\text { Dete }\end{array}$} & \multirow[b]{2}{*}{$\begin{array}{l}\text { Tot. } \\
\text { Pinn }\end{array}$} \\
\hline & & 1st & 2nd & $3 n t$ & 4 th & & \\
\hline \multirow[t]{8}{*}{ DOE } & $\mathbf{P}$ & 72 & 72 & 11 & 0 & 496 & 507 \\
\hline & $A$ & 80 & 31 & & & 501 & \\
\hline & $P$ & & & & & & \\
\hline & A & & & & & & \\
\hline & $P$ & & & & & & \\
\hline & A & & & & & & \\
\hline & 8 & & & & & & \\
\hline & $\mathrm{A}$ & & & & & & \\
\hline \multicolumn{2}{|c|}{ Total P } & 72 & 72 & 11 & 0 & 490 & 80 \\
\hline \multicolumn{2}{|c|}{ Total A } & 88 & 31 & & & 501 & \\
\hline \multicolumn{2}{|c|}{ Vertance } & (16) & 41 & & & [E\} & \\
\hline
\end{tabular}

Total Pansed Costs loe ProgramiProject $\$ 607$

\begin{tabular}{|c|c|}
\hline Planiled & 424 \\
\hline Actural & 470 \\
\hline Volitances & (49) \\
\hline
\end{tabular}

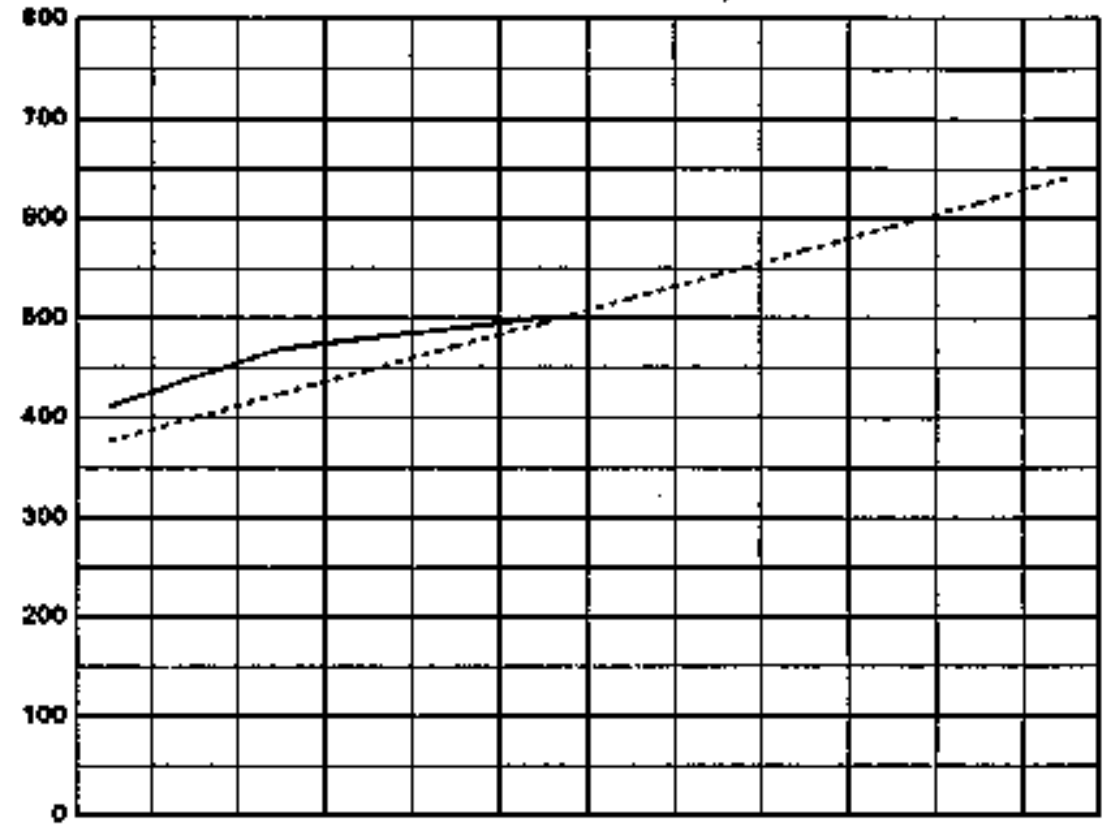

c. Cumulintya Accrued Costs

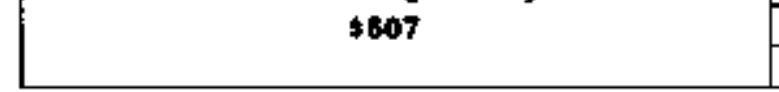

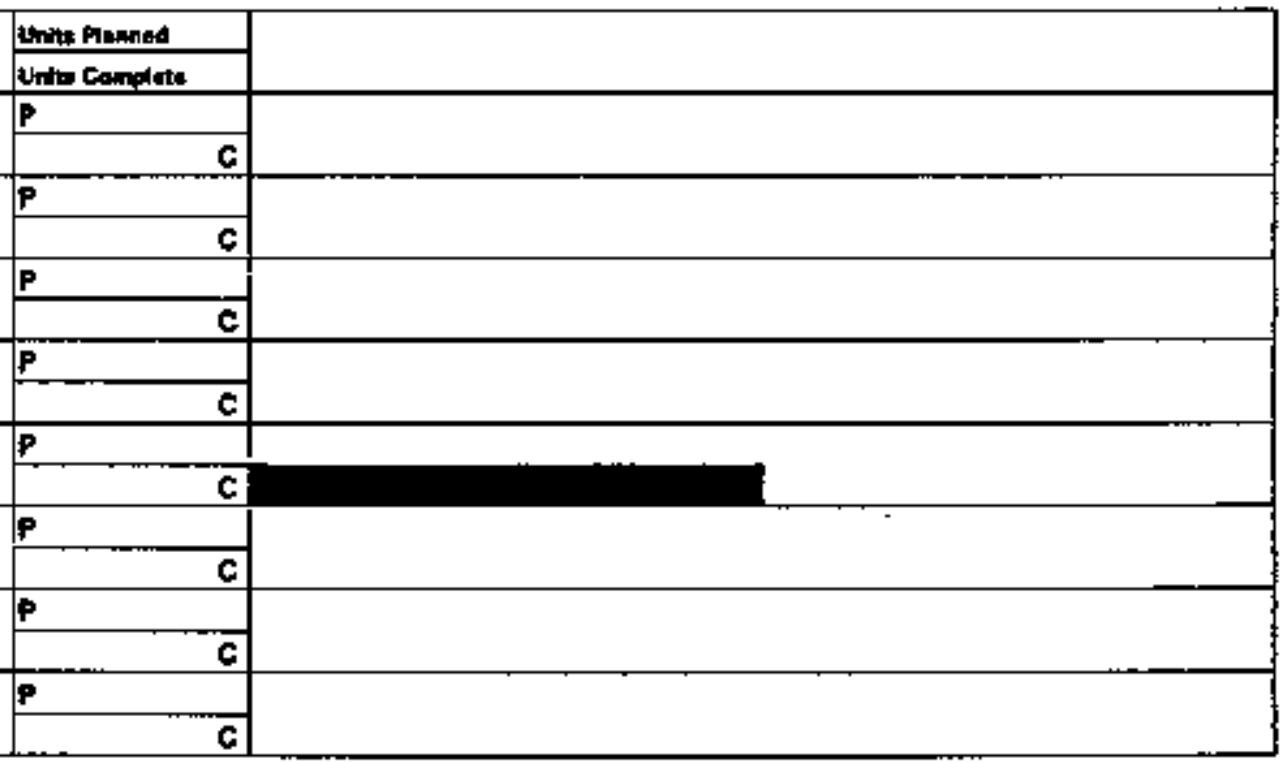

\begin{tabular}{|c|c|c|}
\hline \multirow[t]{2}{*}{ 11. Mujor Midastona Statte } & \multirow{2}{*}{ 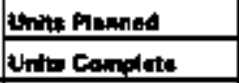 } & \\
\hline & & \\
\hline & $\mathbf{P}$ & \\
\hline & c & \\
\hline \multirow[t]{2}{*}{11,1 Sythoms identification } & $\overline{\mathbf{P}}$ & \\
\hline & c & \\
\hline \multirow[t]{2}{*}{ 1 1.2 sybems Eulduation } & $\mathbf{P}$ & \\
\hline & $\mathbf{c}$ & \\
\hline \multirow[t]{2}{*}{ 1 1.J Repaning } & $P$ & \\
\hline & C & \\
\hline \multirow{8}{*}{ 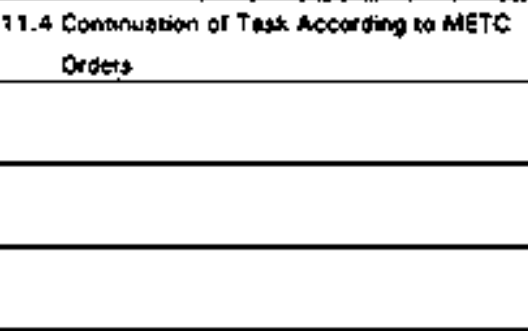 } & $P$ & \\
\hline & C & \\
\hline & $\mathbf{P}$ & 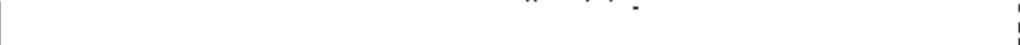 \\
\hline & c & \\
\hline & $\mathbf{P}$ & \\
\hline & C & \\
\hline & $\mathbf{P}$ & \\
\hline & c & \\
\hline
\end{tabular}

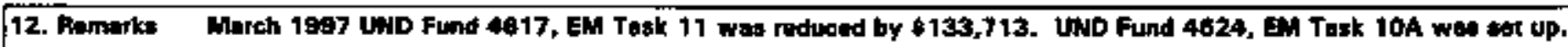


U.S. DEPARTMENT OF ENERGY

Forin ex-45ge (10):0)

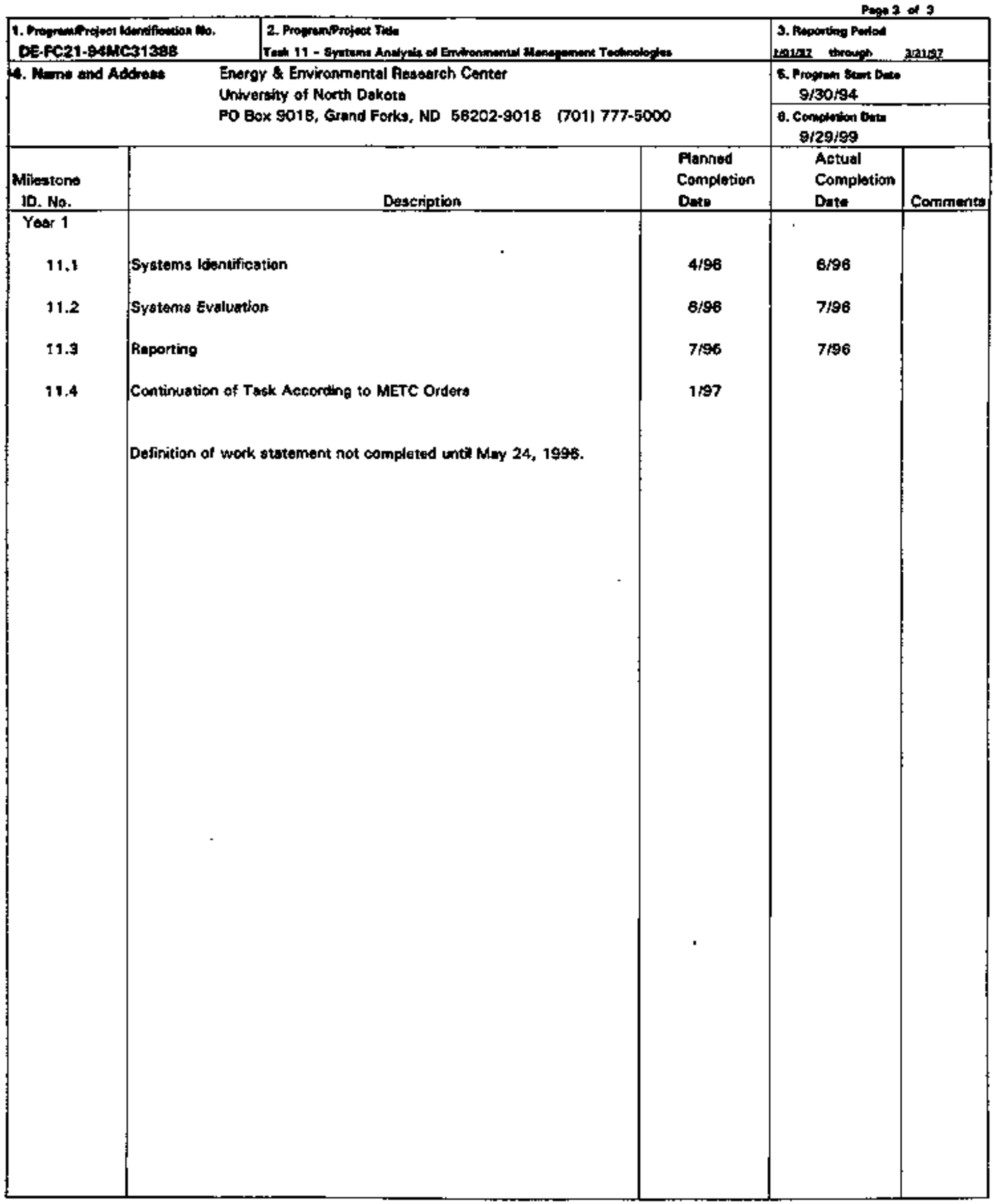

